\title{
Vascular smooth muscle cell phenotype switching governs vascular calcification
}

Citation for published version (APA):

Willems, B. A. G. (2017). Vascular smooth muscle cell phenotype switching governs vascular calcification: Role of harnessing endogenous protective mechanisms. [Doctoral Thesis, Maastricht University]. Maastricht University. https://doi.org/10.26481/dis.20171201bw

Document status and date:

Published: 01/01/2017

DOI:

10.26481/dis.20171201bw

Document Version:

Publisher's PDF, also known as Version of record

\section{Please check the document version of this publication:}

- A submitted manuscript is the version of the article upon submission and before peer-review. There can be important differences between the submitted version and the official published version of record.

People interested in the research are advised to contact the author for the final version of the publication, or visit the DOI to the publisher's website.

- The final author version and the galley proof are versions of the publication after peer review.

- The final published version features the final layout of the paper including the volume, issue and page numbers.

Link to publication

\footnotetext{
General rights rights.

- You may freely distribute the URL identifying the publication in the public portal. please follow below link for the End User Agreement:

www.umlib.nl/taverne-license

Take down policy

If you believe that this document breaches copyright please contact us at:

repository@maastrichtuniversity.nl

providing details and we will investigate your claim.
}

Copyright and moral rights for the publications made accessible in the public portal are retained by the authors and/or other copyright owners and it is a condition of accessing publications that users recognise and abide by the legal requirements associated with these

- Users may download and print one copy of any publication from the public portal for the purpose of private study or research.

- You may not further distribute the material or use it for any profit-making activity or commercial gain

If the publication is distributed under the terms of Article $25 \mathrm{fa}$ of the Dutch Copyright Act, indicated by the "Taverne" license above, 
Vascular smooth muscle cell phenotype switching governs vascular calcification Role of harnessing endogenous protective mechanisms 


\section{Colofon}

(C)Brecht Willems, Maastricht 2017

ISBN: $978-94-6295-767-1$

Lay-out and print by: ProefschriftMaken // http://www.proefschriftmaken.nl

All rights reserved. No part of this thesis may be reproduced, stored in a retrieval system or transmitted in any form or by any means, without the permission in writing from the author, or, when appropriate, of the publisher of the publication. 


\title{
Vascular smooth muscle cell phenotype switching governs vascular calcification \\ Role of harnessing endogenous protective mechanisms
}

\begin{abstract}
PROEFSCHRIFT
Ter verkrijging van de graad doctor aan de Universiteit Maastricht op gezag van Rector Magnificus, Prof. dr. Rianne M. Letschert, volgens het besluit van het College van Decanen in het openbaar te verdedigen op vrijdag 1 December 2017 om 10.00 uur
\end{abstract}

Door

Brecht Andy Ghislaine Willems

Geboren op 12 februari 1988 te Hasselt 


\section{Promotor}

Prof. dr. C.P.M. Reutelingsperger

\section{Copromotoren}

Dr. L.J. Schurgers

Dr. C. Vermeer

\section{Beoordelingscommissie:}

Prof. dr. B.A.A. Kroon (voorzitter)

Prof. dr. V. Brandenburg (RWTH Aachen, Aachen, Germany)

Prof. Dr. P. Habibovic

Dr. B. Kietselaar

Dr. M. Vervloet (VUMC Amsterdam. Amsterdam, the Netherlands) 
Voor mijn ouders 



\section{CONTENTS}

$\begin{array}{lll}\text { Chapter } 1 & \text { General Introduction } & 9\end{array}$

Chapter 2 The realm of vitamin $\mathrm{K}$ dependent proteins:

Chapter 3 Nicotine increases oxidative stress and exosome secretion in human vascular smooth muscle cells and induces microcalcifications in human atherosclerosis

Chapter 4 Gla-Rich Protein acts as a calcification inhibitor in the human cardiovascular system

Chapter 5 Ucma is involved in osteogenic transdifferentiation of vascular smooth muscle cells:

role in phosphate-induced vascular calcification

Chapter 6 Apoptosis of medial vascular smooth muscle cells accelerates atherogenesis and induces a vulnerable plaque phenotype

Chapter 7 General Discussion

Chapter 8 Summary

Chapter 9 Nederlandse Samenvatting

Chapter 10 Valorization 



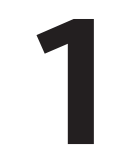

General Introduction 



\section{Cardiovascular Disease}

Cardiovascular disease and cancer have the disputable honour to combat for the number one mortality cause in the western world $(1,2)$. Today, there is still an increasing number of deaths in developing countries due to globalization of the western life-style. Cardiovascular disease includes, but is not limited to, myocardial infarction, congestive heart failure, stroke, aneurysm and peripheral artery disease (3).

Western type diet, lack of exercise/obesity and smoking are traditional risk factors which greatly increase the risk of developing cardiovascular disease (4-6). However, exact mechanisms to explain how these risk factors contribute to cardiovascular disease remain to be unravelled. Additionally, vascular calcification was recently added to this growing list as a novel risk factor $(7,8)$.

\section{Vascular Calcification}

Clinically, the presence of vascular calcifications translates into an increased risk of getting a cardiovascular event. It can contribute to development of cardiovascular disease or cause a cardiovascular event in different ways depending on its anatomical location in the vascular wall (9).

\section{Intimal Calcification}

Vascular vessel calcifications typically may occur at 2 different sites in the vascular wall (Figure 1). When it is present in the intimal layer, it is often associated with atherosclerosis. Atherosclerosis is a chronic, inflammatory disease of the vessel wall that is initiated by lodging of lipids underneath the endothelial layer in regions where endothelial integrity is compromised (10). Often, this is at regions with disturbed hemodynamics. Oxidation of these lipids evokes an inflammatory response causing circulating cells such as monocytes to extravasate into the vessel wall further fuelling the inflammatory response. Macrophages that phagocytose these oxidised lipids become foam cells that secrete pro-inflammatory cytokines that cause VSMC to differentiate and migrate into the atherosclerotic lesion. Migration of VSMC into an atherosclerotic plaque can have different effects depending on the stage of atherosclerosis. It can stabilize the atherosclerotic plaque by depositing extracellular matrix proteins and contribute to formation of a fibrous cap. On the contrary, it can make a plaque more prone to rupture by contributing to plaque inflammation and lipid retention (11). The intra-plaque environment can cause VSMC to execute apoptosis or they can transform into foam cells by engulfing oxidised cholesterol $(12,13)$. Calcification is often used as measure of atherosclerotic burden because it was regarded as a late-stage phenomenon of atherosclerosis. However, during recent years calcification has been recognised as an early feature of atherogenesis. As such, calcification has different effects on an atherosclerotic plaque depending on the location and the size and quantity of the calcium crystals. When calcification is deposited over large areas, it is known as macrocalcification. Macrocalcification is thought to have a stabilizing effect on atherosclerotic plaques 


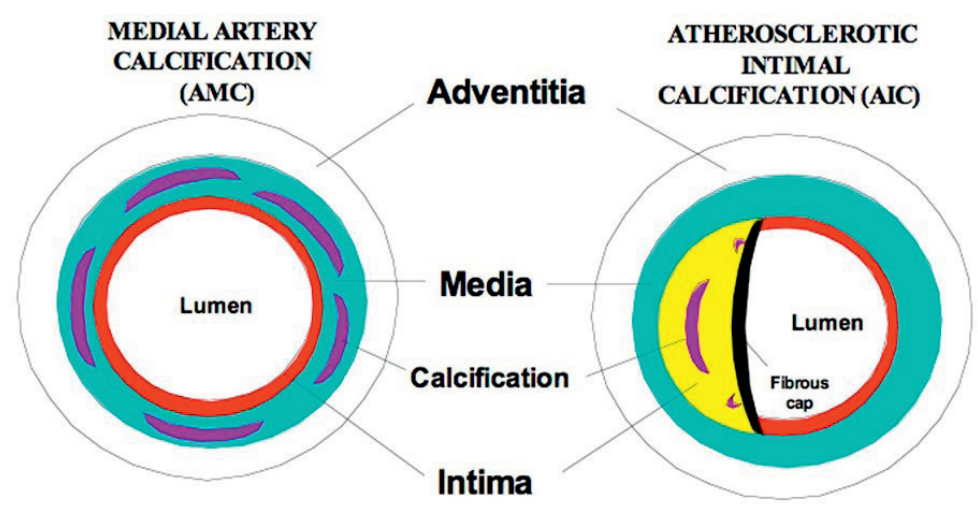

Figure 1: Medial and intimal calcification.

Figure adopted from Towler DA, Vascular calcification: A perspective on an imminent disease epidemic.BMS BoneKEy (2008) 5, 41-58 (2008)

(14). It is now acknowledged that part of the stabilizing effect of statins on atherosclerotic plaques is through promoting macrocalcification of atherosclerotic plaques (15). On the contrary, when calcification is deposited in spotty areas, not associated with each other, calcification is thought to destabilize the plaque and make it more prone to rupture (16). These spotty, small mineral deposits are described as micro calcifications.

\section{Medial Calcification}

Medial calcification, also known as Mönckeberg's sclerosis, can occur throughout the entire vascular tree and occurs independently of atherosclerosis (17). This suggests different routes through which it can develop. Calcification of the tunica media is accompanied by loss of VSMC contractile properties (3). It is associated with the deposition of calcificationregulating proteins and elastin degradation in the media causing the vessel wall to stiffen $(18,19)$. Stiffening of the vessel wall alters hemodynamics and increases blood pressure, causing the myocardium to thicken and giving rise to congestive heart failure. It is highly prevalent in the elderly and end stage renal disease or diabetes patients. In diabetes patients, it is an important cause of leg amputation. Additionally, it has been demonstrated that there is an interaction between both intimal and medial calcification. Studies have shown that both can give rise to one another $(20,21)$. This may be due to the interaction of mechanisms involved in both processes which affect one another.

\section{Mechanisms of vascular calcification}

Vascular calcification has long been considered a passive process caused by spontaneous precipitation of calcium phosphate crystals. However, it is now appreciated that vascu- 
lar calcification is a complex, regulated and active process with a central role for VSMC. Different pathways have been identified that can cause a blood vessel to start calcifying depending on the anatomical location.

\section{Phenotypical transdifferentiation of VSMC}

Another key mechanism through which vascular calcification may occur is the phenotypical differentiation of VSMC into an osteogenic phenotype (22). In healthy blood vessels, most VSMC have a contractile phenotype to play a role in regulating hemodynamics. In vitro experiments have demonstrated that contractile VSMC are less prone to vascular calcification. However, extracellular stress signals such as uremic toxins, inflammatory cytokines or exposure to elevated phosphate concentrations can trigger differentiation of contractile VSMC into an osteochondrogenic phenotype (23-25). The osteochondrogenic phenotype has functional similarities to chondrocytes and osteoblasts in bone and in extreme cases, bone like tissue has been observed in atherosclerotic plaques $(26,27)$. In vitro experiments have shown that the osteochondrogenic phenotype is potent at calcifying the extracellular matrix. Additionally, osteochondrogenic VSMC lose contractile markers and gain synthetic properties such as increased vesicle secretion, expression of bone-related proteins and downregulation of mineralization inhibitors.

It has extensively been described that vitamin $\mathrm{K}$ dependent proteins are involved in controlling vascular calcification. The presence of MGP in VSMC has been shown to allow VSMC to maintain a contractile phenotype. When VSMC assume an osteogenic phenotype, other vitamin K-dependent proteins have been identified such as osteocalcin, a vitamin K-dependent protein which is normally involved in bone metabolism but has recently also been shown to be involved in vascular calcification. Recently, a new vitamin K-dependent protein, Ucma, has been described which potentially is involved in control of bone mineralization $(28,29)$. The role of Ucma in vascular calcification remains to be elucidated.

\section{Apoptosis and extracellular vesicles}

It is now appreciated that extracellular vesicles and their cargo are involved in the development of vascular calcification $(30,31)$. These vesicles can originate from different origins. A first source of extracellular vesicles are apoptotic cells. Apoptotic cells can accelerate vascular calcification through the release of apoptotic bodies (32). Secondly, exosomes/ matrix vesicles secreted by viable VSMC have been shown capable of inducing vascular calcification $(33,34)$. Finally, these vesicles can also originate from bone when they are secreted during the resorption of bone in the skeleton $(20,35)$. These vesicles are thought to lodge in the vascular wall and form a negatively charged surface which, when not phagocytosed efficiently, can serve as a nidus for initiation of calcium phosphate crystal growth, causing the vascular wall to start calcifying. 


\section{Loss of calcification inhibitors}

Vascular calcification is a consequence of deposition of minerals in the vessel wall. Human body fluids are supersaturated with calcium and phosphate $(22,36)$. This supersaturation would cause spontaneous formation of calcium-phosphate crystals under normal physicochemical conditions. However, in the human body formation of these crystals is prevented. The inhibition of this crystal formation is attributed to the activity of calcification inhibitors such as MGP and fetuin $A(37,38)$.

Both vitamin $\mathrm{K}$ and vitamin $\mathrm{K}$-dependent proteins have been shown to be key players in controlling the calcification process $(39,40)$. Research has demonstrated that Matrix Gla Protein (MGP), a vitamin K-dependent protein is a potent local calcification inhibitor (38). The posttranslational modifications of MGP, including $\gamma$-carboxylation and serine phosphorylation, were shown to play a crucial role in this activity (41). Uncarboxylated MGP has been shown to be associated with the presence of vascular calcifications and consequently, manifestation of cardiovascular disease (40). This suggests that low levels of vitamin $\mathrm{K}$ and reduced carboxylation of vitamin $\mathrm{K}$-dependent proteins indicate an increased risk of a cardiovascular event $(42,43)$. Additionally, other vitamin K-dependent proteins including prothrombin, factor $X$, osteocalcin and the recently discovered Ucma (Upper zone of growth plate and cartilage matrix associated protein) have been shown to be involved in vascular calcification (3). These findings further point towards a significant role of vitamin $\mathrm{K}$-dependent proteins and vitamin $\mathrm{K}$ in regulation of vascular calcification.

When these calcification inhibitors are inactive or downregulated, formation of calcium crystals can occur. A striking example of the consequences of the loss of inhibitors occurs in thrombotic patients receiving treatment with vitamin K-antagonists such as warfarin. Warfarin inhibits carboxylation of vitamin $\mathrm{K}$ dependent proteins, which perform key functions in blood coagulation and hence, reduces hypercoagulability in patients. However, a less well known side effect of warfarin is that it also inactivates vitamin K-dependent proteins not involved in coagulation such as MGP $(3,44)$. Consequently, use and duration of warfarin is associated with increased vascular calcification in both humans and experimental animals. 


\section{Outline of this thesis}

The research presented in this thesis aims to gain further insight in the role and contribution of VSMC in atherosclerosis and vascular calcification. I investigated molecular and biological processes in VSMC and their involvement in the initiation and development of calcification.

Chapter 2 elaborates on vitamin K-dependent proteins and both their classical (blood coagulation) and novel (regulation of vascular calcification) roles. In chapter 2 , we discuss the clinical relevance of vitamin $\mathrm{K}$ and vitamin $\mathrm{K}$-dependent proteins. We review in detail how vitamin K-dependent proteins execute the different molecular mechanisms involved in vascular calcification inhibition.

In Chapter 3 I investigated effects of smoking on atherosclerotic plaque calcification. In a clinical cohort of patients suffering from cardiovascular disease with established atherosclerotic plaques, I identified that smoking is associated with an increased prevalence of microcalcifications in atherosclerotic plaques. Using a translational approach, I identified a molecular mechanism by which nicotine induced phenotypic switching of VSMC and induced vascular calcification via increased extracellular vesicle secretion.

In chapters 4 and 5, I investigated the role of Ucma in osteochondrogenic mediated vascular calcification using VSMC deficient in Ucma. The data presented in this thesis show a novel direct relationship between Ucma and vascular calcification. We have identified that the BMP2 dependent VSMC phenotypical differentiation and vascular calcification is inhibited by Ucma.

Chapter 6 focusses on the role of VSMC in the tunica media in the initiation and development of atherosclerosis. I have employed an Apo ${ }^{-1}$ mouse model that has knocked in a human diphtheria receptor specifically in VSMC which allowed me to reduce VSMC number in the vessel wall prior to initiation of atherosclerosis. I present data on the role and contribution of medial VSMC in the development of intimal atherosclerosis.

In chapter 7 , key findings of my thesis are summarised. The results of this thesis are discussed and put in perspective in relation to existing evidence in literature. 


\section{References}

1. Borissoff JI, Spronk HMH, ten Cate H. The Hemostatic System as a Modulator of Atherosclerosis. New England Journal of Medicine. 2011;364(18):1746-60.

2. Wang H, Naghavi M, Allen C, Barber RM, Bhutta ZA, Carter A, et al. Global, regional, and national life expectancy, all-cause mortality, and cause-specific mortality for 249 causes of death, 19802015: a systematic analysis for the Global Burden of Disease Study 2015. The Lancet.388(10053): 1459-544.

3. Willems BA, Vermeer C, Reutelingsperger CP, Schurgers LJ. The realm of vitamin K dependent proteins: shifting from coagulation toward calcification. Mol Nutr Food Res. 2014 Aug;58(8):162035.

4. Hu FB, Rimm EB, Stampfer MJ, Ascherio A, Spiegelman D, Willett WC. Prospective study of major dietary patterns and risk of coronary heart disease in men. The American journal of clinical nutrition. 2000;72(4):912-21.

5. Thompson PD, Buchner D, Piña IL, Balady GJ, Williams MA, Marcus BH, et al. Exercise and Physical Activity in the Prevention and Treatment of Atherosclerotic Cardiovascular Disease. A Statement From the Council on Clinical Cardiology (Subcommittee on Exercise, Rehabilitation, and Prevention) and the Council on Nutrition, Physical Activity, and Metabolism (Subcommittee on Physical Activity). 2003;107(24):3109-16.

6. White WB. Smoking-Related Morbidity and Mortality in the Cardiovascular Setting. Preventive cardiology. 2007;10(s2):1-4.

7. Sage AP, Tintut Y, Demer LL. Regulatory mechanisms in vascular calcification. Nat Rev Cardiol. 2010 Sep; 7(9):528-36.

8. Rennenberg RJ, Kessels AG, Schurgers LJ, van Engelshoven JM, de Leeuw PW, Kroon AA. Vascular calcifications as a marker of increased cardiovascular risk: a meta-analysis. Vasc Health Risk Manag. 2009;5(1):185-97.

9. Demer LL, Tintut Y. Vascular calcification pathobiology of a multifaceted disease. Circulation. 2008;117(22):2938-48.

10. Ross R. The Pathogenesis of Atherosclerosis - An Update. New England Journal of Medicine. 1986;314(8):488-500.

11. Dzau VJ, Braun-Dullaeus RC, Sedding DG. Vascular proliferation and atherosclerosis: New perspectives and therapeutic strategies. Nat Med. 2002;8(11):1249-56.

12. Clarke MC, Figg N, Maguire JJ, Davenport AP, Goddard M, Littlewood TD, et al. Apoptosis of vascular smooth muscle cells induces features of plaque vulnerability in atherosclerosis. Nat Med. 2006 Sep;12(9):1075-80.

13. Allahverdian S, Chehroudi AC, McManus BM, Abraham T, Francis GA. Contribution of intimal smooth muscle cells to cholesterol accumulation and macrophage-like cells in human atherosclerosis. Circulation. 2014 Apr 15;129(15):1551-9.

14. Huang H, Virmani R, Younis H, Burke AP, Kamm RD, Lee RT. The impact of calcification on the biomechanical stability of atherosclerotic plaques. Circulation. 2001 Feb 27;103(8):1051-6. 
15. Libby P. How does lipid lowering prevent coronary events? New insights from human imaging trials. European Heart Journal. 2015;36:472-474.

16. Maldonado N, Kelly-Arnold A, Vengrenyuk Y, Laudier D, Fallon JT, Virmani R, et al. A mechanistic analysis of the role of microcalcifications in atherosclerotic plaque stability: potential implications for plaque rupture. Am J Physiol Heart Circ Physiol. 2012 Sep 1;303(5):H619-28.

17. Mönckeberg J. Über die reine Mediaverkalkung der Extremitätenarterien und ihr Verhalten zur Arteriosklerose. Virchows Archiv. 1903;171(1):141-67.

18. Pai A, Leaf EM, El-Abbadi M, Giachelli CM. Elastin degradation and vascular smooth muscle cell phenotype change precede cell loss and arterial medial calcification in a uremic mouse model of chronic kidney disease. The American journal of pathology. 2011;178(2):764-73.

19. Shanahan CM, Cary NR, Salisbury JR, Proudfoot D, Weissberg PL, Edmonds ME. Medial localization of mineralization-regulating proteins in association with Mönckeberg's sclerosis evidence for smooth muscle cell-mediated vascular calcification. Circulation. 1999;100(21):2168-76.

20. Giachelli CM. Vascular calcification mechanisms. Journal of the American Society of Nephrology. 2004;15(12):2959-64.

21. Clarke MC, Littlewood TD, Figg N, Maguire JJ, Davenport AP, Goddard M, et al. Chronic apoptosis of vascular smooth muscle cells accelerates atherosclerosis and promotes calcification and medial degeneration. Circ Res. 2008 Jun 20;102(12):1529-38.

22. Shanahan CM, Crouthamel MH, Kapustin A, Giachelli CM. Arterial calcification in chronic kidney disease: key roles for calcium and phosphate. Circ Res. 2011 Sep 2;109(6):697-711.

23. Jono S, McKee MD, Murry CE, Shioi A, Nishizawa Y, Mori K, et al. Phosphate regulation of vascular smooth muscle cell calcification. Circ Res. 2000 Sep 29;87(7):E10-7.

24. Alexander MR, Owens GK. Epigenetic control of smooth muscle cell differentiation and phenotypic switching in vascular development and disease. Annu Rev Physiol. 2012;74:13-40.

25. Chen NX, O'Neill KD, Duan D, Moe SM. Phosphorus and uremic serum up-regulate osteopontin expression in vascular smooth muscle cells. Kidney Int. 2002 Nov;62(5):1724-31.

26. Speer MY, Li X, Hiremath PG, Giachelli CM. Runx2/Cbfa1, but not loss of myocardin, is required for smooth muscle cell lineage reprogramming toward osteochondrogenesis. J Cell Biochem. 2010 Jul 1;110(4):935-47.

27. Doherty TM, Asotra K, Fitzpatrick LA, Qiao J-H, Wilkin DJ, Detrano RC, et al. Calcification in atherosclerosis: bone biology and chronic inflammation at the arterial crossroads. Proceedings of the National Academy of Sciences. 2003;100(20):11201-6.

28. Tagariello A, Luther J, Streiter M, Didt-Koziel L, Wuelling M, Surmann-Schmitt C, et al. Ucma-A novel secreted factor represents a highly specific marker for distal chondrocytes. Matrix Biol. 2008 Jan;27(1):3-11.

29. Surmann-Schmitt C, Dietz U, Kireva T, Adam N, Park J, Tagariello A, et al. Ucma, a novel secreted cartilage-specific protein with implications in osteogenesis. J Biol Chem. 2008 Mar 14;283(11): 7082-93. 
30. New SE, Aikawa E. Role of extracellular vesicles in de novo mineralization an additional novel mechanism of cardiovascular calcification. Arteriosclerosis, thrombosis, and vascular biology. 2013;33(8):1753-8.

31. Tanimura A, McGregor DH, Anderson HC. Matrix vesicles in atherosclerotic calcification. Experimental Biology and Medicine. 1983;172(2):173-7.

32. Proudfoot D, Skepper JN, Hegyi L, Bennett MR, Shanahan CM, Weissberg PL. Apoptosis regulates human vascular calcification in vitro: evidence for initiation of vascular calcification by apoptotic bodies. Circ Res. 2000 Nov 24;87(11):1055-62.

33. Kapustin AN, Chatrou ML, Drozdov I, Zheng Y, Davidson SM, Soong D, et al. Vascular smooth muscle cell calcification is mediated by regulated exosome secretion. Circ Res. 2015 Apr 10; 116(8):1312-23.

34. Kapustin AN, Davies JD, Reynolds JL, McNair R, Jones GT, Sidibe A, et al. Calcium Regulates Key Components of Vascular Smooth Muscle Cell-Derived Matrix Vesicles to Enhance Mineralization. Circulation research. 2011;109(1):e1-e12.

35. Persy V, D'Haese P. Vascular calcification and bone disease: the calcification paradox. Trends in molecular medicine. 2009;15(9):405-16.

36. Jahnen-Dechent W, Schafer C, Heiss A, Grotzinger J. Systemic inhibition of spontaneous calcification by the serum protein alpha 2-HS glycoprotein/fetuin. Z Kardiol. 2001;90 Suppl 3:47-56.

37. Jahnen-Dechent W, Heiss A, Schafer C, Ketteler M. Fetuin-A regulation of calcified matrix metabolism. Circ Res. 2011 Jun 10;108(12):1494-509.

38. Luo G, Ducy P, McKee MD, Pinero GJ, Loyer E, Behringer RR, et al. Spontaneous calcification of arteries and cartilage in mice lacking matrix GLA protein. Nature. 1997 Mar 6;386(6620):78-81.

39. Schurgers LJ, Joosen IA, Laufer EM, Chatrou ML, Herfs M, Winkens MH, et al. Vitamin K-antagonists accelerate atherosclerotic calcification and induce a vulnerable plaque phenotype. PLoS One. 2012; 7(8):e43229.

40. Schurgers LJ, Uitto J, Reutelingsperger CP. Vitamin K-dependent carboxylation of matrix Glaprotein: a crucial switch to control ectopic mineralization. Trends Mol Med. 2013 Apr;19(4): 217-26.

41. Murshed M, Schinke T, McKee MD, Karsenty G. Extracellular matrix mineralization is regulated locally; different roles of two gla-containing proteins. J Cell Biol. 2004 Jun 7;165(5):625-30.

42. Cranenburg EC, Schurgers LJ, Uiterwijk HH, Beulens JW, Dalmeijer GW, Westerhuis R, et al. Vitamin K intake and status are low in hemodialysis patients. Kidney Int. 2012 Sep;82(5):605-10.

43. Rennenberg RJ, de Leeuw PW, Kessels AG, Schurgers LJ, Vermeer C, van Engelshoven JM, et al. Calcium scores and matrix Gla protein levels: association with vitamin K status. Eur J Clin Invest. 2010 Apr;40(4):344-9.

44. Kruger T, Oelenberg S, Kaesler N, Schurgers LJ, van de Sandt AM, Boor P, et al. Warfarin induces cardiovascular damage in mice. Arterioscler Thromb Vasc Biol. 2013 Nov;33(11):2618-24. 
The realm of vitamin $\mathrm{K}$ dependent proteins: Shifting from coagulation toward calcification

Brecht A.G. Willems, Cees Vermeer, Chris P.M. Reutelingsperger, Leon J Schurgers

Mol. Nutr. Food Res. 2014, 58, 1620-1635 



\section{Introduction}

Vitamin $\mathrm{K}$ is arguably the least known vitamin and a member of the fat-soluble vitamins. The function of vitamin K remained unresolved until 1974, when Stenflo and colleagues described the presence of a modified glutamate (Glu) residue in prothrombin, a protein involved in blood coagulation (1). Shortly thereafter it was discovered that vitamin $\mathrm{K}$ is an essential cofactor in the post-translational modification of glutamate residues known as y-glutamylcarboxylation (2). Today, these modified, protein-bound glutamate residues are known as $\gamma$-carboxyglutamate (Gla) residues. The conversion of Glu into Gla turned out to be essential for biological activity of prothrombin by granting its calcium binding activity (1).

Since the discovery of prothrombin, at least 14 more proteins have been identified that contain Gla-residues. These proteins together build the so-called vitamin K-dependent protein (VKDP) family. VKDPs can be categorized into two groups; hepatic and extra-hepatic VKDPs. Hepatic VKDPs are mainly involved in balancing blood coagulation by bridging their Gla residues through calcium with negatively charged phospholipids (3, 4). Extra-hepatic VKDPs have distinct functions, yet their Gla-residues also have high affinity for calcium. Osteocalcin was the first extra-hepatic VKDP identified and is involved in regulation of calcification of bone matrix (5). Some 10 years later, another extra-hepatic VKDP associated with calcification was isolated from demineralized bone (6). This VKDP was termed matrix Gla-protein (MGP) and is involved in the inhibition of ectopic calcification. A more recently identified VKDP, Gla-rich protein (GRP), is also isolated from bone and cartilage. GRP is also known as upper zone of growth plate and cartilage matrix associated protein (Ucma) $(7,8)$. Similar to MGP, GRP has been purified from calcified cartilage (9). In this review we discuss the functions of VKDPs beyond coagulation and describe their role in physiological and pathological calcification.

\section{Vitamin $\mathrm{K}$}

Vitamin K was identified in the early 1930s by the Danish researcher Hendrik Dam (10). He observed that chickens fed a low fat diet displayed an increased bleeding tendency. When substituting the diet with cholesterol, the bleeding phenotype did not disappear. It turned out that the lipid fraction contained an antihaemorrhagic factor which was designated "Koagulations vitamin", nowadays abbreviated as vitamin K (10).

All forms of vitamin $\mathrm{K}$ share a common 2-methyl-1,4-naphthoquinone ring structure called menadione (vitamin $\mathrm{K}_{3}$ ) and an isoprenoid side chain at the 3-position. Menadione is a synthetic chemical compound (Figure $1 \mathrm{~A})(11)$. Depending on length and saturation of the side chain, vitamin $\mathrm{K}$ is classified as phylloquinone (vitamin $\mathrm{K}_{1}$ ) or as one of the menaquinones (vitamin $\mathrm{K}_{2}$ ) (Figure 1A). Phylloquinone contains a phytyl side chain and is found in green as well as non-green leafy vegetables (12). Menaquinones consist of a side chain with repeating isoprene residues containing an unsaturated bond. Depending on the number of repeats, menaquinones are subcategorized as MK-n with $n$ being the number of isoprenoid residues. The longer the side chain, the more lipophilic menaquinones are. Menaquinones are found 
A.<smiles>CC1=C(/C=C/C(C)=C\CCC(C)CCCC(C)CCCC(C)C)C(=O)c2ccccc2C1=O</smiles>

Vitamin $\mathrm{K} 1$ (Phylloquinone)<smiles>CC=C(C)C=C(C)CC(C)=CC1=C(C)C(=O)c2ccccc2C1=O</smiles>

Vitamin K2 (Menaquinone)<smiles>CC1=CC(=O)c2ccccc2C1=O</smiles>

Vitamin K3 (Menadione)
B.

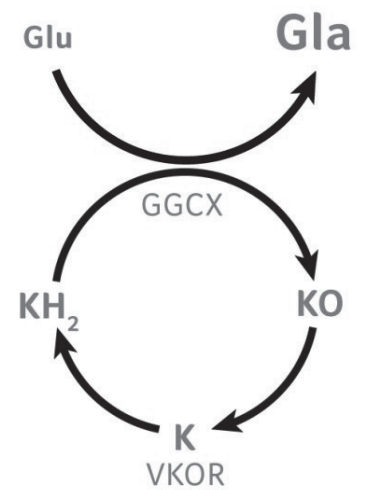

\section{Figure 1. Chemical structures of vitamin K and the vitamin K cycle.}

Panel A displays the 3 basic forms of vitamin $\mathrm{K}$. The upper structure represents vitamin $\mathrm{K} 1$, also known as phylloquinone. The middle structure represents vitamin $\mathrm{K} 2$, also known as menaquinones with $n$ representing the length of the isoprenoid side chain thereby indicating the respective menaquinone. The bottom structure represents vitamin $\mathrm{K} 3$, also known as menadione. Vitamin $\mathrm{K} 3$ is a 2-methyl-1,4-naphthoquinone ring structure which forms the basis for all $\mathrm{K}$-vitamins. Panel $\mathrm{B}$ represents the carboxylation cycle in which glutamate (Glu) residues are converted into $\gamma$-carboxyglutamate $(\mathrm{Gla})$ residues through conversion of reduced vitamin $\mathrm{K}(\mathrm{KH} 2)$ to vitamin $\mathrm{K}$ epoxide (KO). $\mathrm{KO}$ is recycled by vitamin $\mathrm{K}$ epoxide reductase (VKOR) such that it can be reused.

in bacterially fermented food and in liver. In addition to nutritional uptake, intestinal bacteria also synthesize menaquinones. In human intestines, microorganisms of the genera Bacteroides and Lactococcus synthesize menaquinones $(13,14)$. However, Suttie and colleagues postulated that the contribution of bacteria-derived menaquinones to human vitamin $\mathrm{K}$ status is limited due to the limited absorption of fat-soluble vitamins in the colon (15). In a typical western diet, phylloquinone presents the major fraction of vitamin K intake (16).

Vitamin K exerts its biological function as a cofactor for post-translational modification of specific Glu-residues in VKDPs. Glu-residues are modified by an enzymatic reaction known as the vitamin $\mathrm{K}$ cycle (Figure $1 \mathrm{~B}$ ). In this reaction both $\mathrm{\gamma}$-glutamyl carboxylation and vitamin K recycling take place. Gamma-glutamyl carboxylase (GGCX) converts reduced vitamin $\mathrm{K}$ hydroquinone $\left(\mathrm{KH}_{2}\right)$ into vitamin $\mathrm{K}$ epoxide $(\mathrm{KO})$ thereby facilitating the addition of a carboxylic acid to a Glu-residue. This results in formation of a Gla residue in the VKDP. Next, KO is recycled by vitamin K epoxide reductase (VKOR). VKOR is a multimer that efficiently reduces $\mathrm{KO}$ so it can be reused several hundred times to fuel the carboxylation reaction $(12,17)$. 


\subsection{Vitamin K-antagonists}

Around the same time vitamin K was discovered, a VKOR inhibitor was identified. Cattle fed spoiled clover showed increased bleeding tendency when being dehorned resulting in lethal haemorrhages. The spoiled clover contained a compound, later termed dicoumarol, responsible for the observed haemorrhages (18). Because of the potency to cause severe bleedings, warfarin, a coumarin derivative, was synthesized and used as a rodenticide. After a failed suicide attempt with warfarin by a US military soldier, it became clear that warfarin could be used as a drug to treat coagulation-related problems. Coumarins act as vitamin $\mathrm{K}$ antagonists (VKA). They neither interfere with absorption and transport of vitamin $\mathrm{K}$, nor with carboxylation. They inhibit vitamin $\mathrm{K}$ recycling by blocking VKOR activity (19). As a consequence, depletion of tissue vitamin $K$ reserves occurs, resulting in undercarboxylation of VKDPS.

As VKA treatment is not liver specific, extra-hepatic VKDPs are also affected. This sideeffect of VKA has only recently been recognized. One such consequence of VKA treatment is increased calcification of the vasculature (20-22). Calcification of the vasculature induced by warfarin was first observed by Price and colleagues (23). They injected rats with daily doses of warfarin combined with vitamin $\mathrm{K} 1$ to prevent lethal hemorrhages. Administration of the combination of warfarin and vitamin $\mathrm{K}$ resulted in depletion of vitamin $\mathrm{K} 1$ in extrahepatic tissue but not in liver because of the biodistribution kinetics of vitamin $\mathrm{K} 1$. After 2 weeks of treatment, aortic calcifications occurred which progressively increased at 3, 4 and 5 weeks of treatment. Calcification was ascribed to the inhibition of $\gamma$-carboxylation of MGP. This was confirmed by two other experiments in which mice were fed a warfarinenriched diet. In addition to calcifications, histochemical analysis revealed the presence of chondrocyte-like cells in the vessel wall associated with calcifications $(20,22)$.

\section{Calcification}

Calcification is a physiological process required to create mineralized tissue such as teeth and bones. Mineralized tissues perform various functions ranging from internal support to protecting vital organs (24). However, calcification can also be detrimental. Ectopic calcification of soft tissues is pathological and presents a risk factor for increased mortality (25, 26). Below, we will address the involvement of VKDP in both physiological and pathological calcification.

\subsection{Physiological calcification}

Physiological calcification is a multifactorial, complex process which is tightly regulated (27). The main site of physiological calcification is the bone matrix of the skeleton (28). Both bone formation and remodeling are performed by bone cells: osteoblasts, osteoclasts and osteocytes (29-31). Osteoblasts originate from mesenchymal cells. They synthesize an extracellular matrix which then becomes mineralized by precipitation of insoluble 
calcium salts from the extracellular fluids following matrix maturation (30). Osteoclasts are specialized hematopoietic cells that resorb bone by solubilizing calcium-phosphate crystal deposits and breaking down the matrix structure (31, 32). Osteocytes are derived from osteoblasts and are the most abundant cells in the mature bone matrix. They are involved in regulation of both systemic and local mineralization, bone formation and bone
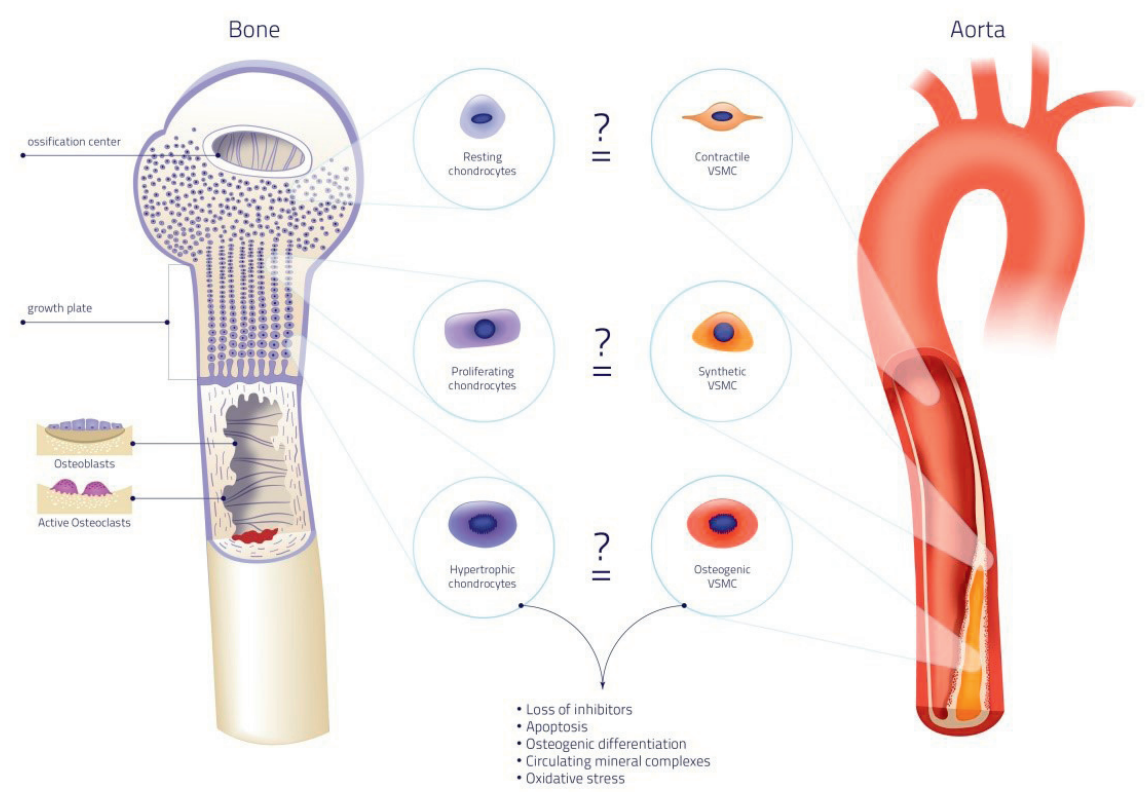

\section{Figure 2. Similarities of physiological and pathological calcification.}

In the cartilage growth plate chondrocytes mature. Resting chondrocytes proliferate and become hypertrophic. The onset of hypertrophy is accompanied with loss of calcification inhibitors. This causes HA crystal formation in matrix vesicles which serve as a nidus for calcification. Eventually, hypertrophic chondrocytes become apoptotic and these apoptotic bodies serve as calcification nidus. Calcification is further accelerated by activation of osteogenic genes such as Runx2/Cbfa1 and osteocalcin. Similar mechanisms are involved in vascular calcification. Stress signals such as increased calcium and phosphate induce calcification through VSMC phenotypic switching: they lose calcification inhibitors, and contractility markers. This is accompanied by upregulation of osteoregulatory genes. Additionally, VSMCs start secreting matrix vesicles that calcify in the extracellular matrix of the vessel wall. Phagocytosis of calcium crystals by neighboring VSMCs induces apoptosis which further accelerates calcification. Finally, bone mineralization and vascular calcification are intertwined by bone remodeling (126). Remodeling is performed by bone multicellular units and causes release of mineral complexes from the bone into the blood. These mineral complexes can lodge in soft tissues to form a nidus for calcification. Thus, physiological and pathological calcification share striking similarities. Resting chondrocytes share many similarities with contractile VSMCs. Both cell types are resistant to calcification. Proliferating chondrocytes share similarities to synthetic VSMCs which possess a limited capacity to calcify. Finally, hypertrophic chondrocytes share similarities with osteogenic VSMCs. Both lose calcification inhibitors, shed matrix vesicles and have expression of genes associated with osteogenesis. 
resorption (33). Chondrocytes, constituting cartilage, are a special type of bone-associated cells with a crucial role in skeletal development and growth.

Bone formation starts from a cartilage template. This template is replaced by bone in a process called endochondral ossification. Intramembranous ossification is another essential process for skeletal development independent of a cartilage template. Prior to calcification of the cartilage template, chondrocytes become hypertrophic (Figure 2). Hypertrophy induces expression of typical bone markers such as runt-related transcription factor 2/ core-binding factor subunit alpha-1 (Runx2/Cbfa1), collagen type X and alkaline phosphatase (ALP), a hydrolytic enzyme that inactivates pyrophosphate, a potent calcification inhibitor. ALP is secreted by chondrocytes in matrix vesicles, the nidus for calcification of the cartilage template (34). Inside these vesicles, hydroxyapatite (HA) crystals composed of calcium and phosphate are formed (35). Finally, calcified cartilage is invaded by blood vessels, osteoclasts and osteoblast precursor cells. Osteoclasts remove the cartilage extracellular matrix and osteoblasts deposit bone onto the remnants. After calcification, a cartilage growth plate, responsible for future longitudinal growth remains. In the growth plate, chondrocytes maturate and calcify until bone growth stops (Figure 2) (36).

Bone is continuously remodeled to preserve skeletal health. This is performed by bone multicellular units composed of osteoblasts and osteoclasts (Figure 2) (24). Alterations in the balance between bone formation and degradation change the bone mass and density. This results in compromised bone health, which is seen in osteoporosis and osteopetrosis $(37,38)$. Thus control of mineralization is crucial for normal functioning of the body and is partially regulated by extra-hepatic VKDPs.

\subsection{VKDPs in physiological calcification}

VKDPs have high affinity for calcium-based matrices through their Gla residues (39). Osteocalcin and MGP were, until recently the only VKDPs known to be involved in physiological calcification. With the recent discovery of GRP, a new kid on the block has appeared (9).

\subsubsection{Osteocalcin}

Osteocalcin is the most abundant, non-collagenous protein in bone. It is expressed by mature osteoblasts and early hypertrophic chondrocytes (40,41). Two different roles of osteocalcin in calcification have been proposed: 1) regulation of bone mineralization and 2) regulation of osteoblast and osteoclast activity $(42,43)$. Osteocalcin-deficient mice have increased bone mass and increased ALP levels indicating that osteocalcin is involved in regulation of bone mineralization (44). Using Fourier transform infrared microspectroscopy, it was shown that bones from osteocalcin-deficient mice had less matured and smaller HA crystals as compared to wild-type mice (45). Osteocalcin has, in the carboxylated conformation, a high affinity for calcium. It has been reported that osteocalcin modulates HA crystal morphology and growth $(42,46)$. Hunter et al. demonstrated that osteocalcin interferes with early stages of calcification through delaying HA nucleation without influencing the 
final amount of HA crystals formed (46). However, the carboxylation status of osteocalcin in these experiments was not reported. Additionally, osteocalcin is involved in regulation of osteoblast and osteoclast activity. The increased bone mass seen in osteocalcin-deficient mice suggests osteoblast activity is increased in the absence of osteocalcin (44). Contradictory, it has been shown that osteocalcin stimulates osteoblast activity and increases bone formation by enhancing the initial adherence of osteoblasts in vitro (47). Additionally, mice with a HA/collagen composite implant had increased bone healing and active osteoblasts in the presence of osteocalcin (48). It has been suggested that osteocalcin performs this effect through a G-protein coupled receptor (49). Taking advantage of the effects of osteocalcin on bone, mouse models have been developed to study osteogenic processes and skeletal repair in vivo (50). However, once again the carboxylation status of the osteocalcin used in these studies was not reported.

Osteocalcin affects osteoclasts and consequently, bone remodeling, which is dependent on the carboxylation status. It serves as a chemotactic signal for osteoclasts, stimulates osteoclast differentiation, maturation and activity thereby increasing bone turnover rates (51-55). These effects are moderated by calcium release from stores into the cytosol and were shown to be independent of vitamin K-dependent carboxylation (53).

Serum osteocalcin levels are currently considered to be one of the most sensitive markers of bone formation (56). This makes osteocalcin an attractive target to study pharmaceutical and nutraceutical effects on bone (57). Indeed, serum levels of uncarboxylated osteocalcin have been reported to be a measure for vitamin K status in bone (58). However, clinical trials with vitamin $\mathrm{K}$ supplementation did not find a consistent protective effect on bone loss, even though the carboxylation status of osteocalcin was improved (59-61). This observation is in accordance with part of the in vitro work, where some of the effects of osteocalcin were found to be independent of its carboxylation status.

Recently, the skeleton was put-forward as an endocrine tissue with a hormonal function for osteocalcin regulating male fertility and energy metabolism $(62,63)$. A detailed review on this topic has been provided by Karsenty and Ferron (64).

\subsubsection{Matrix Gla Protein}

MGP is widely expressed and accumulates in cartilage and calcified tissues (65). In cartilage, MGP is expressed by resting, proliferative and late hypertrophic chondrocytes (66). In contrast to osteocalcin, MGP expression is absent in early hypertrophic chondrocytes and osteoblasts. Furthermore, MGP levels are elevated early on during bone formation (67). MGP is present in matrix vesicles in cartilage, suggesting its function as a regulator of cartilage calcification (68). It was demonstrated that both cartilage and bone derived MGP was carboxylated. The role of MGP in cartilage and bone calcification was elucidated in MGPdeficient mice (69). MGP-deficient mice have normal size and weight at birth, however as they age, growth is retarded compared to wild-type animals. Age-matched MGP-deficient animals are significantly smaller than wild-type mice and histological analysis shows un- 
regulated calcification of growth plate cartilage. Consequently, the growth plate becomes disorganized. Newman and colleagues demonstrated an anti-apoptotic effect of MGP in proliferative chondrocytes and suggested that increased apoptosis is the cause of growth plate disorganization (70). This effect appears to be independent of MGP carboxylation, as warfarin treatment of proliferative chondrocytes of chickens had no effect on chondrocyte survival (71). Warfarin treatment to inhibit vitamin K-dependent carboxylation did however induce calcification in hypertrophic chondrocyte cultures(71). Calcification could be counteracted by co-treatment with vitamin K. Additionally, MGP overexpression in resting and hypertrophic chondrocytes delayed chondrocyte maturation, inhibited cartilage calcification and blocked endochondral ossification.

The calcification inhibitory effect of MGP is partly based on its direct HA-binding ability through Gla residues (72). Keutel disease is caused by mutations in the MGP gene resulting in non-functional protein (73). In Keutel disease patients, increased cartilage calcification is observed, similar to MGP-deficient mice. MGP overexpression in teeth of mice caused severe hypo-mineralization (74). Moreover, inhibition of calcification was shown to be dependent on Gla residues: transgenic mice with an MGP mutant that cannot be carboxylated acquired a phenotype similar to MGP-deficient mice (75). The lack of carboxylated MGP has also been associated with pathological calcification in osteoarthritic cartilage (76).

MGP affects osteogenesis, chondrocyte maturation and consequently inhibits calcification through interaction with bone morphogenetic protein-2 (BMP-2) (77, 78). BMP-2 is a potent inducer of bone formation in both skeletal and soft tissues $(79,80)$. MGP regulates BMP-2 activity via binding to BMP-2 with its Gla residues (81). This emphasizes the need of carboxylation of MGP in bone and cartilage formation.

\subsubsection{Gla Rich Protein}

GRP is a recently discovered VKDP with a high number of Gla residues. The first report in 2008 identified GRP as novel transcript in a human fetal growth plate cartilage cDNA library (8). It was hypothesized that GRP is a secretory marker for resting chondrocytes. This was confirmed by Stock and colleagues who showed that GRP is cartilage specific (7). More recently, GRP was shown to be widely expressed by both skeleton-associated tissues and soft tissues (9).

In vitro experiments showed that GRP is involved in regulation of osteogenesis by delaying osteoblast maturation (7). Subsequently, GRP was knocked down in zebrafish which caused severe growth retardation and perturbance of skeletal development (82). Additionally, collagen type II and aggrecan content in cartilage was reduced. This phenotype could be reproduced by treating zebrafish with VKA. The effect was ascribed to inhibition of GRP carboxylation since other VKDPs are not expressed during that phase of zebrafish development (82). Surprisingly, GRP-deficient mice did not display a clear phenotype during normal development (83). Cartilage development was normal indicating that GRP is not essential for normal bone formation. Current studies aim to investigate the involvement of GRP in skeletal homeostasis and in mechanical properties of the skeleton during disease. 


\subsection{Pathological calcification}

\subsubsection{Background}

Under physiological conditions soft tissues such as skin, kidneys and blood vessels do not calcify (84). Vascular calcification is a disease which was described as being present already over 5,000 years ago (85). Additionally, the presence of calcification in atherosclerosis in 4000 year old mummies was reported (86). Already more than 100 years ago, pathologists reported the presence of bone-like structures in extra-skeletal tissues (87). Pathological triggers cause soft tissues to become prone to calcify (88). This is pathological or ectopic calcification. Here we focus on the role of vascular smooth muscle cells (VSMCs) in vascular calcification.

Calcification of the vascular system is mainly present in the arterial vessel wall, and results in reduced arterial elasticity and subsequent altered hemodynamics. This contributes to development of aortic stenosis, cardiac hypertrophy, hypertension, heart failure and myocardial ischemia $(89,90)$. Since vascular calcification has an impact on cardiovascular disease development, coronary artery calcium content is now used as a measure for atherosclerotic plaque burden in asymptomatic individuals (91, 92)

Vascular calcification can manifest as intimal or medial calcification (Figure 3). It was long considered to be a passive bystander, not amendable for intervention. However, recent evidence clearly put forward that vascular calcification is a regulated process sharing similarities with bone formation (93).

\subsubsection{Intimal calcification}

Atherosclerosis is the leading cause of death and disability in western societies and often associated with calcification (Figure 3) (94). Intimal or atherosclerotic calcification is often caused by a combination of single-risk factors, such as hypertension, inflammation or dyslipidemia (95). Recently, inflammation was linked to microcalcifications in atherosclerotic plaques (96). Atherosclerosis is known to be a chronic inflammatory disease (97). Vascular calcification contributes to this inflammatory state as macrophages phagocytose HA crystals subsequently activating inflammatory cytokine expression (98). Intimal calcification can either manifest as spotty microcalcifications or as diffuse mineral deposits (Figure 3) $(20,99)$. The effect of calcification on atherosclerotic plaque stability is still a matter of debate. It was shown in post-mortem coronary arteries that massive calcification is not related to plaque stability (100). However, the presence of microcalcifications has been shown to be detrimental for plaque stability $(101,102)$. Of the microcalcifications present in coronary arteries, only the calcification spots in the fibrous cap seem to have an adverse effect on biomechanical plaque stability. The presence of microcalcifications in lipid pools or necrotic cores has little influence on biomechanical stability (103). 


\subsubsection{Medial calcification}

In medial calcification, also known as Mönckeberg sclerosis, amorphous mineral deposits are formed along the elastin fibers of the tunica media (Figure 3) (104). Medial calcification has been found throughout the entire vascular tree and is highly prevalent in the aging population, in chronic kidney disease (CKD) patients and people with diabetes mellitus $(105,106)$. VSMCs have been shown to play a key role in regulating medial calcification.

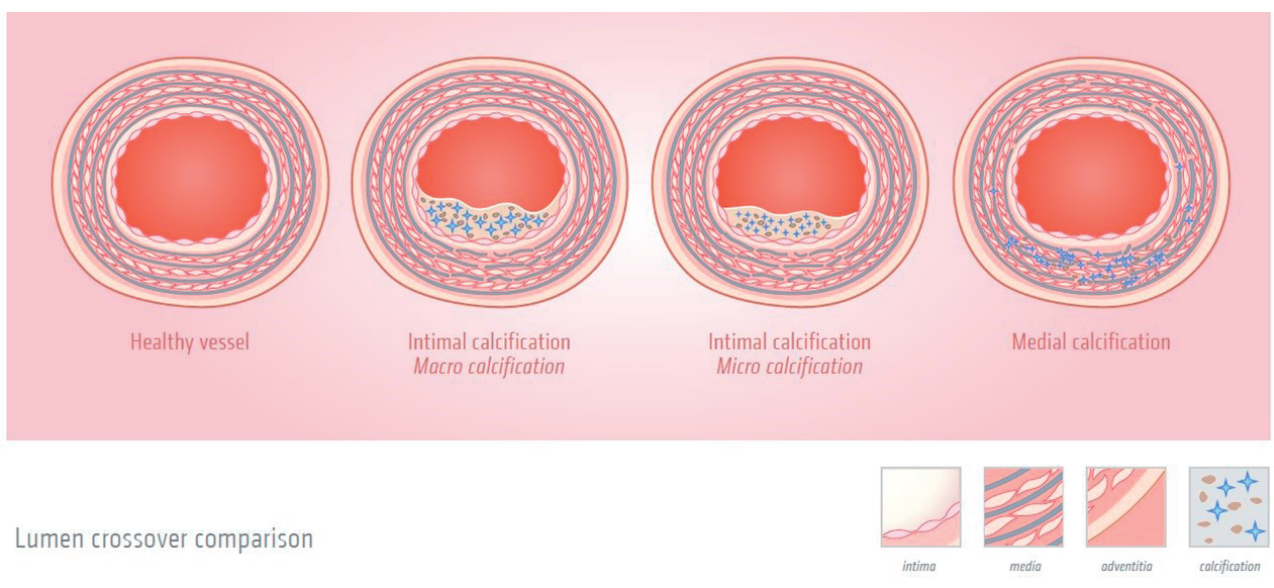

Figure 3. Different manifestations of vascular calcification.

Different types of vascular calcification can occur in the vasculature. A) healthy blood vessel in the absence of calcification. B) blood vessel containing an atherosclerotic plaque in which macrocalcification is present. C) blood vessel with an atherosclerotic plaque in which microcalcifications are present. Microcalcifications are responsible for destabilizing the plaque, causing an increased risk of plaque rupture. D) blood vessel with medial calcification with calcium deposits present along the elastic laminae of the tunica media.

\subsection{Molecular mechanisms of vascular calcification}

Based on literature, at least 4 different processes involved in development of vascular calcification have been identified including: 1) loss of calcification inhibitors, 2) circulating mineral complexes, 3) apoptosis and 4) osteochondrogenic differentiation of VSMCs. In all of these processes, an important role for VKDPs has been put forward.

\subsubsection{Loss of calcification inhibitors}

Human body fluids are supersaturated with regard to both calcium and phosphate (107). However, spontaneous precipitation of calcium-phosphate crystals does not occur. This is due to tight control of calcium precipitation by calcification inhibitors. Fetuin-A and MGP are both proteins with strong anti-calcification properties $(108,109)$. Fetuin-A is a circulatory protein that inhibits calcium-phosphate crystal precipitation through formation of a fetuin-MGP mineral complex (110). In fetuin A-deficient mice, spontaneous soft tissue mineralization is present (111). MGP prevents calcification of the tunica media by preventing precipitation of calcium-phosphate crystals onto elastin fibers $(73,112)$. The ability of MGP 
to bind calcium-phosphate crystals is dependent on its Gla residues and consequently, vitamin K status $(23,113)$.

\subsubsection{Circulating mineral complexes}

Bone remodeling and vascular calcification are connected. By prevention of vascular calcification, the low bone mineral density phenotype in MGP-deficient mice can be restored (114). A circulating mineral complex, called the fetuin mineral complex (FMC), was detected in serum of rats treated with etidronate to prevent bone calcification (115, 116). The FMC originates from bone and contains MGP (117). Vitamin K-dependent $\gamma$-carboxylation of MGP is essential for the presence of MGP in the FMC (118). Upon warfarin treatment of the rats, MGP can no longer be detected in the FMC. Additionally, this study also showed that MGP serum levels rise dramatically upon prevention of bone calcification. Virtually all serum MGP seems associated with the FMC. Additionally, upon inhibition of hydroxyapatite precipitation FMC is formed (110).

\subsubsection{Apoptosis}

Apoptosis is a common feature in various tissues, including the vasculature where it regulates cell number. However, sometimes apoptosis may be upregulated or phagocytosis may be impaired. Apoptosis in atherosclerosis is associated with plaque instability (119). Additionally, the observed paucity of VSMCs in ruptured plaques when compared to stable plaques suggests VSMC apoptosis might play a role in a phase prior to rupture. Apoptotic VSMC generate negatively charged membrane particles, which - if not phagocytosed properly - promote initiation of calcification by serving as the initial nidus for calcium-phosphate crystal precipitation (120-122). Calcification-inhibitory proteins like MGP tend to block the HA nidus on these membrane structures or form stabilized crystal forms. In 1967, Anderson first used the name "matrix vesicles" in cartilage development and calcification (123). Tanimura and co-workers were the first to reported an association between matrix vesicles and vascular calcification (124). Vesicular structures have been found in both the tunica intima and media and were likely derived from vascular smooth muscle cells (VSMCs).

\subsubsection{Osteogenic differentiation of VSMC}

As described above VSMCs display a high degree of phenotypic plasticity that is triggered by both extra- and intracellular signals (Figure 4) $(125,126)$. VKDPs are involved in controlling this phenotypical plasticity. In the development of vascular calcification VSMCs play an important role as contractile, synthetic and osteogenic VSMCs (19). In normal vasculature, contractile VSMCs in the tunica media regulate vessel tone and diameter to maintain hemodynamic balance (126). Phenotypic switching of VSMCs is necessary to deal with varying conditions of vascular tissue (127). VSMCs can transdifferentiate towards a synthetic or osteogenic phenotype that can calcify the vascular wall (Figure 4) (128). Osteogenic dif- 


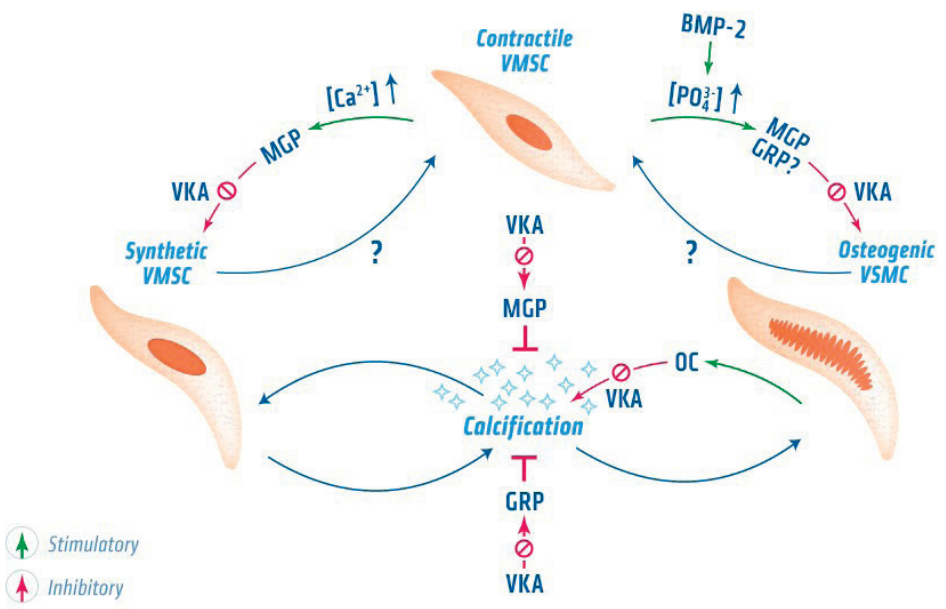

\section{Figure 4. Control of the VSMC phenotypic switch by VKDPs.}

Normally, VSMCs are in the contractile phenotype. However upon exposure to stress signals such as elevated calcium and phosphate levels, transdifferentiation towards a synthetic or osteochondrogenic phenotype occurs. Whether VSMCs can directly switch towards to an osteogenic phenotype or first go through the synthetic state remains to be determined. VKDPs are involved in regulating these phenotypical switches. Carboxylated MGP is involved in maintaining the contractile phenotype of VMSCs and supports vascular elasticity. It further assists in maintaining the contractile phenotype by inhibiting BMP-2 through its Gla residues. VKA treatment accelerates VSMC phenotypical switching by preventing carboxylation of VKDPs. Uncarboxylated MGP was shown to be incapable of preventing vascular calcification. In VSMCs transdifferentiated towards an osteogenic phenotype, osteogenic genes become activated such as osteocalcin that can modulate vascular calcification by binding HA crystals through its Gla residues. However, osteocalcin has also been shown to stimulate osteogenic differentiation which promotes vascular calcification. Both synthetic and osteochondrogenic differentiation result in calcification of the vascular extracellular matrix. GRP, a recently discovered VKDP, is thought to be involved in regulating phenotypic switching of VSMCs. In osteoblast cells, GRP was found to inhibit osteogenic differentiation. However, it still remains to be determined whether GRP is also involved in osteogenic differentiation of VSMC and whether this effect is affected by VKA treatment.

ferentiation of VSMCs can be initiated by exposure to elevated phosphate concentrations and by BMP-2 (129).

A crucial step in osteogenic transdifferentiation is activation of cyclic AMP (cAMP) (130). CAMP causes phosphorylation of extracellular signal regulated kinase $1 / 2$ (Erk 1/2) via the MAPK pathway. Phosphorylated Erk $1 / 2$ upregulates expression of Runx2/Cbfa1, a gene essential for osteoblast differentiation and bone development (131, 132). Once Runx2/Cbfa1 expression is upregulated, other osteoregulatory genes such as ALP and osteocalcin that promote calcification of the vascular matrix are activated (90). 


\subsection{VKDPs in vascular calcification}

\subsubsection{Osteocalcin}

Osteocalcin is specific to bone and teeth and is not expressed by VSMCs under physiological conditions. However, in the atherosclerotic vessel wall osteocalcin is abundantly present, produced by osteoblast-like VSMCs (133-135). Recently, it was shown that also platelets contain and secrete osteocalcin in atherosclerotic plaques (136). Osteocalcin serum levels are elevated in rats fed a warfarin diet which correlated with the observed medial calcification (137). Clinically, osteocalcin might serve as a predictor of vascular calcification (138-140). However, to introduce undercarboxylated osteocalcin as a biomarker for vascular calcification, more research is required as it is essential to take bone metabolism into account.

Many studies show both Runx2/Cbfa1 and osteocalcin upregulation by VSMCs when exposed to elevated extracellular phosphate concentrations. This has put osteocalcin forward as marker of osteochondrogenic VSMCs. Osteocalcin-deficient mice did not display increased vascular calcification. However, high levels of osteocalcin corroborate with increased calcification of VSMCs in vitro (141). Additionally overexpressing osteocalcin in the VSMC cell line MOVAS causes upregulation of markers of osteogenic differentiation (139). This was ascribed to stabilizing HIF-1a thereby altering glucose metabolism. Moreover, knockdown of osteocalcin in MOVAS cells reduced osteogenic differentiation (139). These findings indicate that osteocalcin is not simply a passive bystander of calcification but acts as an active regulator in osteochondrogenic differentiation of VSMCs (142).

Osteocalcin positive endothelial progenitor cells have been isolated from patients with coronary atherosclerosis or type 2 diabetes $(140,143)$. These cells bear calcification potential, and were associated with severity of aortic calcification (144). The calcification potential was further demonstrated in cell culture where they formed calcified nodules and expression of osteogenic markers in response to inflammatory signals (145).

\subsubsection{Matrix Gla Protein}

MGP was first linked to vascular calcification by Shanahan and coworkers in the early 90s. They found upregulated MGP expression in late passage, dedifferentiated VSMCs as compared to freshly transplanted VSMCs. Moreover, they observed high MGP expression in human atherosclerotic plaques $(146,147)$. These reports caused a paradigm shift. Until that time calcification of soft tissues was considered to be a passive process. Nowadays, evidence is present that vascular calcification is a highly regulated cell-mediated process (93).

Different groups demonstrated in vitro that MGP mRNA levels are upregulated in VSMCs in response to high calcium levels $(148,149)$. High extracellular calcium is a key signal regulating expression of MGP via a G-protein coupled mechanism similar to the calcium-sensing receptor (CaR) (150). However, the function of MGP only became clear in MGP-deficient 
mice, which died within 2 months after birth as a consequence of massive hemorrhages due to blood vessel rupture caused by arterial calcification (69). The same group showed that VSMC-specific MGP knock-in rescued the calcification phenotype of MGP-deficient mice (75). Additionally, elastin haploinsufficiency in MGP-deficient mice reduced vascular calcification (128). The necessity of carboxylation for MGPs proper functioning was also demonstrated using in vivo mutagenesis experiments (75). Here glutamic acid residues were replaced by aspartic acid residues which cannot be carboxylated. The GlaMGP-deficient mice died due to massive calcification of the vascular system, even though uncarboxylated MGP was present.

Although MGP is present in the circulation, increasing circulating levels did not prevent calcification of the vascular matrix suggesting MGP inhibits calcification through a local rather than a systemic effect (75). Therefore it is assumed that plasma MGP levels reflect local synthesis and thus might serve as predictor of vascular calcification (151-153).

The significance of vitamin $\mathrm{K}$ dependent carboxylation in regulating vascular calcification became clear in rats fed a warfarin enriched diet. These animals developed rapid calcification of the elastic lamellae and heart valves (23). Vascular calcification induced by warfarin was similar to that seen in MGP-deficient mice. In accordance with in vitro assays, warfarin treatment in rats caused an increase in MGP mRNA and protein levels in the vasculature. The effect of warfarin on MGP was confirmed by in vitro calcification experiments (154, 155). This prompted researchers to investigate the effect of VKA in patients. Since the first report, this detrimental effect of VKA has been demonstrated in multiple experiments (20, $156,157)$. However, some trials in which VKA was administered found no association with increased coronary artery calcification $(158,159)$. More research is needed to reveal the precise mechanism by which VKA exert this clinical manifestation.

In addition to MGP's affinity for HA crystals, the presence of chondrocyte-like cells in the vascular wall of MGP-deficient mice implicated MGP is involved in controlling VSMC transdifferentiation (Figure 4) (160). Indeed, MGP has been shown to inhibit osteogenic transdifferentiation by interacting with BMP-2 $(78,161)$. BMP-2 is a potent inducer of calcification via osteogenic transdifferentiation of VSMCs (162). VSMCs exposed to BMP-2 increase activin-like kinase receptor 1 (ALK1) expression (163). Consequently, ALK1 activation upregulates MGP expression, which in turn inhibits BMP-2 activity thereby reducing osteogenic transdifferentiation of VSMCs. Inactivation of BMP-2 required the carboxylation of MGP (164). Chronic kidney disease (CKD) patients suffer from increased circulating calcium and phosphate concentrations and subsequently high mortality due to vascular calcification. Osteogenic transdifferentiation of VSMCs is further accelerated by VKA and is associated with up- and down regulation of a number of genes including MGP $(165,166)$. The bisphosphonate etidronate, a drug used to inhibit bone loss, has been shown to up regulate MGP expression in the vessel wall and reduce vascular calcification (167). 


\subsubsection{Gla Rich Protein}

GRP is present in the normal vasculature and expression is increased when calcification occurs (168). GRP co-localized with mineral deposits in the vascular media of CKD and diabetes mellitus patients. GRP accumulation might be due to binding of HA crystals through Gla residues, similar to the function of MGP. Whether GRP fulfills a back-up mechanism for MGP to inhibit vascular calcification, has to be investigated.

In vitro, GRP delayed osteoblast maturation and downregulated both ALP activity and osteocalcin expression (7). Interestingly, BMP-2 was shown to downregulate GRP expression in chondrocytes (169). This suggests a possible role for GRP in the regulation of VSMC transdifferentiation and consequently, calcification of the vessel wall (Figure 4). However, in contrast to MGP-deficient mice GRP-deficient mice did not develop vascular calcifications under physiological conditions (83). It remains to be investigated whether GRP-deficient mice develop vascular calcification in challenging situations such as nephrectomy.

\section{Clinical consequences of vitamin K-deficiency}

As explained above vitamin $\mathrm{K}$ deficiency entails risk of soft tissue calcification. In addition vitamin $\mathrm{K}$ deficiency is associated with increased bleeding tendency. The most life threatening complication of vitamin $K$ deficiency occurs in newborns, especially those who are breastfed. Due to the placental barrier newborns have vitamin $\mathrm{K}$ deficiency and an thus increased risk of bleeding, also known as vitamin $K$ deficiency bleeding (VKDB). In most countries, vitamin $\mathrm{K}$ is administered prophylactically at birth which has resulted in a dramatic decrease of VKDB demonstrating the importance of vitamin K intake (170). CKD patients are also known to have a poor vitamin K status $(106,171,172)$. Vitamin K deficiency in the CKD population has been shown by decreased vitamin $\mathrm{K}$ levels in serum as well as with increased circulating levels of undercarboxylated VKDPs (172-175). CKD patients suffer from increased vascular calcification. Patients treated with VKA to control thrombotic tendencies have functional vitamin $\mathrm{K}$ deficiency and are at risk to develop vascular calcification $(21,176)$. Additionally, patients on long-term VKA treatment have a 30\% increased risk of bone fractures as compared to controls (177). However, this observation is inconsistent since other studies showed no effect of VKA treatment on bone loss (178-181). Vitamin $\mathrm{K}$ deficiency also occurs as a consequence of disturbed intestinal absorption, antibiotic therapy or dietary deficiency (12). Our knowledge about vitamin $\mathrm{K}$ and its biological functions has revealed a number of assays and circulating biomarkers that report vitamin K status including coagulation assays, measurement of undercarboxylated VKDPS (prothrombin, MGP, osteocalcin) in serum, vitamin K intake and serum levels and vitamin $\mathrm{K}$ metabolites in urine (182-184). Due to the omnipresence of vitamin K deficiency, it is of interest to look into the therapeutical administration of vitamin K. Vitamin K administration might be able to counteract or attenuate vascular or bone disease progression. 


\subsection{Therapeutic applications of vitamin K}

Since observational studies demonstrated a relationship between vitamin $\mathrm{K}$ status and bone mineral density, a number of placebo-controlled trials have been conducted to investigate this relationship. In the VIKI dialysis study, vitamin K deficiency was observed in hemodialysis patients and found to be a strong predictor of vertebral fractures and vascular calcifications (185). Hip fracture risk and bone mineral loss have been reported to be decreased in people consuming high amounts of vitamin K $(177,186)$.

Literature is inconclusive as to whether vitamin K supplementation has an effect on bone health. Several groups report no or marginal effects of vitamin K supplementation (187, 188). In contrast, other studies found vitamin K supplementation to preserve BMD (186, 189). In addition to bone health, vascular calcification has been associated with vitamin $K$ status (190). In post-menopausal women, receiving $1 \mathrm{mg}$ vitamin K1 for 3 years, increased vascular compliance, distensibility and intima-media thickness was reported (191). Moreover, vitamin $\mathrm{K} 1$ was found to slow down progression of coronary artery calcification in healthy, elderly adults (192). A randomized pilot trial in which different concentrations of vitamin K2 were administered to hemodialysis patients, confirmed that vitamin $\mathrm{K}$ deficiency of hemodialysis patients could be reversed by vitamin K-supplementation and that VKDP all showed improved carboxylation $(193,194)$.

Currently, several clinical trials such as the VitavasK (NCT01742273), VitaK-CAC (NCT01002157), VITAKANDOP (NCT01232647), SAFEK (NCT01533441), OVWAK VII (NCT00990158) are underway. The results of these trials will provide further insights into the therapeutic potential of vitamin $\mathrm{K}$ in treating both bone disorders and vascular diseases.

\section{Conclusion}

Although first discovered as the coagulation vitamin, vitamin K's biological functionality through $y$-carboxylation extends to VKDPs involved in vascular disease. Osteocalcin, MGP and GRP are all three VKDPs involved in regulation of both physiological mineralization of bone and pathological calcification of soft tissues. They regulate calcification at different levels including inhibition of calcium crystal formation and VSMC phenotypic switching. Soft tissue calcification is characteristic in CKD patients, patients suffering from diabetes mellitus and in the aging population. In these populations vitamin $\mathrm{K}$ deficiency is common. Vitamin $\mathrm{K}$ supplementation trials in healthy elderly have been performed, and vitamin $\mathrm{K}$ supplementation in patients suffering from vascular calcification are currently underway. Although based on indirect evidence, these results suggest that the use vitamin $\mathrm{K}$ is potentially beneficial in attenuating the progression of vascular calcification. The outcome of these trials will further evaluate the therapeutic potential of vitamin $\mathrm{K}$ administration to improve outcomes for populations at risk of vascular calcification. 


\section{References}

1. Stenflo J, Fernlund P, Egan W, Roepstorff P. Vitamin K dependent modifications of glutamic acid residues in prothrombin. Proc Natl Acad Sci U S A. 1974, 71(7),2730-2733.

2. Nelsestuen GL, Suttie JW. Mode of action of vitamin K. Calcium binding properties of bovine prothrombin. Biochemistry. 1972, 11(26),4961-4964.

3. Sunnerhagen M, Drakenberg T, Forsen S, Stenflo J. Effect of Ca2+ on the structure of vitamin K-dependent coagulation factors. Haemostasis. 1996, 26 Suppl 1,45-53.

4. Ellison EH, Castellino FJ. Adsorption of vitamin K-dependent blood coagulation proteins to spread phospholipid monolayers as determined from combined measurements of the surface pressure and surface protein concentration. Biochemistry. 1998, 37(22),7997-8003.

5. Hauschka PV, Lian JB, Gallop PM. Direct identification of the calcium-binding amino acid, gamma-carboxyglutamate, in mineralized tissue. Proceedings of the National Academy of Sciences. 1975, 72(10),3925-3929.

6. Price PA, Urist MR, Otawara Y. Matrix Gla protein, a new $\mathrm{Y}$-carboxyglutamic acid-containing protein which is associated with the organic matrix of bone. Biochem Biophys Res Commun. 1983, 117(3),765-771.

7. Surmann-Schmitt C, Dietz U, Kireva T, Adam N, et al. Ucma, a novel secreted cartilage-specific protein with implications in osteogenesis. J Biol Chem. 2008, 283(11),7082-7093.

8. Tagariello A, Luther J, Streiter M, Didt-Koziel L, et al. Ucma-A novel secreted factor represents a highly specific marker for distal chondrocytes. Matrix Biol. 2008, 27(1),3-11.

9. Viegas CS, Simes DC, Laize V, Williamson MK, et al. Gla-rich protein (GRP), a new vitamin Kdependent protein identified from sturgeon cartilage and highly conserved in vertebrates. J Biol Chem. 2008, 283(52),36655-36664.

10. Dam H, Schonheyder F. The occurrence and chemical nature of vitamin K. Biochem J. 1936, 30(5),897-901.

11. Martius C, Esser HO. The constitution of vitamin $\mathrm{K}$ formed from methylnaphthoquinone in animal body. Biochem Z. 1958, 331(1),1-9.

12. Shearer MJ, Newman P. Metabolism and cell biology of vitamin K. Thromb Haemost. 2008, 100(4),530-547.

13. Conly JM, Stein K. Quantitative and qualitative measurements of K vitamins in human intestinal contents. Am J Gastroenterol. 1992, 87(3),311-316.

14. Morishita T, Tamura N, Makino T, Kudo S. Production of menaquinones by lactic acid bacteria. $J$ Dairy Sci. 1999, 82(9),1897-1903.

15. Suttie JW. The importance of menaquinones in human nutrition. Annu Rev Nutr. 1995, 15,399417.

16. Thane CW, Wang LY, Coward WA. Plasma phylloquinone (vitamin K1) concentration and its relationship to intake in British adults aged 19-64 years. Br J Nutr. 2006, 96(6),1116-1124. 
17. Rishavy MA, Hallgren KW, Wilson LA, Usubalieva A, et al. The vitamin K oxidoreductase is a multimer that efficiently reduces vitamin K epoxide to hydroquinone to allow vitamin K-dependent protein carboxylation. J Biol Chem. 2013.

18. Link KP. The discovery of dicumarol and its sequels. Circulation. 1959, 19(1),97-107.

19. Chatrou ML, Winckers K, Hackeng TM, Reutelingsperger CP, et al. Vascular calcification: the price to pay for anticoagulation therapy with vitamin K-antagonists. Blood Rev. 2012, 26(4),155-166.

20. Schurgers LJ, Joosen IA, Laufer EM, Chatrou ML, et al. Vitamin K-antagonists accelerate atherosclerotic calcification and induce a vulnerable plaque phenotype. PLoS One. 2012, 7(8),e43229.

21. McCabe KM, Booth SL, Fu X, Shobeiri N, et al. Dietary vitamin K and therapeutic warfarin alter the susceptibility to vascular calcification in experimental chronic kidney disease. Kidney Int. 2013, 83(5),835-844.

22. Kruger T, Oelenberg S, Kaesler N, Schurgers LJ, et al. Warfarin Induces Cardiovascular Damage in Mice. Arterioscler Thromb Vasc Biol. 2013.

23. Price PA, Faus SA, Williamson MK. Warfarin causes rapid calcification of the elastic lamellae in rat arteries and heart valves. Arterioscler Thromb Vasc Biol. 1998, 18(9),1400-1407.

24. Kawasaki K, Buchanan AV, Weiss KM. Biomineralization in humans: making the hard choices in life. Annu Rev Genet. 2009, 43,119-142.

25. Leening MJ, Elias-Smale SE, Kavousi M, Felix JF, et al. Coronary calcification and the risk of heart failure in the elderly: the Rotterdam Study. JACC Cardiovasc Imaging. 2012, 5(9),874-880.

26. Rifkin DE, IX JH, Wassel CL, Criqui MH, et al. Renal artery calcification and mortality among clinically asymptomatic adults. J Am Coll Cardiol. 2012, 60(12),1079-1085.

27. Akkus O, Adar F, Schaffler MB. Age-related changes in physicochemical properties of mineral crystals are related to impaired mechanical function of cortical bone. Bone. 2004, 34(3),443-453.

28. Hessle L, Johnson KA, Anderson HC, Narisawa S, et al. Tissue-nonspecific alkaline phosphatase and plasma cell membrane glycoprotein-1 are central antagonistic regulators of bone mineralization. Proc Natl Acad Sci U S A. 2002, 99(14),9445-9449.

29. Knothe Tate ML, Adamson JR, Tami AE, Bauer TW. The osteocyte. The International Journal of Biochemistry \& Cell Biology. 2004, 36(1),1-8.

30. Harada S, Rodan GA. Control of osteoblast function and regulation of bone mass. Nature. 2003, 423(6937),349-355.

31. Teitelbaum SL. Bone resorption by osteoclasts. Science. 2000, 289(5484),1504-1508.

32. Boyle WJ, Simonet WS, Lacey DL. Osteoclast differentiation and activation. Nature. 2003, 423(6937),337-342.

33. Kennedy OD, Schaffler MB. The roles of osteocyte signaling in bone. J Am Acad Orthop Surg. 2012, 20(10),670-671.

34. Murshed M, McKee MD. Molecular determinants of extracellular matrix mineralization in bone and blood vessels. Curr Opin Nephrol Hypertens. 2010, 19(4),359-365. 
35. Studer D, Millan C, Ozturk E, Maniura-Weber K, et al. Molecular and biophysical mechanisms regulating hypertrophic differentiation in chondrocytes and mesenchymal stem cells. Eur Cell Mater. 2012, 24(24),118-135.

36. Mackie EJ, Tatarczuch L, Mirams M. The skeleton: a multi-functional complex organ: the growth plate chondrocyte and endochondral ossification. J Endocrinol. 2011, 211(2),109-121.

37. Raisz LG. Pathogenesis of osteoporosis: concepts, conflicts, and prospects. J Clin Invest. 2005, 115(12),3318-3325.

38. Tolar J, Teitelbaum SL, Orchard PJ. Osteopetrosis. N Engl J Med. 2004, 351(27),2839-2849.

39. Bone mineral crystal size. Osteoporos Int. 2003, 14 Suppl 5,S16-20; discussion S20-11.

40. Aubin J, Liu F, Malaval L, Gupta A. Osteoblast and chondroblast differentiation. Bone. 1995, 17(2),S77-S83.

41. Lian JB, McKee MD, Todd AM, Gerstenfeld LC. Induction of bone-related proteins, osteocalcin and osteopontin, and their matrix ultrastructural localization with development of chondrocyte hypertrophy in vitro. J Cell Biochem. 1993, 52(2),206-219.

42. Hoang QQ, Sicheri F, Howard AJ, Yang DS. Bone recognition mechanism of porcine osteocalcin from crystal structure. Nature. 2003, 425(6961),977-980.

43. Katagiri T, Takahashi N. Regulatory mechanisms of osteoblast and osteoclast differentiation. Oral Diseases. 2002, 8(3),147-159.

44. Ducy P, Desbois C, Boyce B, Pinero G, et al. Increased bone formation in osteocalcin-deficient mice. Nature. 1996, 382(6590),448-452.

45. Boskey AL, Gadaleta S, Gundberg C, Doty SB, et al. Fourier transform infrared microspectroscopic analysis of bones of osteocalcin-deficient mice provides insight into the function of osteocalcin. Bone. 1998, 23(3),187-196.

46. Hunter G, Hauschka P, Poole A, Rosenberg L, et al. Nucleation and inhibition of hydroxyapatite formation by mineralized tissue proteins. Biochem J. 1996, 317,59-64.

47. Knepper-Nicolai B, Reinstorf A, Hofinger I, Flade K, et al. Influence of osteocalcin and collagen I on the mechanical and biological properties of Biocement D. Biomol Eng. 2002, 19(2-6),227-231.

48. Rammelt S, Neumann M, Hanisch U, Reinstorf A, et al. Osteocalcin enhances bone remodeling around hydroxyapatite/collagen composites. Journal of Biomedical Materials Research Part A. 2005, 73(3),284-294.

49. Bodine PV, Komm BS. Evidence that conditionally immortalized human osteoblasts express an osteocalcin receptor. Bone. 1999, 25(5),535-543.

50. Pelled G, Gazit D. Imaging using osteocalcin-luciferase. J Musculoskelet Neuronal Interact. 2004, 4(4),362-363.

51. Mundy GR, Poser JW. Chemotactic activity of the gamma-carboxyglutamic acid containing protein in bone. Calcif Tissue Int. 1983, 35(2),164-168.

52. DeFranco DJ, Glowacki J, Cox KA, Lian JB. Normal bone particles are preferentially resorbed in the presence of osteocalcin-deficient bone particles in vivo. Calcif Tissue Int. 1991, 49(1),43-50. 
53. Chenu C, Colucci S, Grano M, Zigrino P, et al. Osteocalcin induces chemotaxis, secretion of matrix proteins, and calcium-mediated intracellular signaling in human osteoclast-like cells. J Cell Biol. 1994, 127(4),1149-1158.

54. Liggett WH, Jr., Lian JB, Greenberger JS, Glowacki J. Osteocalcin promotes differentiation of osteoclast progenitors from murine long-term bone marrow cultures. J Cell Biochem. 1994, 55(2),190-199.

55. Ishida M, Amano S. Osteocalcin fragment in bone matrix enhances osteoclast maturation at a late stage of osteoclast differentiation. J Bone Miner Metab. 2004, 22(5),415-429.

56. Lian JB, Gundberg CM. Osteocalcin. Biochemical considerations and clinical applications. Clin Orthop Relat Res. 1988, (226),267-291.

57. Kruger MC, Booth CL, Coad J, Schollum LM, et al. Effect of calcium fortified milk supplementation with or without vitamin $\mathrm{K}$ on biochemical markers of bone turnover in premenopausal women. Nutrition. 2006, 22(11-12),1120-1128.

58. Vermeer C, Gijsbers BL, Craciun AM, Groenen-van Dooren MM, et al. Effects of vitamin K on bone mass and bone metabolism. J Nutr. 1996, 126(4 Suppl),1187S-1191S.

59. Booth SL, Dallal G, Shea MK, Gundberg C, et al. Effect of vitamin K supplementation on bone loss in elderly men and women. J Clin Endocrinol Metab. 2008, 93(4),1217-1223.

60. Cheung AM, Tile L, Lee Y, Tomlinson G, et al. Vitamin K supplementation in postmenopausal women with osteopenia (ECKO trial): a randomized controlled trial. PLoS Med. 2008, 5(10),e196.

61. Binkley N, Harke J, Krueger D, Engelke J, et al. Vitamin K treatment reduces undercarboxylated osteocalcin but does not alter bone turnover, density, or geometry in healthy postmenopausal North American women. J Bone Miner Res. 2009, 24(6),983-991.

62. Lee NK, Sowa H, Hinoi E, Ferron M, et al. Endocrine Regulation of Energy Metabolism by the Skeleton. Cell. 2007, 130(3),456-469.

63. Oury F, Sumara G, Sumara O, Ferron M, et al. Endocrine Regulation of Male Fertility by the Skeleton. Cell. 2011, 144(5),796-809.

64. Karsenty G, Ferron M. The contribution of bone to whole-organism physiology. Nature. 2012, 481(7381),314-320.

65. Hale JE, Fraser JD, Price PA. The identification of matrix Gla protein in cartilage. J Biol Chem. 1988, 263(12),5820-5824.

66. Luo G, D'Souza R, Hogue D, Karsenty G. The matrix Gla protein gene is a marker of the chondrogenesis cell lineage during mouse development. J Bone Miner Res. 1995, 10(2),325-334.

67. Otawara Y, Price PA. Developmental appearance of matrix GLA protein during calcification in the rat. J Biol Chem. 1986, 261(23),10828-10832.

68. Loeser R, Carlson CS, Tulli H, Jerome WG, et al. Articular-cartilage matrix gamma-carboxyglutamic acid-containing protein. Characterization and immunolocalization. Biochem J. 1992, 282 ( Pt $1), 1-6$.

69. Luo G, Ducy P, Mckee MD, Pinero GJ, et al. Spontaneous calcification of arteries and cartilage in mice lacking matrix GLA protein. Nature. 1997, 386(6620),78-81. 
70. Newman B, Gigout LI, Sudre L, Grant ME, et al. Coordinated expression of matrix Gla protein is required during endochondral ossification for chondrocyte survival. J Cell Biol. 2001, 154(3),659666.

71. Yagami K, Suh JY, Enomoto-Iwamoto M, Koyama E, et al. Matrix GLA protein is a developmental regulator of chondrocyte mineralization and, when constitutively expressed, blocks endochondral and intramembranous ossification in the limb. J Cell Biol. 1999, 147(5),1097-1108.

72. Roy ME, Nishimoto SK. Matrix Gla protein binding to hydroxyapatite is dependent on the ionic environment: calcium enhances binding affinity but phosphate and magnesium decrease affinity. Bone. 2002, 31(2),296-302.

73. Munroe PB, Olgunturk RO, Fryns JP, Van Maldergem L, et al. Mutations in the gene encoding the human matrix Gla protein cause Keutel syndrome. Nat Genet. 1999, 21(1),142-144.

74. Kaipatur NR, Murshed M, McKee MD. Matrix Gla protein inhibition of tooth mineralization. J Dent Res. 2008, 87(9),839-844.

75. Murshed M, Schinke T, McKee MD, Karsenty G. Extracellular matrix mineralization is regulated locally; different roles of two gla-containing proteins. J Cell Biol. 2004, 165(5),625-630.

76. Wallin R, Schurgers LJ, Loeser RF. Biosynthesis of the vitamin K-dependent matrix Gla protein (MGP) in chondrocytes: a fetuin-MGP protein complex is assembled in vesicles shed from normal but not from osteoarthritic chondrocytes. Osteoarthritis Cartilage. 2010, 18(8),1096-1103.

77. Wallin R, Cain D, Hutson SM, Sane DC, et al. Modulation of the binding of matrix Gla protein (MGP) to bone morphogenetic protein-2 (BMP-2). Thromb Haemost. 2000, 84(6),1039-1044.

78. Zebboudj AF, Imura M, Bostrom K. Matrix GLA protein, a regulatory protein for bone morphogenetic protein-2. J Biol Chem. 2002, 277(6),4388-4394.

79. Rosen V. BMP2 signaling in bone development and repair. Cytokine Growth Factor Rev. 2009, 20(5-6),475-480.

80. Okubo Y, Bessho K, Fujimura K, Konishi Y, et al. Osteoinduction by recombinant human bone morphogenetic protein-2 at intramuscular, intermuscular, subcutaneous and intrafatty sites. International Journal of Oral \& Maxillofacial Surgery. 2000, 29(1),62-66.

81. Zebboudj AF, Shin V, Bostrom K. Matrix GLA protein and BMP-2 regulate osteoinduction in calcifying vascular cells. J Cell Biochem. 2003, 90(4),756-765.

82. Neacsu CD, Grosch M, Tejada M, Winterpacht A, et al. Ucmaa (Grp-2) is required for zebrafish skeletal development. Evidence for a functional role of its glutamate gamma-carboxylation. Matrix Biol. 2011, 30(7-8),369-378.

83. Eitzinger N, Surmann-Schmitt C, Bosl M, Schett G, et al. Ucma is not necessary for normal development of the mouse skeleton. Bone. 2012, 50(3),670-680.

84. Giachelli CM. Inducers and inhibitors of biomineralization: lessons from pathological calcification. Orthodontics \& Craniofacial Research. 2005, 8(4),229-231.

85. Murphy WA, Jr., Nedden Dz D, Gostner P, Knapp R, et al. The iceman: discovery and imaging. Radiology. 2003, 226(3),614-629.

86. Thompson RC, Allam AH, Lombardi GP, Wann LS, et al. Atherosclerosis across 4000 years of human history: the Horus study of four ancient populations. The Lancet. 381(9873),1211-1222. 
87. Virchow RLK. Cellular pathology, John Churchill,1860.

88. Speer MY, Giachelli CM. Regulation of cardiovascular calcification. Cardiovascular Pathology. 2004, 13(2),63-70.

89. van Varik BJ, Rennenberg RJ, Reutelingsperger CP, Kroon AA, et al. Mechanisms of arterial remodeling: lessons from genetic diseases. Front Genet. 2012, 3,290.

90. Demer LL, Tintut Y. Vascular calcification: pathobiology of a multifaceted disease. Circulation. 2008, 117(22),2938-2948.

91. Greenland P, LaBree L, Azen SP, Doherty TM, et al. Coronary artery calcium score combined with Framingham score for risk prediction in asymptomatic individuals. JAMA: the journal of the American Medical Association. 2004, 291(2),210-215.

92. LaMonte MJ, FitzGerald SJ, Church TS, Barlow CE, et al. Coronary artery calcium score and coronary heart disease events in a large cohort of asymptomatic men and women. American journal of epidemiology. 2005, 162(5),421-429.

93. Sage AP, Tintut Y, Demer LL. Regulatory mechanisms in vascular calcification. Nat Rev Cardiol. 2010, 7(9),528-536.

94. Strong Jp, Malcom GT, McMahan CA, Tracy RE, et al. Prevalence and extent of atherosclerosis in adolescents and young adults: Implications for prevention from the pathobiological determinants of atherosclerosis in youth study. JAMA. 1999, 281(8),727-735.

95. Achenbach S, Ropers D, Pohle K, Leber A, et al. Influence of Lipid-Lowering Therapy on the Progression of Coronary Artery Calcification A Prospective Evaluation. Circulation. 2002, 106(9),1077-1082.

96. New SE, Aikawa E. Molecular imaging insights into early inflammatory stages of arterial and aortic valve calcification. Circ Res. 2011, 108(11),1381-1391.

97. Libby P. Inflammation in atherosclerosis. Nature. 2002, 420(6917),868-874.

98. Nadra I, Mason JC, Philippidis P, Florey O, et al. Proinflammatory activation of macrophages by basic calcium phosphate crystals via protein kinase $\mathrm{C}$ and MAP kinase pathways: a vicious cycle of inflammation and arterial calcification? Circ Res. 2005, 96(12),1248-1256.

99. Roijers RB, Debernardi N, Cleutjens JP, Schurgers LJ, et al. Microcalcifications in early intimal lesions of atherosclerotic human coronary arteries. Am J Pathol. 2011, 178(6),2879-2887.

100. Huang H, Virmani R, Younis H, Burke AP, et al. The impact of calcification on the biomechanical stability of atherosclerotic plaques. Circulation. 2001, 103(8),1051-1056.

101. Vengrenyuk Y, Carlier S, Xanthos S, Cardoso L, et al. A hypothesis for vulnerable plaque rupture due to stress-induced debonding around cellular microcalcifications in thin fibrous caps. Proc Natl Acad Sci U S A. 2006, 103(40),14678-14683.

102. Maldonado N, Kelly-Arnold A, Vengrenyuk Y, Laudier D, et al. A mechanistic analysis of the role of microcalcifications in atherosclerotic plaque stability: potential implications for plaque rupture. Am J Physiol Heart Circ Physiol. 2012, 303(5),H619-628.

103. Kelly-Arnold A, Maldonado N, Laudier D, Aikawa E, et al. Revised microcalcification hypothesis for fibrous cap rupture in human coronary arteries. Proc Natl Acad Sci U S A. 2013, 110(26),1074110746 . 
104. Mizobuchi M, Towler D, Slatopolsky E. Vascular calcification: the killer of patients with chronic kidney disease. Journal of the American Society of Nephrology. 2009, 20(7),1453-1464.

105. Edmonds M. Medial arterial calcification and diabetes mellitus. Z Kardiol. 2000, 89(2),S101-S104.

106. Garimella PS, Sarnak MJ. Cardiovascular disease in CKD in 2012: moving forward, slowly but surely. Nat Rev Nephrol. 2013, 9(2),69-70.

107. Jahnen-Dechent W, Schafer C, Heiss A, Grotzinger J. Systemic inhibition of spontaneous calcification by the serum protein alpha 2-HS glycoprotein/fetuin. Z Kardiol. 2001, 90 Suppl3,47-56.

108. Jahnen-Dechent W, Heiss A, Schafer C, Ketteler M. Fetuin-A regulation of calcified matrix metabolism. Circ Res. 2011, 108(12),1494-1509.

109. Schurgers LJ, Uitto J, Reutelingsperger CP. Vitamin K-dependent carboxylation of matrix Glaprotein: a crucial switch to control ectopic mineralization. Trends Mol Med. 2013, 19(4),217-226.

110. Price PA, Lim JE. The inhibition of calcium phosphate precipitation by fetuin is accompanied by the formation of a fetuin-mineral complex. Journal of Biological Chemistry. 2003, 278(24),2214422152.

111. Merx MW, Schafer C, Westenfeld R, Brandenburg V, et al. Myocardial stiffness, cardiac remodeling, and diastolic dysfunction in calcification-prone fetuin-A-deficient mice. J Am Soc Nephrol. 2005, 16(11),3357-3364.

112. Schurgers LJ, Dissel PEP, Spronk HMH, Soute BAM, et al. Role of vitamin K and vitamin K-dependent proteins in vascular calcification. Z Kardiol. 2001, 90(3),57-63.

113. Price PA, Chan WS, Jolson DM, Williamson MK. The Elastic Lamellae of Devitalized Arteries Calcify When Incubated in Serum Evidence for a Serum Calcification Factor. Arterioscler Thromb Vasc Biol. 2006, 26(5),1079-1085.

114. Marulanda J, Gao C, Roman H, Henderson JE, et al. Prevention of arterial calcification corrects the low bone mass phenotype in MGP-deficient mice. Bone. 2013.

115. Price PA, Thomas GR, Pardini AW, Figueira WF, et al. Discovery of a high molecular weight complex of calcium, phosphate, fetuin, and matrix gamma-carboxyglutamic acid protein in the serum of etidronate-treated rats. J Biol Chem. 2002, 277(6),3926-3934.

116. Matsui I, Hamano T, Mikami S, Fujii N, et al. Fully phosphorylated fetuin-A forms a mineral complex in the serum of rats with adenine-induced renal failure. Kidney Int. 2009, 75(9),915-928.

117. Price PA, Caputo JM, Williamson MK. Bone origin of the serum complex of calcium, phosphate, fetuin, and matrix Gla protein: biochemical evidence for the cancellous bone-remodeling compartment. J Bone Miner Res. 2002, 17(7),1171-1179.

118. Price PA, Nguyen TM, Williamson MK. Biochemical characterization of the serum fetuin-mineral complex. J Biol Chem. 2003, 278(24),22153-22160.

119. Kolodgie FD, Narula J, Burke AP, Haider N, et al. Localization of apoptotic macrophages at the site of plaque rupture in sudden coronary death. Am J Pathol. 2000, 157(4),1259-1268.

120. Proudfoot D, Skepper JN, Hegyi L, Bennett MR, et al. Apoptosis regulates human vascular calcification in vitro: evidence for initiation of vascular calcification by apoptotic bodies. Circ Res. 2000, 87(11),1055-1062. 
121. Reynolds JL, Joannides AJ, Skepper JN, McNair R, et al. Human vascular smooth muscle cells undergo vesicle-mediated calcification in response to changes in extracellular calcium and phosphate concentrations: a potential mechanism for accelerated vascular calcification in ESRD. J Am Soc Nephrol. 2004, 15(11),2857-2867.

122. Shroff RC, McNair R, Figg N, Skepper JN, et al. Dialysis accelerates medial vascular calcification in part by triggering smooth muscle cell apoptosis. Circulation. 2008, 118(17),1748-1757.

123. Anderson HC. Electron microscopic studies of induced cartilage development and calcification. J Cell Biol. 1967, 35(1),81-101.

124. Tanimura A, McGregor DH, Anderson HC. Matrix vesicles in atherosclerotic calcification. Proc Soc Exp Biol Med. 1983, 172(2),173-177.

125. Rensen S, Doevendans P, Van Eys G. Regulation and characteristics of vascular smooth muscle cell phenotypic diversity. Netherlands Heart Journal. 2007, 15(3),100-108.

126. Alexander MR, Owens GK. Epigenetic control of smooth muscle cell differentiation and phenotypic switching in vascular development and disease. Annu Rev Physiol. 2012, 74,13-40.

127. Leroux-Berger M, Queguiner I, Maciel TT, Ho A, et al. Pathologic calcification of adult vascular smooth muscle cells differs on their crest or mesodermal embryonic origin. J Bone Miner Res. 2011, 26(7),1543-1553.

128. Khavandgar Z, Roman H, Li J, Lee S, et al. Elastin haploinsufficiency impedes the progression of arterial calcification in MGP-deficient mice. J Bone Miner Res. 2013.

129. Shanahan CM, Crouthamel MH, Kapustin A, Giachelli CM. Arterial calcification in chronic kidney disease: key roles for calcium and phosphate. Circ Res. 2011, 109(6),697-711.

130. Tintut Y, Parhami F, Bostrom K, Jackson SM, et al. cAMP stimulates osteoblast-like differentiation of calcifying vascular cells. Potential signaling pathway for vascular calcification. J Biol Chem. 1998, 273(13),7547-7553.

131. Byon CH, Javed A, Dai Q, Kappes JC, et al. Oxidative stress induces vascular calcification through modulation of the osteogenic transcription factor Runx2 by AKT signaling. Journal of Biological Chemistry. 2008, 283(22),15319-15327.

132. Speer MY, Li X, Hiremath PG, Giachelli CM. Runx2/Cbfa1, but not loss of myocardin, is required for smooth muscle cell lineage reprogramming toward osteochondrogenesis. J Cell Biochem. 2010, 110(4),935-947.

133. Severson AR, Ingram RT, Fitzpatrick LA. Matrix proteins associated with bone calcification are present in human vascular smooth muscle cells grown in vitro. In Vitro Cell Dev Biol Anim. 1995, 31(11),853-857.

134. Dhore CR, Cleutjens JP, Lutgens E, Cleutjens KB, et al. Differential expression of bone matrix regulatory proteins in human atherosclerotic plaques. Arterioscler Thromb Vasc Biol. 2001, 21(12),1998-2003.

135. Trion A, van der Laarse A. Vascular smooth muscle cells and calcification in atherosclerosis. Am Heart J. 2004, 147(5),808-814.

136. Foresta C, Strapazzon G, De Toni L, Fabris F, et al. Platelets express and release osteocalcin and co-localize in human calcified atherosclerotic plaques. J Thromb Haemost. 2013, 11(2),357-365. 
137. Price PA, Roublick AM, Williamson MK. Artery calcification in uremic rats is increased by a low protein diet and prevented by treatment with ibandronate. Kidney Int. 2006, 70(9),1577-1583.

138. Okura T, Kurata M, Enomoto D, Jotoku M, et al. Undercarboxylated osteocalcin is a biomarker of carotid calcification in patients with essential hypertension. Kidney Blood Press Res. 2010, 33(1),66-71.

139. Idelevich A, Rais Y, Monsonego-Ornan E. Bone Gla protein increases HIF-1alpha-dependent glucose metabolism and induces cartilage and vascular calcification. Arterioscler Thromb Vasc Biol. 2011, 31(9),e55-71.

140. Flammer AJ, Gossl M, Widmer RJ, Reriani M, et al. Osteocalcin positive CD133+/CD34-/KDR+ progenitor cells as an independent marker for unstable atherosclerosis. Eur Heart J. 2012, 33(23),2963-2969.

141. Balica M, Bostrom K, Shin V, Tillisch K, et al. Calcifying subpopulation of bovine aortic smooth muscle cells is responsive to 17 beta-estradiol. Circulation. 1997, 95(7),1954-1960.

142. Kapustin AN, Shanahan CM. Osteocalcin A Novel Vascular Metabolic and Osteoinductive Factor? Arterioscler Thromb Vasc Biol. 2011, 31(10),2169-2171.

143. Fadini GP, Albiero M, Menegazzo L, Boscaro E, et al. Widespread increase in myeloid calcifying cells contributes to ectopic vascular calcification in type 2 diabetes. Circ Res. 2011, 108(9),11121121.

144. Pal SN, Rush C, Parr A, Van Campenhout A, et al. Osteocalcin positive mononuclear cells are associated with the severity of aortic calcification. Atherosclerosis. 2010, 210(1),88-93.

145. Fadini GP, Albiero M, Menegazzo L, Boscaro E, et al. Procalcific phenotypic drift of circulating progenitor cells in type 2 diabetes with coronary artery disease. Exp Diabetes Res. 2012, 2012,921685.

146. Shanahan CM, Weissberg PL, Metcalfe JC. Isolation of gene markers of differentiated and proliferating vascular smooth muscle cells. Circ Res. 1993, 73(1),193-204.

147. Shanahan CM, Cary NR, Metcalfe JC, Weissberg PL. High expression of genes for calcificationregulating proteins in human atherosclerotic plaques. J Clin Invest. 1994, 93(6),2393-2402.

148. Proudfoot D, Skepper JN, Shanahan CM, Weissberg PL. Calcification of human vascular cells in vitro is correlated with high levels of matrix Gla protein and low levels of osteopontin expression. Arterioscler Thromb Vasc Biol. 1998, 18(3),379-388.

149. Mendoza FJ, Martinez-Moreno J, Almaden Y, Rodriguez-Ortiz ME, et al. Effect of calcium and the calcimimetic AMG 641 on matrix-Gla protein in vascular smooth muscle cells. Calcif Tissue Int. 2011, 88(3),169-178.

150. Farzaneh-Far A, Proudfoot D, Weissberg PL, Shanahan CM. Matrix gla protein is regulated by a mechanism functionally related to the calcium-sensing receptor. Biochem Biophys Res Commun. 2000, 277(3),736-740.

151. Schurgers LJ, Teunissen KJ, Knapen MH, Kwaijtaal M, et al. Novel conformation-specific antibodies against matrix gamma-carboxyglutamic acid (Gla) protein: undercarboxylated matrix Gla protein as marker for vascular calcification. Arterioscler Thromb Vasc Biol. 2005, 25(8),1629-1633.

152. Cranenburg EC, Vermeer C, Koos R, Boumans ML, et al. The circulating inactive form of matrix Gla Protein (ucMGP) as a biomarker for cardiovascular calcification. J Vasc Res. 2008, 45(5),427-436. 
153. Dalmeijer GW, van der Schouw YT, Vermeer C, Magdeleyns EJ, et al. Circulating matrix Gla protein is associated with coronary artery calcification and vitamin $\mathrm{K}$ status in healthy women. $J$ Nutr Biochem. 2013, 24(4),624-628.

154. Schurgers LJ, Spronk HM, Skepper JN, Hackeng TM, et al. Post-translational modifications regulate matrix Gla protein function: importance for inhibition of vascular smooth muscle cell calcification. J Thromb Haemost. 2007, 5(12),2503-2511.

155. O’Young J, Liao Y, Xiao Y, Jalkanen J, et al. Matrix Gla protein inhibits ectopic calcification by a direct interaction with hydroxyapatite crystals. J Am Chem Soc. 2011, 133(45),18406-18412.

156. Rennenberg RJ, van Varik BJ, Schurgers LJ, Hamulyak K, et al. Chronic coumarin treatment is associated with increased extracoronary arterial calcification in humans. Blood. 2010, 115(24),5121-5123.

157. Weijs B, Blaauw Y, Rennenberg RJ, Schurgers LJ, et al. Patients using vitamin K antagonists show increased levels of coronary calcification: an observational study in low-risk atrial fibrillation patients. Eur Heart J. 2011, 32(20),2555-2562.

158. Villines TC, O'Malley PG, Feuerstein IM, Thomas S, et al. Does prolonged warfarin exposure potentiate coronary calcification in humans? Results of the warfarin and coronary calcification study. Calcif Tissue Int. 2009, 85(6),494-500.

159. Palaniswamy C, Aronow WS, Sekhri A, Adapa S, et al. Warfarin Use and Prevalence of Coronary Artery Calcification Assessed by Multislice Computed Tomography. Am J Ther. 2012.

160. El-Maadawy S, Kaartinen MT, Schinke T, Murshed M, et al. Cartilage formation and calcification in arteries of mice lacking matrix Gla protein. Connect Tissue Res. 2003, 44 Suppl 1,272-278.

161. Yao Y, Bennett BJ, Wang X, Rosenfeld ME, et al. Inhibition of bone morphogenetic proteins protects against atherosclerosis and vascular calcification. Circ Res. 2010, 107(4),485-494.

162. Li X, Yang HY, Giachelli CM. BMP-2 promotes phosphate uptake, phenotypic modulation, and calcification of human vascular smooth muscle cells. Atherosclerosis. 2008, 199(2),271-277.

163. Yao Y, Zebboudj AF, Shao E, Perez M, et al. Regulation of bone morphogenetic protein-4 by matrix GLA protein in vascular endothelial cells involves activin-like kinase receptor 1. J Biol Chem. 2006, 281(45),33921-33930.

164. Wallin R, Schurgers L, Wajih N. Effects of the blood coagulation vitamin K as an inhibitor of arterial calcification. Thromb Res. 2008, 122(3),411-417.

165. Price PA, Faus SA, Williamson MK. Warfarin-induced artery calcification is accelerated by growth and vitamin D. Arterioscler Thromb Vasc Biol. 2000, 20(2),317-327.

166. Tyson KL, Reynolds JL, McNair R, Zhang Q, et al. Osteo/chondrocytic transcription factors and their target genes exhibit distinct patterns of expression in human arterial calcification. Arterioscler Thromb Vasc Biol. 2003, 23(3),489-494.

167. Tamura K, Suzuki Y, Matsushita M, Fujii H, et al. Prevention of aortic calcification by etidronate in the renal failure rat model. Eur J Pharmacol. 2007, 558(1-3),159-166.

168. Viegas CS, Cavaco S, Neves PL, Ferreira A, et al. Gla-rich protein is a novel vitamin K-dependent protein present in serum that accumulates at sites of pathological calcifications. Am J Pathol. 2009, 175(6),2288-2298. 
169. Le Jeune M, Tomavo N, Tian TV, Flourens A, et al. Identification of four alternatively spliced transcripts of the Ucma/GRP gene, encoding a new Gla-containing protein. Exp Cell Res. 2010, 316(2),203-215.

170. Shearer MJ. Vitamin K deficiency bleeding (VKDB) in early infancy. Blood Rev. 2009, 23(2),49-59.

171. Krueger T, Westenfeld R, Ketteler M, Schurgers LJ, et al. Vitamin K deficiency in CKD patients: a modifiable risk factor for vascular calcification? Kidney Int. 2009, 76(1),18-22.

172. Cranenburg EC, Schurgers LJ, Uiterwijk HH, Beulens JW, et al. Vitamin K intake and status are low in hemodialysis patients. Kidney Int. 2012, 82(5),605-610.

173. Malyszko J, Wolczynski S, Skrzydlewska E, Malyszko JS, et al. Vitamin K status in relation to bone metabolism in patients with renal failure. Am J Nephrol. 2002, 22(5-6),504-508.

174. Pilkey RM, Morton AR, Boffa MB, Noordhof C, et al. Subclinical vitamin K deficiency in hemodialysis patients. Am J Kidney Dis. 2007, 49(3),432-439.

175. Schlieper G, Westenfeld R, Kruger T, Cranenburg EC, et al. Circulating nonphosphorylated carboxylated matrix gla protein predicts survival in ESRD. J Am Soc Nephrol. 2011, 22(2),387-395.

176. Goodman WG. Vascular calcification in chronic renal failure. The Lancet. 2001, 358(9288),11151116.

177. Gage BF, Birman-Deych E, Radford MJ, Nilasena DS, et al. Risk of osteoporotic fracture in elderly patients taking warfarin: results from the National Registry of Atrial Fibrillation 2. Arch Intern Med. 2006, 166(2),241-246.

178. Lafforgue P, Daver L, Monties JR, Chagnaud C, et al. Bone mineral density in patients given oral vitamin K antagonists. Rev Rhum Engl Ed. 1997, 64(4),249-254.

179. Mamdani M, Upshur RE, Anderson G, Bartle BR, et al. Warfarin therapy and risk of hip fracture among elderly patients. Pharmacotherapy. 2003, 23(1),1-4.

180. Pilon D, Castilloux AM, Dorais M, LeLorier J. Oral anticoagulants and the risk of osteoporotic fractures among elderly. Pharmacoepidemiol Drug Saf. 2004, 13(5),289-294.

181. Stenova E, Steno B, Killinger Z, Baqi L, et al. Effect of long-term oral anticoagulant therapy on bone mineral density and bone turnover markers: a prospective 12 month study. Bratis/ Lek Listy. 2011, 112(2),71-76.

182. Shearer MJ, Rahim S, Barkhan P, Stimmler L. Plasma vitamin K1 in mothers and their newborn babies. Lancet. 1982, 2(8296),460-463.

183. Clarke P, Mitchell SJ, Sundaram S, Sharma V, et al. Vitamin K status of preterm infants with a prolonged prothrombin time. Acta Paediatr. 2005, 94(12),1822-1824.

184. Harrington DJ, Clarke P, Card DJ, Mitchell SJ, et al. Urinary excretion of vitamin K metabolites in term and preterm infants: relationship to vitamin K status and prophylaxis. Pediatr Res. 2010, 68(6),508-512.

185. Fusaro M, Noale M, Viola V, Galli F, et al. Vitamin K, vertebral fractures, vascular calcifications, and mortality: VItamin K Italian (VIKI) dialysis study. Journal of Bone and Mineral Research. 2012, 27(11),2271-2278. 
186. Knapen MH, Drummen NE, Smit E, Vermeer C, et al. Three-year low-dose menaquinone-7 supplementation helps decrease bone loss in healthy postmenopausal women. Osteoporos Int. 2013, 24(9),2499-2507.

187. Fu X, Moreines J, Booth SL. Vitamin K supplementation does not prevent bone loss in ovariectomized Norway rats. Nutr Metab (Lond). 2012, 9(1),12.

188. Martini LA, Booth SL, Saltzman E, do Rosario Dias de Oliveira Latorre M, et al. Dietary phylloquinone depletion and repletion in postmenopausal women: effects on bone and mineral metabolism. Osteoporos Int. 2006, 17(6),929-935.

189. Knapen MH, Schurgers LJ, Vermeer C. Vitamin K2 supplementation improves hip bone geometry and bone strength indices in postmenopausal women. Osteoporos Int. 2007, 18(7),963-972.

190. Shea MK, Booth SL, Miller ME, Burke GL, et al. Association between circulating vitamin K1 and coronary calcium progression in community-dwelling adults: the Multi-Ethnic Study of Atherosclerosis. Am J Clin Nutr. 2013, 98(1),197-208.

191. Braam LA, Hoeks AP, Brouns F, Hamulyak K, et al. Beneficial effects of vitamins D and K on the elastic properties of the vessel wall in postmenopausal women: a follow-up study. Thromb Haemost. 2004, 91(2),373-380.

192. Shea MK, O'Donnell CJ, Hoffmann U, Dallal GE, et al. Vitamin K supplementation and progression of coronary artery calcium in older men and women. Am J Clin Nutr. 2009, 89(6),1799-1807.

193. Westenfeld R, Krueger T, Schlieper G, Cranenburg ECM, et al. Effect of Vitamin K2 Supplementation on Functional Vitamin K Deficiency in Hemodialysis Patients: A Randomized Trial. American journal of kidney diseases. 2012, 59(2),186-195.

194. Shea MK, Holden RM. Vitamin K status and vascular calcification: evidence from observational and clinical studies. Adv Nutr. 2012, 3(2),158-165. 



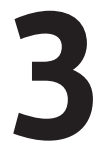

Nicotine increases oxidative stress and exosome secretion in human vascular smooth muscle cells and induces microcalcifications in human atherosclerosis

Brecht Willems, Mathias Burgmaier, Sylvia Heenemann, Felix Gremse, Gosia Furmanik, Sebastian Reith, Florian Kahles, Nikolaus Marx, Chris Reutelingsperger and Leon Schurgers 


\section{Abstract}

Background: Smokers are at increased risk for cardiovascular events including acute myocardial infarctions, which usually result from the rupture of a vulnerable coronary plaque. Given that smoking is associated with vascular calcification and since microcalcifications are linked to a vulnerable plaque feature, we investigated effects of smoking on vascular smooth muscle cell-mediated microcalcifications.

Methods: Presence of microcalcifications was assessed using micro-computed tomography (microCT) scanning of 62 carotid atherosclerotic lesions of 30 patients. In vitro, human primary vascular smooth muscle cells (hVSMCs) were used to gain mechanistic insight.

Results: Calcification as assessed by microCT scanning was present significantly more often in carotid plaques of smokers (22 (73.3\%)) compared to non-smokers (11 (34.3\%), $p<0.001)$. More importantly, number of microcalcifications in carotid atherosclerotic lesions increased more than 17 -fold in smokers compared to nonsmokers (917.7 \pm 1303.7 vs. $53.7 \pm 145.8, p=0.001$ ) suggesting a more vulnerable plaque phenotype.

In vitro, nicotine increased calcification in hVSMCs by $89 \%(p<0.001)$, which was mediated via the nicotinic acetylcholine receptor. Nicotine significantly increased oxidative stress and increased exosome secretion in hVSMCs whereas it had no effect on cell viability. Western blotting and real-time qPCR revealed that nicotine induced loss of contractile properties of hVSMCs thereby inducing a pro-calcifying phenotype.

Conclusion: Smoking is associated with increased number of microcalcifications in human atherosclerotic lesions suggesting a more vulnerable plaque phenotype in these patients. These microcalcifications are at least in part mediated via nicotine. Activation of the nicotinic acetylcholine receptor increases oxidative stress and induces a pro-calcifying hVSMC phenotype via enhanced exosome secretion resulting in higher propensity for vascular smooth muscle cell-mediated calcification. 


\section{Introduction}

The presence of vascular calcifications is associated with atherosclerotic burden and with increased cardiovascular risk (1-3). For a long time however, it was unclear whether vascular calcification destabilizes the atherosclerotic lesion or whether it is merely a reflection of an increased presence of advanced atherosclerosis. Recent studies revealed that in particular microcalcifications are important features of the vulnerable plaque (4-7). In line with this, clinical data show that $\mathrm{Na}^{18} \mathrm{~F}$ uptake identifies coronary active mineralisation and predicts disease progression and plaque vulnerability (8). Furthermore, microcalcifications by themselves are biologically active and induce the secretion of tumor necrosis factor (TNF)-a in macrophages via NFuB-activation in vitro (9). Additionally, a study using intracoronary optical coherence tomography in patients with acute coronary syndrome identified culprit lesions with calcified nodules, which protruded through a ruptured fibrous cap into the vessel lumen (7), suggesting a major role of microcalcifications in the genesis of acute cardiovascular events.

Smoking is associated with increased cardiovascular morbidity and mortality in a dosedependent manner $(10,11)$. However, the underlying mechanisms are incompletely understood. Nicotine, the major component of cigarette smoking, has pro-atherosclerotic effects in endothelial cells and induces proliferation of vascular smooth muscle cells (VSMCs) via a functional nicotinic acetylcholine receptor (12). Furthermore, nicotine enhances the secretion of pro-inflammatory and pro-atherosclerotic cytokines such as transforming growth factor $\beta 1$ (13) and platelet-derived growth factor (14) and induces the expression of matrix metalloproteinases (15). Despite this knowledge about the vascular effects of nicotine, it is presently unclear how nicotine induces the genesis of vulnerable plaques. Moreover, the molecular mechanisms how smoking translates into increased cardiovascular morbidity and mortality in patients are incompletely understood.

As smoking is associated with both increased cardiovascular mortality as well as vascular calcification and given that microcalcifications are vulnerable plaque features, we investigated effects of nicotine on VSMC-mediated microcalcification in vitro and in vivo.

\section{Methods}

\section{Quantification of microcalcifications in patients}

Human carotid artery lesion specimen were obtained from 30 patients autopsied at the University Hospital Maastricht, Maastricht, NL via the Maastricht Pathology Tissue Collection as previously described (16). The collection, storage and processing of tissue and patient data are in accordance with the "Code for Proper Use of Secondary Human Tissue in the Netherlands" and the Declaration of Helsinki (16). Micro-computed tomography (microCT) images were achieved using a microCT scanner (Tomoscope DUO, CT-Imaging, Erlangen, Germany). Sources of the microCT were operated with voltage of $65 \mathrm{kV}$ and current of $0.5 \mathrm{~mA}$. 
720 projections with $1032 \times 1012$ pixels were acquired during one revolution with duration of 90 seconds. Volumetric images were reconstructed using a Feldkamp Reconstruction at voxel size $35 \mu \mathrm{m}$ using a medium sharp reconstruction kernel (T60). Volumetric images were visualized and analyzed using the Imalytics Preclinical Software(17). Calcifications were interactively segmented and counted using a fixed threshold (100 HU) and connected component analysis(17). Segmented components were grouped into small, medium and large classes based on their volumes $\left(>0.01 \mathrm{~mm}^{3},>0.1 \mathrm{~mm}^{3}\right.$, and $\left.>1000 \mathrm{~mm}^{3}\right)$. Volumes were determined based on the segmentation size, i.e. proportional to the number of segmented voxels. Calcifications amount per voxel was assumed to be proportional to the voxel intensity and the amount of calcification per plaque was computed as the sum of the corresponding voxels.

\section{Cell culture and calcification}

Human VSMCs (hVSMC) were isolated from non-atherosclerotic areas in aortas from organ donors of various ages (both males and females; age range 15-65 years). Cells were prepared from explants of these aortas. hVSMCs were cultured in M199 medium (Gibco, Bleiswijk, the Netherlands) supplemented with 20\% FCS and 1\% penicillin/streptomycin (P/S) and split upon reaching 90\% confluency. For calcification experiments, hVSMC were seeded into 12-well plates at 20000 cells/well and incubated for 7 days with nicotine (150 $\mathrm{nM}, 1 \mu \mathrm{M}$ or $1 \mathrm{mM}$ ) (Sigma, Zwijndrecht, the Netherlands) or ethanol in culture medium. Subsequently, hVSMC were switched to calcification medium (M199, 2.5\% FCS, 1\% P/S and $5.4 \mathrm{mM} \mathrm{Ca2+)}$ for 3 to 5 days. After incubation, calcification was quantified using the cresolphtalein method (Randox, London, United Kingdom) and normalized to protein content determined by BCA assay (Thermo Scientific, Bleiswijk, the Netherlands). Calcification in the presence of inhibitors was assessed by adding either hexamethonium bromide (Sigma, Zwijndrecht, the Netherlands) or a-bungarotoxin (Life Technologies, Bleiswijk, the Netherlands) to the cell culture medium in the concentrations indicated.

\section{Oxidative stress}

In order to determine oxidative stress, hVSMC were seeded in 96 well plates at 5000 cells/ well and were incubated with nicotine $(150 \mathrm{nM}, 1 \mu \mathrm{M}$ or $1 \mathrm{mM})$ or control (ethanol) for 7 days in culture medium. Next, oxidative stress was measured for 2 hours using the amplex red assay. Oxidative stress was normalized to protein content determined by BCA assay.

\section{cDNA synthesis and quantitative analysis}

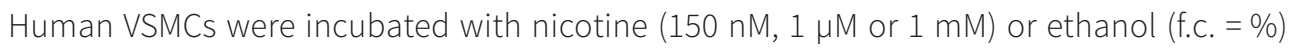
for 7 days in cultured medium. After incubation, total RNA was extracted using a phenolchloroform method as previously described by Chomczynski et al (18). RNA concentration was quantified spectrophotometrically at $260 \mathrm{~nm}$. RNA integrity was evaluated using denaturing agarose gel electrophoresis. 250 ng of total RNA was treated with DNase I (Promega) 
and reverse transcribed using Moloney Murine Leukemia Virus Reverse Transcriptase (M-MLV RT), RNAse Out, dNTPs, dithiothreitol (all Invitrogen), and an oligo(dT)adapter (Eurogentec) for 1 hour at $37^{\circ} \mathrm{C}$. Gene expression levels were quantified by real-time quantitative PCR (qPCR) on a LightCycler 480 Real-Time PCR instrument (Roche Applied Science). Amplification reactions were carried out in a volume of $10 \mu \mathrm{l}$ including $100 \mathrm{ng}$ of total cDNA, $5 \mu \mathrm{l}$ QuantiTect SYBR Green PCR Kit (Qiagen) and $0.5 \mu \mathrm{M}$ of each primer (Supplemental table I). The Runx2 primers were purchased from Qiagen (Cat. No. QT00020517). An initial denaturation step $\left(15\right.$ minutes at $\left.95^{\circ} \mathrm{C}\right)$ was followed by 50 cycles of amplification (denaturation: 15 seconds at $95^{\circ} \mathrm{C}$, annealing: 30 seconds at $57^{\circ} \mathrm{C}$, extension: 45 seconds at $72^{\circ} \mathrm{C}$ ). The specificity of amplification products was checked by melting curve genotyping. Fluorescence curves were analyzed with LightCycler 480 Software (Version 1.5) and relative quantification by plotting N0 ratios. All samples were assayed in triplicate.

\section{Analysis of exosome secretion by nicotine-treated hVSMC}

Human VSMC were seeded into 12-well plates at 20000 cells/well and incubated with nicotine (150 nM, 1 MM or $1 \mathrm{mM}$ ) or ethanol in culture medium for 7 days. After incubation, medium was changed to calcification medium and incubated for 24 hours. Subsequently, medium was harvested and exosomes were quantified as described previously (19). In short, anti-human CD63 antibody (BD Biosciences, Temse, The Netherlands) was immobilized on aldehyde-sulfate functionalized beads. After centrifugation for 5 minutes at 700G (Thermo Scientific Heraeus Multifuge 3SR+ centrifuge, rotor Sorvall 75006441K), the supernatant was incubated overnight with the CD63 beads at $4^{\circ} \mathrm{C}$. hVSMC were incubated with Hoechst medium and counted using a Cytation-3 Cell Imaging multi-mode system (BioTek, Bad Friedrichshall, Germany). After incubating overnight, the beads were washed with 2\% BSA in PBS and incubated with anti-CD81-PE conjugated antibodies for 1 hour at room temperature. Beads were washed once more with 2\% BSA in PBS, analysed by flow cytometry (Accuri C6, BD biosciences, Temse, the Netherlands) and expressed as arbitrary units. Arbitrary units were calculated as mean fluorescence units x percentage of positive beads and normalized to the number of viable hVSMCs.

\section{Statistical analysis}

Differences between groups were analyzed by Student's or Welch's t-test dependent on inequality of variances. Proportions were compared using Pearson's chi-square test. Differences between more than two groups were tested by 1-way-ANOVA with the LSD-test for post-hoc analyses. A p-value < 0.05 was regarded as significant. All clinical data were analysed on a per lesion basis and the statistical test did not account for the correlation of multiples lesions within patients. All computations were performed using SPSS (IBM Corp., Armonk, NY, USA). 


\section{Results}

\section{Presence of calcifications in patients with and without smoking}

Presence of (micro)calcifications was assessed using microCT-scanning in 30 lesions of 15 patients that smoked and compared to 32 lesions of 15 patients that had not smoked. Representative images of microCT-scans are presented in Figure 1.

Carotid artery calcification was present in 22 (73.3\%) lesions of patients that smoked compared to 11 (34.4\%) lesions of patients that did not smoke ( $p=0.002)$. More importantly, smoking was associated with a significantly higher number of plaques with microcalcifications (21 (70.0\%) lesions vs 8 (25.0\%) lesions, $p<0.001$ for smoking vs. non-smoking). These data were consistent with other calcification parameters including a higher total number of microcalcifications (NOC, $917.7 \pm 1303.7$ vs $53.7 \pm 145.8, p=0.001$ for smoking vs. nonsmoking), volume of microcalcification $\left(0.180 \pm 0.235 \mathrm{~mm}^{3}\right.$ vs $0.018 \pm 0.045 \mathrm{~mm}^{3}, p=0.001$ for smoking vs. non-smoking), and total microcalcification (207.8 \pm 268.7 vs. $22.5 \pm 55.3$, $p=0.001$ for smoking vs. non-smoking) in specimen of smoking patients.

However, smoking not only increased the presence of microcalcification, but also that of intermediate size calcifications (20 (77.7\%) lesions vs 7 (21.9\%) lesions, $p<0.001$ for smoking vs. non-smoking) and macrocalcifications (18 (60.0\%) lesions vs 4 (12.5\%) lesions, $p<0.001$ for smoking vs. non-smoking). For further detail, please see Table 1 and Figure 2.

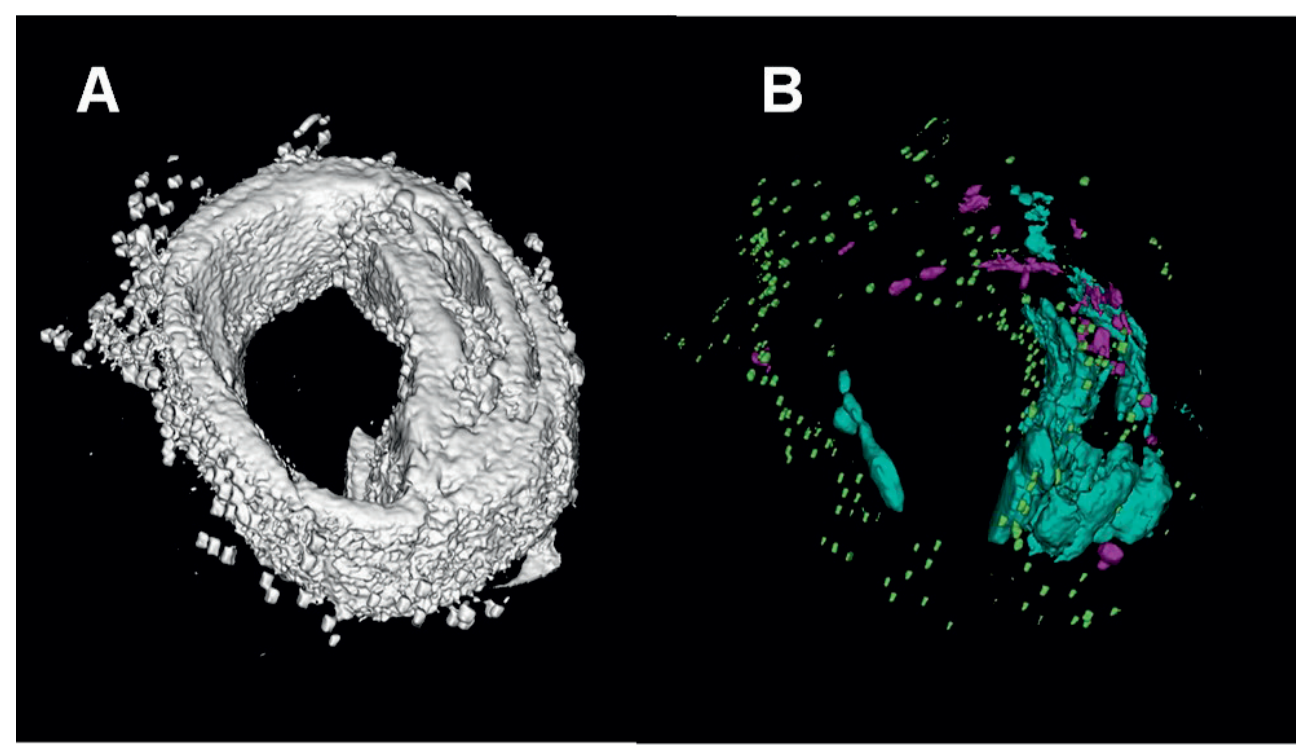

Figure 1: Micro-CT scanning was used to image carotid plaques.

A representative micro-CT image of a carotid plaque including soft tissues are displayed in (A). (B) displays the same plaque without soft tissues and a compartimentation of microcalcifications (green), intermediate size calcifications (magenta) and macrocalcifications (blue). 
Table 1: Lesion characteristics of patients with smoking vs non-smoking

\begin{tabular}{|c|c|c|c|}
\hline & Smoking & Non-Smoking & \\
\hline Clinical data & $n=30$ & $n=32$ & p-value \\
\hline Age (years) & $74.5 \pm 11.5$ & $75.2 \pm 10.4$ & NS \\
\hline Male (n, \%) & $14(46.7)$ & $17(53.1)$ & NS \\
\hline Calcification (n, \%) & $22(73.3)$ & $11(34.4)$ & 0.002 \\
\hline Overall NOC (n, \%) & $921.5 \pm 1305.5$ & $54.3 \pm 146.2$ & 0.001 \\
\hline \multicolumn{4}{|l|}{ Microcalcification } \\
\hline Present & $21(70.0)$ & $8(25.0)$ & $<0.001$ \\
\hline NOC & $917.7 \pm 1303.7$ & $53.7 \pm 145.8$ & 0.001 \\
\hline Volume $\left(\mathrm{mm}^{2}\right)$ & $0.180 \pm 0.235$ & $0.018 \pm 0.045$ & 0.001 \\
\hline Total calcification & $207.8 \pm 268.7$ & $22.5 \pm 55.3$ & 0.001 \\
\hline \multicolumn{4}{|c|}{ Intermediate size calcification } \\
\hline Present & $20(66.7)$ & $7(21.9)$ & $<0.001$ \\
\hline NOC & $2.43 \pm 2.40$ & $0.38 \pm 1.10$ & $<0.001$ \\
\hline Volume $\left(\mathrm{mm}^{2}\right)$ & $0.069 \pm 0.068$ & $0.011 \pm 0.034$ & $<0.001$ \\
\hline Total calcification & $89.55 \pm 91.97$ & $15.79 \pm 45.59$ & $<0.001$ \\
\hline \multicolumn{4}{|l|}{ Macrocalcification } \\
\hline Present & $18(60.0)$ & $4(12.5)$ & $<0.001$ \\
\hline NOC & $1.37 \pm 1.38$ & $0.31 \pm 1.00$ & 0.001 \\
\hline Volume $\left(\mathrm{mm}^{2}\right)$ & $2.47 \pm 4.07$ & $1.28 \pm 6.77$ & NS \\
\hline Total calcification & $4610.8 \pm 9766.4$ & $2360.9 \pm 12654.4$ & NS \\
\hline
\end{tabular}

The data are presented as mean \pm SD or $\mathrm{n}(\%)$. Abbreviations: NOC=number of calcification;

\section{Nicotine increases hVSMC calcification through interaction with the $\alpha 7$ nicotinic acetylcholine receptor}

To investigate the underlying mechanisms for the increased calcification observed with smoking, we investigated the effect of nicotine, the major component of smoking, on hVSMC in vitro. Nicotine significantly increased calcification of hVSMC in a dose-dependent manner (89\% increase at $1 \mathrm{mM}, \mathrm{p} \leq 0.01$, Figure 3).

To elucidate the intracellular signaling pathways involved, we performed experiments using inhibitors of the nicotinic acetylcholine receptors (nAchR). In these experiments, the antagonists hexmethonium and a-bungarotoxin both reduced the nicotine-induced calcification of hVSMC ( $p=N S$, Figure 4), suggesting an involvement of a7 nAchR in the nicotine-induced calcification of hVSMCs. 
A

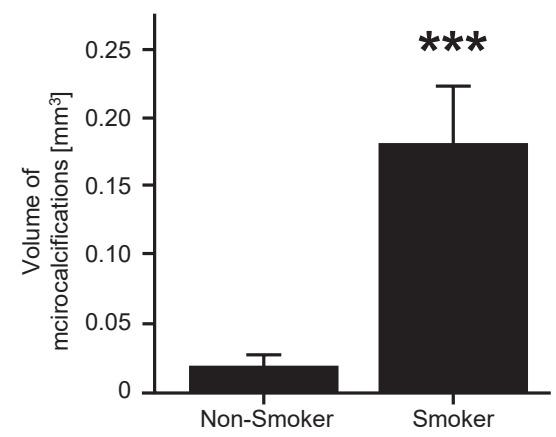

C

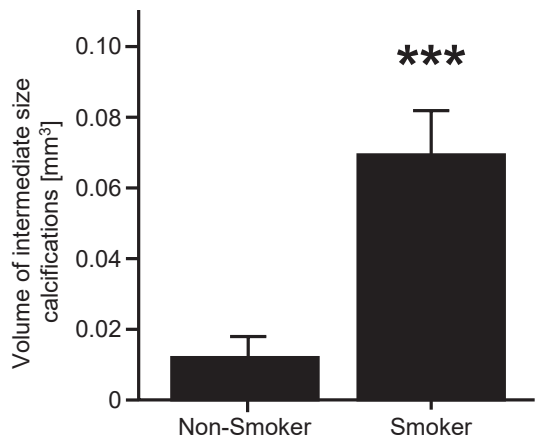

E

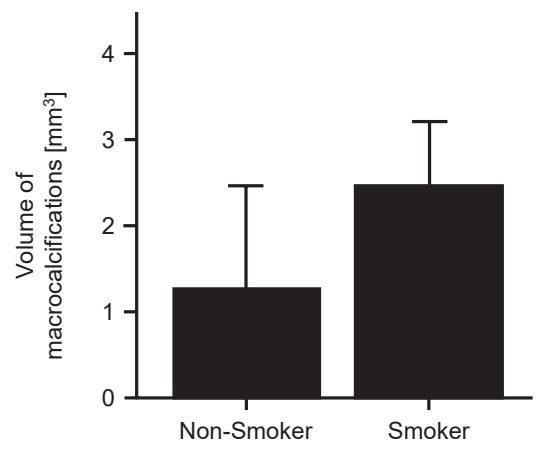

B

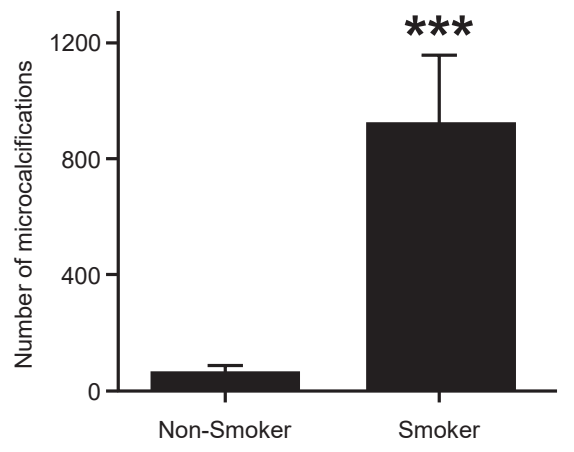

D

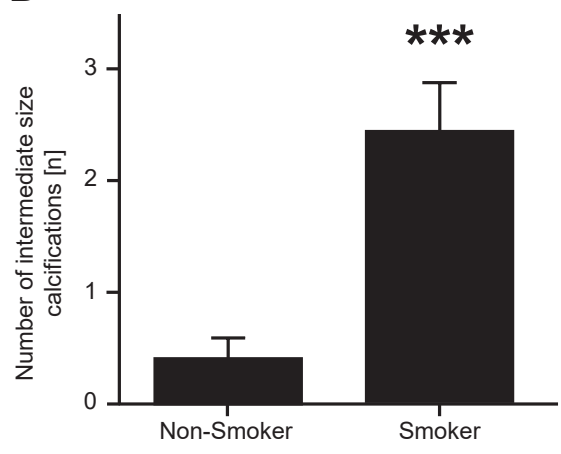

$\mathbf{F}$

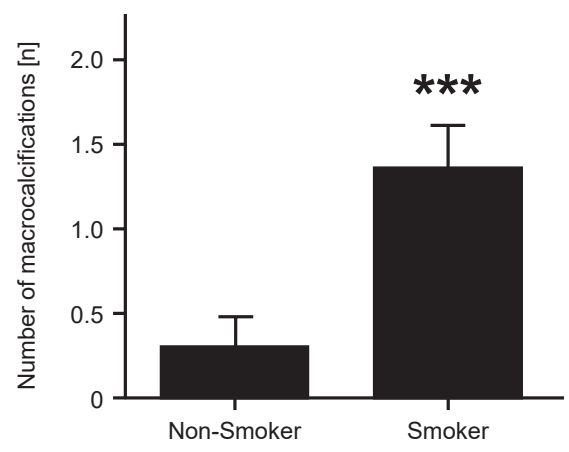

Figure 2: Calcifications in carotid artery lesions.

Volume (A, C, E) and number (B, D, F) of microcalcifications (A, B), intermediate size calcification (C, D) and macrocalcifications $(E, F)$ of carotid artery lesions of smoking and non-smoking patients are displayed as bar graphs with SEM. $N=62,{ }^{\star \star \star} p \leq 0.001$. 


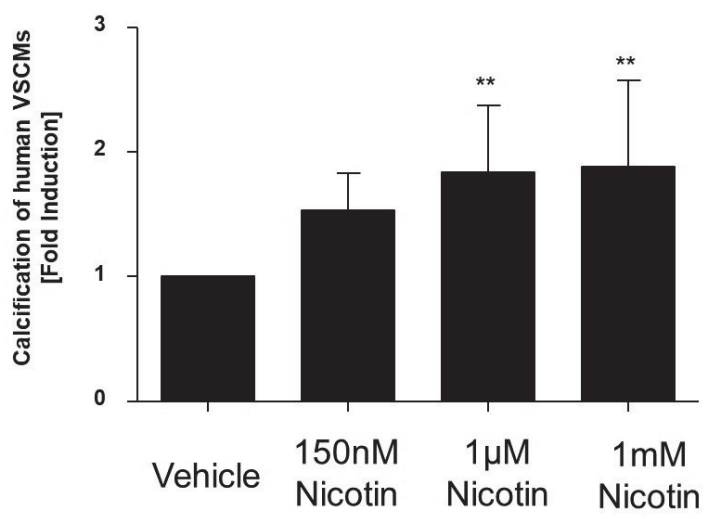

Figure 3 hVSMC were calcified under increasing nicotin concentrations.

Incubation with nicotin induced an increase in calcification by respectively $53.4 \%$ ( $p=N S ; 150 \mathrm{nM}), 84 \%(p \leq 0.01$; $1 \mu \mathrm{M})$ and $(89 \%, \mathrm{p} \leq 0.01 ; 1 \mathrm{mM})$ as compared to the vehicle. Calcification is displayed as bar graphs with SD, ${ }^{*}$ $\mathrm{p} \leq 0.01$.

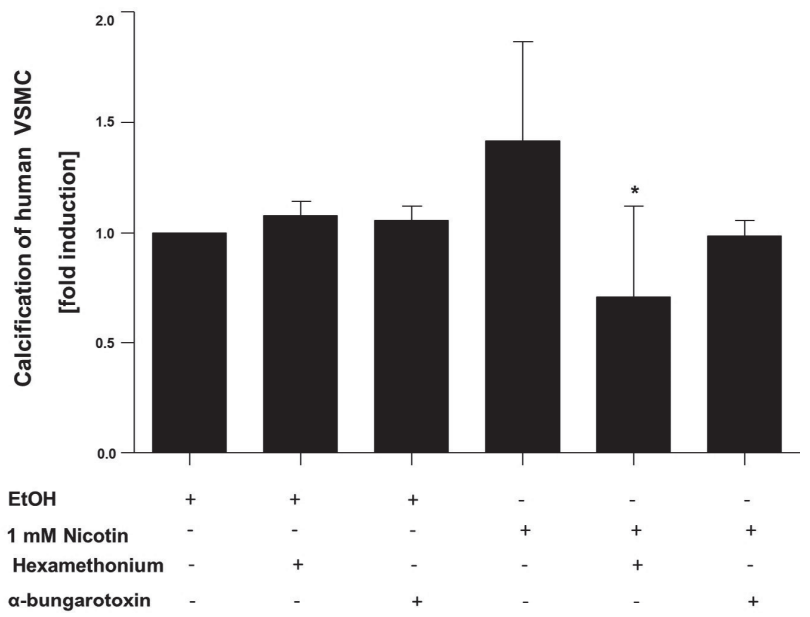

Figure 4: hVSMC were calcified in the presence of nicotine $(1 \mathrm{mM})$ and either hexamethonium (100 $\mu \mathrm{M})$, a broad spectrum nicotinergic receptor blocker or a-bungarotoxin $(1 \mu \mathrm{M})$, an a7 nicotinergic receptor blocker.

Hexamethonium significantly reduced nicotine-induced calcification by $50 \%(p \leq 0.05)$. a-bungarotoxin reduced nicotin induced calcification by $30 \%$ ( $p=$ NS). When incubated with vehicle, both blockers did not affect calcification. Calcification is displayed as bar graphs with SD. ${ }^{*} p \leq 0.05$.

\section{Nicotine induces oxidative stress in hVSMC and alters hVSMC phenotype}

Given that oxidative stress is associated with hVSMC calcification, we investigated if nicotine induces oxidative stress in hVSMCs. Nicotine significantly increased hVSMC oxidative stress in a dose-dependent manner (30\% increase at $1 \mathrm{mM}, \mathrm{p} \leq 0.05$; Figure 5). 


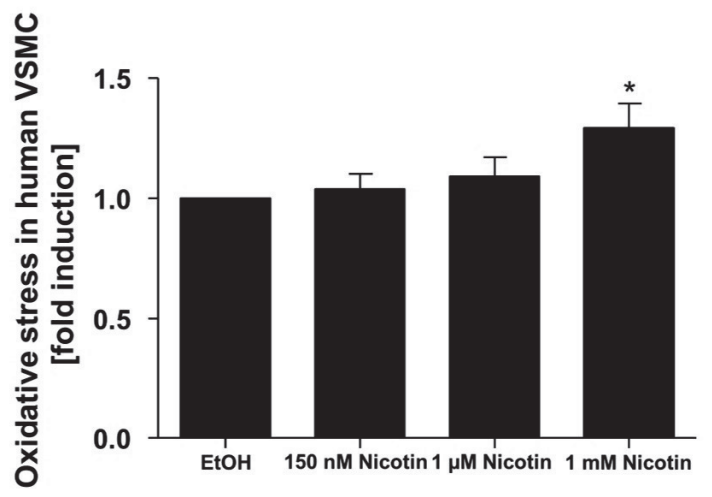

Figure 5: The development of oxidative stress in hVSMC under increasing nicotin concentrations was determined.

$1 \mathrm{mM}$ of nicotine significantly increased ROS levels in hVSMC after 7 days of incubation by $30 \%(p \leq 0.05)$ as compared to vehicle. Oxidative stress levels are displayed as bars with SD. ${ }^{*} \mathrm{p} \leq 0.05$
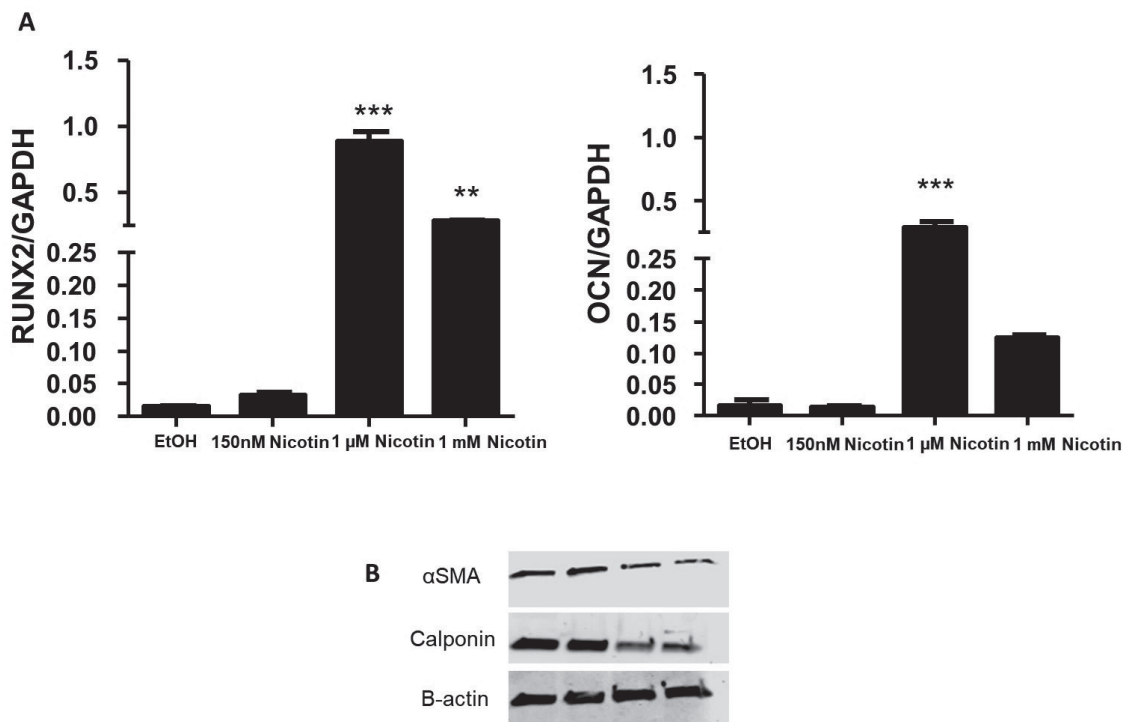

\section{Figure 6: Effects of nicotine on gene and protein expression.}

RNA was isolated from hVSMC incubated with increasing nicotine concentrations Both Runx2and osteocalcin (A) were amplified using RT-qPCR. At $1 \mathrm{mM}$ of nicotine and higher, Runx2 and osteocalcin expression were increased respectively $18(p \leq 0.001)$ and 8 -fold $(p=N S)$. Additionally, semi-quantitative protein expression of both a smooth muscle actin and calponin was determined using western blot (B) in relation to $\beta$-actin. Increasing concentrations of nicotine decreased both expression of a smooth muscle actin and calponin in relation to $\beta$-actin. This indicates hVSMC lose their contractile properties. RNA expression levels are displayed as bars with $\mathrm{SEM}$. At $1 \mu \mathrm{M}$ nicotine concentrations, ${ }^{\star \star *} \mathrm{p} \leq 0.01$ for both Run $\times 2$ and osteocalcin expression. At $1 \mathrm{mM}$ nicotine, ${ }^{* \star} p \leq 0.01$ for Run $x 2$ and $p=$ NS for osteocalcin. Figure 6 B displays western blots imaged using enhanced chemiluminescence and captured with a CCD camera. 
As oxidative stress has been shown to correlate with hVSMC phenotype, we assessed if nicotine alters hVSMC phenotype. Expression analysis of Runx2 and osteocalcin (OC), two markers of the osteogenic hVSCMs phenotype, were highly upregulated in cells incubated with nicotine. Runx2 expression was increased 18 -fold at $1 \mathrm{mM}, \mathrm{p} \leq 0.01$. Osteocalcin expression was increased 8-fold at $1 \mathrm{mM}$ ( $p \leq 0.01$, Figure 6A and B). Additionally, analysis of cell lysates for aSMA and calponin, two markers of the non-calcifying, contractile phenotype, showed a concentration-dependent reduction of both aSMA and calponin (Figure 6B). These data suggest that nicotine-exposed hVSMC loose contractile properties and assume a pro-calcifying phenotype.

\section{Nicotine increases exosome secretion by hVSMC}

After we observed that nicotine influences a 7 nAchR signaling as well as oxidative stress and hVSMC phenotype, we investigated if this translates into an altered exosome secretion as a down-stream target of hVSMC calcification. In these experiments, nicotine increases the secretion of exosomes by hVSMCs by 4 -fold at $1 \mathrm{mM}$ ( $p \leq 0.001$, Figure 7 ). Additionally, nicotine did not affect hVSMC viability (data not shown).

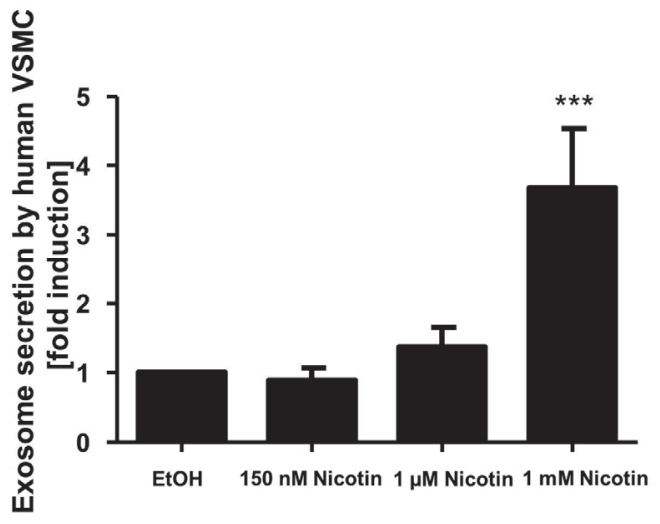

\section{Figure 7: Induction of exosome secretion by nicotine.}

Using FACS, exosome secretion by hVSMC on increasing nicotine concentrations was measured. Both $150 \mathrm{nM}$ and $1 \mu \mathrm{M}$ of nicotine did not have a significant effect on exosome secretion. $1 \mathrm{mM}$ significantly increased exosome secretion by hVSMC 4 -fold in comparison to vehicle $(p \leq 0.001)$. Exosome secretion levels are displayed as bars with SD. ${ }^{\star \star \star} ; p \leq 0.001$.

\section{Discussion}

In this study we demonstrate that smoking is associated with a significant, more than 17fold increase in carotid artery plaque microcalcifications. Furthermore, we demonstrate that nicotine, the main component in cigarette smoking, induces in vitro calcification in hVSMCs which is mediated via nicotine interaction with the a7 nicotinic acetylcholine 
receptor, thereby increasing oxidative stress and a more osteogenic hVSMC phenotype, which translates into more exosome secretion of hVSMCs with nicotine.

Smoking has a vast impact on public health, resulting in increased cardiovascular morbidity and mortality $(10,11)$. In the past it has been suggested that nicotine has pro-atherogenic effects on various vascular cells (12-15). However, the exact mechanism through which smoking influences vascular biology and results in a vulnerable plaque phenotype is unknown. We extend the current knowledge by demonstrating that smoking is associated with a significant 17 -fold increase in microcalcifications within atherosclerotic lesions. Microcalcifications are biologically active $(20,21)$ and are thought to destabilize the lesion biomechanically $(6,22)$. Given that microcalcifications are vulnerable plaque features, it is tempting to speculate in the light of our data that nicotine increases cardiovascular morbidity and mortality via increased number of microcalcifications in atherosclerotic lesions and induce a more vulnerable plaque type which is more prone to plaque rupture.

In this work we elucidated the mechanisms by which nicotine results in calcification of hVSMCs. Using experiments with various inhibitors of the nicotinic acetylcholine receptor, we demonstrate that nicotine-induced calcification in hVSMCs is dependent on a functional nicotinic acetylcholine receptor. Furthermore, nicotine changes the phenotype of hVSMCs from a contractile towards a pro-calcifying phenotype associated with loss of contractility markers and upregulation of proteins associated with bone formation such as Runx2 and osteocalcin. In the next step we investigated the intracellular mechanisms how nicotine induces vascular calcification. hVSMCs drive vascular calcification either via shedding apoptotic bodies or via exosome secretion (19). In our work we did not find changes in smooth muscle cell viability when treated with nicotine. In contrast, nicotine induces oxidative stress and exosome secretion in hVSMCs suggesting that nicotine induces vascular calcification via increasing extracellular exosomes that serve as nidus for calcification. Indeed, recently exosomes have been put forward as nucleation sites for microcalcifications (19). Moreover, it has been described that nicotine has a proliferative and pro-migratory effect on hVSMCs $(12,15,23)$ which is associated with increased exosome secretion (19).

It is important to understand the detrimental effects of nicotine on our vasculature, not only with respect to the global health problem associated with smoking, but also regarding nicotine replacement therapy (NRT). NRT increases smoking-abstinent rates. Whereas NRT appears to be safe in patients without coronary artery disease or patients with stable coronary artery disease $(24,25)$, its long-term effects on plaque morphology and vulnerability of lesions is currently unknown. Further studies are necessary to elucidate the effects of NRT on vascular microcalcification following smoking cessation and NRT.

In conclusion, we demonstrate that smoking is associated with an increase in number of microcalcifications of atherosclerotic lesions in patients suggesting a more vulnerable plaque phenotype. The effect of nicotine is mediated via the nicotinic acetylcholine receptor resulting in increased oxidative stress and exosome secretion and associated with osteochondrogenic switching, thereby enhancing the propensity of hVSMC calcification. 


\section{References}

1. Criqui MH, Denenberg JO, McClelland RL, Allison MA, Ix JH, Guerci A, et al. Abdominal aortic calcium, coronary artery calcium, and cardiovascular morbidity and mortality in the Multi-Ethnic Study of Atherosclerosis. Arterioscler Thromb Vasc Biol. 2014 Jul;34(7):1574-9.

2. Budoff MJ, Nasir K, McClelland RL, Detrano R, Wong N, Blumenthal RS, et al. Coronary calcium predicts events better with absolute calcium scores than age-sex-race/ethnicity percentiles: MESA (Multi-Ethnic Study of Atherosclerosis). J Am Coll Cardiol. 2009 Jan 27;53(4):345-52.

3. Detrano R, Guerci AD, Carr JJ, Bild DE, Burke G, Folsom AR, et al. Coronary calcium as a predictor of coronary events in four racial or ethnic groups. N Engl J Med. 2008 Mar 27;358(13):1336-45.

4. Yun YS, Choi SJ, Lee JY, Kim YS, Yoon SA, Park SC, et al. Impact of arterial microcalcification of the vascular access on cardiovascular mortality in hemodialysis patients. Hemodial Int. 2014 Jan; 18(1):54-61.

5. Ehara S, Kobayashi Y, Yoshiyama M, Shimada K, Shimada Y, Fukuda D, et al. Spotty calcification typifies the culprit plaque in patients with acute myocardial infarction: an intravascular ultrasound study. Circulation. 2004 Nov 30;110(22):3424-9.

6. Hutcheson JD, Maldonado N, Aikawa E. Small entities with large impact: microcalcifications and atherosclerotic plaque vulnerability. Curr Opin Lipidol. 2014 Oct;25(5):327-32.

7. Jia H, Abtahian F, Aguirre AD, Lee S, Chia S, Lowe H, et al. In vivo diagnosis of plaque erosion and calcified nodule in patients with acute coronary syndrome by intravascular optical coherence tomography. J Am Coll Cardiol. 2013 Nov 5;62(19):1748-58.

8. Joshi NV, Vesey AT, Williams MC, Shah AS, Calvert PA, Craighead FH, et al. 18F-fluoride positron emission tomography for identification of ruptured and high-risk coronary atherosclerotic plaques: a prospective clinical trial. Lancet. 2014 Feb 22;383(9918):705-13.

9. Nadra I, Boccaccini AR, Philippidis P, Whelan LC, McCarthy GM, Haskard DO, et al. Effect of particle size on hydroxyapatite crystal-induced tumor necrosis factor alpha secretion by macrophages. Atherosclerosis. 2008 Jan;196(1):98-105.

10. White WB. Smoking-related morbidity and mortality in the cardiovascular setting. Prev Cardiol. 2007 Spring;10(2 Suppl 1):1-4.

11. Willett WC, Green A, Stampfer MJ, Speizer FE, Colditz GA, Rosner B, et al. Relative and absolute excess risks of coronary heart disease among women who smoke cigarettes. N Engl J Med. 1987 Nov 19;317(21):1303-9.

12. Cucina A, Fuso A, Coluccia P, Cavallaro A. Nicotine inhibits apoptosis and stimulates proliferation in aortic smooth muscle cells through a functional nicotinic acetylcholine receptor. J Surg Res. 2008 Dec;150(2):227-35.

13. Cucina A, Sapienza P, Corvino V, Borrelli V, Mariani V, Randone B, et al. Nicotine-induced smooth muscle cell proliferation is mediated through bFGF and TGF-beta 1. Surgery. 2000 Mar;127(3): 316-22.

14. Cucina A, Sapienza P, Borrelli V, Corvino V, Foresi G, Randone B, et al. Nicotine reorganizes cytoskeleton of vascular endothelial cell through platelet-derived growth factor BB. J Surg Res. 2000 Aug;92(2):233-8. 
15. Wang S, Zhang C, Zhang M, Liang B, Zhu H, Lee J, et al. Activation of AMP-activated protein kinase alpha2 by nicotine instigates formation of abdominal aortic aneurysms in mice in vivo. Nat Med. 2012 Jun;18(6):902-10.

16. Stadler N, Heeneman S, Voo S, Stanley N, Giles GI, Gang BP, et al. Reduced metal ion concentrations in atherosclerotic plaques from subjects with type 2 diabetes mellitus. Atherosclerosis. 2012 Jun;222(2):512-8.

17. Gremse F, Stark M, Ehling J, Menzel JR, Lammers T, Kiessling F. Imalytics Preclinical: Interactive Analysis of Biomedical Volume Data. Theranostics. 2016;6(3):328-41.

18. Chomczynski P, Sacchi N. Single-step method of RNA isolation by acid guanidinium thiocyanatephenol-chloroform extraction. Anal Biochem. 1987 Apr;162(1):156-9.

19. Kapustin AN, Chatrou ML, Drozdov I, Zheng Y, Davidson SM, Soong D, et al. Vascular smooth muscle cell calcification is mediated by regulated exosome secretion. Circ Res. 2015 Apr 10; 116(8):1312-23.

20. Irkle A, Vesey AT, Lewis DY, Skepper JN, Bird JL, Dweck MR, et al. Identifying active vascular microcalcification by (18)F-sodium fluoride positron emission tomography. Nat Commun. 2015;6: 7495.

21. Chatrou ML, Cleutjens JP, van der Vusse GJ, Roijers RB, Mutsaers PH, Schurgers LJ. Intra-Section Analysis of Human Coronary Arteries Reveals a Potential Role for Micro-Calcifications in Macrophage Recruitment in the Early Stage of Atherosclerosis. PLoS One. 2015;10(11):e0142335.

22. Vengrenyuk Y, Carlier S, Xanthos S, Cardoso L, Ganatos P, Virmani R, et al. A hypothesis for vulnerable plaque rupture due to stress-induced debonding around cellular microcalcifications in thin fibrous caps. Proc Natl Acad Sci U S A. 2006 Oct 3;103(40):14678-83.

23. Li S, Zhao T, Xin H, Ye LH, Zhang X, Tanaka H, et al. Nicotinic acetylcholine receptor alpha7 subunit mediates migration of vascular smooth muscle cells toward nicotine. J Pharmacol Sci. 2004 Mar;94(3):334-8.

24. Kimmel SE, Berlin JA, Miles C, Jaskowiak J, Carson JL, Strom BL. Risk of acute first myocardial infarction and use of nicotine patches in a general population. J Am Coll Cardiol. 2001 Apr;37(5): 1297-302.

25. Joseph AM, Norman SM, Ferry LH, Prochazka AV, Westman EC, Steele BG, et al. The safety of transdermal nicotine as an aid to smoking cessation in patients with cardiac disease. N Engl J Med. 1996 Dec 12;335(24):1792-8. 


\section{Supplemental Information}

Table I: Primer characteristics

\begin{tabular}{lll}
\hline Gene & Forward primer & Reverse primer \\
\hline GAPDH & AACGGATTTGGTCGTATTGGGC & CTTGACGGTGCCATGGAATTTG \\
Runx2 & Hs_RUNX2_1_SG QuantiTect Primer Assay & \\
Osteocalcin & GGCAGCGAGGTAGTGAAGAG & CGATAGGCCTCCTGAAAGC \\
\hline
\end{tabular}





\section{4}

\section{Gla-Rich Protein acts as a calcification inhibitor in the human cardiovascular system}

Carla S.B Viegas, Marta S. Rafael, Jose L. Enriquez, Alexandra Teixeira, Rui Vitorino, Ines M. Luis, Ruben M. Costa, Sofia Santos, Sofia Cavaco, Jose Neves, Anjos L. Macedo, Brecht A.G. Willems, Cees Vermeer and Dina C. Simes

ATVB. 2015, 35(2), 399-408 Reprinted with permission 


\section{Abstract}

Objective: Vascular and valvular calcifications are pathological processes, regulated by resident cells and depending on a complex interplay between calcification promoters and inhibitors, resembling skeletal metabolism. Here, we study the role of the vitamin K-dependent Gla-rich protein (GRP) in vascular and valvular calcification processes.

Approach and Results: Immunohistochemistry and qPCR showed that GRP expression and accumulation are up-regulated with calcification, simultaneously with osteocalcin (OC) and matrix gla protein (MGP). Using conformation-specific antibodies, both $\mathrm{y}$-carboxylated (cGRP) and undercarboxylated (ucGRP) species were found accumulated at sites of mineral deposits, whereas ucGRP was predominant in CAVD valvular intersticial cells (VICS). Mineral-bound GRP, MGP and fetuin-A were identified by mass spectrometry. Using an ex vivo model of vascular calcification cGRP but not ucGRP was shown to inhibit calcification and osteochondrogenic differentiation through a-smooth muscle actin up-regulation and osteopontin down-regulation. Immunoprecipitation assays showed that GRP is part of an MGP-fetuin-A complex at sites of valvular calcification. Moreover, extracellular vesicles (EVs) released from normal VSMCs are loaded with GRP, MGP and fetuin-A, while under calcifying conditions, released EVs show increased calcium loading and GRP and MGP depletion.

Conclusions: GRP is an inhibitor of vascular and valvular calcification involved in calcium homeostasis. Its function might be associated with prevention of calciuminduced signaling pathways and direct mineral-binding to inhibit crystal formation/ maturation. Our data show that GRP is a new player in mineralization-competence of EVs possibly associated with the fetuin-A-MGP calcification inhibitory system. GRP activity was found to be dependent on its $\gamma$-carboxylation status, with potential clinical relevance. 


\section{Introduction}

Cardiovascular calcification is a life-threatening complication of cardiovascular disease, affecting tissues such as arteries, heart valves, and cardiac muscle. Although many aspects concerning the pathogenesis of calcific aortic valve disease (CAVD) are still unclear, it has been shown to share a number of features with the mostly studied vascular calcification (VC), such as chronic inflammation, increased extracellular matrix (ECM) remodeling, proliferation and differentiation of resident cells, and the development of calcific lesions (1, 2). Both VC and CAVD are active, naturally occurring, controlled cell-mediated processes of osteochondrogenic differentiation of vascular smooth muscle cells (VSMCS) and valvular interstitial cells (VICs), resembling developmental skeletal formation (1-5). A number of growth factors, matrix inhibitory proteins and other bone-related proteins, including osteocalcin (OC), alkaline phosphatase (ALP), runt-related transcription factor 2 (Runx2), bone morphogenetic protein 2 (BMP2), collagen type I and osteopontin (OPN), were found to be associated with VC and CAVD (2, 3, 5-7). Importantly, VC is a process that must be actively inhibited, relaying on the presence of functional calcification inhibitors including matrix gla protein (MGP) and fetuin-A $(3,8,9)$. MGP is a vitamin K-dependent protein (VKDP) widely accepted as playing a pivotal role in preventing soft tissue calcification and local mineralization of the vascular wall $(3,8)$, whereas fetuin-A is a liver-derived blood protein acting as a potent inhibitor of ectopic calcification $(9,10)$. An association between both proteins has been observed at tissue and systemic circulation levels, forming a potent calcification inhibitory system, while decreased levels of functional $\curlyvee$-carboxylated MGP (cMGP) and fetuin-A have been linked to an enhanced calcification environment (11-15). A key event in the initiation of VSMCs calcification is the release of mineralization-competent extracellular vesicles (EVs), capable of efficiently nucleate hydroxyapatite in the absence of calcification inhibitors such as MGP (3, $5,15)$. However, the existence of additional calcification inhibitors has been repeatedly suggested (16-17). Gla-rich protein (GRP) is a VKDP (18) whose function and molecular mechanisms of action remain unknown, albeit zebrafish knockdown (19) and knockout mouse (20) studies have been performed. Also, different alternatively spliced transcripts, the function of which remains to be clarified, were shown to exist in mouse/zebrafish $(19,21)$ and human (22), highlighting the existence of distinct gene regulation in animal models and humans. However, GRP has been suggested to act as a negative regulator of osteogenic differentiation (23), a modulator of calcium availability in the ECM $(11,24)$, and as a potential inhibitor of soft tissue calcification in connective tissues (24). In concordance, its potential calcium-binding properties and association with calcification processes have been demonstrated through immunohistochemical and in vitro studies showing i) high levels of protein accumulation at sites of pathological calcification $(22,24,25)$ and ii) its capacity to directly bind basic calcium phosphate (BCP) crystals (25). $\gamma$-carboxylation of human GRP has been recently evidenced using a conformation-specific antibody for the $Y$-carboxylated GRP conformation (25), while an impaired $\curlyvee$-carboxylation status has been associated with pathological calcification related diseases, as osteoarthritis (OA) (22) and certain cancers (25). In this work we aimed to 
study the relation of GRP, at gene and protein levels, with valvular and vascular calcification processes, highlighting GRP function and molecular mechanisms of action.

\section{Material and Methods}

An expanded and detailed Materials and Methods section is available in the supplemental information.

\section{Results}

\section{Up-regulation of GRP-F1 in cardiovascular tissues is associated with mineral deposition}

The expression pattern of GRP splice variants was qualitatively evaluated by RT-PCR in several fetal and adult tissues composing the cardiovascular system, and showed the preponderancy of GRP-F1 in all tissues analyzed (Supplemental Figure I). Quantitative analysis of GRP-F1 gene expression determined by qPCR in aorta (Ao), aortic valve (AV) and pulmonary valve (PV) adult tissues (Supplemental Table I), showed different levels of expression among each tissue set, which however correlate with levels of OC: higher levels of GRP were found in samples presenting higher levels of OC (Figure 1A). Tissue histomorphological evaluation, using haematoxylineosin and von Kossa stainings, revealed the presence of detectable mineral deposits in 41\% of the analyzed samples, which correlates with detectable atherosclerotic lesions at autopsy (Supplemental Table I) and high levels of OC expression (Supplemental Table I).

IHC analysis using the CTerm-GRP antibody, recognizing total GRP (tGRP), clearly showed higher levels of protein deposition in calcified positive von Kossa samples (VK) from both aorta and aortic valve tissues (Figure 1B), while in non-calcified normal histopathological (HE) areas GRP was sporadically detected in association with VSMCs in aorta and VICs in aortic valve (Figure 1B). In these samples, no differences were observed between cGRP and UcGRP accumulation; moreover, the distribution patterns of both conformations were similar to that of tGRP (Supplemental Figure IIA). Negative controls showed absence of signal (Supplemental Figure IIB).

\section{GRP accumulation is associated with calcification and VIC disarray in CAVD}

Histological characterization of eleven CAVD samples analyzed (Supplemental Table II), using $\mathrm{HE}$ and von Kossa staining, revealed a highly heterogeneous phenotype, with heterogeneous disruption of ECM, VICs disorganization and calcification (Supplemental Figure III), as previously described $(1,2,7)$.

The accumulation pattern of the different GRP protein forms associated with CAVD was determined through IHC using the conformation-specific CGRP and UcGRP antibodies (Figure 2). Levels and patterns of GRP accumulation were found heterogeneously among the CAVD group. At regions of disperse mineralization, GRP was mainly detected in association 
A

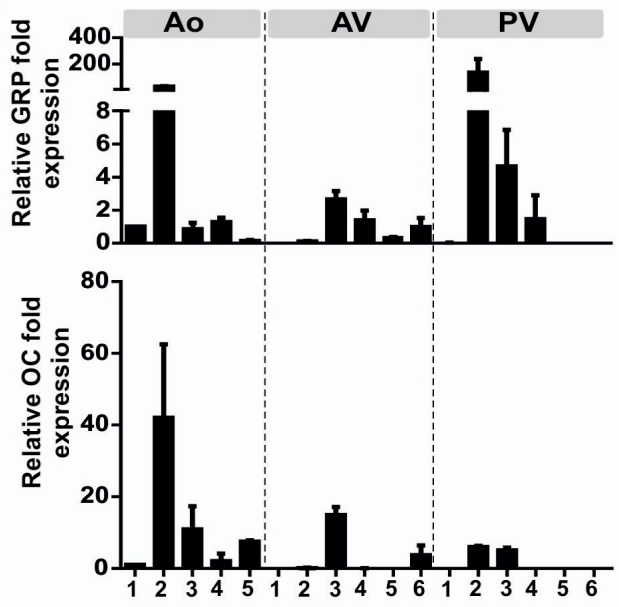

B
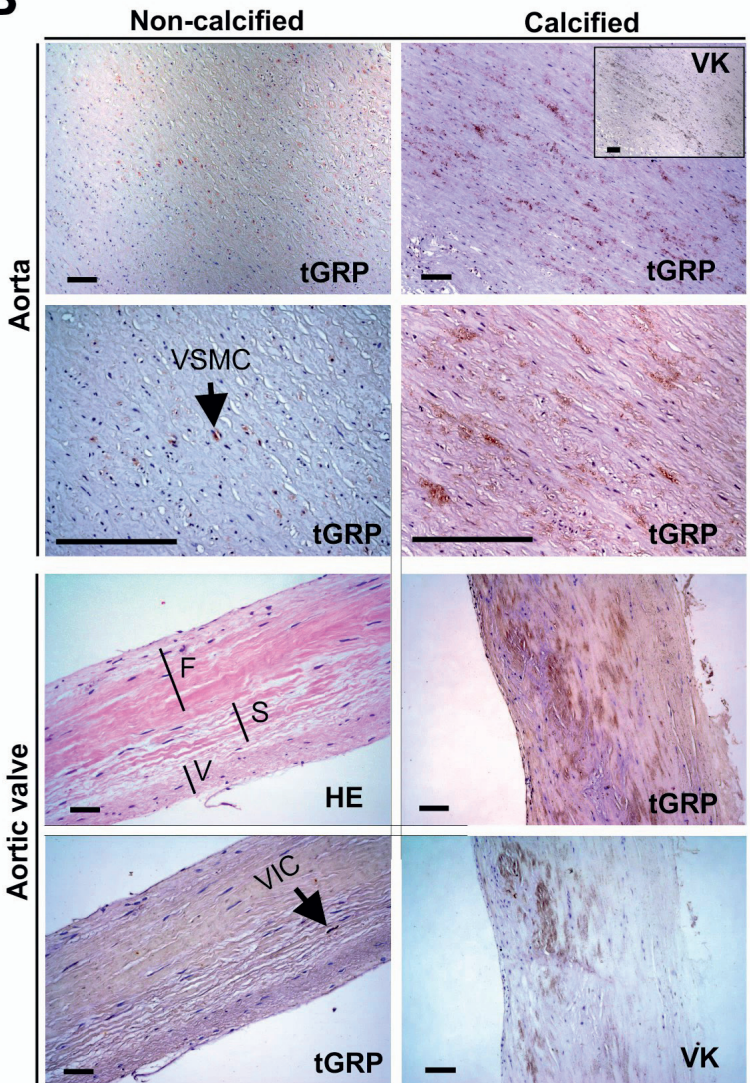

Figure 1: Gla-rich protein (GRP) is expressed in cardiovascular tissues both at transcriptional and translational levels.

A, Quantitative GRP-F1 and osteocalcin (OC) gene expression determined by quantitative polymerase chain reaction in several aortas (Ao; $n=5)$, aortic valves $(A V ; n=6)$, and pulmonary valves $(P V ; n=6)$ obtained from individuals without diagnosed cardiovascular disease (with exception of sample 4; Table I in the online-only Data Supplement), showing a strong relationship between levels of GRP and OC. Fold change in expression values are relative to Ao1 sample and SD are indicated $(n=3) . B$, Representative immunodetection of total GRP (tGRP) in aorta and aortic valve samples by immunohistochemistry, using the CTerm-GRP antibody. In noncalcified aorta and aortic valve tissues, tGRP is found sporadically associated with vascular smooth muscle cells (VSMCs) and valvular interstitial cells (VICs), respectively, whereas in calcified tissues, tGRP is highly accumulated at sites of mineral deposition, as demonstrated by von Kossa staining (VK) of consecutive sections. Hematoxylin-eosin staining (HE) shows the typical trilaminar structure of normal aortic valve tissue, constituted of the fibrosa $(\mathrm{F})$, spongiosa (S), and ventricularis (V). Positive signal in brown and counterstaining with HE. Scale bar, $100 \mu \mathrm{m}$. 
with mineral and sporadic VICs (Figure 2A-C), while higher GRP accumulation was found to be associated with atheromatous regions, heavy calcified areas and high cellularity (Figure 2D-O). In atheromatous areas, all GRP protein forms were detected with a similar pattern surrounding atheroma and localized to specific regions containing the remaining residual mineral (asterisk, Figure 2D-F, decalcified tissue samples). Similar cGRP and ucGRP protein accumulation patterns were observed at regions of massive calcification in non-decalcified tissue sections, colocalizing with mineralized material (Supplemental Figure IV). Foam cells (FC), found at regions of lipid accumulation mostly present in atheromas surrounding areas, were shown to accumulate tGRP (Figure $2 \mathrm{G}$ ). The lower staining observed for cGRP (Figure $2 \mathrm{H}$ ), as compared to ucGRP (Figure 2I), and the co-localization of ucGRP with tGRP indicates ucGRP as the predominant protein form in FC. Both CGRP and ucGRP were detected in VICs at regions of high and disarrayed cellularity, although with different patterns of accumulation: while ucGRP is mostly found intracellularly in most VICs (Figure 2L, O), cGRP is predominantly localized in the ECM on the vicinity of cells while a lower percentage of cells are also stained intracellularly (Figure $2 \mathrm{~K}, \mathrm{~N}$ ). Of notice, some of the fibroblast-like cells were GRP negative (white arrow head), a pattern confirmed with all antibodies (Figure 2J-O). Cells accumulating GRP were mostly assumed as VICs, and although at this stage we cannot rule out the possibility of GRP co-localization with T lymphocytes, the majority of cells accumulating GRP were found to be CD68 and CD3 negatives (results not shown). Overall, these results indicate that higher GRP accumulation in CAVD is associated with calcification together with VIC disarray, and specifically associated with particular VIC populations. While uCGRP is apparently predominant in CAVD, CGRP seems to be mostly targeted to sites of calcification. Negative controls showed absence of signal (Supplemental Figure V).

\section{GRP, MGP and OC are concomitantly up-regulated in CAVD}

GRP gene expression profiles in CAVD was evaluated to correlate it with the degree of cellular differentiation and calcification. Gene expression of known osteoblastic, differentiation and inflammation markers - MGP, OC, OPN, aSMA, and TNFa were determined in CAVD and non-CAVD groups (Figure 3). While no significant differences in GRP, MGP and OC levels were found between samples in each sample group, GRP was clearly up-regulated in the majority of CAVD samples with an expression pattern highly similar to MGP and OC. In concordance with the IHC results showing specific GRP accumulation in certain VICs, gene expression is higher in the particular set of samples presenting higher levels of MGP and OC. In contrast, a significant up-regulation of OPN, aSMA and TNFa is shown between all CAVD and non-CAVD samples, indicative of typical stenotic processes occurring in CAVD, characterized by VICs phenotypic transitions. These results suggest that GRP is up-regulated in specific differentiation stages of VIC populations, concomitantly expressing MGP and OC, probably in a later stage of VICs osteochondrogenic differentiation. Gene expression of GRP-F5 and F6 was also analyzed and results showed barely detectable expression of both transcripts in the majority of CAVD samples (Supplemental Figure VI). 

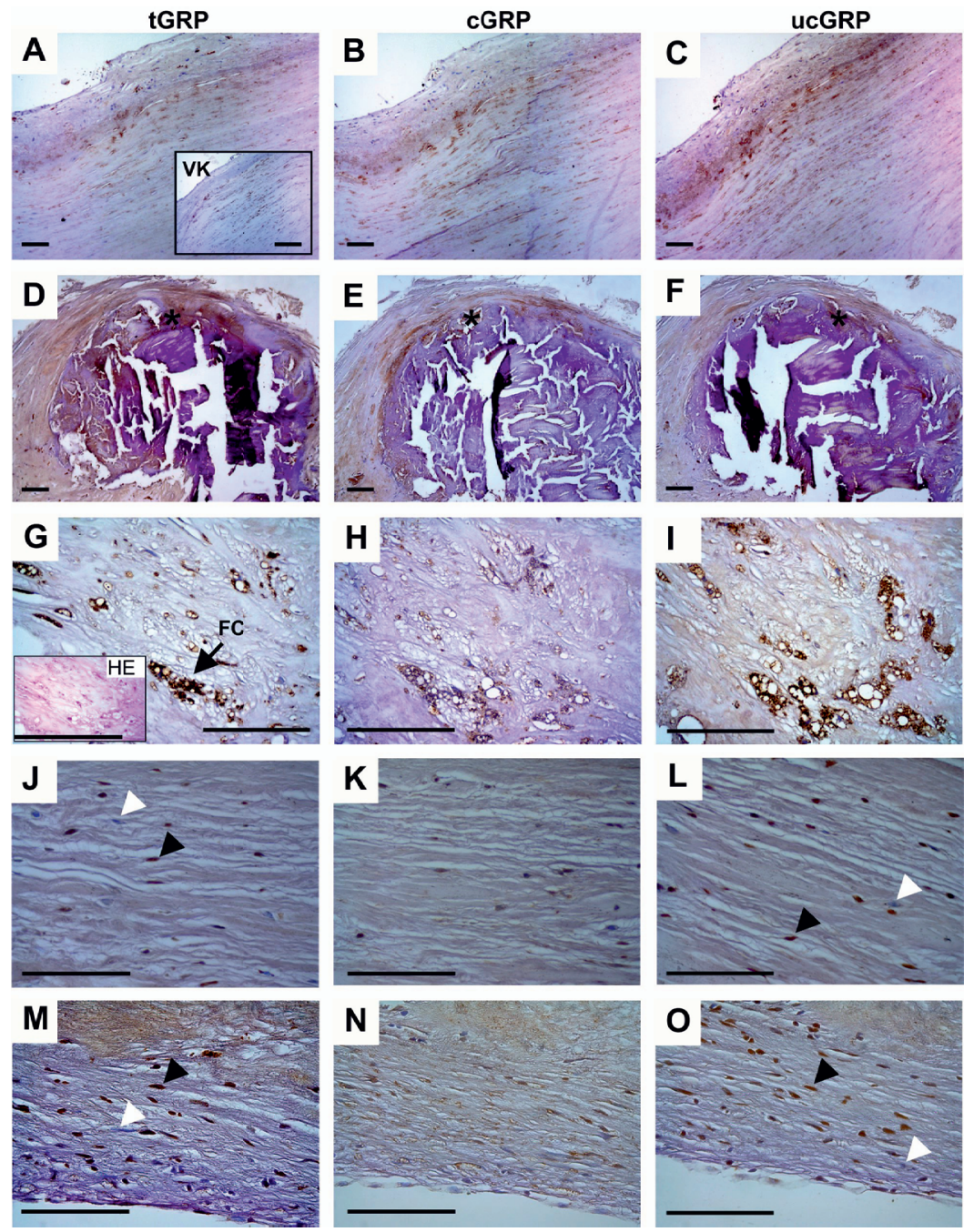

Figure 2: Differential accumulation pattern of $\gamma$-carboxylated Gla-rich protein (cGRP)/undercarboxylated GRP (UcGRP) species in calcified aortic valve disease (CAVD).

Representative immunohistochemistry experiments of CAVD tissue samples for total GRP (tGRP) (A, D, G, J and $\mathbf{M}$ ), cGRP (B, E, H, K and $\mathbf{N}$ ), and ucGRP (C, F, I, L, and $\mathbf{0}$ ) performed with CTerm-GRP, cGRPpAb, and ucGRPmAb antibodies, respectively. In the regions of disperse mineral deposits (A-C), determined by von Kossa (VK) staining (inset in A), similar patterns of tGRP (A), CGRP (B), and ucGRP (C) are observed and mainly colocalized with mineral deposits. All protein forms are similarly accumulated and colocalized with minerals in atheromatous regions (asterisk) and surrounding the atheroma (D-F). Foam cells (FC), identified by hematoxylin-eosin (HE) staining (inset in G) predominantly accumulate tGRP (G) and ucGRP (H). GRP is also detected associated with valvular interstitial cells (VICS) in the regions of high cellularity (J-O); ucGRP staining ( $\mathbf{L}$ and $\mathbf{O}$ ) is similar to tGRP ( $\mathbf{J}$ and $\mathbf{M}$ ), intracellularly associated with a particular set of VICs (black arrowheads), whereas CGRP staining is less predominant in VICS and diffuse in the extracellular matrix ( $\mathbf{K}$ and $\mathbf{N})$. White arrowheads represent GRPnegative VICS. Positive signal in brown and counterstaining with HE. Scale bar, $100 \mu \mathrm{m}$. Representative negative controls are presented in Figure $\mathrm{V}$ in the supplementary information. mAb indicates monoclonal antibodies; and pAb polyclonal antibodies 


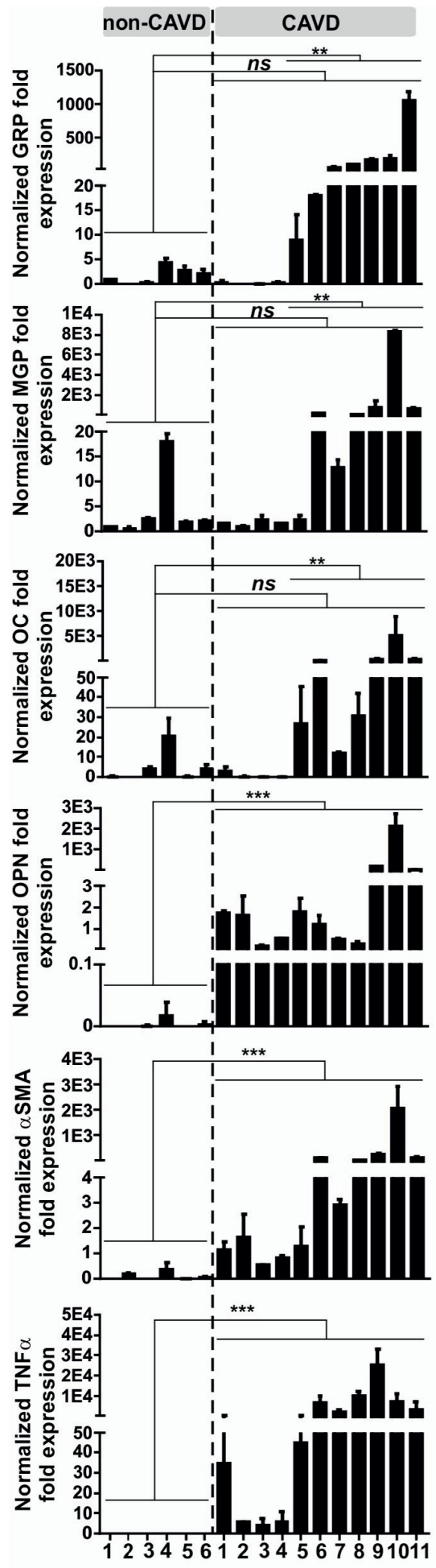

Figure 3: Gla-rich protein (GRP) is upregulated in calcified aortic valve disease (CAVD) concomitantly with matrix Gla protein (MGP) and osteocalcin (OC).

Gene expression of GRP and calcification/differentiation/inflammation marker genes was determined by quantitative polymerase chain reaction in aortic valves from control non-CAVD $(n=6)$ and CAVD $(n=11)$ samples. GRP, MGP, and OC are similarly upregulated in the majority of CAVD samples compared with control non-CAVD $(P<0.01)$, although no significant (ns) differences are obtained when both entire groups are compared. In contrast, a significant upregulation of osteopontin (OPN), a-smooth muscle actin (aSMA), and tumor necrosis factor-a (TNFa) is observed between control non-CAVD and CAVD sample groups $(P<0.001)$. Normalized fold expression (arbitrary units) was determined relative to zero, and SDs are indicated $(n>2)$. Nonparametric Mann-Whitney $U$ test was performed in all analyses 


\section{GRP, MGP and fetuin-A, are associated with the mineral phase of CAVD, resembling bone and vascular calcification}

To characterize GRP protein forms associated with the mineral phase of calcified aortic valves and to further identify additional proteins involved in aortic valve calcification, the mineral-associated (M-P) and two extractions of organic matrix (E1 and E2) protein content, extracted from calcified aortic valves, were analyzed by SDS-PAGE and WB (Figure 4).

SDS-PAGE analysis revealed distinct protein profiles, showing an efficient protein extraction of the organic matrix (E1 and E2, Figure 4A), and a clear preponderance of low molecular weight proteins associated with the mineral phase (M-P, Figure 4A). Both GRP and MGP were confirmed to be present mainly in the M-P (Figure 4B). Four protein bands were detected with CTerm-GRP and ucGRP antibodies (tGRP and ucGRP in Figure 4B), cor-

A

E1 E2 M-P

C

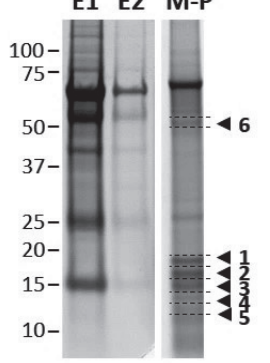

\begin{tabular}{c|c} 
Band & Protein ID \\
\hline 1 & GRP/MGP \\
\hline 2 & GRP/MGP \\
\hline 3 & MGP \\
\hline 4 & MGP \\
\hline 5 & MGP \\
\hline 6 & Fetuin-A \\
\hline
\end{tabular}

B

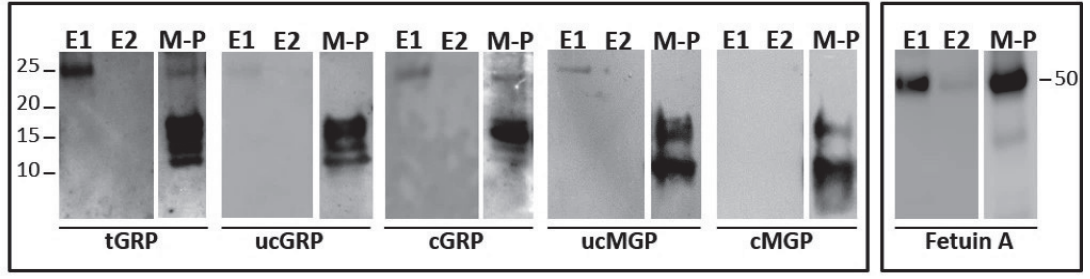

Figure 4: Gla-rich protein (GRP), matrix Gla protein (MGP), and fetuin-A are associated with the mineral phase of calcified aortic valves.

A, SDS-PAGE analysis of protein extracts corresponding to 2 sequential extractions of the aortic matrix components (E1 and E2) and the demineralized fraction containing mineral-bound proteins (M-P), stained with Coomassie Brilliant Blue. Numbers 1 to 6 indicate the relative positions of protein bands that were further analyzed and identified by nano-high-performance liquid chromatography (HPLC)-matrix-assisted laser desorption/ ionization time-of-flight mass spectrometry (MALDI-TOF)/TOF (C and Tables IV and V in the online-only Data Supplement). B, Western blot detection of total GRP (tGRP), $\gamma$-carboxylated GRP (cGRP), undercarboxylated GRP (ucGRP), $Y$-carboxylated MGP (CMGP), undercarboxylated MGP (ucMGP), and fetuin-A in E1, E2, and M-P extracts. Both forms of GRP and MGP are mainly detected in the M-P extract, whereas fetuin-A is preferentially detected in $\mathrm{E} 1$ and $\mathrm{M}-\mathrm{P}$ extracts (corresponding to band 6 in A). Four protein bands are detected with both CTerm-GRP (tGRP) and ucGRP antibodies corresponding to bands 1 to 4 marked in $\mathbf{A}$, whereas the cGRP antibody majorly detects band 2. C, Identification of target proteins present in gel band slices 1 to 6 by nano-HPLC-MALDI-TOF/ TOF. Additional information of identified proteins is given in Tables IV and $V$ in the supplementary information. The position of relevant molecular mass markers $(\mathrm{kDa})$ is indicated on the side of $\mathbf{A}$ and $\mathbf{B}$. 
responding to the protein profile marked as 1, 2, 3 and 4 on SDS-PAGE gel (Figure 4A), while cGRP antibodies preferably detect band 2 (cGRP in Figure 4B). In E-1 and M-P extracts a 25 kDa protein band was also detected, particularly with CTerm-GRP and CGRP antibodies, which may either represent intracellular non-processed protein or aggregated forms of GRP (Figure 4B). Both ucMGP and CMGP protein forms were detected in M-P, where two main protein bands named 2 and 5 were detected with both specific antibodies (Figure $4 \mathrm{~B}$ ). Fetuin-A was found mostly present in the M-P and E1 extracts, while E2 showed only residual detection (Figure 4B). Further identification of proteins present in SDS-PAGE gel slices marked as 1, 2, 3, 4, 5 and 6 was performed through nano-LC-MS/MS analysis (Figure 4C and Supplemental Tables IV, V). Protein identities were confirmed in bands 1 and 2 for GRP, bands 1-5 for MGP, and fetuin-A in band 6 (Figure 4C and Supplemental table IV), in concordance with WB detections. These results indicate that GRP species present in bands 3 and 4 are predominantly undercarboxylated, although identification by mass spectrometry was not successful, most possibly due to lower abundance. Identification of additional known osteogenic markers such as OPN, calcium-binding proteins such as protein S100-A9 (S10A9), and lipid associated proteins such as apolipoprotein E (APOE), were also identified in the M-P extract (Supplemental Table V).

Identification of Gla residues was not achieved by LC-MS/MS neither for GRP nor MGP, most possibly because Gla residues may undergo neutral loss of $\mathrm{CO} 2$ from the $\mathrm{Y}$-carboxy carbon, either during ionization by MALDI or following collision-induced dissociation (CID) tandem mass spectrometry (MS/MS) (26). Overall, our results showed that GRP is associated with the mineral phase of calcified stenotic valves together with other calcification inhibitors known to accumulate at sites of calcification, both in bone and vascular tissues.

\section{Y-carboxylated GRP inhibits calcification in an ex vivo aortic calcification model, by up- regulating aSMA and down-regulating OPN expression.}

To determine whether GRP directly affects vascular calcification and to examine the relevance of its -carboxylation status, we adapted an ex vivo model of aortic rings, by culturing small human aortic fragments both under control or mineralizing conditions; these cultures were supplemented with either noncarboxylated (ucGRP) or $\gamma$-carboxylated (cGRP) GRP. Calcification obtained under Ca + P supplementation was characterized by substantial accumulation of calcium deposits along the media, while aortic fragments cultured under control (C) conditions had generally no detectable calcification (results not shown); only in a few cases, the control tissues contained some minor disperse calcium spots (Figure 5A). After 14 days of in vitro culture, HE staining showed an intact structure of the vessels and an apparently normal VSMC phenotype in all conditions (Supplemental Figure VIIA); at this stage, no outgrowth or proliferation of VSMCs was observed (results not shown). A significant increase in $\mathrm{Ca}$ accumulation was determined in $\mathrm{Ca}+\mathrm{P}$ relative to control, while addition of UCGRP did not significantly affect $\mathrm{Ca}$ levels relatively to $\mathrm{Ca}+$ P (Figure 5B and Supplemental Figure VIIB, C). However, Ca + P supplemented with 500 
$\mathrm{ng} / \mathrm{ml}$ of cGRP results in a significant decrease in Ca, whereas $250 \mathrm{ng} / \mathrm{ml}$ showed a nonsignificant tendency for calcification inhibition (Figure 5B and Supplemental Figure VIIB, C). Reduction of calcium deposits in vessels treated with $500 \mathrm{ng} / \mathrm{ml}$ cGRP was confirmed by von Kossa staining (Figure 5A). Different inhibition degrees were obtained in the three experiments performed with $500 \mathrm{ng} / \mathrm{ml}$ cGRP (28.2\% (Supplemental Figure VIIB), 42.6\%

A

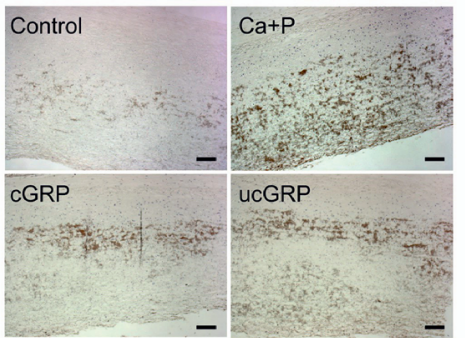

B

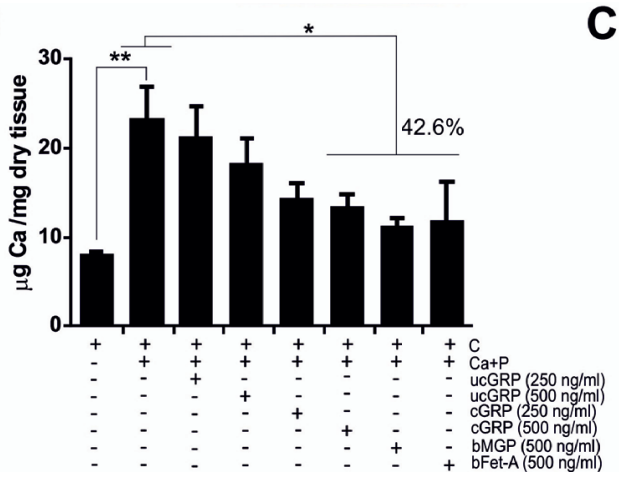

C

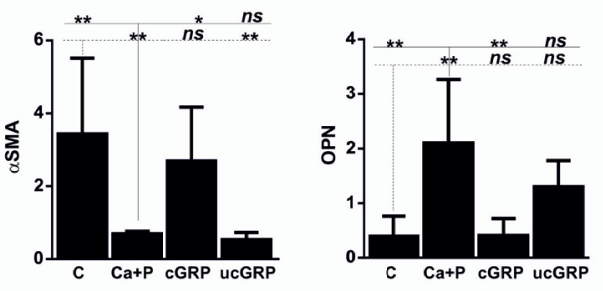

Figure 5: Gla-rich protein (GRP) inhibits calcification in an aortic tissue ex vivo model while increasing a-smooth muscle actin (aSMA) and downregulating osteopontin (OPN) expression.

A, Qualitative characterization of calcium deposits was determined through von Kossa staining of aortic segments, cultured under control, $\mathrm{Ca}+\mathrm{P}$, and $\mathrm{Ca}+\mathrm{P}$ supplemented with $\gamma$-carboxylated GRP (cGRP) and undercarboxylated GRP (ucGRP) media for 14 days. Results show high levels of calcium deposition in the media of tissues cultured under mineralizing conditions and a decrease in the case of cGRP supplementation. Scale bar, $100 \mu \mathrm{m}$. B, Calcium quantification per milligram of aortic segment dry weight, after 14 days in culture under conditions defined below the graph. $\mathrm{Ca}+\mathrm{P}$ calcifying media induce significant increase in Ca relative to control $(P<0.01)$, and treatments with $500 \mathrm{ng} / \mathrm{mL}$ of cGRP, bovine MGP (bMGP), and bovine fetuin-A (bFet-A) result in similar $42.6 \%$ reduction in Ca relative to $C a+P$ conditions $(P<0.05)$. No significant effects are observed neither with ucGRP nor with $250 \mathrm{ng} / \mathrm{mL}$ of cGRP. This represents the results of 1 experiment performed in triplicates, and additional experiments are presented as Figure VIIB and VIIC in the supplementary information. SD was calculated $(n=3)$, and ANOVA with comparison between groups by Dunnett test was performed. C, aSMA and OPN gene expression determined by quantitative polymerase chain reaction in aortic segments cultured for 14 days under the conditions described above, showing decreased aSMA and increased OPN in calcifying media, whereas CGRP treatment results in increased aSMA and decreased OPN expression relative to $\mathrm{Ca}+\mathrm{P}$, to levels similar to control. No significant differences were observed with ucGRP media supplementation. SD was calculated $(n>4)$, and ANOVA with comparison between groups by Dunnett test was performed. Solid and dashed lines represent comparisons relative to $\mathrm{Ca}+\mathrm{P}$ and to $\mathrm{C}$ conditions, respectively 
(Figure 5B) and 50\% (Supplemental Figure VIIC)), but were found similar to those obtained with $500 \mathrm{ng} / \mathrm{ml}$ of both bMGP and bfetuin-A (Figure 5B and Supplemental Figure VIIB). Mineralizing conditions induced a decrease of aSMA and an increase in OPN expression, indicative of an osteochondrogenic differentiation occurring in VSMCs, while exogenous CGRP is able to induce an increased aSMA and decreased OPN expression relative to $\mathrm{Ca}+$ $P$ (Figure 5C). Non-significant changes were observed with ucGRP treatment (Figure 5C). These results clearly show that (i) calcification inhibition is dependent on GRP dosage and $\mathrm{Y}$-carboxylation status, indicating a preponderant role of Gla residues in the calcification inhibitory function of GRP; (ii) carboxylated GRP has similar capacity of preventing calcification as the two widely accepted vascular calcification inhibitors, MGP and fetuin-A, and (iii) GRP interferes with osteochondrogenic differentiation process by retaining VSMCs in a contractile phenotype.

\section{A GRP-MGP-fetuin-A complex is present at calcification sites and calcium loading of VSMCs derived- EVs is accompanied by GRP and MGP depletion.}

Immunohistochemistry of double-staining experiments, using the respective antibodies, showed the colocalization of i) CGRP and CMGP, ii) CGRP and fetuin-A, iii) and CMGP and fetuin-A, all in association with the mineral phase (von Kossa, Figure 6A). These data point to a possible association of the three proteins at sites of calcification. To further test this hypothesis, immunoprecipitation (IP) of an M-P extract resuspended in $10 \mathrm{mM}$ Tris- $\mathrm{HCl}$ pH 7.5 was carried out using either CTerm-GRP or CMGP as capture antibodies. Prior to IP assays, the presence of both GRP and MGP in the Tris-HCl buffer was confirmed by WB, since both proteins are known to have poor solubility in neutral buffers $(18,27)$. Only part of the initially resuspended proteins was recovered in the soluble fraction (Sol), while the predominant GRP soluble protein form was detected as a $15 \mathrm{kDa}$ band with the CGRP antibody (Supplemental Figure VIII). Western blot analysis of the resulting eluted proteins after GRP and MGP IP assays, showed positive detection of the $15 \mathrm{kDa}$ GRP band in the anti-GRP and anti-MGP immunoprecipitates. Control IgG IP gave negative results (Figure 6B). In concordance, MGP was also detected in both IP assays (Figure 6B) and was further identified through LC-MS/ MS in the eluted GRP-IP proteins (results not shown). Additionally, fetuin-A was detected in both GRP- and MGP-IP eluted proteins, and a residual signal was observed in the IgG-IP reaction, most certainly corresponding to the heavy IgG chain of antibodies (Figure 6B). To discard a possible cross-reactivity of CMGP antibody with GRP, IP assays were reproduced as described for M-P extract, using conditioned media of transiently transfected HEK293T cells with GRP-F1-mkate2 fusion protein and the control pmkate2-N plasmid. Protein immunodetection was achieved with the CTerm-GRP antibody showing positive detection of GRP-F1-mkate2 fusion protein only in the GRP-IP eluted proteins (Supplemental Figure $I X)$, further confirming the specificity of the IP assays. Overall, these results provide strong evidences for the existence of a GRP-MGP-fetuin-A containing complex at sites of vascular calcification. 
A
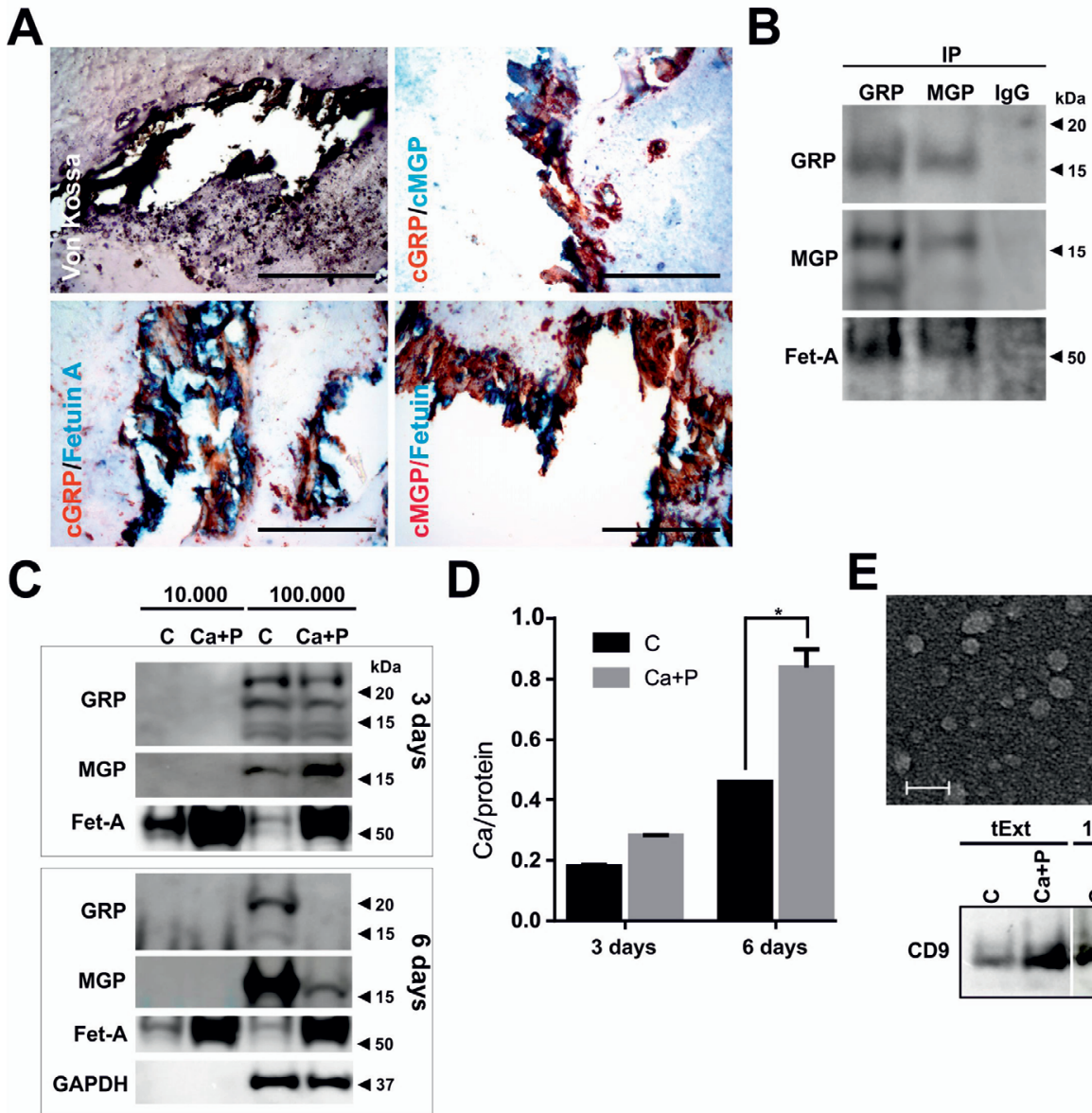

D

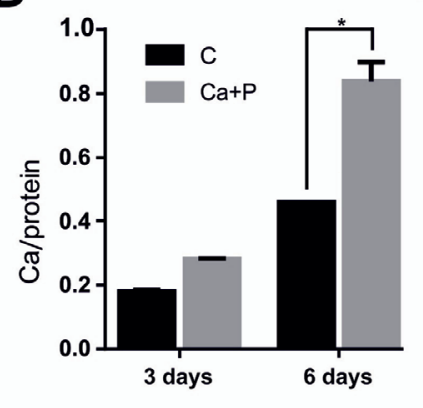

E

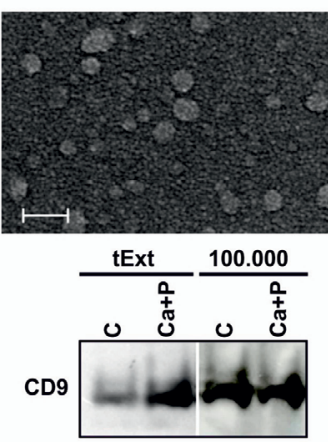

Figure 6: A Gla-rich protein (GRP)-matrix Gla protein (MGP)-fetuin-A (Fet-A) complex exists at calcification sites, and vascular smooth muscle cell-derived extracellular vesicles (EVs) are differentially loaded with GRP, MGP, and Fet-A under control and calcifying conditions.

A, Glycol methacrylate calcified aortic valve disease tissue samples show massive mineralized areas (von Kossa) with colocalization of $\gamma$-carboxylated GRP (cGRP), $\gamma$-carboxylated MGP (cMGP), and Fet-A, as determined by double immunohistochemistry staining using the following combination of antibodies: cGRP/CMGP (cGRP in red and CMGP in blue), cGRP/Fet-A (Santa Cruz; CGRP in red and Fet-A in blue), and cMGP/Fet-A (cMGP in red and Fet-A in blue). Scale bar, $100 \mu \mathrm{m}$. B, Western blot (WB) with CTerm-GRP, CMGP, and Fet-A (Santa Cruz) antibodies (indicated on the left side) of eluted proteins obtained after immunoprecipitation (IP) reactions with CTerm-GRP, CMGP, and IgG antibodies (IP-GRP, IP-MGP, and IP-IgG, respectively), using mineral-bound proteins extract (described in Figure 4 legend). GRP, CMGP, and Fet-A are detected in both IP-GRP and IP-MGP immunoprecipitants and not in the negative IgG-IP reaction. C, WB analysis of EVs isolated from cultured aortic segments for 3 and 6 days by differential centrifugation at $10000 \mathrm{~g}$ and $100000 \mathrm{~g}$, using CTerm-GRP, CMGP, and Fet-A (BioVendor) antibodies. GRP and MGP are only detected in $100000 \mathrm{~g}$ isolated EVs and are similarly present under tested conditions at day 3 , whereas a strong subsequent reduction is observed after long-term calcifying treatment. D, EVs isolated at $100000 \mathrm{~g}$. are loaded with significantly higher levels of calcium after long-term calcifying treatment. E, Scanning electron microscopy of $100000 \mathrm{~g}$ isolated EVs shows a homogenous population of small vesicles (<100 nm), enriched in cluster of differentiation 9 (CD9) expression. Total cell extracts lysates (tExt) were used as CD9 control. Scale bar, $100 \mathrm{~nm}$. Relevant molecular mass markers $(\mathrm{kDa})$ are shown on the right side of $\mathbf{B}$ and $\mathbf{C}$ 
Since $V C$ is a process highly related with the mineralization capacity of extracellular vesicles (EVs), and with the presence of $\gamma$-carboxylated MGP and fetuin-A $(3,5,9,15)$, the association of GRP with EVs in VSMCs mineralization was investigated using the developed human vessel ex vivo culture system. EVs were isolated from media of aortic segments cultured under $\mathrm{C}$ and $\mathrm{Ca}+\mathrm{P}$ conditions, by differential centrifugation after 3 and 6 days in culture, and the presence of GRP, MGP and fetuin-A was analyzed by WB. Overall, GRP and MGP were only detected in EVs obtained by ultracentrifugation at $100.000 \times$ g, while high levels of fetuin-A were found in Ca+P EVs obtained at both 10.000 and $100.000 \times \mathrm{g}$ (Figure 6C). Importantly, although at day 3, levels of GRP and MGP are similar between $C$ and $\mathrm{Ca}+\mathrm{P}$, a strong reduction is observed for both proteins in mineralizing conditions at day 6 (Figure 6C). This reduction of MGP and GRP loading in EVs is also related with increased EVs calcium loading (Figure 6D). Further characterization of isolated EVs containing MGP and GRP was performed by scanning electron microscopy, showing a highly homogenous population of small vesicles with an average size range of $65.7+-11.9 \mathrm{~nm}$, which were found positive for CD9 (Figure 6E).

\section{Discussion}

In this study we demonstrated that GRP has a function in calcium homeostasis in the cardiovascular system, most likely by acting as a calcification inhibitor through its calcium chelator and mineral binding capacity, and involvement in the mineralization competence of VSMCs derived EVs.

VSMCs and VICs synthetize low basal levels of GRP in normal histopathological human aortas and aortic valves, but its levels of protein accumulation and gene expression highly increases with calcification. IHC results evidence the colocalization of GRP with the mineral phase while gene expression analysis reveals a GRP up-regulation concomitant with the osteoblastic marker OC. The parallel up-regulation of GRP with OC and MGP, and not necessarily with an increase in OPN, aSMA, or TNFa, further suggests an association of GRP with osteoblast-like VICs after myofibroblast-VICs differentiation. VICs are a highly plastic population of valvular resident cells with the ability to differentiate into a variety of other cell types, such as myofibroblasts and osteoblast-like cells with calcifying potential $(1,2)$. Under endothelial damage and lipid deposition, inflammation is triggered with consequent macrophage differentiation and accumulation, expressing TNFa and OPN $(1,28,29)$. Inflammatory activity initiates a subpopulation of VICs to differentiate into myofibroblasts expressing aSMA and matrix metalloproteinases (1, 2). Consequently, disease progression from sclerotic to stenotic states is thought to be driven by the differentiation of myofibroblasts into osteoblast-like cells, with local production of factors, such as OC, commonly associated with bone and vascular calcification $(1-3,7)$. Although abnormal circulating MGP levels have been associated with CAVD (30), studies of MGP at tissue level in CAVD are lacking. However, MGP expression is known to increase with osteoblast development/ 
maturation, and has been considered a late marker of osteoblast-like differentiation in calcifying vascular cells (CVC). MGP up-regulation in areas of extracellular VC both in vivo $(31,32)$ and in vitro $(33)$ precludes a mechanism to limit further the extent of calcification, through cell differentiation modulation and control of matrix calcification.

We have recently reported that although both c/ucGRP protein forms possess Ca/P mineral binding affinity and are present in healthy connective tissues, the increased accumulation of UcGRP protein is associated with a pathological condition (22, 25). In concordance, both CGRP and UCGRP were detected in VSMCs and VICs in normal tissues, and similarly highly accumulated at sites of mineral deposition. Also, a predominance of ucGRP relative to CGRP was confirmed in CAVD by IHC. The pattern of cGRP accumulation further suggests that the reduced amount of cGRP produced may be directed to sites of calcification where it accumulates probably as a mechanism to control or limit the levels of calcification. In concordance, both GRP species were detected in extracts of mineral-bound proteins derived from calcified valvular material. The pattern of GRP in WB was shown to be complex with multiple positive bands consistently detected with all available anti-GRP antibodies. The presence of the alternatively spliced variants F5 and F6 in this protein profile can be excluded, since its expression was nearly undetectable in both normal and calcified valves. Moreover, the conformation-specific antibodies were raised against synthetic peptides comprising partial Gla/Glu domains, so multiple patterning may represent different degrees of $\gamma$-carboxylation, with a predominant $\gamma$-carboxylated protein form migrating at 15 kDa. In fact, Gla proteins with different degrees of $\gamma$-carboxylation have been shown to alter their migration behavior on SDS-PAGE gels (34). In addition, the fact that we used a pool of individual aortic valves may have contributed to the high Gla content heterogeneity. GRP identification was confirmed by mass spectrometry analysis of two immuno-positive bands. With this approach we have also identified MGP and fetuin-A as mineral-bound proteins associated with CAVD. Other proteins involved in vascular and bone mineralization (e.g OPN) were also identified, providing additional evidence that common mechanisms exist in valvular, VC and physiological bone mineralization.

The similar patterns of GRP and MGP up-regulation, and mineral colocalization showed in CAVD, further support the previously proposed calcification-inhibitory function of GRP. More importantly, using an ex vivo model of human vessel culture we showed that $\gamma$-carboxylated GRP is able to inhibit calcification to the same extent as $\gamma$-carboxylated MGP and fetuin-A. Although a reduction in calcification was observed to some extent with noncarboxylated GRP supplementation, only with $\gamma$-carboxylated GRP a clear dose-dependent calcification inhibition was obtained, suggesting that $\gamma$-carboxylation is essential for GRP's calcification-inhibitory function. $y$-carboxylation has been shown to be required for biological activity of VKDPs whose function is known, and under- or uncarboxylated species are generally regarded as proteins with low or no functional activity $(17,32,36$, 37). This has been extensively shown for MGP, the inhibitory function of which is highly dependent on its $\mathrm{Y}$-carboxylation status, in particular in $\operatorname{VSMCs}(3,5,9)$. In our model, ves- 
sel calcification was characterized mostly by a medial localization, decreased aSMA and simultaneous increased OPN expression. These events are counteracted by $\gamma$-carboxylated GRP through the up-regulation of aSMA and down-regulation of OPN, indicating a protective effect on the Ca/P induced effect on VSMCs, shifting from a contractile to a synthetic osteochondrogenic phenotype. High extracellular calcium has been shown to act as a key trigger for VSMCs calcification by activation of intracellular signaling pathways that culminate in the secretion of mineralization-competent EVs (5). Inhibition of calcium or cytosolic calcium chelation efficiently prevents VSMCs calcification (15). It is conceivable to propose that addition of exogenous $\gamma$-carboxylated GRP to VSMCs could act as a calcium chelator agent, decreasing extracellular calcium levels and reducing calcification. In addition, we have previously showed that GRP can directly bind BCP crystals in vitro, and in this way it may interfere with crystal growth and/or maturation through a similar mechanism previously proposed for the calcification inhibitory activity of MGP (25). Altogether, our in vitro and ex-vivo results show that although both cGRP and ucGRP have calcium mineral affinity, CGRP is a more efficient vascular calcification inhibitor.

To uncover additional mechanisms involving GRP in cardiovascular calcification, we further explored the relationship between GRP and MGP. Our results from IP assays strongly suggest that GRP is part of a larger complex containing MGP and fetuin-A, acting at sites of calcification. A relation between MGP and fetuin-A has been documented previously, at both circulation (13) and tissue levels (12). It is known that vascular calcification is a process initiated with the deposition in the ECM of BCP containing EVs derived from VSMCs, forming a nidus of calcification in a process similar to bone mineralization $(3,5,9,11,15)$. It has been reported that under normal conditions VSMCs-derived EVs do not calcify due to their loading with mineralization inhibitors such as $\gamma$-carboxylated MGP and fetuin-A, which act to block mineral nucleation $(3,5,9,11,15)$. In this context, it was important to further understand whether GRP was also involved in EVs biogenesis and/or mineralization competence associated with ECM calcification. The presence of GRP was confirmed in EVs released by aortic fragments, with less than $100 \mathrm{~nm}$ size and expressing CD9, consistent with exosome profiling $(38,39)$. Importantly, these EVs were also loaded with MGP and fetuin-A in control conditions, while MGP and GRP EVs content dramatically decrease after long-term calcifying conditions, concomitantly with an increase in calcium loading. These results are in agreement with the knowledge that loss of mineralization inhibitors is crucial for promoting EVs mineralization $(5,15)$. Like previously shown for MGP, GRP is loaded in non-calcifying EVs and absent in high calcium loaded vesicles, suggesting GRP as an important mineralization inhibitor highly related in the EVs mineralization process. Furthermore, it is possible that constitutively inhibition of EVs calcification capacity might occur via a GRP-MGP-fetuin-A containing complex, forming a potent inhibitory system. Moreover, an MGP-fetuin-A complex was described in chondrocyte-derived EVs (12), and it was proposed that the calcification inhibitory function of MGP-fetuin-A complex in circulation (FMC) results from the strong calcium phosphate binding capacity of these 
proteins (13). This GRP-MGP-fetuin-A complex was detected at sites of calcification and associated with known EVs components, such as annexin A2 and S100A9 (15, 40), and ECM calcification is well known to be initiated with the deposition of BCP-containing vesicles $(5,15)$.Considering the characterization of VSMCs derived vesicles we found loaded with GRP and MGP, it could be suggested that those were mainly exosomes, as previously suggested for MGP EVs due to identification of proteins from endosomal origin (15). Additional characterization on biogenesis, mechanisms of protein loading and mineralization-related regulation are further required.

From a research point of view, our study was pioneer in establishing GRP as a key factor involved in cardiovascular calcification, providing new data in the field of CAVD. While it provides new insights into the GRP function as a calcification inhibitor, probably through mechanisms involving the MGP-fetuin-A calcification inhibitory system, acting on the inhibition of EVs mineralization capacity, it raises new and important questions requiring further investigation.

From a clinical perspective, our work reinforces the notion that special care should be given to the widely used anticoagulant agents such as warfarin, acting as vitamin $\mathrm{K}$ antagonists (41), and interfering with MGP and GRP functionality. Further studies aiming to correlate circulating levels and $y$-carboxylation status of GRP with the degree of calcification and disease progression are currently in progress, and will enable us to evaluate the potential use of GRP as an additional marker for ectopic calcification. 


\section{References}

1. Dweck MR, Boon NA, Newby DE. Calcific aortic stenosis: a disease of the valve and the myocardium. J Am Coll Cardiol. 2012; 60:1854-1863.

2. Rajamannan NM, Evans FJ, Aikawa E, Grande-Allen KJ, Demer LL, Heistad DD, Simmons CA, Masters KS, Mathieu P, O’Brien KD, Schoen FJ, Towler DA, Yoganathan AP, Otto CM. Calcific aortic valve disease: not simply a degenerative process: A review and agenda for research from the $\mathrm{Na}$ tional Heart and Lung and Blood Institute Aortic Stenosis Working Group. Executive summary: Calcific aortic valve disease-2011 update. Circulation 2011;124:1783-1791.

3. Shroff R, Long DA, Shanahan C. Mechanistic insights into vascular calcification in CKD. J Am SoC Nephrol. 2013;24:179-189.

4. Demer LL, Tintut Y. Vascular calcification: pathobiology of a multifaceted disease. Circulation 2008;117:2938-2948.

5. Kapustin AN, Shanahan CM. Calcium regulation of vascular smooth muscle cell-derived matrix vesicles. Trends Cardiovasc Med. 2012;22:133-137.

6. Wirrig EE, Hinton RB, Yutzey KE. Differential expression of cartilage and bone-related proteins in pediatric and adult diseased aortic valves. J Mol Cell Cardiol. 2011;50:561-569.

7. Rajamannan NM, Subramaniam M, Rickard D, Stock SR, Donovan J, Springett M, Orszulak T, Fullerton DA, Tajik AJ, Bonow RO, Spelsberg T. Human aortic valve calcification is associated with an osteoblast phenotype. Circulation 2003;107:2181-2184.

8. Luo G, Ducy P, McKee MD, Pinero GJ, Loyer E, Behringer RR, Karsenty G. Spontaneous calcification of arteries and cartilage in mice lacking matrix GLA protein. Nature 1997;386:78-81.

9. Reynolds JL, Skepper JN, McNair R, Kasama T, Gupta K, Weissberg PL, Jahnen-Dechent W, Shanahan CM. Multifunctional roles for serum protein fetuin-a in inhibition of human vascular smooth muscle cell calcification. J Am Soc Nephrol. 2005;16:2920-2930.

10. Jahnen-Dechent W, Heiss A, Schäfer C, Ketteler M. Fetuin-A regulation of calcified matrix metabolism. Circ Res. 2011;108:1494-1509.

11. Shroff RC, McNair R, Figg N, Skepper JN, Schurgers L, Gupta A, Hiorns M, Donald AE, Deanfield $J$, Rees L, Shanahan CM. Dialysis accelerates medial vascular calcification in part by triggering smooth muscle cell apoptosis. Circulation 2008;118:1748-1757.

12. Wallin R, Schurgers LJ, Loeser RF. Biosynthesis of the vitamin K-dependent matrix Gla protein (MGP) in chondrocytes: a fetuin-MGP protein complex is assembled in vesicles shed from normal but not from osteoarthritic chondrocytes. Osteoarthritis Cartilage 2010;18:1096-1103.

13. Price PA, Lim JE. The inhibition of calcium phosphate precipitation by fetuin is accompanied by the formation of a fetuin-mineral complex. J Biol Chem. 2003;278:22144-22152.

14. Ketteler M, Rothe H, Krüger T, Biggar PH, Schlieper G. Mechanisms and treatment of extraosseous calcification in chronic kidney disease. Nat Rev Nephrol. 2011;7:509-16.

15. Kapustin AN, Davies JD, Reynolds JL, McNair R, Jones GT, Sidibe A, Schurgers LJ, Skepper JN, Proudfoot D, Mayr M, Shanahan CM. Calcium regulates key components of vascular smooth muscle cell-derived matrix vesicles to enhance mineralization. Circ Res. 2011;24:109:e1-12. 
16. Schinke T, Karsenty G. Vascular calcification-a passive process in need of inhibitors. Nephrol Dial Transplant. 2000;15:1272-1274.

17. Cranenburg ECM, Schurgers LJ, Vermeer C. Vitamin K: the coagulation vitamin that became omnipotent. Thromb Haemost. 2007;98:120-125.

18. Viegas CS, Simes DC, Laizé V, Williamson MK, Price PA, Cancela ML. Gla-rich protein (GRP), a new vitamin K-dependent protein identified from sturgeon cartilage and highly conserved in vertebrates. J Biol Chem. 2008;283:36655-36664.

19. Neacsu CD, Grosch M, Tejada M, Winterpacht A, Paulsson M, Wagener R, Tagariello A. Ucmaa (Grp-2) is required for zebrafish skeletal development. Evidence for a functional role of its glutamate -carboxylation. Matrix Biol. 2011;30:369-378.

20. Eitzinger N, Surmann-Schmitt C, Bösl M, Schett G, Engelke K, Hess A, von der Mark K, Stock M. Ucma is not necessary for normal development of the mouse skeleton. Bone 2012;50:670-680.

21. Le Jeune M, Tomavo N, Tian TV, Flourens A, Marchand N, Camuzeaux B, Mallein-Gerin F, Duterque-Coquillaud M. Identification of four alternatively spliced transcripts of the Ucma/GRP gene, encoding a new Gla-containing protein. Exp Cell Res. 2010;316:203-215.

22. Rafael MS, Cavaco S, Viegas CS, Santos S, Ramos A, Willems B, Herfs M, Theuwissen E, Vermeer C, Simes DC. Insights into the association of Gla-rich protein (GRP) and osteoarthritis: novel splice variants and Y-carboxylation status. Mol Nutr Food Res. DOI 10.1002/mnfr.201300941; in press.

23. Surmann-Schmitt C, Dietz U, Kireva T, Adam N, Park J, Tagariello A, Onnerfjord P, Heinegård D, Schlötzer-Schrehardt U, Deutzmann R, von der Mark K, Stock M. Ucma, a novel secreted cartilage-specific protein with implications in osteogenesis. J Biol Chem. 2008;283:7082-7093.

24. Viegas CS, Cavaco S, Neves PL, Ferreira A, João A, Williamson MK, Price PA, Cancela ML, Simes DC. Gla-rich protein is a novel vitamin K-dependent protein present in serum that accumulates at sites of pathological calcifications. Am J Pathol. 2009;175:2288-2298.

25. Viegas CS, Herfs M, Rafael MS, Enriquez JL, Teixeira A, Luís IM, van 't Hoofd CMR, João A, Maria VL, Cavaco S, Ferreira A, Serra M, Theuwissen E, Vermeer C, Simes DC. Gla-rich protein is a potential new vitamin $\mathrm{K}$ target in cancer: Evidences for a direct GRP-mineral interaction. Biomed Res Int. 2014:340216 doi:10.1155/2014/340216.

26. Hallgren KW, Zhang D, Kinter M, Willard B, Berkner KL. Methylation of Y-carboxylated Glu (Gla) allows detection by liquid chromatography-mass spectrometry and the identification of Gla residues in the $\gamma$-glutamyl carboxylase. J Proteome Res. 2013;12:2365-2374.

27. Hackeng TM, Rosing J, Spronk HM, Vermeer C. Total chemical synthesis of human matrix Gla protein. Protein Sci. 2001;10:864-870.

28. O’Brien KD, Kuusisto J, Reichenbach DD, Ferguson M, Giachelli C, Alpers CE, Otto CM. Osteopontin is expressed in human aortic valvular lesions. Circulation 1995;92:2163-2168.

29. Kaden JJ, Dempfle CE, Grobholz R, Fischer CS, Vocke DC, Kiliç R, Sarikoç A, Piñol R, Hagl S, Lang S, Brueckmann M, Borggrefe M. Inflammatory regulation of extracellular matrix remodeling in calcific aortic valve stenosis. Cardiovasc Pathol. 2005;14:80-87. 
30. Ueland T, Gullestad L, Dahl CP, Aukrust P, Aakhus S, Solberg OG, Vermeer C, Schurgers LJ. Undercarboxylated matrix Gla protein is associated with indices of heart failure and mortality in symptomatic aortic stenosis. J Intern Med. 2010;268:483-492.

31. Shanahan CM, Cary NR, Metcalfe JC, Weissberg PL. High expression of genes for calcificationregulating proteins in human atherosclerotic plaques. J Clin Invest. 1994;93:2393-2402.

32. Schurgers LJ, Teunissen KJF, Knapen MHJ, Kwaijtaal M, van Diest R, Appels A, Reutelingsperger CP, Cleutjens JPM, Vermeer C. Novel conformation-specific antibodies against matrix gammacarboxyglutamic acid (Gla) protein: undercarboxylated matrix Gla protein as marker for vascular calcification. Arterioscler Thromb Vasc Biol. 2005;25:1629-1633.

33. Tintut Y, Parhami F, Boström K, Jackson SM, Demer LL. cAMP stimulates osteoblast-like differentiation of calcifying vascular cells. Potential signaling pathway for vascular calcification. J Biol Chem. 1998;273:7547-7553.

34. Cavaco S, Williamson MK, Rosa J, Roberto V, Cordeiro O, Price PA, Cancela ML, Laizé V, Simes DC. Teleost fish osteocalcin 1 and 2 share the ability to bind the calcium mineral phase. Fish Physiol Biochem. 2014; 40:731-738.

35. Shroff RC, McNair R, Skepper JN, Figg N, Schurgers LJ, Deanfield J, Rees L, Shanahan CM. Chronic mineral dysregulation promotes vascular smooth muscle cell adaptation and extracellular matrix calcification. J Am Soc Nephrol. 2010;21:103-112.

36. McCann JC, Ames BN. Vitamin K, an example of triage theory: is micronutrient inadequacy linked to diseases of aging? Am J Clin Nutr. 2009;90:889-907.

37. Schurgers LJ, Spronk HMH, Skepper JN, Hackeng TM, Shanahan CM, Vermeer C, Weissberg PL, Proudfoot D. Post-translational modifications regulate matrix Gla protein function: importance for inhibition of vascular smooth muscle cell calcification. J Thromb Haemost. 2007;5:2503-2511.

38. Comelli L, Rocchiccioli S, Smirni S, Salvetti A, Signore G, Citti L, Trivella MG, Cecchettini A. Characterization of secreted vesicles from vascular smooth muscle cells. Mol Biosyst. 2014;10:1146-52.

39. Pant S, Hilton H, Burczynski ME. The multifaceted exosome: biogenesis, role in normal and aberrant cellular function, and frontiers for pharmacological and biomarker opportunities. Biochem Pharmacol. 2012;83:1484-94.

40. New SE, Goettsch C, Aikawa M, Marchini JF, Shibasaki M, Yabusaki K, Libby P, Shanahan CM, Croce K, Aikawa E. Macrophage-derived matrix vesicles: an alternative novel mechanism for microcalcification in atherosclerotic plaques. Circ Res. 2013;113:72-7.

41. Schurgers LJ, Aebert H, Vermeer C, Bültmann B, Janzen J. Oral anticoagulant treatment: friend or foe in cardiovascular disease? Blood 2004;104:3231-2322. 


\section{Supplemental Information}

\section{Materials}

Antibodies against: tGRP and cGRP were provided by GenoGla Diagnostics (Faro, Portugal); ucGRP was provided by VitaK BV (Maastricht, The Netherlands), CMGP and ucMGP by IDS (Boldon, UK); CD68, CD3, Fetuin A were purchased from Santa Cruz Biotechnology, Inc (Santa Cruz, CA). Secondary goat anti-rabbit-HRP, goat anti-chicken-HRP, rabbit antimouse-HRP, and goat anti-mouse-ALP antibodies, primers, fetal bovine serum (FBS) and all other chemical/reagents were purchased from Sigma-Aldrich, unless otherwise stated.

\section{Sample processing}

For gene expression and IHC studies samples were collected into RNAlater or sterile 4\% (w/v) PFA solution, respectively, and for protein extraction samples were frozen until processing. Tissue samples were embedded either in paraffin or glycol methacrylate as described $(19,20)$ and histologically classified by pathologists. Physiological structures were identified by regular haematoxylin-eosin staining and mineral deposits were detected with silver nitrate by the von Kossa method, and counterstained with haematoxylin.

\section{RNA extraction and gene expression}

Total RNA was extracted from fetal, non-CAVD, CAVD and cultured aortic fragment tissues as described by Chomczynski and Sacchi (30). RNA integrity was evaluated by agaroseformaldehyde gel electrophoresis and concentration determined by spectrophotometric analysis at $260 \mathrm{~nm}$.

One microgram of total RNA was treated with RQ1 RNase-free DNase (Promega) and reverse-transcribed at $37^{\circ} \mathrm{C}$ with MMLV-RT (Invitrogen) using a dT-adapter. PCR amplifications for GRP-F1, -F5 and -F6 splice variants were performed as previously described with SsoFast EvaGreen Supermix (BioRad) for 50 cycles and specific primer sets GRP_F1Fw/ GRP_F1Rv, GRP_F5_F6Fw/GRP_F5Rv and GRP_F5_F6Fw/GRP_F6Rv, respectively. Ribosomal $18 \mathrm{~S}$ was used as loading control. A list of all PCR primer sequences is presented in Supplemental Table III.

Quantitative PCR was performed with an iCycler iQ apparatus (Bio-Rad) using 25 ng cDNA and the conditions described above. In addition to GRP-F1, -F5, -F6 and 18S, MGP, OC (OSteocalcin), OPN (osteopontin), alpha smooth muscle actin (aSMA), TNFa (Tumor necrosis factor alpha), and GAPDH were amplified using primer sets as described in Supplemental Table III. Fluorescence was measured at the end of each extension cycle in the FAM-490 channel and melting profiles of each reaction were performed to check for unspecific product amplification. Levels of gene expression were calculated using the comparative method (ddCt) and normalized using gene expression levels of both GAPDH and 18S housekeeping genes, with the iQ5 software (BioRad); qPCR was performed in minimum of duplicates and a normalized SD was calculated. 


\section{Immunolocalization}

Single immunohistochemical staining was performed on paraffin-embedded tissue sections as described elsewhere (2). Briefly, endogenous peroxidase activity was blocked with 3\% (v/v) $\mathrm{H}_{2} \mathrm{O}_{2}$ in TBST buffer (TBST: $0.1 \mathrm{~mol} / \mathrm{L}$ Tris, $0.15 \mathrm{~mol} / \mathrm{L} \mathrm{NaCl}, 0.1 \%$ (v/v) Triton $X-100)$ for 15 min. Nonspecific antibody binding was blocked with TBT (0.5\% (w/v) BSA in TBST) for 1 hour at $37^{\circ} \mathrm{C}$. Incubations with CTerm-GRP, cGRP pAb and ucGRP mAb were performed as previously described. Primary antibodies were detected using species specific HRP-conjugated secondary antibodies, and 0.025\% (w/v) 3,3-diaminobenzidine. Double staining was performed on glycol methacrylate using a combination of cGRP/CMGP (1:200), cGRP/fetuin A (1:200) and cMGP/fetuin A primary antibodies. First and second antibodies were detected with ImmPACT NovaRED substrate kit (Vector laboratories) originating a red color and Vector Blue-ALP substrate kit (Vector laboratories) originating a blue color, respectively, using species specific HRP-conjugated secondary antibodies. Negative controls consisted in the substitution of primary antibody with TBT. Single staining experiments were counterstaining with haematoxylin. Microscopic images were acquired in a Zeiss AXIOIMAGER Z2 microscope, with an AxioCam ICc3 camera and AxioVision software version 4.8 (Carl Zeiss), at the light microscopy facility, Department of Biomedical Sciences and Medicine, University of Algarve (Portugal).

\section{Protein extraction}

A pool of CAV tissue samples was ground to powder in a mortar, and the organic matrix proteins were extracted twice with RIPA buffer $(50 \mathrm{mM}$ Tris $\mathrm{HCl}$ pH 8, $150 \mathrm{mM} \mathrm{NaCl}, 1 \%$ NP40, 0.5\% sodium deoxycholate, 0.1\% SDS) (Ext_1 and Ext_2) for two hours each extraction at $4^{\circ} \mathrm{C}$ with rotation. After separation of the remaining mineral phase by centrifugation at $16000 \mathrm{xg}$ for $20 \mathrm{~min}$ at $4^{\circ} \mathrm{C}$, mineral-bound proteins (Min-P) were extracted using a 10-fold excess of $10 \%(\mathrm{v} / \mathrm{v})$ formic acid for $4 \mathrm{~h}$ at $4^{\circ} \mathrm{C}$ as previously described (17). Extracted proteins were separated from the insoluble material by centrifugation and then dialyzed at $4^{\circ} \mathrm{C}$ against $50 \mathrm{mM} \mathrm{HCl}$ using 3,500 molecular weight tubing (Spectrum) over 2 days. Aliquots of the dialyzed extracts were freeze-dried until further use.

Sturgeon GRP (sGRP) was extracted and purified as previously described (1). Identification of purified protein, obtained after RP-HPLC purification, was confirmed by N-terminal amino acid sequence. Bovine MGP (bMGP) was extracted from bovine calcified costal cartilage, obtained from local slaughterhouse, as described (31). Briefly, the formic acid demineralized fraction containing mineral-binding proteins was dialyzed against $50 \mathrm{mM}$ $\mathrm{HCl}$ using 3,500 molecular weight tubing, over two days, then freeze-dried and dissolved in $6 \mathrm{M}$ guanidine- $\mathrm{HCl}$, 0.1 M Tris, pH 9.0. Precipitated bMGP, obtained after dialysis against $5 \mathrm{mM}$ ammonium bicarbonate, was dissolved in $6 \mathrm{M}$ guanidine- $\mathrm{HCl}, 0.1 \mathrm{M}$ Tris, $\mathrm{pH}$ 9.0, and purified through RP-HPLC using the conditions described for sGRP purification. Recombinant human GRP (rGRP) was produced and purified through affinity chromatography followed by RP-HPLC as previously reported. 


\section{Electrophoresis and Western blot}

Aliquots of total protein extracts were size-separated on a 4-12\% (w/v) gradient polyacrylamide precast gel containing $0.1 \%$ (w/v) SDS (NuPage, Invitrogen) and either stained with G-250 coomassie brilliant blue or transferred onto a nitrocellulose membrane (Bio-Rad) as previously described (23). Detection of tGRP, cGRP, UcGRP, cMGP, UcMGP, and fetuin-A proteins was performed through overnight $(\mathrm{O} / \mathrm{N})$ incubation with CTerm-GRP $(5 \mu \mathrm{g} / \mathrm{ml})$, cGRP $(1 \mu \mathrm{g} / \mathrm{ml})$, ucGRP $(1 \mu \mathrm{g} / \mathrm{ml})$, cMGP (1:1000), ucMGP (1:1000), and fetuin A (1:200) antibodies, respectively. Immunodetection was achieved using species-specific secondary horseradish peroxidase-conjugated antibodies and Western Lightning Plus-ECL (PerkinElmer).

\section{Protein identification by nano-HPLC-MALDI-TOF/TOF}

Protein bands were excised manually from SDS-PAGE gel, destained with $25 \mathrm{mM}$ ammonium bicarbonate $/ 50 \%$ acetonitrile and dried under vacuum (SpeedVac ${ }^{\circledR}$, Thermo Savant). The dried gel pieces were rehydrated with $25 \mu \mathrm{L}$ of $10 \mu \mathrm{g} / \mathrm{mL}$ trypsin (Promega V5111) in $50 \mathrm{mM}$ ammonium bicarbonate and digested $\mathrm{O} / \mathrm{N}$ at $37^{\circ} \mathrm{C}$. Tryptic peptides were extracted from the gel with 10\% formic acid/ 50\% acetonitrile, dried in a vacuum concentrator, and re-suspended in $10 \mu \mathrm{L}$ of a $50 \%$ acetonitrile/0.1\% formic acid solution. Separation of tryptic peptides by nano-HPLC was performed on the module separation Ultimate 3000 (Dionex) using a capillary column (Pepmap100 C18; $3 \mu \mathrm{m}$ particle size, $0.75 \mu \mathrm{m}$ internal diameter, $15 \mathrm{~cm}$ in length). A gradient of solvent $\mathrm{A}$, (water/acetonitrile/trifluoroacetic acid (98:2:0.05, v/v/v)) to solvent B (water/acetonitrile/trifluoroacetic acid (10:90:0.045, v/v/v)) was used. The separation of $2 \mu \mathrm{g} / \mu \mathrm{L}$ sample was performed using a linear gradient (5-50\% B for 30 minutes, $50-70 \%$ B for 10 minutes and $70-5 \%$ A for 5 minutes) with a flow rate of $0.3 \mu \mathrm{L} /$ minute. The eluted peptides were mixed with a continuous flow of a-CHCA matrix solution (270 nL/min, 2 mg/mL in 70\% ACN/0.1\% TFA and internal standard Glu-Fib at 15 ftmol) and applied directly on a MALDI plate in 7 seconds fractions using an automatic fraction collector Probot (Dionex).

Mass spectra were obtained on a matrix-assisted laser desorption/ionizationtime-of-flight MALDI-TOF/TOF mass spectrometer (4800 Proteomics Analyzer, Applied Biosystems) in the positive ion reflector mode and obtained in the mass range from 700-4500 Da with 900 laser shots. Glu-Fib was used for internal calibration. A data-dependent acquisition method was created to select the 16 most intense peaks in each sample spot (considering 2 spots per fraction) for subsequent tandem mass spectrometry (MS/MS) data acquisition, excluding those from the matrix, due to trypsin autolysis or acrylamide peaks. A fragmentation voltage of $2 \mathrm{kV}$ was used throughout the automated runs. The spectra were processed and analyzed by the T2S (v1.0, Matrix Science) and submitted in Mascot software (v.2.1.0.4, Matrix Science) for protein/peptide identification based on MS/MS data using the following criteria: trypsin as enzyme; a maximum of two missed cleavages; mass tolerances of 30 ppm for peptide precursors, mass tolerance of 0.3 Da was set for fragment ions. Protein identifications based on MS/MS data were considered as reliable when the Mascot 
ion score confidence level for each individual peptide was higher than 32. The local FDR was calculated by searching the spectra against SwissProt (Homo sapiens, release date 01052013) decoy (random) database.

\section{Aortic segments ex vivo assay}

After adventitia removal by careful dissection, the aortas were cut in small fragments of 2- to $3 \mathrm{~mm}$ squares and cultured in the following media for 14 days at $37^{\circ} \mathrm{C}$ and $5 \% \mathrm{CO}_{2}$ atmosphere, with medium changes every 2 days. Aortic segments were cultured in control conditions (C: DMEM/ 10\% FBS/ 1\% PS/ 1\% Gln) and in high P and Ca conditions (Ca + P: C supplemented with $3.6 \mathrm{mM}$ Ca and $1.6 \mathrm{mM} \mathrm{P}$ ). Tested proteins were added to Ca + P media at the concentrations of $250 \mathrm{ng} / \mathrm{ml}$ and $500 \mathrm{ng} / \mathrm{ml}$ for rGRP and sGRP, and $500 \mathrm{ng} / \mathrm{ml}$ for bMGP and fetuin-A. rGRP, sGRP and bMGP were dialyzed against miliQ water prior experiments, and protein quantification estimated through measurement of absorbance at 280 $\mathrm{nm}$, based on the assumption that E0.1\%1cm =1.0. Fetuin-A was dissolved in miliQ water as manufacturer's recommendations. Solubility and stability of rGRP, sGRP and bMGP in water was determined by SDS-PAGE analysis immediately after dialysis and after 24 hours at room temperature. After 14 days the aortic segments were washed three times in PBS and three times in water, dried and weighted. Dried tissues were completely digested with nitric acid and Ca content was measured by cresolphthalein complexone chemistry using a colorimetric assay (Randox) according to manufacturer's recommendations, and normalized to aortic segments dry weight. rGRP and sGRP proteins were tested in three independent experiments and bMGP and fetuin A were tested in two experiments. Each of the three experiments was performed at least in duplicates with a minimum of two fragments per duplicate.

For gene expression and histology studies performed in $\mathrm{C}$ and $\mathrm{Ca}+\mathrm{P}$ conditions, experiments were performed as described and fragments were either immediately used for RNA extraction or collected to 4\% (w/v) PFA solution, respectively, after washing. Gene expression and von Kossa staining were performed as described above.

\section{Immunoprecipitation}

Immunoprecipitation was performed according to a method previously used to detect MGP from blood using protein A sepharose with cross-linked CTerm-GRP, cMGP and rabbit IgG antibodies. In brief, 100 Mg of each antibody were incubated for 1 hour at room temperature with $500 \mathrm{mg}$ of Protein A-sepharose (GE Healthcare). After incubation, antibodies were cross-linked with dimethyl pimelimidate and the remaining groups were quenched with ethanolamine. Aliquots of Min_P extract were ressuspended for 4 hours in $10 \mathrm{mM}$ Tris- $\mathrm{HCl} \mathrm{pH} 7.5$ and then centrifuged for $20 \mathrm{~min}$ at $16000 \mathrm{xg}$ and $4^{\circ} \mathrm{C}$, to remove eventual non-resuspended proteins. 48 hours conditioned media of HEK293T cells transfected with GRP-F1-mkate fusion protein and pmkate2-N vector, obtained as previously described (ref), were dialyzed against $10 \mathrm{mM}$ Tris- $\mathrm{HCl}$ pH 7.5. Min_P extract and conditioned media 
in $10 \mathrm{mM}$ Tris $\mathrm{HCl}$ pH 7.5 were added to the protein A-antibody complexes and incubated with rotation overnight for binding of target proteins. After extensive washes, elution was performed with 100 mM glycine pH 2.5 and eluted proteins were either analyzed by staining with CBB for protein identification, or western blot for protein detection.

\section{Statistical analysis}

Data are presented as mean \pm standard error (SE). Student's t-test was used for comparison between two groups. Non-parametric Mann-Whitney $U$ test was performed to confirm the difference of 2 group comparison. For more than two groups, significance was determined using one-way analysis of variance (ANOVA) with comparison between groups by Dunnett test. Statistical significance was defined as $P \leq 0.05\left(^{*}\right)$ and $P \leq 0.005\left(^{* *}\right)$. 


\section{Supplemental figures}

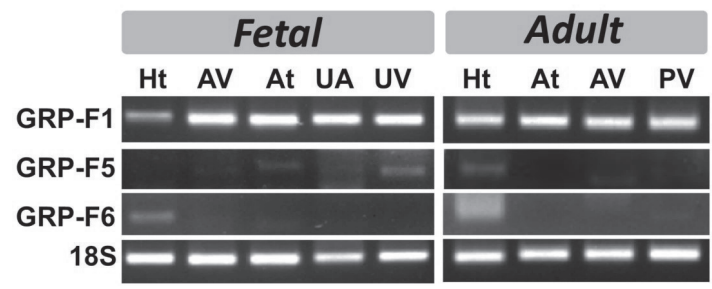

Supplemental Figure I: GRP-F1 is the main transcript expressed in adult cardiovascular tissues.

Qualitative gene expression of GRP splice variants F1, F5 and F6 in fetal (heart ( $\mathrm{Ht}$ ); aortic valve (AV); aorta (At); umbilical artery (UA); umbilical vein (UV)) and adult (heart (Ht); aorta (At); aortic valve (AV); pulmonary valve (PV)) tissues, showing the predominance of GRP-F1 transcript in all tissues analyzed. 18S was used as loading control for sample integrity.

A
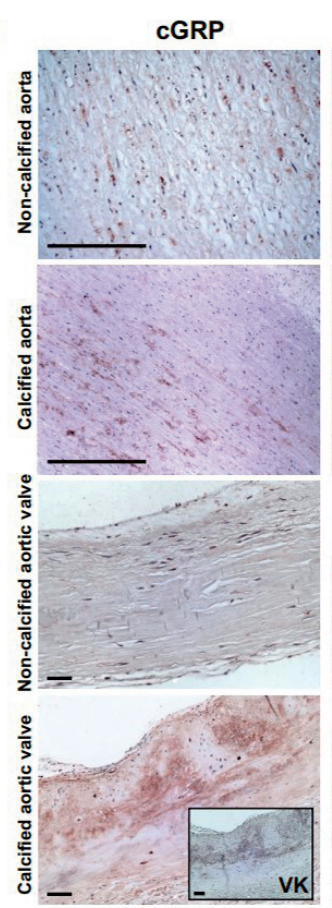

ucGRP
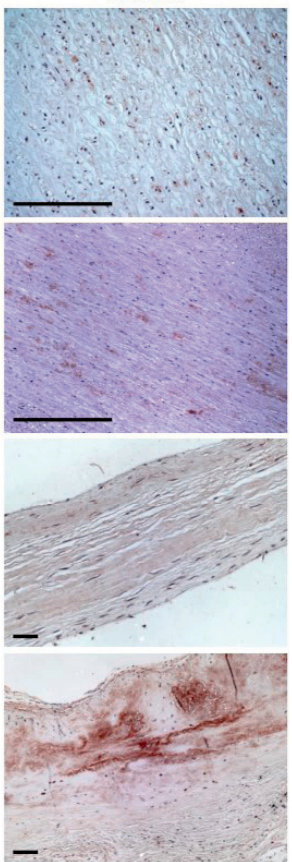

B
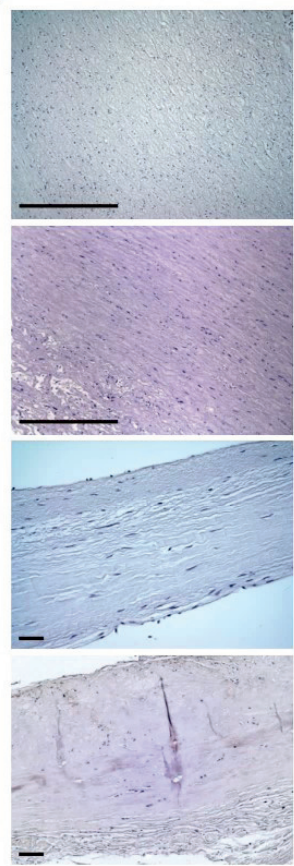

\section{Supplemental Figure II:}

A, c/ucGRP accumulation patterns are similar to tGRP in control non-calcified and calcified aorta and aortic valve tissues. A, Representative immunodetection of $\mathrm{c}$ and ucGRP protein forms by IHC using the conformationspecific c/ucGRP antibodies. VK, von Kossa staining of consecutive tissue sections. B, Representative negative controls performed by omitting primary antibodies in consecutive tissue sections. Positive signal in brown and counterstaining with HE. Scale bar represents $100 \mu \mathrm{m}$. 

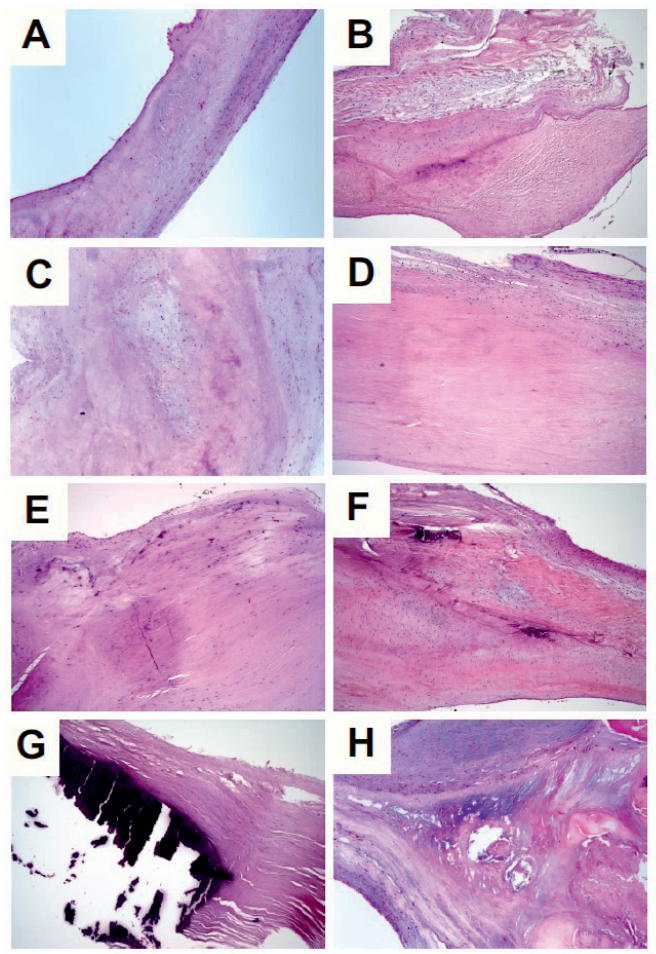

Supplemental Figure III: Representative histopathological features of CAVD samples by staining with haematoxylin-eosin, showing heterogeneous phenotype.

The degree of the normal trilaminar stratification was variable, ranging from normal structure (A) to highly disorganized ECM (B). Leaflets thickness and cellularity were variable in affected tissue, with either VICs disarray forming clusters (C) or dense regions of almost acellular ECM (D). Detected calcifications ranged from early mineralization characterized by disperse spots ( $\mathrm{E}$ ) to localize and dense areas of mineral in the fibrosa layer (F), or massive areas of calcification occupying almost all leaflet (G), or within atheromas (H). Scale bar represents $100 \mu \mathrm{m}$.
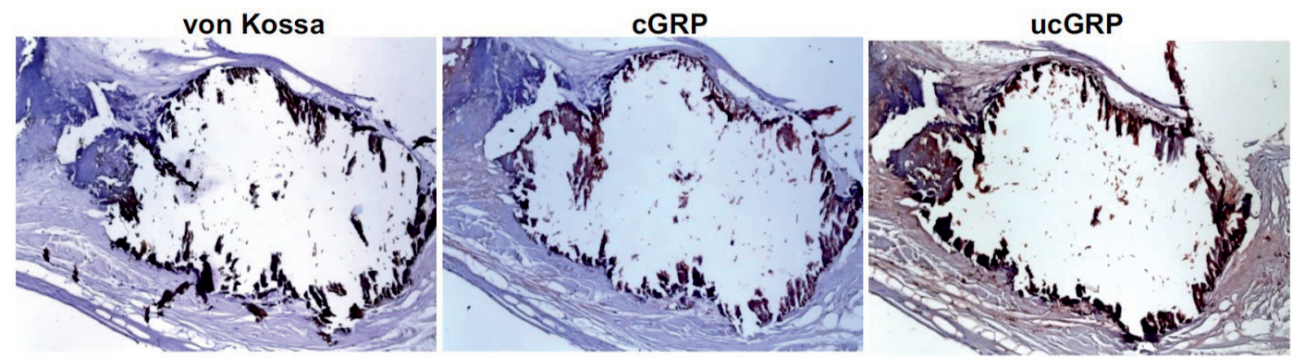

\section{Supplemental Figure IV:}

GRP is highly accumulated at regions of massive mineral accumulation with similar c/ucGRP patterns. IHC staining was performed as described in Figure 2 and Supplemental Figure II legends and shows high accumulation of cGRP (B) and ucGRP (C) at regions of massive mineral deposition (von Kossa), with similar patterns. Positive signal in brown and counterstaining with HE. Scale bar represents $100 \mu \mathrm{m}$. 

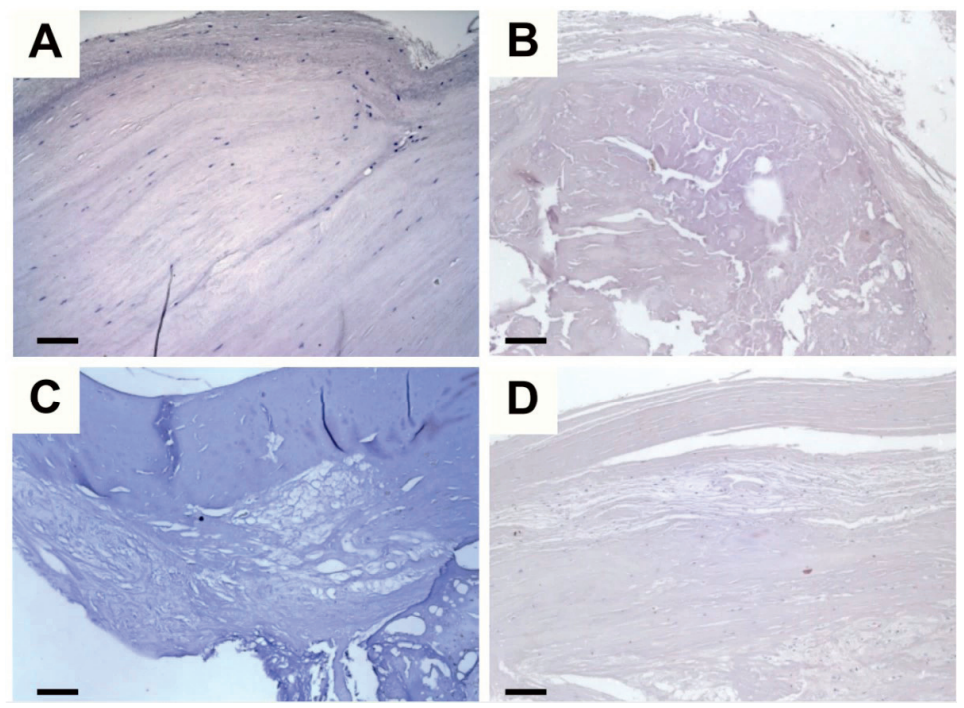

\section{Supplemental Figure V:}

Representative negative controls performed by omitting primary antibodies, in consecutive tissue sections presented in Figure 2. A, negative control of tissues presented in panels A-C of Figure 2. B, negative control of tissues in panels D-F of Figure 2. C, negative control of tissues in panels G-I of Figure 2. D, negative control of tissues in panels J-O of Figure 2. Tissues were counterstaining with HE. Scale bar represents $100 \mu \mathrm{m}$

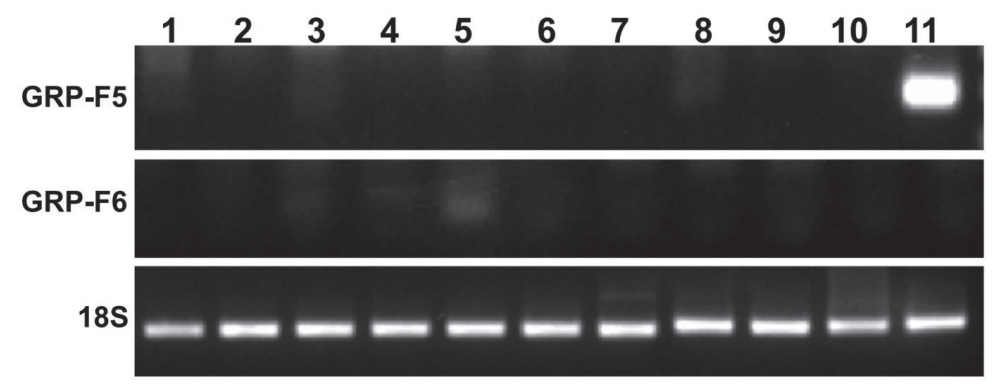

\section{Supplemental Figure VI:}

GRP-F5 and F6 are barely detected in the majority of the eleven CAVD samples analyzed. $18 \mathrm{~S}$ was used as loading control for sample integrity. 


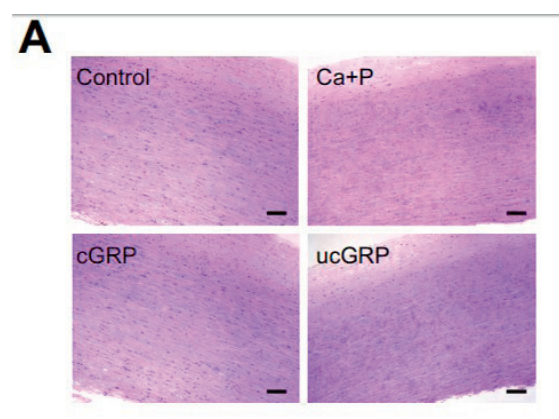

B

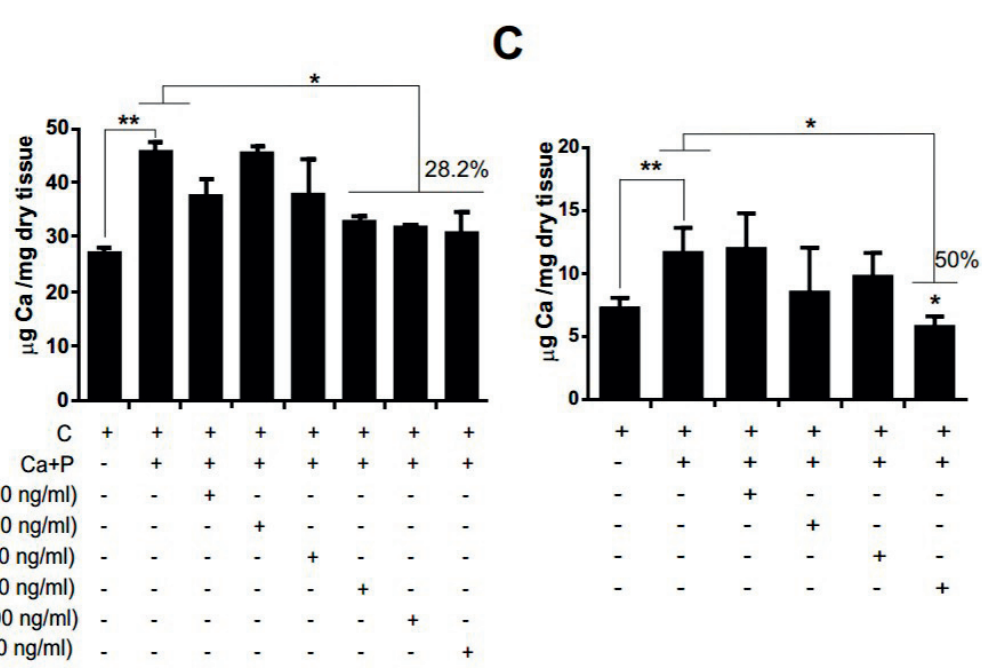

Supplemental Figure VII: Experimental duplicates of assay described in Figure 5B legend, showing the effect of $\gamma$ - carboxylated (CGRP) and noncarboxylated GRP (UCGRP) in an ex vivo model of aortic tissue calcification.

A, HE histological characterization of aortic segments cultured for 14 days in control, $\mathrm{Ca}+\mathrm{P}$, and $\mathrm{Ca}+$ $P$ supplemented with cGRP and ucGRP conditions, showing an intact structure of the vessel with apparent VSMCs phenotype. Darker purple spots in $\mathrm{Ca}+\mathrm{P}$ and ucGRP indicate mineral deposition. Scale bar represents $100 \mu \mathrm{m}$. B, Ca + P calcifying media induce significant increase in Ca relative to control $(P<0.01)$, and treatments with $500 \mathrm{ng} / \mathrm{ml}$ of cGRP, bMGP and bFet-A result in similar $28.2 \%$ reduction in $\mathrm{Ca}$ relative to $\mathrm{Ca}+\mathrm{P}$ condition $(P<0.05)$. No significant effects are observed with ucGRP neither with $250 \mathrm{ng} / \mathrm{ml} \mathrm{cGRP.} \mathrm{C,} \mathrm{Ca} \mathrm{+} \mathrm{P} \mathrm{calcifying} \mathrm{media} \mathrm{induce} \mathrm{significant} \mathrm{increase} \mathrm{in} \mathrm{Ca} \mathrm{relative} \mathrm{to} \mathrm{control}$ $(P<0.01))$, and treatments with $500 \mathrm{ng} / \mathrm{ml}$ of cGRP result in $50 \%$ reduction in Ca relative to $\mathrm{Ca}+\mathrm{P}$ condition $(P<0.05)$. No significant effects are observed with ucGRP neither with $250 \mathrm{ng} / \mathrm{ml} \mathrm{cGRP}$. SD was calculated $(n=2)$ and ANOVA with comparison between groups by Dunnett test was performed. 


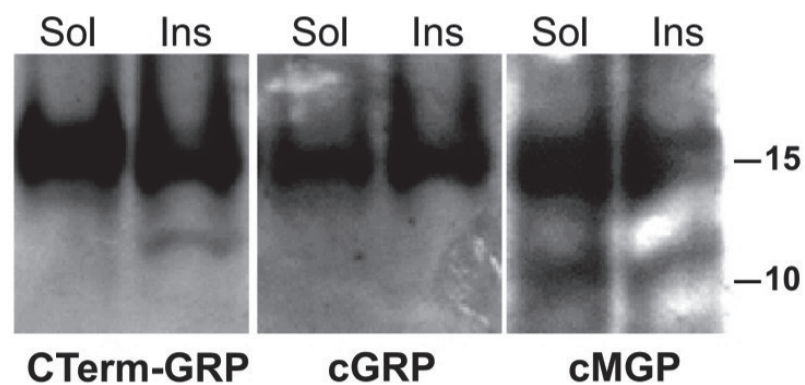

\section{Supplemental Figure VIII:}

Patterning of GRP and MGP prior to IP assays. M-P was resuspended in $10 \mathrm{mM}$ Tris- $\mathrm{HCl}, \mathrm{pH} 7.5$ buffer, and centrifuged to remove eventual insoluble components (Ins). Both Ins and soluble (Sol) fractions were analyzed by WB using CTerm-GRP, cGRP and CMGP antibodies, and indicate that only part of the initially resuspended proteins (Figure 4B) are in the soluble fraction, and that the predominant GRP soluble protein form is detected with the cGRP antibody as a $15 \mathrm{kDa}$ band.

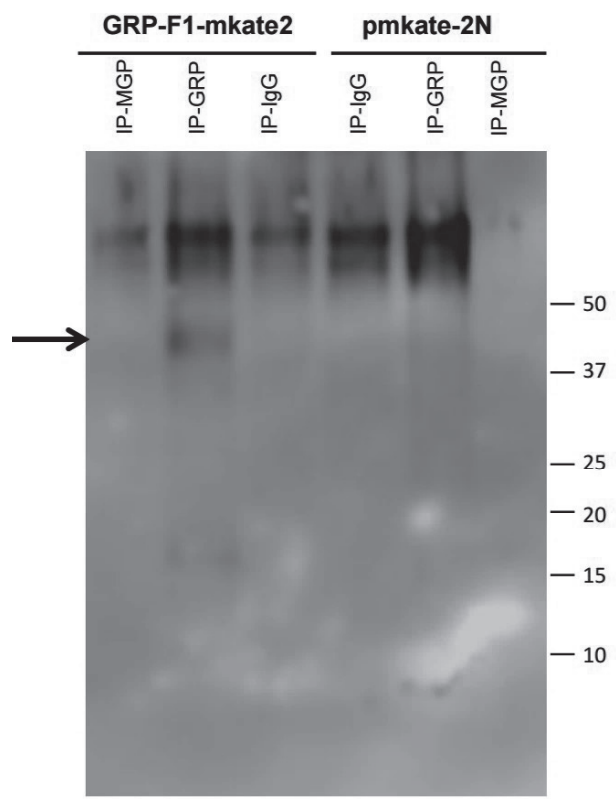

\section{Supplemental Figure IX: Cross-reactivity test of cMGP antibody to GRP detection.}

WB analysis with CTerm-GRP antibody of IP assays performed as described in Figure 6B legend, using conditioned media of transiently transfected HEK293T cells with GRP-F1-mkate2 fusion protein and respective control, the empty plasmid pmkate2-N. GRP is detected in IP-GRP assay from GRP-F1-mkate2 conditioned media but not in the IP-MGP assay from GRP-F1- mkate2 media, indicating that CMGP antibody cannot pull-down GRPF1-mkate2 fusion protein. Arrow indicates positive GRP detection with CTerm-GRP antibody at expected size of $43 \mathrm{kDa}$. Relevant molecular weight markers are indicated $(\mathrm{kDa})$ on the right side of the panel. 
Supplemental Table I. Post mortem cardiovascular samples obtained from individuals at autopsy*

\begin{tabular}{|c|c|c|c|c|c|}
\hline Individual & Gender & Age & $\begin{array}{l}\text { Collected } \\
\text { samples }{ }^{\star *}\end{array}$ & $\begin{array}{c}\text { Features at } \\
\text { autopsy }\end{array}$ & Qualitative Calcium analysis \\
\hline 1 & M & 47 & $\begin{array}{l}\text { Aol } \\
\text { AV1 } \\
\text { PV1 }\end{array}$ & - & $\begin{array}{l}- \\
- \\
-\end{array}$ \\
\hline 2 & M & 58 & $\begin{array}{l}\mathrm{Ao2} \\
\mathrm{AV} 2 \\
\mathrm{PV} 2\end{array}$ & $\begin{array}{c}\text { Severe } \\
\text { atherosclerosis }\end{array}$ & $\begin{array}{c}+ \\
- \\
++\end{array}$ \\
\hline 3 & $\mathrm{~F}$ & 69 & $\begin{array}{l}\text { Ao3 } \\
\text { AV3 } \\
\text { PV3 }\end{array}$ & $\begin{array}{c}\text { Acute } \\
\text { atherosclerosis }\end{array}$ & $\begin{array}{c}++ \\
++ \\
+\end{array}$ \\
\hline 4 & $\mathrm{~F}$ & 52 & $\begin{array}{l}\text { Ao4 } \\
\text { AV4 } \\
\text { PV4 }\end{array}$ & Stroke & $\begin{array}{l}+ \\
- \\
-\end{array}$ \\
\hline 5 & F & 44 & $\begin{array}{l}\text { AV5 } \\
\text { PV6 }\end{array}$ & - & - \\
\hline 6 & M & 43 & $\begin{array}{l}\text { Ao6 } \\
\text { AV6 } \\
\text { PV6 }\end{array}$ & - & $\begin{array}{l}- \\
+ \\
-\end{array}$ \\
\hline
\end{tabular}

*Samples collected at the Histopathology department, Algarve Medical Centre and National Institute of Legal Medicine and Forensic Sciences, Public Institute.

${ }^{\star \star}$ Ao, aorta; AV, aortic valve; PV, pulmonary valve.

Supplemental Table 2. CAVD samples obtained from patients at surgery for aortic valve replacement.*

\begin{tabular}{lcccc}
\hline Patient & Gender & Age & Diagnosed pathology & Purpose \\
\hline 1 & M & 85 & Aortic valve stenosis & qPCR/IHC \\
2 & M & 69 & Aortic valve stenosis & qPCR/IHC \\
3 & F & 82 & Aortic valve stenosis & qPCR/IHC \\
4 & F & 70 & Aortic valve stenosis and coronary & qPCR/IHC \\
& & & artery disease & \\
5 & M & 50 & Aortic valve stenosis & qPCR/IHC \\
6 & F & 75 & Aortic valve stenosis & qPCR/IHC \\
7 & M & 78 & Aortic valve stenosis and coronary & qPCR/IHC \\
& & & artery disease & \\
9 & M & 52 & Aortic valve stenosis & qPCR/IHC \\
10 & F & 72 & Aortic valve stenosis & qPCR/IHC \\
11 & M & 83 & Aortic valve stenosis & qPCR/IHC \\
\hline
\end{tabular}

*Samples collected at Hospital Santa Crus, Lisbon 


\section{Supplemental Table III: Specific primers used for RT-PCR and qPCR analysis.}

\begin{tabular}{|c|c|c|}
\hline Primer & Sequence $\left(5^{\prime}\right.$ to $\left.3^{\prime}\right)$ & Purpose/Amplicon \\
\hline Universal dT-adapter & ACGCGTCGACCTCGAGATCGATG $(T)_{13}$ & RT \\
\hline GRP_F1FW & GTCCCCCAAGTCCCGAGATGAGG & \multirow{2}{*}{ qPCR/GRP-F1 } \\
\hline GRP_F1RV & СCTCCACGAAGTTCTCAAATTCATTCC & \\
\hline GRP_F5/F6Fw & TCCTGGACGGAGCCCCTA & qPCR/GRP-F5, F6 \\
\hline GRP_F5RV & GCTTCTGCCTGTTTTCCACTTCAC & qPCR/GRP-F5 \\
\hline GRP_F6RV & GCTTCTGCCTGTTTTCCATAGACA & qPCR/GRP-F6 \\
\hline 18S_Fw & GGAGTATGGTTGCAAAGCTGA & \multirow{2}{*}{ qPCR/18S } \\
\hline 18S_Rv & GGAGTATGGTTGCAAAGCTGA & \\
\hline MGP_Fw & TGGAGGCTGGCACCTGATTTTG & \multirow{2}{*}{ qPCR/MGP } \\
\hline MGP_RV & AAAAGGGGTGCAGCCAGACAAG & \\
\hline OC_FW & CAGCGAGGTAGTGAAGAGACCCAGG & \multirow{2}{*}{ qPCR/OC } \\
\hline OC_Rv & AGGGCAAGGGGAAGAGGAAAGAAGG & \\
\hline OPN_FW & ACGGACCTGCCAGCAACCGAAGT & \multirow{2}{*}{ qPCR/OPN } \\
\hline OPN_RV & TACTGGATGTCAGGTCTGCGAAA & \\
\hline aSMA_Fw & TGGCTATTCCTTCGTTACTACTGCTGAG & \multirow{2}{*}{ qPCR/aSMA } \\
\hline aSMA_Rv & GCCCATCAGGCAACTCGTAACTCT & \\
\hline TNFa_F & AGGGCCTGTACCTCATCTACTCCCA & \multirow{2}{*}{ qPCR/TNFa } \\
\hline TNFa_R & AGCTGGAAGACCCCTCCCAGATAGA & \\
\hline GAPDH_F & AAGGTGAAGGTCGGAGTCAACGGA & \multirow{2}{*}{ qPCR/GAPDH } \\
\hline GAPDH_R & TCGCTCCTGGAAGATGGTGATGGG & \\
\hline
\end{tabular}




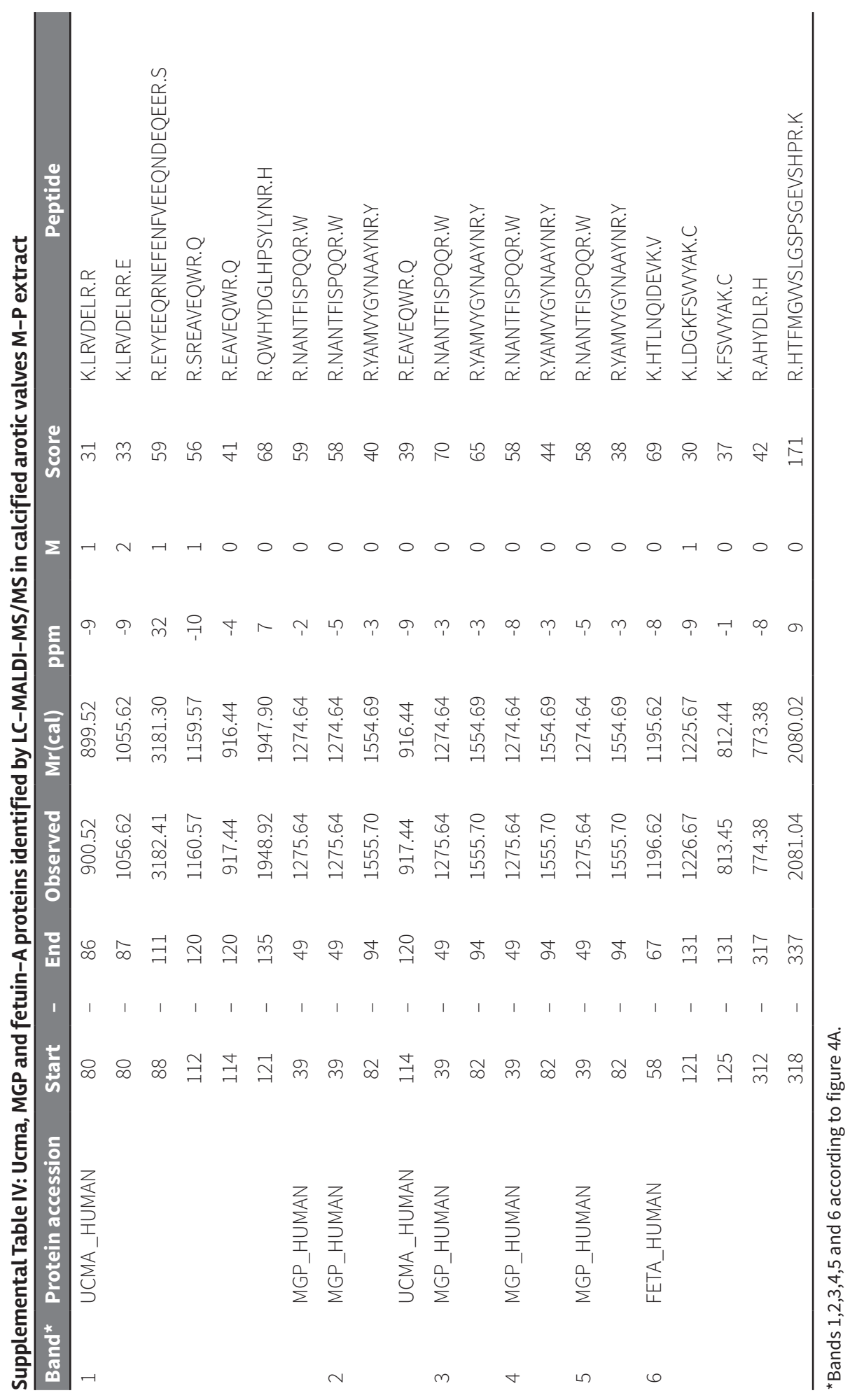




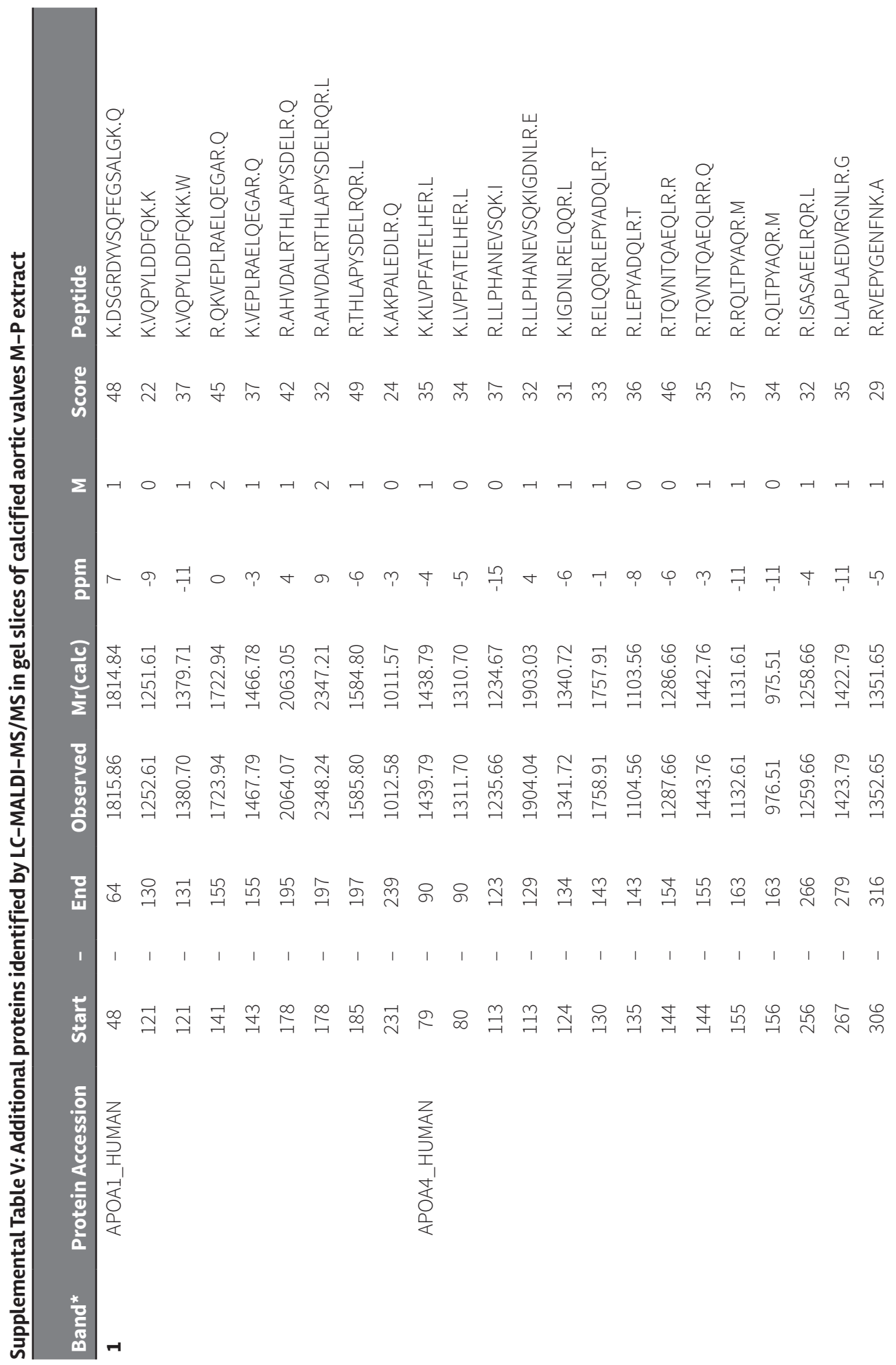




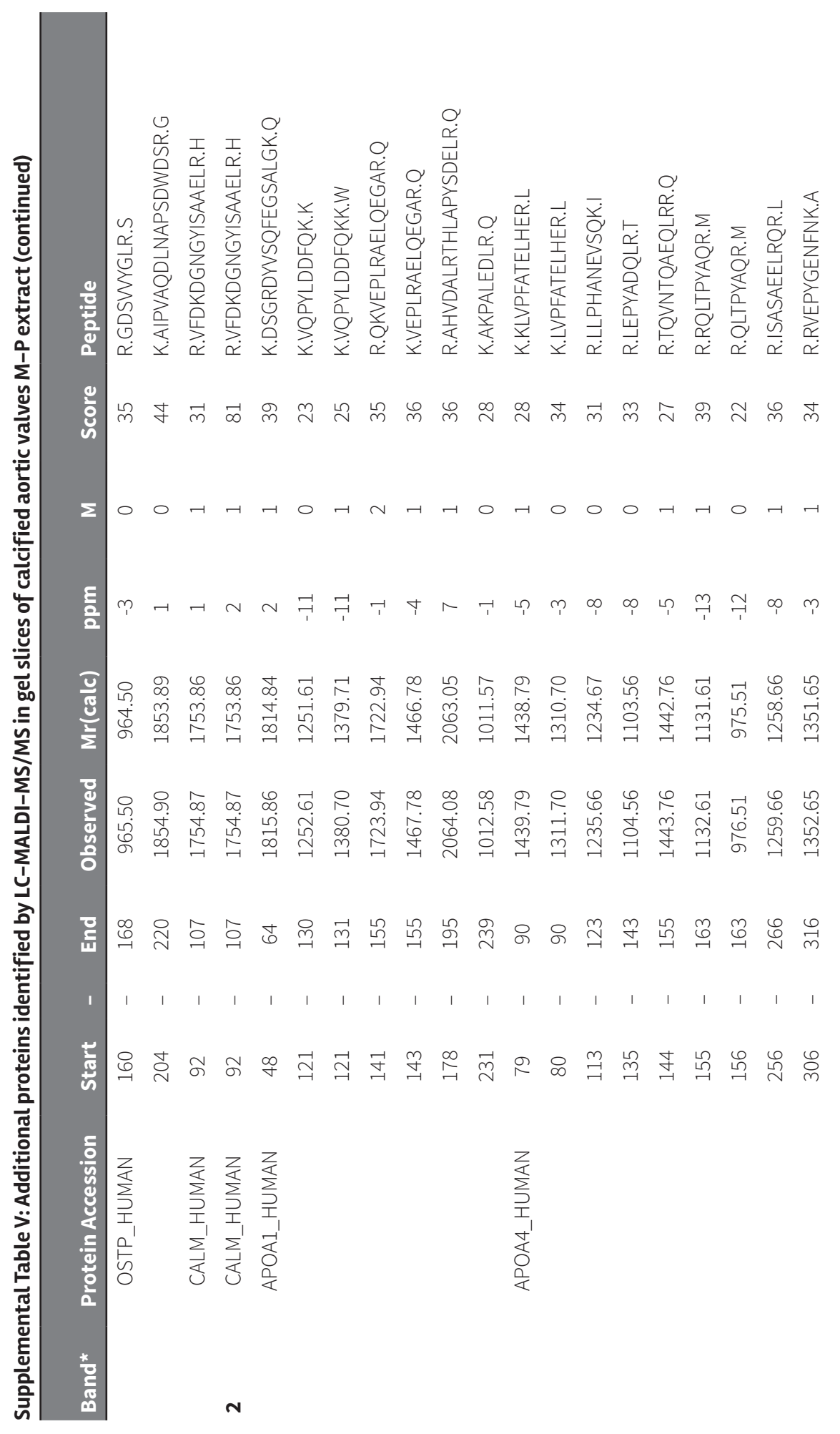




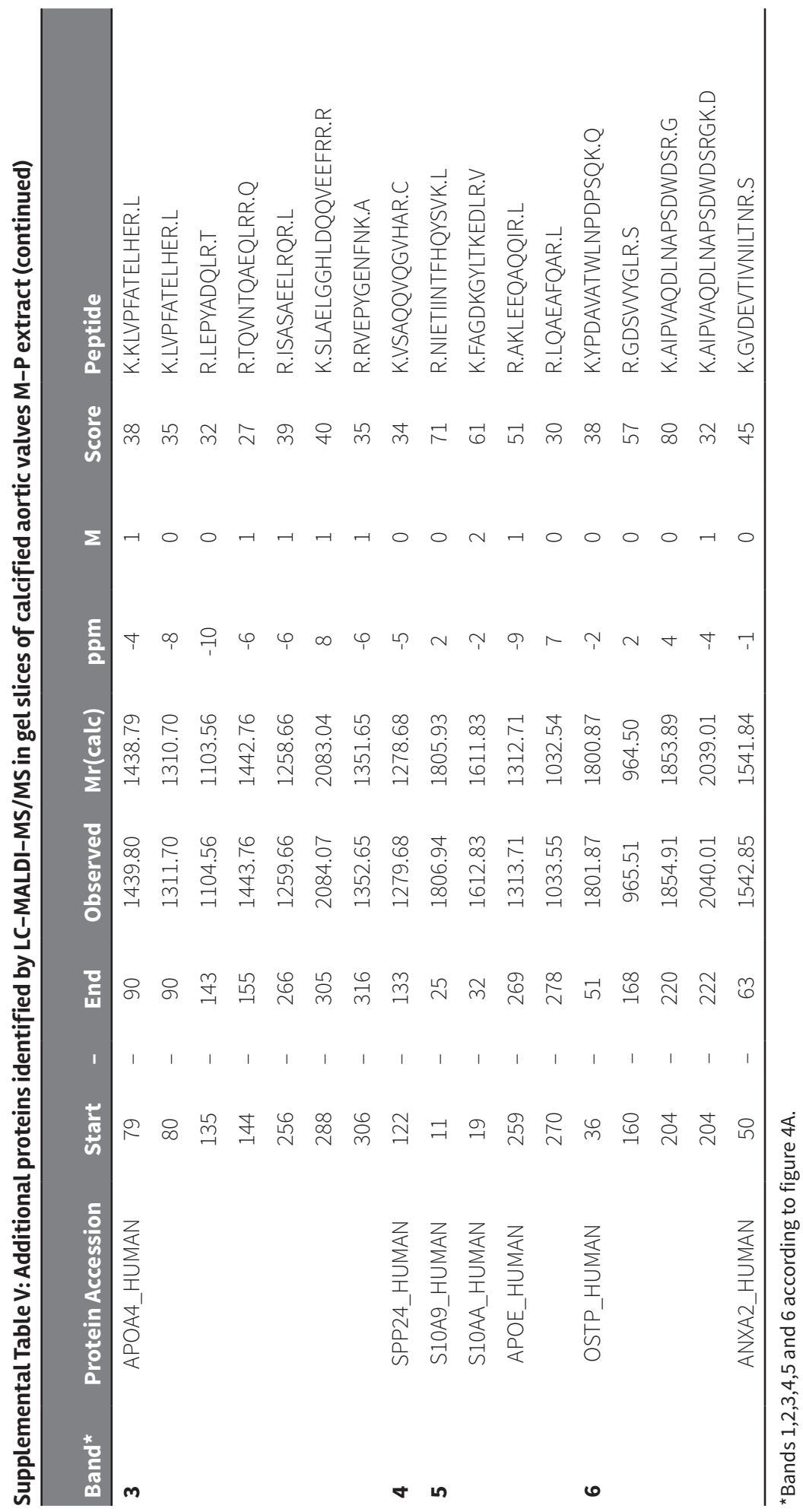




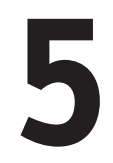

\section{Ucma is involved in osteogenic transdifferentiation of vascular smooth muscle cells: role in phosphate-induced vascular calcification}

Brecht A.G. Willems, Malgorzata Furmanik, Martijn L.L. Chatrou, Dennis H.M. Kusters, Marjolein M.J. Caron, Tim J.M. Welting, Michael Stock, Marta Rafael, Carla Viegas, Dina Simes, Cees Vermeer, Chris P.M. Reutelingsperger and Leon Schurgers 


\section{Abstract}

Vascular calcification (VC) is the process of deposition of calcium phosphate crystals in the blood vessel wall, with a central role for vascular smooth muscle cells (VSMCs). VC is highly prevalent in chronic kidney disease (CKD) patients and thought, in part, to be induced by phosphate imbalance. The molecular mechanisms that regulate VC are not fully known. Here we propose a novel role for the mineralisation regulator Ucma in phosphate-induced VSMC calcification. We show that Ucma is present in calcified atherosclerotic plaques and that it is highly expressed in calcifying VSMCS in vitro. VSMCs from Ucma ${ }^{-1}$ mice showed increased mineralisation and expression of osteo/chondrogenic markers (BMP-2, Runx2, $\beta$-catenin, p-SMAD1/5/8, ALP, OCN), and decreased expression of mineralisation inhibitor MGP, suggesting that Ucma is an inhibitor of mineralisation. Using BMP signalling inhibitor noggin and SMAD1/5/8 signalling inhibitor dorsomorphin we showed that Ucma is involved in inhibiting the BMP-2-SMAD1/5/8 osteo/chondrogenic signalling pathway in VSMCs treated with elevated phosphate concentrations. These results demonstrate an important role of Ucma in regulating osteo/chondrogenic differentiation and phosphate-induced mineralisation of VSMCs. 


\section{Introduction}

Vascular calcification (VC) is a process of deposition of calcium phosphate crystals in the form of hydroxyapatite in the intima and media of the vessel wall $(1,2)$. The presence of VC reduces arterial wall elasticity and alters the hemodynamic profile, increasing the risk of cardiovascular events. VC is an independent risk factor predicting cardiovascular mortality and frequently measured as marker of atherosclerotic burden (3). Nearly all patients suffering from cardiovascular disease have some degree of calcification, and in asymptomatic patients prevalence of coronary calcification corresponds with age. Amongst cardiovascular disease patients, approximately $60 \%$ of over 60 -year-olds suffer from VC $(3,4)$. Chronic kidney disease (CKD) patients are known to be especially prone to VC. Mineral homeostasis dysregulation, uremic toxins and warfarin treatment are known to contribute to VC in dialysis patients (5, 6). Elevated phosphate in blood is thought to be one of the main inducers of VC in $\operatorname{CKD}(7,8)$.

VC is an active process regulated by vascular smooth muscle cells (VSMCs). In response to cellular stress VSMCs undergo VC via several mechanisms: apoptosis, release of extracellular vesicles, loss of calcification inhibitors such as matrix Gla protein MGP; reviewed in (9), ageing-related DNA damage and osteo/chondrogenic differentiation (10, 11).

In physiological conditions VSMCs exist in the vessel wall as contractile cells and regulate vascular tone. However, VSMCs are known to have a high degree of phenotypic plasticity (12). In response to stress and injury, VSMCs lose expression of contractility-related genes such as SM22a, calponin (CNN1), and myosin light chain (MLC)(13-16). When vascular injury is persistent, the phenotypic transition is dysregulated and VSMCs can undergo an unfavorable transdifferentiation into cells with characteristics of osteoblasts or chondrocytes $(4,12$, 17-20). Many bone mineralisation-regulating proteins were found to be expressed in the calcifying blood vessel, such as BMP-2 Runx2, MGP, osteocalcin (OCN), osteopontin (OPN) $(18,21,22)$ amongst others and have been shown to play an active part in regulating VC. Additionally, calcifying VSMCs have been shown to release extracellular vesicles in a mechanism similar to release of matrix vesicles from chondrocytes (23). However, the exact molecular mechanisms regulating VSMC osteo/chondrogenic transdifferentiation are unknown.

Ucma (Upper zone of growth plate and Cartilage Matrix Associated protein; also known as Gla Rich Protein - GRP) is a novel mineralisation inhibitor, which was first reported in cartilage (24, $25)$ and later in the vasculature $(26,27)$. Ucma-deficient mice did not develop a clear phenotype (28), however in vitro studies revealed that Ucma regulates differentiation of chondrocytes and osteoblasts (29-31). Using immunohistochemistry, Ucma was shown to be present at sites of VC. Moreover, when added exogenously Ucma inhibited calcification of aortic rings in vitro (26, 27, 29).

Based on the involvement of Ucma in differentiation of osteoblasts and its role in VC, we hypothesized that Ucma is involved in osteo/chondrogenic differentiation of VSMCs. To test our hypothesis we examined expression of Ucma during phosphate-induced calcification of VSMCs. We also examined osteo/chondrogenic gene expression and calcification of Ucma ${ }^{-/}$VSMCs exposed to elevated levels of inorganic phosphate. Our findings indicate that $U \mathrm{cma}$ reduces $\mathrm{VC}$ by inhibiting osteo/chondrogenic VSMC transdifferentiation through a BMP-2-regulated pathway. 


\section{Methods}

\section{Experimental animals}

Ucma $\%$ C57BL 16 mice were generated by Dr. M. Stock at University of Erlangen, Germany, according to local ethical guidelines and kindly provided (28). Mice were maintained in a specific pathogen-free environment with free access to water and western type diet (Arie Block, Woerden, the Netherlands) and sacrificed by portal vein puncture after 12 weeks. Aortas were harvested for immunohistochemistry and VSMC isolation.

\section{Immunohistochemistry}

Aortic sections of atherosclerotic ApoE ${ }^{-/}$mice from a previous study were used (46). Sequential $4 \mu \mathrm{m}$ paraffin sections were cut from the aortic arch and used for immunohistochemical staining as previously described (46). The following antibodies were used: anti- BMP-2 (Santa Cruz, sc-6895), anti-Runx2 (M70, Santa Cruz, sc-10758) anti-total Ucma antibody (Cterm-GRP, GenoGla Diagnostics, Faro, Portugal), HRP conjugated secondary antibodies and Nova-RED substrate (Vector Labs, Amsterdam, the Netherlands). Sections were counterstained with haematoxylin (Klinipath, Duiven, the Netherlands) and mounted in entellan (Merck, Amsterdam, the Netherlands).

\section{VSMC isolation and culture}

Endothelium and adventitia were removed from aortas of $\mathrm{Ucma}^{-}$and WT littermates. Tissue was dissected into $\pm 5 \mathrm{~mm}^{2}$ pieces and digested with $3 \mathrm{mg} / \mathrm{ml}$ collagenase (Sigma, Zwijndrecht, the Netherlands) and $1 \mathrm{mg} / \mathrm{ml}$ elastase (Sigma) for 4 hours at $37^{\circ} \mathrm{C}$ in DMEM (Gibco, Bleiswijk, the Netherlands). The cells were washed, resuspended in growth medium (DMEM with 10\% FCS, Gibco, $100 \mathrm{U} / \mathrm{ml}$ penicillin and $100 \mathrm{mg} / \mathrm{ml}$ streptomycin, Gibco) and transferred to culture dishes. Success of the isolation was determined by immunofluorescent staining for aSMA (Sigma), SM22a (Abcam, Cambridge, United Kingdom), phosphorylated myosin light chain 2 (Cell Signalling, Leiden, the Netherlands) and western blotting for aSMA. Cells at passage 4-12 were used for experiments. Cells were maintained in culture medium and passaged when 90\% confluent. The following inhibitors were added to media for treatments: 2 MM of $U 0126$ (Merck, Amsterdam, the Netherlands), 100 ng/ml noggin (R\&D systems, Abingdon, United Kingdom), 2 MM dorsomorphin dihydrochloride (sc-361173, Santa Cruz).

Human primary VSMCs (hVSMCs) were used for exosome quantification assay. They were maintained in M199 with 20\% FCS, $100 \mathrm{U} / \mathrm{ml}$ penicillin and $100 \mathrm{mg} / \mathrm{ml}$ streptomycin (Gibco).

\section{Calcification assays}

$4 \times 10^{4}$ cells were seeded per well of a 12-well plate. After 24 hours medium was changed to osteogenic medium (growth medium $+2.6 \mathrm{mM} \mathrm{PO}_{4}{ }^{3-}, \mathrm{OM}$ ) or growth medium (control medium, CM). Quantification of deposited calcium was carried out using a calcium determination kit (Randox, London, United Kingdom) according to the manufacturer's instruction, after solu- 
bilising mineral deposits in $0.1 \mathrm{M} \mathrm{HCl}$. Calcium measurements were normalised to protein content using micro BCA assay (Thermo Scientific, Bleiswijk, the Netherlands). Calcification was additionally visualised using Alizarin Red S staining adapted from Gregory et al. (47).

\section{RNA isolation and quantitative real-time PCR}

Total RNA was isolated using TRI Reagent (Sigma). RNA concentration and quality were determined using a Nanodrop 2000 spectrophotometer (Thermo Scientific, Bleiswijk, the Netherlands) and agarose-denaturing gel electrophoresis. 1 mg of total RNA was treated with DNAse I (Promega, Leiden, the Netherlands) and reverse transcribed using M-MLV reverse transcriptase (Invitrogen, Bleiswijk, the Netherlands), an oligo dT adapter (Eurogentec, Maastricht, the Netherlands) and RNAse Out (Invitrogen, Bleiswijk, the Netherlands). Real-time qPCR was performed using the Quantitect SYBR green PCR kit (Qiagen, Venlo, the Netherlands) in a LightCycler 480 II (Roche, Woerden, the Netherlands) with 50 ng of cDNA and $0.5 \mu \mathrm{M}$ of each primer. The following primers were used BMP-2 (F) GTG-CTT-CTT-AGACGG-ACT-GCG-GTC-TCC-TA, BMP-2 (R) GCC-TGA-GTG-CCT-GCG-GTA-CAG-ATC-TAG, Runx2 (F) GAC-GAG-GCA-AGA-GTT-TCA-CC, Runx2 (R) GGA-CCG-TCC-ACT-GTC-ACT-TT, HPRT1 (F) AGCCAA-ATA-CAA-AGC-CTA-AGA-TGA-GCG, HPRT1 (R) GAA-ATG-TCA-GTT-GCT-GCG-TCC-CCA-GA, MGP (F) ACA-CAG-AGG-CAG-ACT-CAC-AGG-ACA-CCC, MGP (R) CTG-AGG-GGA-CAT-AAA-GGTGTT-GGC-AT, OCN (F) AAG-CAG-GAG-GGC-AAT-AAG-GT, OCN (R) TTT-GTA-GGC-GGT-CTTCAA-GC, OPN (F) TGA-CCA-CAT-GGA-CGA-CGA-TGA-TGA-CGA-TGA, OPN (R) GGG-ACG-ATTGGA-GTG-AAA-GTG-TCT-GCT-TGT. Fluorescence curves were analyzed with LightCycler 480 Software (Version 1.5) and relative quantification was performed with the $2^{-\Delta \Delta C t}$ method. Ucma was detected as described previously (44). All samples were assayed in triplicate.

\section{Quantification of exosome release}

Exosomes were quantified using a bead-capture assay as described before (23). Briefly, anti-human CD63 antibody (556019, BD Bioscience) was immobilized on aldehyde-sulfate functionalized beads (Invitrogen). Human primary VSMC culture media was incubated with anti-CD63-coated beads on a shaker overnight at $4^{\circ} \mathrm{C}$. VSMCs were stained with Hoechst 33342 (Thermo Fisher) and counted using a Cytation 3 live-cell imager. Beads were washed and incubated with anti-CD81-PE antibodies for $1 \mathrm{~h}$ at room temperature. Then beads were washed with PBS with 2\% BSA and analyzed by flow cytometry (Accuri C6, BD). Arbitrary units (AU) were calculated as mean fluorescence units times percentage of positive beads and normalized to the number of cells.

\section{Western blotting}

VSMCs were lysed in 0.1M Tris pH8.1, 0.15M NaCl, $1 \%$ triton $\mathrm{x}-1000.2 \mathrm{mM} \mathrm{NaVO}_{3}$ and 1:50 protease inhibitor cocktail (Sigma). Protein concentrations were determined using DC protein assay (Bio-Rad, Veenendaal, the Netherlands) and lysates were separated on Any kD Mini-PROTEAN TGX Precast Protein Gels (BioRad). Samples were transferred to a PVDF or 
nitrocellulose membrane (BioRad) and incubated overnight with anti-aSMA (A2547, Sigma), anti-calponin (ab46794, Abcam), anti-ALP (R\&D Systems, AF290), anti-Runx2 (MBL, D130-3), anti-ß-catenin (BD, 610153), anti-p-SMAD1/5/8 (Cell Signalling, 12820P) and a-tubulin (Sigma, T6074) antibodies. Protein was then detected using HRP-conjugated secondary antibodies (anti-mouse: p0447, Dako; anti-rabbit: 7074S, Cell Signalling, anti-goat: P0449, Dako) and visualized by enhanced chemiluminescence (Pierce ECL Western Blotting Substrate, ThermoFisher Scientific).

\section{Alkaline phosphatase activity}

Cells were lysed in 1\% Triton X-100 in PBS, subjected to 2 freeze-thaw cycles and centrifuged at $13000 \mathrm{~g}$ for 5 minutes. ALP activity in the supernatants was measured at $405 \mathrm{~nm}$ using 4-Nitrophenyl phosphate disodium salt hexahydrate (Sigma) as substrate. Enzyme activity (U) was normalised to protein concentrations.

\section{Statistical analysis}

Data shown are mean \pm SD. All data were verified in $\geq 3$ independent experiments. Statistical analysis was performed by 1-way ANOVA with Bonferroni post hoc test or Student's t-test where appropriate, using PRISM software (GraphPad). Values of $P<0.05$ were considered statistically significant.

\section{Results}

\section{Treatment of VSMCs in vitro with phosphate induces calcification}

We first set out to examine calcification of primary mouse VSMCs in vitro. WT VSMCs were cultured in medium with elevated phosphate as described before $(8,32)$ (osteogenic medium, OM), which induced mineralisation in vitro, as observed by quantification of deposited calcium phosphate crystals (Figure 1A).

To control for spontaneous mineral precipitation on collagen, collagen-coated wells were incubated with OM in the absence of VSMCs. Under these a-cellular conditions, no calcification was observed (data not shown). To examine osteo/chondrogenic differentiation in mineralisation of VSMCS in vitro, Runx2 and Osteocalcin expression was measured using qPCR after 12 days of incubation with osteogenic medium (Figure $1 \mathrm{~B}$ and $\mathrm{C}$ ). Expression of both markers was significantly increased, suggesting that the observed mineralisation is an active process involving osteo/chondrogenic differentiation. Moreover, treatment of human VSMC with osteogenic medium increased secretion of extracellular vesicles (Figure 1D), which have recently been shown to mediate VC (23). 
A

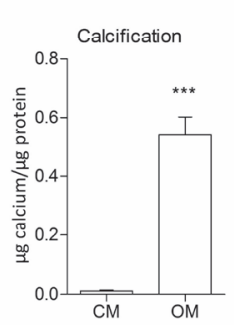

B

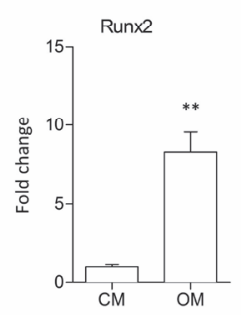

C

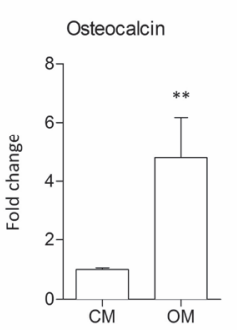

D

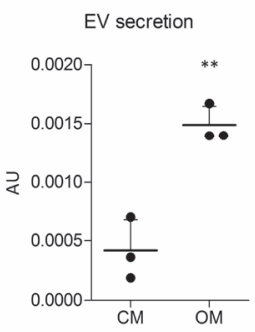

Figure 1. Increased phosphate concentrations induce calcification of mVSMCs in vitro.

Cells were incubated with control medium (full growth medium, $\mathrm{CM}$ ) or osteogenic medium (growth medium with 2.6mM phosphate) for 12 days. A. Quantification of Ca content in mineralised mVSMC cultures. assay. B, C. Calcification of mVSMCs was associated with increased expression of osteogenic genes Runx2 and osteocalcin measured by qPCR D. Calcification of human VSMCs increased exosome secretion measured using a bead capture statistical significance was assessed using t-test or ANOVA. ${ }^{* *} p<0.001-0.01,{ }^{* * *} p<0.001$. graphs show mean+SD. Where appropriate

\section{Ucma is expressed in atherosclerotic plaques of $\mathrm{ApoE}^{-/-}$mice}

Ucma has previously been shown to be expressed in calcified human aortas and aortic valves (27). Here we demonstrate that Ucma is expressed in advanced atherosclerotic lesions of ApoE ${ }^{-/}$mice. Ucma was expressed specifically in fish-eye-like cells in atherosclerotic plaques (Figures $2 \mathrm{C}$ and $\mathrm{D}$ ), which show similarities to chondrocyte morphology. As shown in Figures 2A and B, these cells also expressed osteo/chondrogenic markers BMP2 and Runx2. This suggests that Ucma is involved in osteo/chondrogenic differentiation and calcification of VSMCs in atherosclerotic plaques. Interestingly, not all cells with fish-eye morphology visibly expressed Ucma.
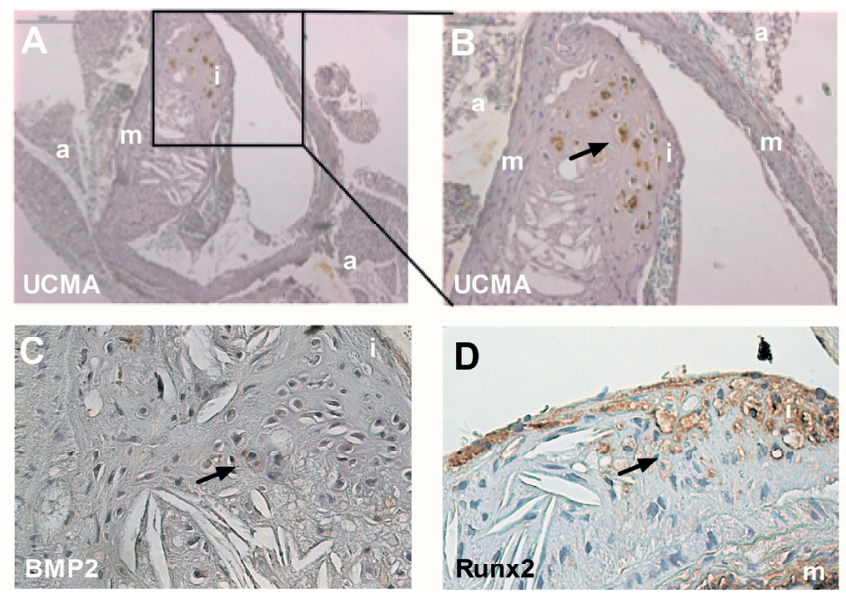

Figure 2. Ucma is expressed in atherosclerotic plaques.

Sections of atherosclerotic plaques from $\mathrm{ApoE}^{-/}$mice fed a high fat diet for 12 weeks were stained for $\mathrm{Ucma}$, BMP-2 and Runx2. Arrows point to cells in the plaque with a chondrocyte-like morphology, which express both osteogenic markers and Ucma; $\mathrm{a}$ - adventitia, i - intima, $\mathrm{m}$ - media. 


\section{Ucma expression in VSMCs in vitro increases in response to osteogenic medium}

The presence of Ucma in murine VSMCs (mVSMCS) in vitro was confirmed using RT-PCR (Figure 3A). Additionally, immunocytochemistry (Figure 3B) has shown expression of Ucma in scattered cytoplasmic foci, which is consistent with its subcellular localization in other cell types (31). Next, in order to examine whether Ucma has a role in mineralisation of

A

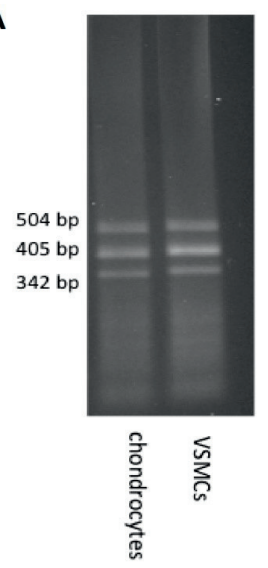

C

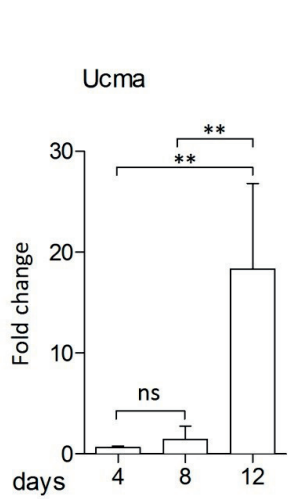

B
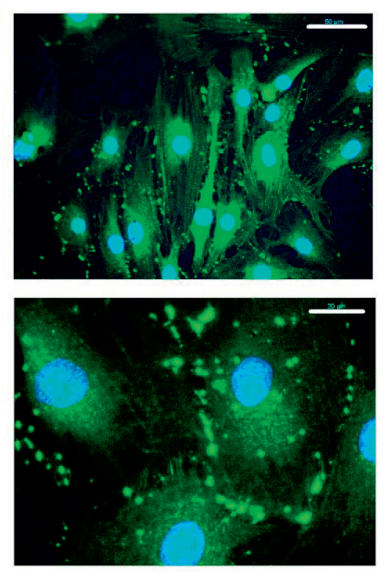

D
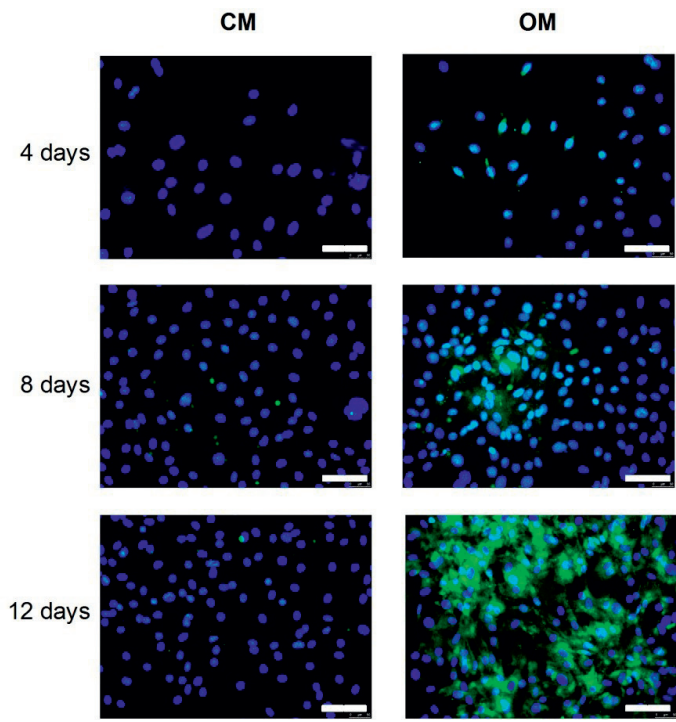

Figure 3. Ucma expression is increased in calcifying mVSMCs.

Cells were incubated in growth medium (CM) or osteogenic medium (OM) containing $2.6 \mathrm{mM}$ phosphate. A. RT PCR of Ucma in mouse chondrocytes and VSMCs. Bands represent several transcript variants of Ucma. B. Im-

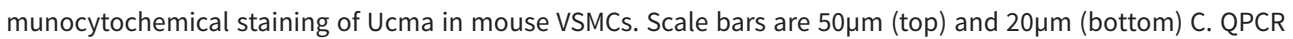
quantification of Ucma expression in calcifying mVSMCs. Graph shows mean+SD. Statistical significance was assessed using ANOVA. ${ }^{* *} p$ between 0.001-0.01. D. Immunocytochemical staining of Ucma in calcifying mVSMCs. Scale bars are $100 \mu \mathrm{m}$. 
VSMCs in vitro, expression was measured in response to treatment with osteogenic medium (Figure 3C). Ucma expression, measured by qPCR, increased in a time-dependent manner with a 20-fold increase after 12 days of culture. Immunocytochemistry analysis confirmed this result and showed that control medium does not induce a similar increase (Figure 3D).

\section{Ucma-deficient VSMCs are more prone to calcification in response to osteogenic medium}

Aortas were harvested from Ucma $\%$ mice (KO) and wild type (WT) counterparts generated as previously described (28). The knock-out of Ucma was confirmed by immunohistochemical staining of the epiphyseal plate (Supplemental Figure 1A). VSMCs were isolated and their identity was verified by immmunocytochemical staining for VSMC markers (aSMA, CNN1, p-MLC) (Supplemental Figure 1B). We and others $(26,27)$ have shown that Ucma is upregulated in response to calcification and that its expression is confined to osteo/chondrogenic cells in atherosclerotic plaques (Figure 2A and figures $3 \mathrm{~A}$ and B). Therefore, we hypothesized that Ucma is involved in controlling osteo/chondrogenic differentiation of VSMCs and consequently calcification. To test this, WT and Ucma ${ }^{-1-}$ VSMCs were incubated in osteogenic medium over a time span of 15 days (Figure $4 \mathrm{~A}$ and $4 \mathrm{~B}$ ).

Both WT and Ucma ${ }^{-/}$VSMCs calcified in response to osteogenic medium, with calcification becoming detectable after 6 days. However, Ucma $\%$ VSMCs calcified approximately twice as much as WT cells after 9, 12 and 15 days. Neither Ucma ${ }^{-\%}$ nor WT VSMCs calcified in control medium (Supplemental Figure 1C). Ucma knock-down in WT cells using siRNA resulted in significantly increased calcification compared to cells transfected with a scramble control (Supplemental Figure 1D), confirming that the observed effects are specific to Ucma. In response to osteogenic medium alkaline phosphatase (ALP) activity was increased in $\mathrm{Ucma}^{-/}$cells but not in WT cells, suggesting increased osteo/chondrogenic potential of $\mathrm{Ccma}^{\%}$ cells (Figure $4 \mathrm{C}$ ).

A

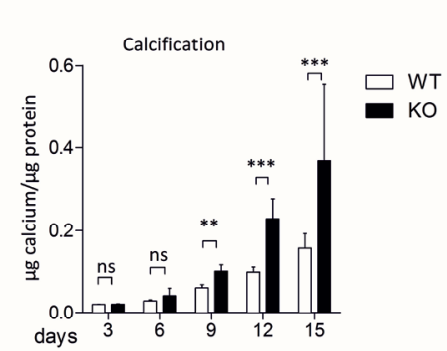

B

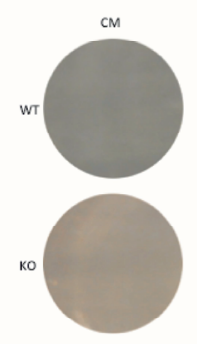

C

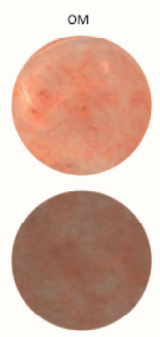

Figure 4. MVSMCs from Ucma ${ }^{-/-}$mice show increased calcification.

Cells from Ucma ${ }^{-/}$mice and WT counterparts were incubated with growth medium (CM) or osteogenic medium (OM) containing $2.6 \mathrm{mM}$ phosphate. A. Quantification of calcification over a 15 day period. B. Alizarin red S staining of calcium deposited by mVSMCs after 12 days. C. Alkaline phosphatase (ALP) in mVSMCs treated with osteogenic medium or control medium for 12 days. All graphs show mean+SD. Where appropriate statistical significance was assessed using t-test or ANOVA. ${ }^{\star} p$ between $0.05-0.01,{ }^{\star \star} p$ between $0.001-0.01,{ }^{\star \star \star} p<0.001$. 


\section{Ucma deficiency results in increased osteo/chondrogenic gene expression}

Since osteo/chondrogenic differentiation is an important mechanism regulating VC and expression of osteo/chondrogenic markers is found in atherosclerotic plaques, we set out to examine whether there were any differences in osteo/chondrogenic marker expression between WT and Ucma ${ }^{-/}$VSMCs. We observed that Ucma ${ }^{-1-}$ cells expressed increased levels of BMP-2 mRNA in baseline conditions (CM, Figure 5A). Additionally, when challenged with osteogenic medium, Ucma $\%$ VSMCs expressed higher levels of OPN, Osteocalcin and BMP2, compared to WT VSMCs (Figure 5A, B and C). MGP mRNA expression was significantly downregulated in Ucma ${ }^{--}$compared to WT VSMCS, both in baseline and osteogenic con-
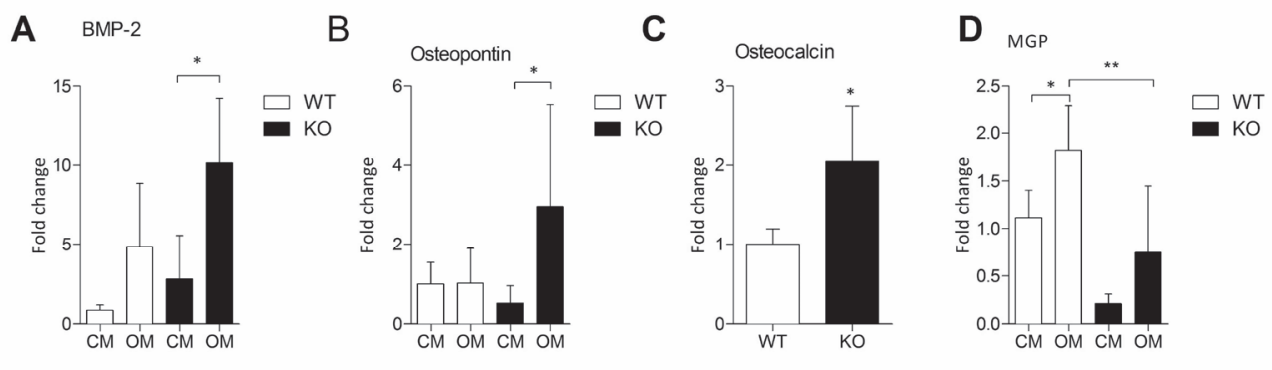

E
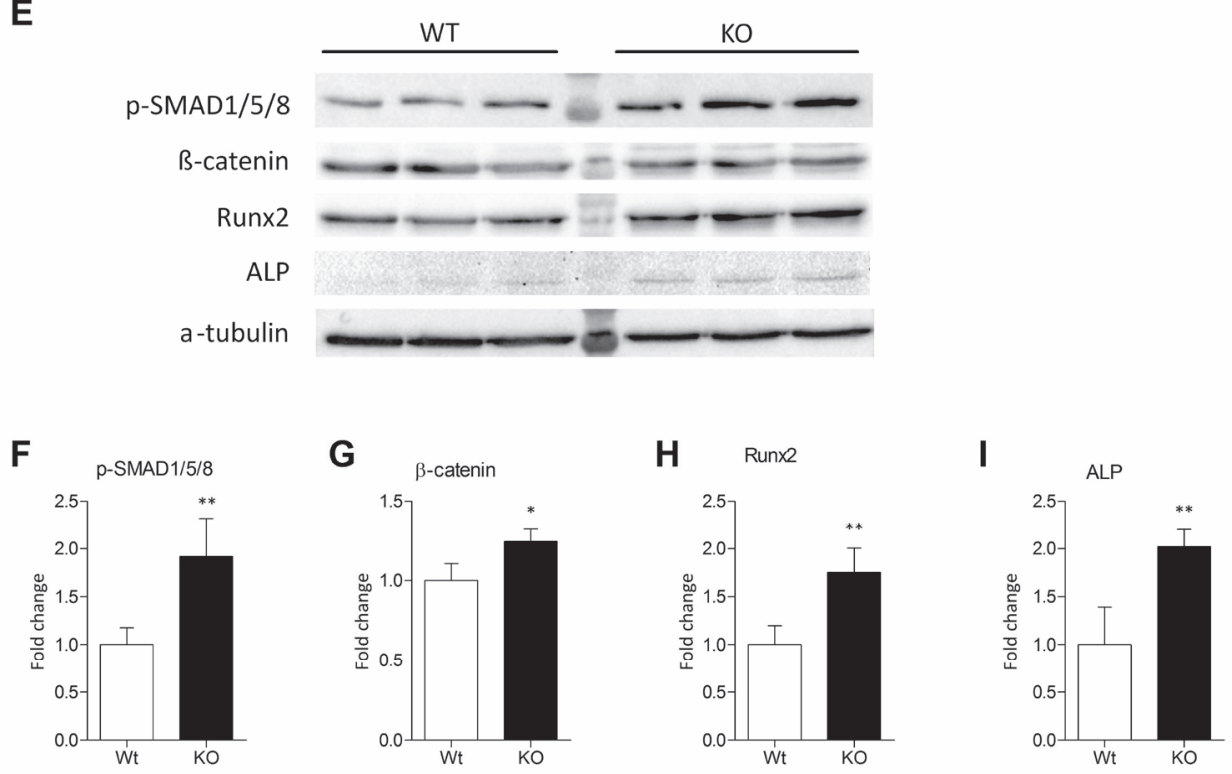

Figure 5. Ucma ${ }^{-/-}$mVSMCs show increased expression of osteo/chondrogenic markers.

Cells were treated with control (CM) or osteogenic medium (OM, with $2.6 \mathrm{mM}$ phosphate) for 12 days. Panels A-D. qPCR analysis of osteo/chondrogenic gene expression. E. Western blotting analysis of osteo/chondrogenic markers. Both WT and KO cells were treated with OM. Panels F-I quantification of western blotting results from panel E. All graphs show mean+SD. Where appropriate statistical significance was assessed using t-test or ANOVA. ${ }^{\star} p$ between $0.05-0.01,{ }^{\star \star} p$ between $0.001-0.01$ 
ditions, in line with the increased calcification potential of these cells (Figure 5D). Upon treatment with osteogenic medium MGP expression increased, both in WT and Ucma ${ }^{-1}$ VSMCs. Western blot analysis demonstrated an increase in $\beta$-catenin and phosphorylated SMAD1/5/8 expression, suggesting the involvement of SMAD signalling pathways (Figures $5 E, F, G)$ known to be involved in osteoblast mineralization and VC. Additionally, expression of Runx2 and ALP was higher in Ucma* cells compared to WT (Figures 5E, H and I). Importantly, we also observed that Ucma $\%$ VSMCs displayed reduced expression levels of contractile phenotype marker aSMA compared to WT VSMCs (Supplemental Figure 1E). Taken together these results show that Ucma ${ }^{--}$VSMCs undergo increased osteo/chondrogenic differentiation, compared to WT VSMCS, both at baseline as well as in osteogenic conditions.

\section{The osteo/chondrogenic phenotype in $\mathrm{Ucma}^{-/-}$VSMCs is induced by lack of inhibition of a BMP-2-p-SMAD1/5/8- $\beta$-catenin dependent-pathway}

BMP-2 is a key modulator in the development of VC $(19,21)$. Since we observed an increase in BMP-2 expression and its downstream targets $p$-SMAD1/5/8, we investigated the involvement of BMP signalling in calcification of Ucma ${ }^{-/}$VSMCs. We blocked BMP-2 and BMP-4 signalling using noggin and treated VSMCs with osteogenic medium (Figure 6A). Noggin treatment decreased calcification of both WT and Ucma ${ }^{-/}$VSMCs. Further to that, to investigate the involvement of specific downstream targets of BMP we treated cells with dorsomorphin, an inhibitor of SMAD1/5/8 activation (AMPK inhibitor). Dorsomorphin decreased calcification of WT VSMCS and restored levels of calcification in Ucma ${ }^{-/}$cells to the levels observed in WT VSMCs (Figure 6B). The reduction in calcification was reflected by a decrease in p-SMAD1/5/8 and ALP expression (Figure 6C, D, E). Taken together, these results suggest that increased osteo/chondrogenic and calcification potential of Ucma ${ }^{-/}$VSMCs is due to impaired inhibition SMAD-dependent of BMP signalling.

As Erk signalling has been known to also activate SMAD signalling (33), we investigated whether inhibiting Erk phosphorylation has an effect on calcification of Ucma ${ }^{-\%}$ VSMCs. Treatment of WT and Ucma ${ }^{-\%}$ VSMCS with Erk phosphorylation inhibitor U0126 did not change calcification levels of cells of either genotype, suggesting that Erk phosphorylation and Ucma are not interacting to inhibit calcification of VSMC cultures (Supplemental Figure 2). 
A

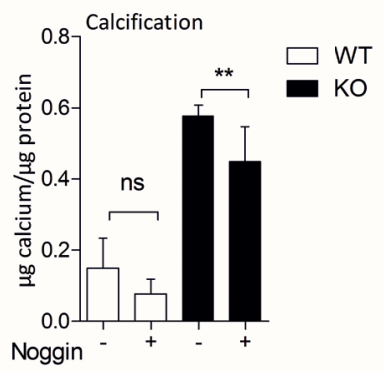

B

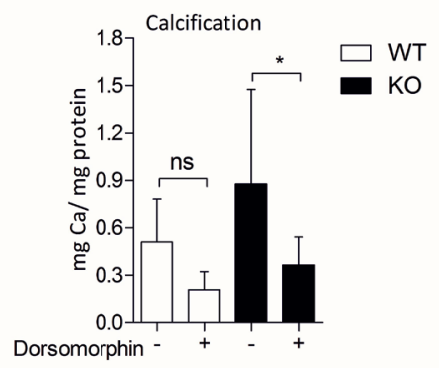

C

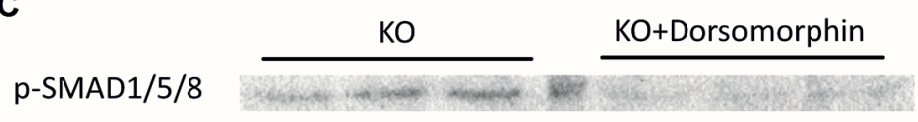

ALP

a-tubulin

D

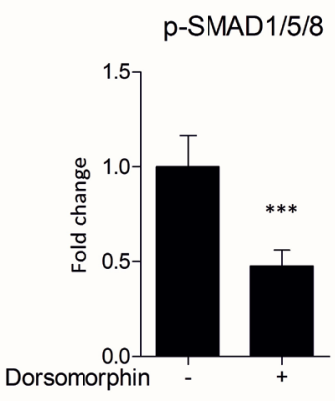

E

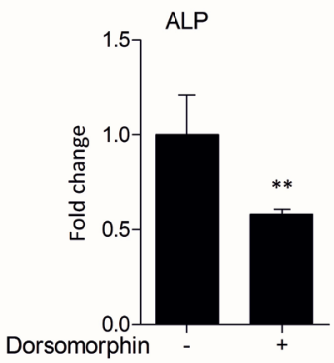

Figure 6. Ucma is involved in suppressing osteo/chondrogenic differentiation by interacting with SMADs.

A. Quantification of calcification deposited by mVSMCs incubated with $100 \mathrm{ng} / \mathrm{ml}$ noggin in the presence of osteogenic medium (2.6mM phosphate) for 12 days. B. Quantification of calcification deposited by mVSMCs from Ucma KO and WT mice. Cells were incubated with $2 \mu \mathrm{M}$ dorsomorphin in osteogenic medium (OM) for 12 days. C. Western blotting analysis of phosphorylated SMAD $1 / 5 / 8$ and ALP and in Ucma ${ }^{-/}$mVSMCs treated with $2 \mu \mathrm{M}$ dorsomorphin in osteogenic medium (OM) for 12 days. D, E. Quantification of Western blots from panel C. All graphs show mean+SD. Where appropriate statistical significance was assessed using t-test or ANOVA. * $p$ between $0.05-$ $0.01,{ }^{\star \star} p$ between $0.001-0.01,{ }^{\star \star \star} p<0.001$. 


\section{Discussion}

VC is an important predictor of cardiovascular mortality. In particular, CKD patients have been shown to be at an increased risk of VC $(5,34)$. However, the mechanisms through which VC develops remain incompletely understood. In the present study we demonstrate that Ucma plays a role in the attenuation of osteo/chondrogenic differentiation of VSMCs through a pathway involving SMAD-dependent BMP signalling. Osteo/chondrogenic switching is accelerated in the absence of $\mathrm{Ucm}$ a and this results in enhanced calcification. We also provide evidence that high phosphate concentrations, which is a common finding in CKD patients (7), induce upregulation of Ucma in VSMCs. Our findings reveal a novel pathway through which Ucma inhibits phosphate-induced SMAD signalling and osteo/ chondrogenic differentiation, thereby reducing the propensity for calcification of the vessel wall.

Ucma was previously shown to inhibit maturation of chondrocytes towards hypertrophic cells and osteogenic differentiation of osteoblasts (29). Ucma is known to be present in low levels in calcified aortic valves and in the media. Ucma inhibits calcification of aortic rings cultured in calcifying medium, when added exogenously to cultures, this was accompanied by an increase in aSMA expression and a decrease of osteopontin expression (27). In our study we confirmed the presence of Ucma in the vasculature and for the first time reveal that Ucma expression is markedly increased in osteo/chondrogenic cells in atherosclerotic plaques of ApoE ${ }^{-}$mice, which implicates its role in this vascular pathology. CKD patients show accelerated atherosclerosis, which suggests that our in vivo findings are relevant for calcification in CKD-related atherosclerosis $(35,36)$.

BMP-2 is a potent inducer of calcification and regulator of osteo/chondrogenic differentiation of VSMCs, known to cause phosphate influx into cells (21). BMP-2 acts by binding its cell surface receptors which transduce the signal to the cytoplasm by phosphorylating pathway-restricted SMADs (SMAD1 and SMAD5) for BMPs (37). This leads to heterodimerization of pathway-restricted SMADs with SMAD4, a common-mediator SMAD, and translocation of the complex to the nucleus, where it binds directly to DNA (38). As a result, changes in gene expression occur, such as upregulation of Runx2, OCN and ALP. Additionally, BMP-2 has been shown to induce accumulation of $\beta$-catenin (39). $\beta$-catenin has been demonstrated to activate Runx2 expression in the context of phosphate-induced VSMC calcification (40). BMP and Wnt pathways have been shown to be co-activated in calcifying VSMCs (41), where SMAD1 and $\beta$-catenin interacted and regulated gene expression together. Our data are in line with these findings, as we demonstrate increased SMAD1/5/8 phosphorylation and expression of $\beta$-catenin, Runx2 and their downstream targets ALP, OCN and OPN in phosphate-treated Ucma ${ }^{--V S M C s}$. Here we demonstrate that Ucma interacts with this BMP-SMAD signalling pathway, as inhibiting BMP-2/-4 signalling with noggin and SMAD1/5/8 phosphorylation with dorsomorphin decreased calcification of VSMCs and osteo/chondrogenic gene expression. 
In our study we confirm that high levels of phosphate induce hallmarks of osteogenic differentiation in VSMCS, such as osteo/chondrogenic gene expression and extracellular vesicle release, and that Ucma expression is increased in VSMCs treated with osteogenic medium in vitro. This, together with the presence of Ucma in advanced atherosclerotic lesions, suggests that calcifying cells increase the expression of this inhibitor in a bid to protect themselves from adverse phenotype changes. This has been shown to happen with MGP, another vitamin K-dependent calcification inhibitor, by us in the present study and others (42). Additionally, insufficient carboxylation of MGP due to warfarin administration is one of the factors contributing to VC in CKD (43). Uncarboxylated Ucma, similar to uncarboxylated MGP, could contribute to these processes. Ucma is a vitamin K-dependent protein, as it undergoes posttranslational carboxylation (44). It has been previously shown that uncarboxylated Ucma accumulates at sites of pathological calcification in human aortic valves and media and only the carboxylated form of Ucma was able to inhibit calcification (27). In our study we have not looked at the carboxylation status of Ucma in atherosclerotic plaques which we examined and this warrants further investigation.

MGP is known to inhibit VC by binding mineral and interacting with BMP-2, preventing it from binding its receptor (9). It is therefore tempting to speculate that vitamin K-dependent inhibitors complement each other with respect to regulating VC: calcium-induced calcification is regulated by MGP and controlled on the level of BMP-2 $(7,23)$ whereas phosphate-

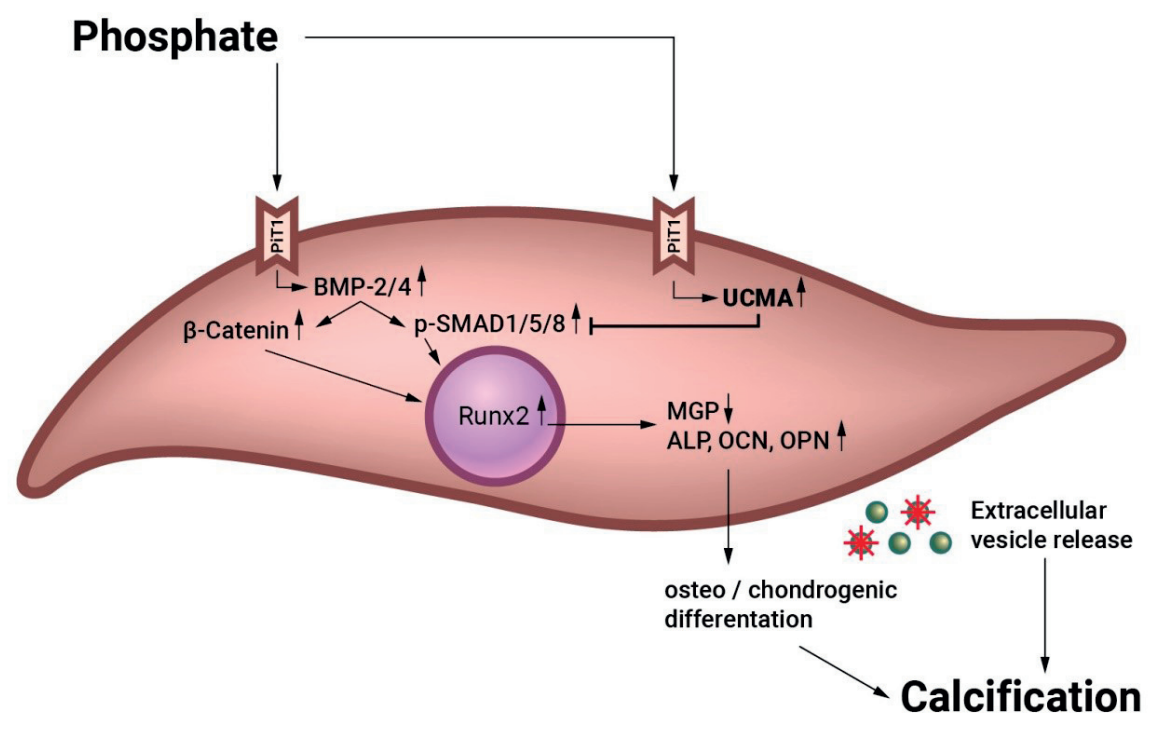

Figure 7. Proposed model of the protective effect of Ucma in calcifying mVSMCs.

Ucma expression is increased as a negative feedback loop mechanism when extracellular phosphate is elevated. Ucma prevents activation of phosphate-induced BMP-2-SMAD signalling in calcifying VSMCs, acting as an inhibitor of signalling cascades that lead to calcification. OCN - osteocalcin, OPN - osteopontin, ALP - alkaline phosphatase, MGP - matrix Gla protein. 
induced calcification is regulated by Ucma and controlled by altering phosphorylation of SMADs. This is further supported by previous studies showing that phosphate increases osteo/chondrogenic differentiation of VSMC in vitro, whereas this was not demonstrated for calcium yet $(8,12)$.

Based on our observations, we propose a model of how Ucma inhibits VC (Figure 7). When VSMCs are exposed to elevated phosphate concentrations in the extracellular environment, as is the case in CKD patients, osteo/chondrogenic differentiation (as evidenced by increased Runx2, $\beta$-catenin, osteocalcin, osteopontin and ALP expression) is initiated via increased BMP-SMAD signalling. We propose that Ucma can ameliorate the effect of increased phosphate by inhibiting this signalling pathway and thus reduce calcification of the vessel wall.

Taken together, we demonstrate that Ucma, a member of a range of inherent calcification inhibitors present in the vasculature (45), plays an important role in regulating osteo/ chondrogenic differentiation of VSMCs. Our findings have implications for vascular pathologies which lead to VC and represent an advancement in our knowledge about the steps resulting in VC. One of the main goals in the treatment of patients with CKD is to reduce the substantially increased risk of cardiovascular comorbidity and mortality, improving both quality and length of life. The increase in CKD stage and cardiovascular risk is accompanied by increased phosphate levels. As shown by our results, the phosphate-Ucma-BMP axis holds promise for novel interventions. Pharmacological manipulation of Ucma levels could represent a novel therapeutic strategy to prevent VC. 


\section{References}

1. Hunt JL, Fairman R, Mitchell ME, Carpenter JP, Golden M, Khalapyan T, et al. Bone formation in carotid plaques: a clinicopathological study. Stroke. 2002 May;33(5):1214-9.

2. Duer MJ, Friscic T, Proudfoot D, Reid DG, Schoppet M, Shanahan CM, et al. Mineral surface in calcified plaque is like that of bone: further evidence for regulated mineralization. Arterioscler Thromb Vasc Biol. 2008 Nov;28(11):2030-4.

3. Rennenberg RJ, Kessels AG, Schurgers LJ, van Engelshoven JM, de Leeuw PW, Kroon AA. Vascular calcifications as a marker of increased cardiovascular risk: a meta-analysis. Vasc Health Risk Manag. 2009;5(1):185-97.

4. Sage AP, Tintut Y, Demer LL. Regulatory mechanisms in vascular calcification. Nat Rev Cardiol. 2010 Sep;7(9):528-36.

5. Shroff R, Long DA, Shanahan C. Mechanistic insights into vascular calcification in CKD. J Am Soc Nephrol. 2013 Feb;24(2):179-89.

6. Chatrou ML, Winckers K, Hackeng TM, Reutelingsperger CP, Schurgers LJ. Vascular calcification: the price to pay for anticoagulation therapy with vitamin K-antagonists. Blood reviews. 2012; 26(4):155-66.

7. Shanahan CM, Crouthamel MH, Kapustin A, Giachelli CM. Arterial calcification in chronic kidney disease: key roles for calcium and phosphate. Circ Res. 2011 Sep 2;109(6):697-711.

8. Jono S, McKee MD, Murry CE, Shioi A, Nishizawa Y, Mori K, et al. Phosphate regulation of vascular smooth muscle cell calcification. Circ Res. 2000 Sep 29;87(7):E10-7.

9. Schurgers LJ, Uitto J, Reutelingsperger CP. Vitamin K-dependent carboxylation of matrix Glaprotein: a crucial switch to control ectopic mineralization. Trends Mol Med. 2013 Apr;19(4): 217-26.

10. Liu Y, Drozdov I, Shroff R, Beltran LE, Shanahan CM. Prelamin A accelerates vascular calcification via activation of the DNA damage response and senescence-associated secretory phenotype in vascular smooth muscle cells. Circ Res. 2013 May 10;112(10):e99-109.

11. Neven E, Dauwe S, De Broe ME, D'Haese PC, Persy V. Endochondral bone formation is involved in media calcification in rats and in men. Kidney Int. 2007 Sep;72(5):574-81.

12. Iyemere VP, Proudfoot D, Weissberg PL, Shanahan CM. Vascular smooth muscle cell phenotypic plasticity and the regulation of vascular calcification. J Intern Med. 2006 Sep;260(3):192-210.

13. Frid MG, Shekhonin BV, Koteliansky VE, Glukhova MA. Phenotypic changes of human smooth muscle cells during development: late expression of heavy caldesmon and calponin. Dev Biol. 1992 Oct;153(2):185-93.

14. Huang QQ, Fisher SA, Brozovich FV. Forced expression of essential myosin light chain isoforms demonstrates their role in smooth muscle force production. J Biol Chem. 1999 Dec 03;274(49): 35095-8.

15. Feil S, Hofmann F, Feil R. SM22alpha modulates vascular smooth muscle cell phenotype during atherogenesis. Circ Res. 2004 Apr 16;94(7):863-5. 
16. Shankman LS, Gomez D, Cherepanova OA, Salmon M, Alencar GF, Haskins RM, et al. KLF4dependent phenotypic modulation of smooth muscle cells has a key role in atherosclerotic plaque pathogenesis. Nat Med. 2015 Jun;21(6):628-37.

17. Alexander MR, Owens GK. Epigenetic control of smooth muscle cell differentiation and phenotypic switching in vascular development and disease. Annu Rev Physiol. 2012;74:13-40.

18. Dhore CR, Cleutjens JP, Lutgens E, Cleutjens KB, Geusens PP, Kitslaar PJ, et al. Differential expression of bone matrix regulatory proteins in human atherosclerotic plaques. Arterioscler Thromb Vasc Biol. 2001 Dec;21(12):1998-2003.

19. Speer MY, Yang HY, Brabb T, Leaf E, Look A, Lin WL, et al. Smooth muscle cells give rise to osteochondrogenic precursors and chondrocytes in calcifying arteries. Circ Res. 2009 Mar 27;104(6): 733-41.

20. Shanahan CM, Cary NR, Salisbury JR, Proudfoot D, Weissberg PL, Edmonds ME. Medial localization of mineralization-regulating proteins in association with Mönckeberg's sclerosis evidence for smooth muscle cell-mediated vascular calcification. Circulation. 1999;100(21):2168-76.

21. Li X, Yang HY, Giachelli CM. BMP-2 promotes phosphate uptake, phenotypic modulation, and calcification of human vascular smooth muscle cells. Atherosclerosis. 2008;199(2):271-7.

22. Giachelli CM, Bae N, Almeida M, Denhardt DT, Alpers CE, Schwartz SM. Osteopontin is elevated during neointima formation in rat arteries and is a novel component of human atherosclerotic plaques. J Clin Invest. 1993 Oct;92(4):1686-96.

23. Kapustin AN, Chatrou ML, Drozdov I, Zheng Y, Davidson SM, Soong D, et al. Vascular smooth muscle cell calcification is mediated by regulated exosome secretion. Circ Res. 2015 Apr 10; 116(8):1312-23.

24. Tagariello A, Luther J, Streiter M, Didt-Koziel L, Wuelling M, Surmann-Schmitt C, et al. Ucma-A novel secreted factor represents a highly specific marker for distal chondrocytes. Matrix Biol. 2008 Jan;27(1):3-11.

25. Viegas CS, Simes DC, Laize V, Williamson MK, Price PA, Cancela ML. Gla-rich protein (GRP), a new vitamin K-dependent protein identified from sturgeon cartilage and highly conserved in vertebrates. J Biol Chem. 2008 Dec 26;283(52):36655-64.

26. Viegas CS, Cavaco S, Neves PL, Ferreira A, Joao A, Williamson MK, et al. Gla-rich protein is a novel vitamin $\mathrm{K}$-dependent protein present in serum that accumulates at sites of pathological calcifications. Am J Pathol. 2009 Dec;175(6):2288-98.

27. Viegas CS, Rafael MS, Enriquez JL, Teixeira A, Vitorino R, Luis IM, et al. Gla-rich protein acts as a calcification inhibitor in the human cardiovascular system. Arterioscler Thromb Vasc Biol. 2015 Feb;35(2):399-408.

28. Eitzinger N, Surmann-Schmitt C, Bosl M, Schett G, Engelke K, Hess A, et al. Ucma is not necessary for normal development of the mouse skeleton. Bone. 2012 Mar;50(3):670-80.

29. Surmann-Schmitt C, Dietz U, Kireva T, Adam N, Park J, Tagariello A, et al. Ucma, a novel secreted cartilage-specific protein with implications in osteogenesis. J Biol Chem. 2008 Mar 14;283(11): 7082-93. 
30. Lee YJ, Park SY, Lee SJ, Boo YC, Choi JY, Kim JE. Ucma, a direct transcriptional target of Runx2 and Osterix, promotes osteoblast differentiation and nodule formation. Osteoarthritis Cartilage. 2015 Aug;23(8):1421-31.

31. Le Jeune M, Tomavo N, Tian TV, Flourens A, Marchand N, Camuzeaux B, et al. Identification of four alternatively spliced transcripts of the Ucma/GRP gene, encoding a new Gla-containing protein. Exp Cell Res. 2010 Jan 15;316(2):203-15.

32. Steitz SA, Speer MY, Curinga G, Yang HY, Haynes P, Aebersold R, et al. Smooth muscle cell phenotypic transition associated with calcification: upregulation of $\mathrm{Cbfa} 1$ and downregulation of smooth muscle lineage markers. Circ Res. 2001 Dec 7;89(12):1147-54.

33. Hough C, Radu M, Doré JJE. TGF-Beta Induced Erk Phosphorylation of Smad Linker Region Regulates Smad Signaling. PLoS One. 2012;7(8):e42513.

34. Mizobuchi M, Towler D, Slatopolsky E. Vascular calcification: the killer of patients with chronic kidney disease. Journal of the American Society of Nephrology. 2009;20(7):1453-64.

35. Cheung AK, Sarnak MJ, Yan G, Dwyer JT, Heyka RJ, Rocco MV, et al. Atherosclerotic cardiovascular disease risks in chronic hemodialysis patients. Kidney international. 2000;58(1):353-62.

36. Olechnowicz-Tietz S, Gluba A, Paradowska A, Banach M, Rysz J. The risk of atherosclerosis in patients with chronic kidney disease. International urology and nephrology. 2013;45(6):1605-12.

37. Liu F, Hata A, Baker JC, Doody J. A human Mad protein acting as a BMP-regulated transcriptional activator. Nature. 1996;381(6583):620.

38. Heldin C-H, Miyazono K, Ten Dijke P. TGF- $\beta$ signalling from cell membrane to nucleus through SMAD proteins. Nature. 1997;390(6659):465-71.

39. de Jesus Perez VA, Alastalo T-P, Wu JC, Axelrod JD, Cooke JP, Amieva M, et al. Bone morphogenetic protein 2 induces pulmonary angiogenesis via Wnt- $\beta$-catenin and Wnt-RhoA-Rac1 pathways. The Journal of Cell Biology. 2009;184(1):83-99.

40. Cai T, Sun D, Duan Y, Wen P, Dai C, Yang J, et al. WNT/beta-catenin signaling promotes VSMCS to osteogenic transdifferentiation and calcification through directly modulating Runx2 gene expression. Exp Cell Res. 2016 Jul 15;345(2):206-17.

41. Guerrero F, Herencia C, Almaden Y, Martinez-Moreno JM, Montes de Oca A, Rodriguez-Ortiz ME, et al. TGF-beta prevents phosphate-induced osteogenesis through inhibition of BMP and Wnt/ beta-catenin pathways. PLoS One. 2014;9(2):e89179.

42. Proudfoot D, Skepper JN, Shanahan CM, Weissberg PL. Calcification of human vascular cells in vitro is correlated with high levels of matrix Gla protein and low levels of osteopontin expression. Arteriosclerosis, thrombosis, and vascular biology. 1998;18(3):379-88.

43. McCabe KM, Booth SL, Fu X, Shobeiri N, Pang JJ, Adams MA, et al. Dietary vitamin K and therapeutic warfarin alter the susceptibility to vascular calcification in experimental chronic kidney disease. Kidney international. 2013;83(5):835-44.

44. Rafael MS, Cavaco S, Viegas CS, Santos S, Ramos A, Willems BA, et al. Insights into the association of Gla-rich protein and osteoarthritis, novel splice variants and gamma-carboxylation status. Mol Nutr Food Res. 2014 Aug;58(8):1636-46. 
45. Willems BA, Vermeer C, Reutelingsperger CP, Schurgers LJ. The realm of vitamin K dependent proteins: shifting from coagulation toward calcification. Mol Nutr Food Res. 2014 Aug;58(8):162035.

46. Schurgers LJ, Joosen IA, Laufer EM, Chatrou ML, Herfs M, Winkens MH, et al. Vitamin K-antagonists accelerate atherosclerotic calcification and induce a vulnerable plaque phenotype. PLoS One. 2012;7(8):e43229.

47. Gregory CA, Gunn WG, Peister A, Prockop DJ. An Alizarin red-based assay of mineralization by adherent cells in culture: comparison with cetylpyridinium chloride extraction. Anal Biochem. 2004 Jun 1;329(1):77-84. 


\section{Supplemental methods}

\section{SiRNA transfections}

10000 human VSMCs were seeded per well of a 48-well plate in M199 (Gibco) supplemented with $20 \%$ FBS, peniciliin and streptomycin. 24 hours later cells were transfected using $3 \mu \mathrm{l}$ HiPerfect reagent (Qiagen, Venlo, the Netherlands) with $1.5 \mu \mathrm{mol}$ Ucma siRNA or a scramble control (Qiagen, Venlo, the Netherlands) per well. After 48 hours osteogenic medium was applied and calcification assays carried out as described in the main article.

\section{Boyden Chamber experiments}

$20000 \mathrm{Ucma}^{-}$or WT VSMCs were seeded per well into the upper or lower chamber and allowed to attach overnight. The next day, cells were treated with control or osteogenic medium. After incubating the cells for 12 days, calcification of cells in lower chambers was quantified and normalized to protein content.

\section{Matrigels - extracellular vesicle-induced calcification}

For coating plates, matrigel solution $(20 \mathrm{mg} / \mathrm{ml})$ was added to each well and incubated for 1 hour. $20000 \mathrm{Ucma}^{-/}$or WT cells were seeded into the upper wells of a Boyden chamber and allowed to attach overnight. Next, the upper wells were placed in the matrigel coated Boyden chambers. Calcification medium was added and after 12 days. $0.1 \mathrm{M} \mathrm{NaOH}$ with $0.1 \%$ SDS were added to matrigels to obtain protein lysates. Calcification was normalised to protein content to correct for the amount of vesicles in the medium.

\section{Conditioned medium experiments}

$20000 \mathrm{Ucma}^{\%}$ or WT VSMCs were seeded per well of 24-well plate (Corning, Amsterdam, the Netherlands). The next day, cells were treated with control, osteogenic or conditioned medium for 12 days and calcification was measured. Medium was conditioned by incubating cells for 7 days in serum free growth medium (DMEM supplemented with penicillin and streptomycin). After harvesting, medium was centrifuged for 5 minutes at 2000 rpm (Rotina 380R, Hettich, Geldermalsen, the Netherlands), filtered through a $0.22 \mu \mathrm{m}$ filter and stored at $4^{\circ} \mathrm{C}$. FCS was added before the conditioned medium was applied to cells. 


\section{Supplemental Figures}

A
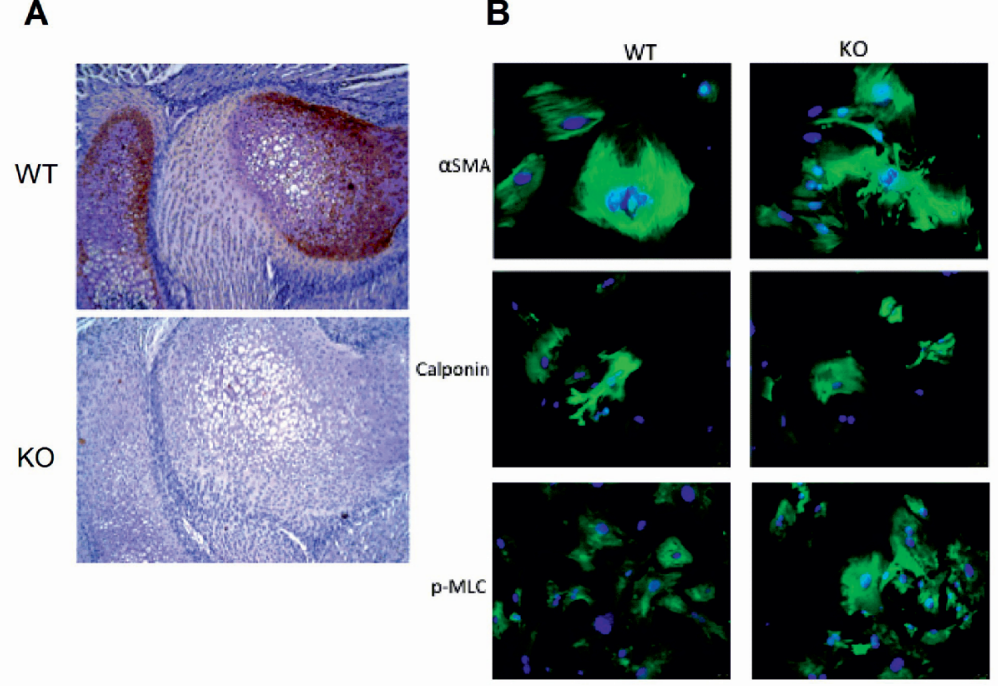

D Calcification

C

Calcification

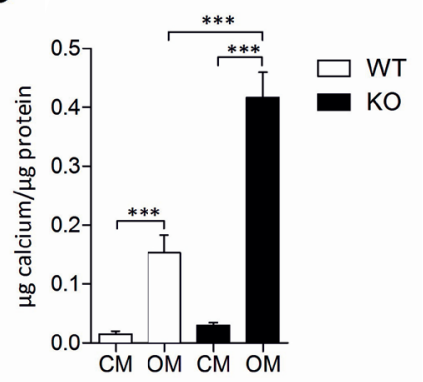

E

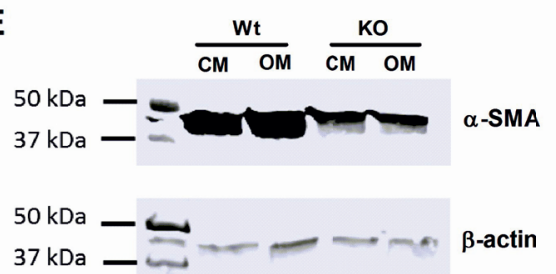

\section{Supplemental Figure 1.}

A. Immunohistochemical staining of Ucma in epiphysae of WT and KO mice confirmed the absence of Ucma in KO mice. B. Immunostaining of contractile markers in VSMCs isolated from WT and U $\mathrm{cma}^{-1-}$ mice to confirm the identity of cells. C. mVSMCs were treated with control growth medium (CM) and osteogenic medium (OM, with $2.6 \mathrm{mM}$ phosphate) and calcification was quantified after 12 days. D. Calcification was measured in WT transfected with Ucma siRNA and treated with osteogenic medium (2.6mM phosphate) for 12 days. E. Western blotting analysis of aSMA expression in Ucma ${ }^{-/}$and WT cells treated with control growth medium (CM) and osteogenic medium (OM, with $2.6 \mathrm{mM}$ phosphate) after 12 days. All graphs show mean+SD. Where appropriate statistical significance was assessed using t-test or ANOVA. ${ }^{\star \star} p<0.001-0.01,{ }^{\star \star *} p<0.001$. 


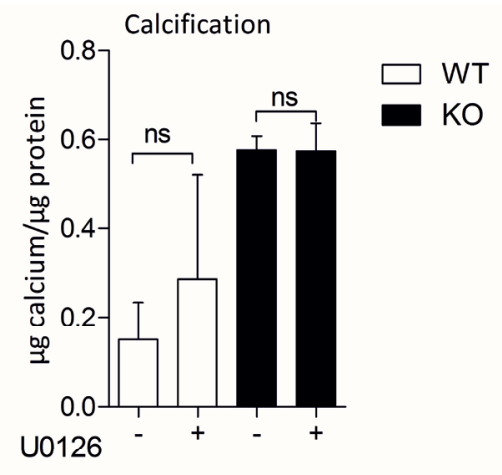

\section{Supplemental Figure 2.}

MVSMCs from Ucma ${ }^{-1}$ and WT mice were treated with an inhibitor of Erk phosphorylation $(U 0126,2 \mu \mathrm{M})$ in the presence of osteogenic medium (OM, with $2.6 \mathrm{mM}$ phosphate) for 12 days, after which calcification was quantified. Graph shows mean+SD. Statistical significance was assessed using t-test or ANOVA. 


\section{Apoptosis of medial vascular smooth muscle cells accelerates atherogenesis and induces a vulnerable plaque phenotype}

Brecht A.G. Willems, Armand Jaminon, Murray Clarke, Martin Bennett, Cees Vermeer, Martijn L.L. Chatrou, Dennis H.M. Kusters, Chris P.M. Reutelingsperger and Leon J. Schurgers 


\section{Abstract}

Vascular smooth muscle cells (VSMC) are involved in many arterial diseases including atherosclerosis and aneurysm formation. VSMC accumulation and apoptosis have implications for atherosclerotic plaque stability and development. In a mouse model of inducible VSMC-specific apoptosis, chronic apoptosis of VSMC has been shown to induce features of plaque instability including fibrous cap thinning, plaque calcification, necrotic core enlargement, medial erosion, elastin breaks and accelerated atherogenesis of established atherosclerotic plaques. Based on previous findings, we questioned the role of medial VSMC in the development of atherosclerotic lesions. To test our research question, $\mathrm{ApoE}^{-/}$and $\mathrm{SM} 22 \mathrm{a}-\mathrm{hDTR} / \mathrm{ApoE} \mathrm{E}^{-/}$mice were injected with diphtheria toxin (DT) for 3 weeks to reduce medial VSMC counts. After 3 weeks, DT treatment was arrested, mice started a Western type diet (0.25\% cholesterol) and were sacrificed after 6 and 18 weeks, respectively. The aortic arch including branches was excised and analysed. A reduction in VSMC counts after 3 weeks of DT treatment was verified by analysing vessel cellularity (cells $/ \mathrm{mm}^{2}$ ) in both control (ApoE ${ }^{-/}$) and SM22a-hDTR/ApoE ${ }^{--}$mice. A 50\% decrease in cellularity was observed in SM22a-hDTR/ApoE ${ }^{-/}$mice as compared to the control. Atherosclerotic plaque size was quantified on HE stained sections. SM22a-hDTR/ApoE ${ }^{-/}$mice displayed significantly accelerated plaque development as compared to control mice. After respectively 6 and 18 weeks of western type diet, atherosclerotic plaques in SM22a-hDTR/ApoE ${ }^{-/}$mice displayed features of plaque vulnerability. 


\section{Introduction}

Cardiovascular disease is the number one cause of death in the western world and manifests in various ways including atherosclerosis, stroke, myocardial infarction and aneurysms $(1,2)$. Moreover, cardiovascular morbidity is still increasing, especially in developing countries, due to globalization of the western way of life.

Under physiological conditions, vascular smooth muscle cells (VSMC) in the tunica media regulate vascular tone and diameter in order to maintain hemodynamic balance (3). Besides VSMC, extracellular matrix proteins including elastin, collagen, fibrinogen and endothelial cells are involved in maintenance of physiological vascular function. Remodelling of the vascular media is caused by various stress factors such as elevated levels of oxidative stress, increased circulating mineral concentrations (e.g. phosphate) or uremic toxins, all affecting the normal functioning of the vessel wall (4). The majority of VSMC in the vascular wall display a contractile phenotype to support vascular tone, however a specific subset of medial VSMCs has the ability to differentiate into a synthetic phenotype (5). This phenotypic flexibility of VSMC is necessary to deal with the varying conditions of vascular tissue. Synthetic VSMC are prone to undergo apoptosis or further phenotypic differentiation towards an osteochondrogenic phenotype (6). Both apoptosis and osteochondrogenic differentiation of VSMC are known to contribute to vascular remodelling, with as a consequence, calcification of the extracellular matrix. In turn, this is related to increased elastin breaks and further induces apoptosis of VSMC (7).

Vascular remodelling also contributes to development of atherosclerosis and stenosis (8-10). Atherosclerosis is known as a chronic inflammatory disease characterized by endothelial activation and lipid accumulation in the vessel wall (11). Accumulation of VSMC into the neointima has long been considered a key event in atherosclerosis progression. Here, VSMC promote atherosclerotic plaque stability by depositing extracellular matrix proteins such as collagen to create a thick fibrous cap.

To investigate the role of VSMC on atherosclerotic plaque stability, Clarke et al. used SM22a$\mathrm{hDTr}^{+} / \mathrm{ApoE}^{-/-}$mice $(12,13)$. Using this mouse model they specifically induced apoptosis of VSMC in mice with early and late phase atherosclerosis and clearly demonstrated a key role for VSMC in plaque stability and vascular remodelling. Medial calcification and remodelling have long been shown to affect atherosclerosis formation $(14,15)$. Aging of the vessel wall is accompanied by a loss of aortic elasticity, increased deposition of calcium in the media and vascular remodelling. Additionally, the prevalence of atherosclerosis also increases with increasing age. It has been shown that the atherosclerotic plaques were observed at areas with reduction in vascular elasticity. Both calcification and remodelling of the tunica media turned out to be an important risk factor for developing atherosclerosis (14).

In our study, we used SM22a-hDTr ${ }^{+} / \mathrm{ApoE}^{-/}$mice to investigate the role of VSMC in the vascular media on the initiation and early progression of atherosclerosis. VSMC apoptosis, and consequently depletion of medial VSMC was induced prior to formation of atherosclerotic plaques. We demonstrate that depletion of medial VSMC accelerates atherogenesis and destabilizes atherosclerotic plaques. 


\section{Methods}

\section{Animal protocols}

$\mathrm{SM} 22 \mathrm{a}-\mathrm{hDTr}+\mathrm{ApoE}{ }^{-/}$mice were kindly provided by Prof. Dr. M. Bennett (12). Control animals were diphtheria toxin receptor negative littermates, SM22a-hDTr/ApoE ${ }^{-/}$mice. Mice were kept in a temperature-controlled environment $\left(20^{\circ} \mathrm{C}\right)$ with a regular day \& night cycle. All animal experiments were conducted under a protocol approved by the ethics committee for animal experiments of Maastricht University.

Purified, recombinant, unnicked human diphtheria toxin (DT) (Quadratech Diagnostics, Surrey, United Kingdom) was dissolved in $0.9 \%$ saline solution containing $0.2 \%$ low endotoxin bovine serum albumin (Sigma, Zwijndrecht, the Netherlands), sterile filtered and stored at $-80^{\circ} \mathrm{C}$ until use.

Experimental animals (12 weeks old males) were weighed and injected 3 times a week intraperitoneally with $1 \mathrm{ng} / \mathrm{g}$ bodyweight of DT for 3 weeks. Next, a 1 week wash-out period was provided. During this period, mice were fed a normal chow diet and water ad libitum.

Blood was collected in 3.2\% sodium citrate by vena cava puncture and the aorta was flushed with $100 \mu \mathrm{M}$ sodium nitroprusside in phosphate buffered saline (PBS). Bone marrow was collected by flushing the femur with PBS. The aortic arch and its main branches were excised and fixated in 1\% paraformaldehyde overnight and embedded in paraffin. In these animals, medial VSMC counts were monitored and the vessel wall was checked for inflammation using Mac3 staining. Remaining mice were fed a western type diet (WTD) containing $0.25 \%$ cholesterol, 15\% cacao butter and 1\% corn oil (AB diets, Woerden, the Netherlands) for either 6 or 18 weeks and sacrificed using the same procedure

\section{Plasma cholesterol and triglyceride determination}

Total cholesterol (Horiba Medical, Montpellier, France) and triglyceride (Horiba Medical, Montpellier, France) measurements were performed as prescribed.

\section{FACS analysis of blood and bone marrow}

The whole blood cell composition was measured using a haematology-analyzer (XP-300, Sysmex, Etten-Leur, the Netherlands). After measurement, erythrocyte lysis was performed and the blood cell composition was further determined using antibodies against CD11b, CD4, Ly6G, B220 (all BD Biosciences, Temse, the Netherlands), Ly6C (Miltenyi Biotec, Leiden, the Netherlands), CD3e, NK1.1 and CD8a (all eBioscience, Vienna, Austria). Bone marrow cell composition was analysed using antibodies versus Ly6G, Ly6C, B220, NK1.1, CD3e, CD11b and CD115 (eBioscience, Vienna, Austria). Flow cytometry was performed using a FACS Canto (BD Biosciences, Temse, the Netherlands) and analysed using FACSDiva software (v6.1.3, BD Biosciences, Temse, the Netherlands). 


\section{Histology and immunohistochemistry}

$5 \mu \mathrm{M}$ serial sections were cut from paraffin embedded aortic arches and stained with haematoxylin and eosin (H\&E). Plaque burden was analysed on these stainings using ImageJ software (v1.47). Total plaque burden was measured in the aortic arch and it's major branching points.

Antigen retrieval was performed by heating samples in target retrieval solution (Dako, Heverlee, Belgium). Subsequently, tissues were blocked and incubated with primary antibodies overnight as described: aSMA (1A4, Dako; 1:500); Mac3 (M3/84; Pharmingen, 1:200). After overnight incubation, sections were incubated for 1 hour with HRP-conjugated secondary antibodies and detected with NovaRED (Vector Labs, Amsterdam, the Netherlands). Apoptotic cells were detected using a terminal deoxynuceotidyl transferase dUTP nick-end labelling(TUNEL) kit (Roche, Woerden, the Netherlands) as described in the manufacturers protocol. Calcification was detected using Von Kossa and collagen fibers using picro sirius red stainings. Additionally, picro sirius red stained sections were also used for determination of the necrotic core size and the thickness of the fibrous cap. Fibrous caps were determined as the collagen rich area overlying the necrotic core. Images were captured using a DM400 microscope (Leica, Eindhoven, the Netherlands) and imaging software (LAS V, Eindhoven, the Netherlands).

\section{Statistical analysis}

All values are shown as mean \pm SEM unless stated differently. Statistical analysis was performed by 1-way ANOVA with Bonferroni post hoc test using PRISM software (GraphPad). Values of $P<0.05$ were considered statistically significant.

\section{Results}

A general overview of the study is displayed in figure $1 \mathrm{~A}$. When fed a standard chow diet, we did not observe established atherosclerotic plaques in the aortic arch and its main branches of either WT or DT mice. This observation is consistent with other reports $(16,17)$.

\section{Human diphteria toxin reduces medial VSMC number in SM22a-hDTr $/ \mathrm{ApoE}^{-/-}$mice}

VSMC of SM22a-hDTr ${ }^{+} / \mathrm{ApoE}^{-/}$mice are sensitive to human diphtheria toxin induced apoptosis whereas VSMC of SM22a-hDTr/ApoE $E^{-/}$mice are not. To this end, both SM22a-hDTr ${ }^{+}$/ $\mathrm{ApoE}^{-/}$and SM22a-hDTr/ApoE $\mathrm{E}^{-/}$mice were injected with DT and, consequently, DT injected prior to atherosclerosis, reduced VSMC numbers and allows us to study atherogenesis. Twelve weeks old animals were fed a normal chow diet and injected 3 times per week with DT for 3 weeks followed by 1 week recovery. After sacrifice, counting nuclei per $\mathrm{mm}^{2}$, a $50 \%$ reduction of cellularity was observed in the vessel wall, confirming that DT reduces medial VSMC number prior to the development of atherosclerosis (Figure 1B). Indeed, we observed no signs of atherosclerotic plaque formation after 3 weeks of injections. Next, mice received a western type diet for either 6 or 18 weeks to induce atherosclerosis. 
A 9 DT injections ( $\mathrm{T}=4$ weeks)

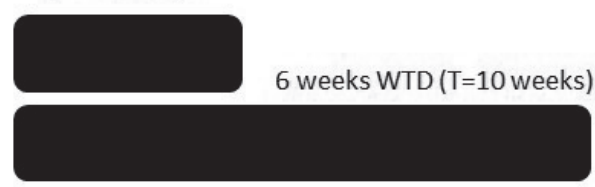

18 weeks WTD ( $\mathrm{T}=22$ weeks $)$

B

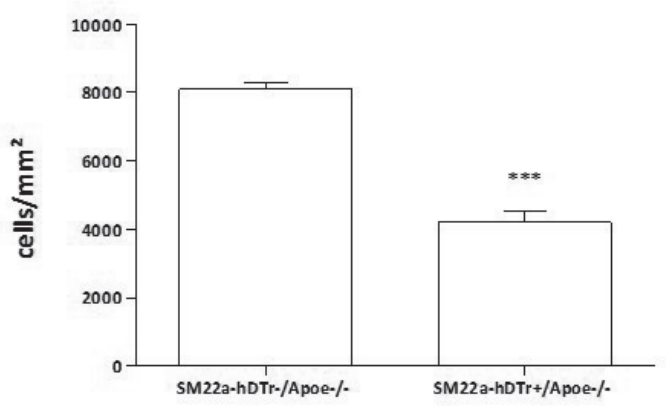

Figure 1. Experimental flow chart and SM22a-hDTr ${ }^{+} / \mathrm{Apoe}^{-/-}$model validation.

A. Timeline representing the study. All mice receive DT injections for 3 weeks followed by a 1 week washout. Subsequently, mice are switched to a western type diet for either 6 or 18 weeks. B. Cellularity of the vessel wall $\left(\right.$ cells $/ \mathrm{mm}^{2}$ ) was determined by quantifying the number of nuclei in the vessel wall after the wash out period. DT treatment invoked a $50 \%$ reduction in vessel wall cellularity

\section{Baseline characteristics of DT and WT mice}

Initially, we investigated parameters that affect atherogenesis in both SM22a-hDTr ${ }^{+} / \mathrm{ApoE}^{-1}$ and SM22a-hDTr ${ }^{-} /$ApoE $^{-/}$mice. At the time of sacrifice, the observed bodyweights after 6 or 18 weeks of western type diet did not significantly differ between SM22a-hDTr ${ }^{+} / \mathrm{ApoE}^{-/}$and SM22a-hDTr/ ApoE ${ }^{-1}$ mice (Table 1). Additionally, blood lipid levels were measured in mice sacrificed after 6 and 18 weeks of western type diet. Similarly, there were no significant differences in cholesterol and triglyceride levels between SM22a-hDTr $/ \mathrm{ApoE}^{-/}$and SM22a-hDTr/ApoE ${ }^{-/}$mice (Table 1). At the time of sacrifice, no organ abnormalities were observed in mice of both strains.

Following treatment with DT, circulating leukocyte profiles had not significantly altered, both in SM22a-hDTr SApoE $^{-/}$and SM22a-hDTr/ApoE ${ }^{-/}$mice (Supplemental table 1). Analysis of the leukocyte populations in bone marrow however did reveal a significant difference. After 6 weeks of western type diet, B-cell levels had increased in SM22a-hDTr $/ \mathrm{ApoE}^{-/}$mice as compared to SM22a-hDTr-/ApoE ${ }^{-/}$mice (Supplemental table 2). No significant differences were observed between other leukocyte populations in bone marrow from SM22a$\mathrm{hDTr}^{+} / \mathrm{ApoE}^{-/}$and SM22a-hDTr/ApoE ${ }^{-/}$mice. 
Table 1. Baseline characteristics of SM22a-hDTr $/ \mathrm{Apoe}^{-/-}$and SM22a-hDTr ${ }^{+} / \mathrm{ApoE}^{-/-}$mouse strains after 6 and 18 weeks of western type diet.

\begin{tabular}{|c|c|c|c|c|}
\hline & $\begin{array}{c}6 \text { weeks } \\
\text { SM22a-hDTr/ } \\
\text { ApoE }^{-/}\end{array}$ & $\begin{array}{c}6 \text { weeks } \\
\text { SM22a-hDTr }^{+} / \\
\text {ApoE }^{--}\end{array}$ & $\begin{array}{c}18 \text { weeks } \\
\text { SM22a-hDTr/ } \\
\text { ApoE }^{-/-}\end{array}$ & $\begin{array}{c}18 \text { weeks } \\
\text { SM22a-hDTr } \\
\text { ApoE }^{-/-}\end{array}$ \\
\hline Weight (g) & $29,00 \pm 1,30$ & $28,40 \pm 1,80$ & $33,20 \pm 3,60$ & $32,2 \pm 3,60$ \\
\hline Cholesterol (mM) & $5,77 \pm 0,70$ & $6,21 \pm 1,24$ & $5,21 \pm 0,80$ & $5,66 \pm 0,59$ \\
\hline Triglycerides (mM) & $1,49 \pm 0,30$ & $1,67 \pm 0,94$ & $1,47 \pm 0,53$ & $1,62 \pm 0,58$ \\
\hline
\end{tabular}

All values are represented as mean \pm SD. Significance was analysed using a one way ANOVA with Bonferroni's multiple comparison test.

\section{DT induced medial VSMC apoptosis accelerates early atherogenesis}

After 6 weeks of western type diet, atherosclerotic plaques were present in both SM22a$\mathrm{hDTr}^{+} / \mathrm{ApoE}^{-/}$and SM22a-hDTr/ApoE ${ }^{-/}$mice (Figures 2A and 2B). Quantification of the plaque size using $\mathrm{H} \& \mathrm{E}$ stained aortic sections showed a 2-fold larger atherosclerotic plaque burden in SM22a-hDTr ${ }^{+} / \mathrm{ApoE}^{-/}$mice as compared to SM22a-hDTr/ApoE ${ }^{-/}$littermates. After 18 weeks of western type diet (Figures 2A and 2B), a similar 2-fold, significantly increased plaque burden was observed in SM22a-hDTr $/ \mathrm{ApoE}^{-/}$mice.

\section{Reduced medial VSMC number is associated with features of plaque vulnerability}

In addition to atherosclerotic plaque burden, atherosclerotic plaques of both SM22a-hDTr / $\mathrm{ApoE}^{-/}$and $\mathrm{SM} 22 \mathrm{a}-\mathrm{hDTr}^{+} / \mathrm{ApoE}^{--}$mice were analysed for features of plaque vulnerability including apoptosis, fibrous cap thickness, collagen content, necrotic core size, plaque VSMC number and plaque inflammation.

TUNEL staining revealed no difference in the degree of apoptosis in plaques of either SM22a-hDTr/ApoE ${ }^{-1}$ or SM22a-hDTr ${ }^{+} / \mathrm{ApoE}^{-/}$mice after 6 or 18 weeks of western type diet (Figures $3 \mathrm{~A}$ and $3 \mathrm{C}$ ). Because DT treatment was performed prior to initiation of atherosclerosis, an increased degree of apoptosis is not to be expected in DT mice (Figures 3A and 3C) as apoptotic cells are normally cleared rapidly. In contrast, SM22a-hDTr ${ }^{+} / \mathrm{ApoE}^{-/}$mice displayed significantly thinner fibrous caps overlying the necrotic core (Figures 3B and 3D).

Additionally, after 6 weeks, plaques of SM22a-hDTr ${ }^{+} / \mathrm{ApoE}^{-/}$mice were composed of less collagen as compared to control mice (Figure 4A and 4B). After 18 weeks of western type diet, there no longer was a significant difference in plaque collagen content between SM22a-hDTr/ApoE ${ }^{-1}$ and SM22a-hDTr $/ \mathrm{ApoE}^{-/}$mice (Figure 4A). However, the thinned fibrous caps combined with reduced collagen point towards a more vulnerable plaque phenotype.

Subsequently, the VSMC content of atherosclerotic plaques in both SM22a-hDTr ${ }^{+} / \mathrm{ApoE}^{-1-}$ and SM22a-hDTr/ApoE ${ }^{-/}$mice after 6 or 18 weeks of western type diet was analysed. Here, after both 6 and 18 weeks, we found significantly less VSMC in plaques of SM22a-hDTr ${ }^{+}$/ $\mathrm{ApoE}^{-/}$mice as compared to SM22a-hDTr/ApoE $\mathrm{E}^{-/}$mice (Figures 5A and 5C). Contrastingly, 


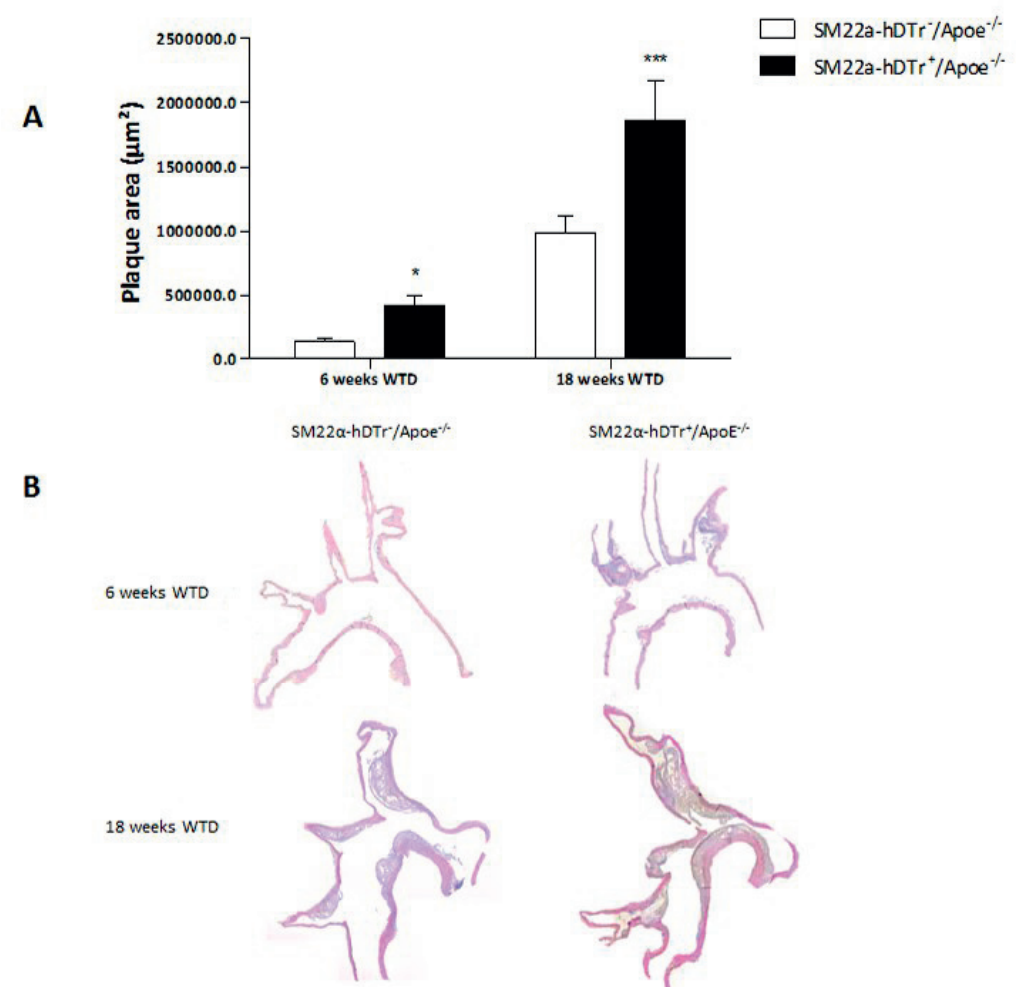

Figure 2. Loss of VSMC causes formation of larger atherosclerotic plaques.

Plaque area was determined throughout the whole aorta by quantification of the surface area of consecutive sections (A). After both 6 and 18 weeks of western type diet, atherosclerotic plaques in DT mice are significantly larger as compared to WT mice. Representative images of the aortic arch and main branch points are shown (B). Images were taken at $10 x$ magnification. All values are represented as mean \pm SEM $(n \geq 8)$ and considered statistically significant if $\mathrm{p} \leq 0.05$.

atherosclerotic plaques of SM22a-hDTr ${ }^{+} / \mathrm{ApoE}^{-/}$mice displayed an increased amount of Mac3 positive staining, indicative of a more inflammatory plaque phenotype, in comparison to SM22a-hDTr/ApoE ${ }^{-/}$mice (Figures 5B and 5D). After 18 weeks of western type diet, the difference in Mac3 positivity between atherosclerotic plaques of SM22a-hDTr ${ }^{+}$/ $\mathrm{ApoE}^{-/}$and SM22a-hDTr/ApoE ${ }^{-/}$mice had disappeared.

After 6 weeks of western type diet, we could not observe a necrotic core in either SM22a$\mathrm{hDTr}^{+} / \mathrm{ApoE}^{-/}$or SM22a-hDTr/ApoE /- mice. After 18 weeks however, necrotic cores were present in atherosclerotic plaques of both SM22a-hDTr $/ \mathrm{ApoE}^{-/}$and SM22a-hDTr/ApoE ${ }^{-/}$mice. $\mathrm{SM} 22 \mathrm{a}-\mathrm{hDTr}^{+} / \mathrm{ApoE}^{-/}$mice had necrotic cores compromising a significantly larger fraction of the total atherosclerotic plaque area as compared to SM22a-hDTr/ApoE ${ }^{-1}$ littermates (Figures 6A and 6C). Because of the effect of plaque calcification on atherosclerotic plaque stability and due to the proven link between apoptosis and calcification, we analysed atherosclerotic plaque calcification in both SM22a-hDTr/ApoE $E^{-/}$and SM22a-hDTr ${ }^{+} / \mathrm{ApoE}^{-/}$mice 

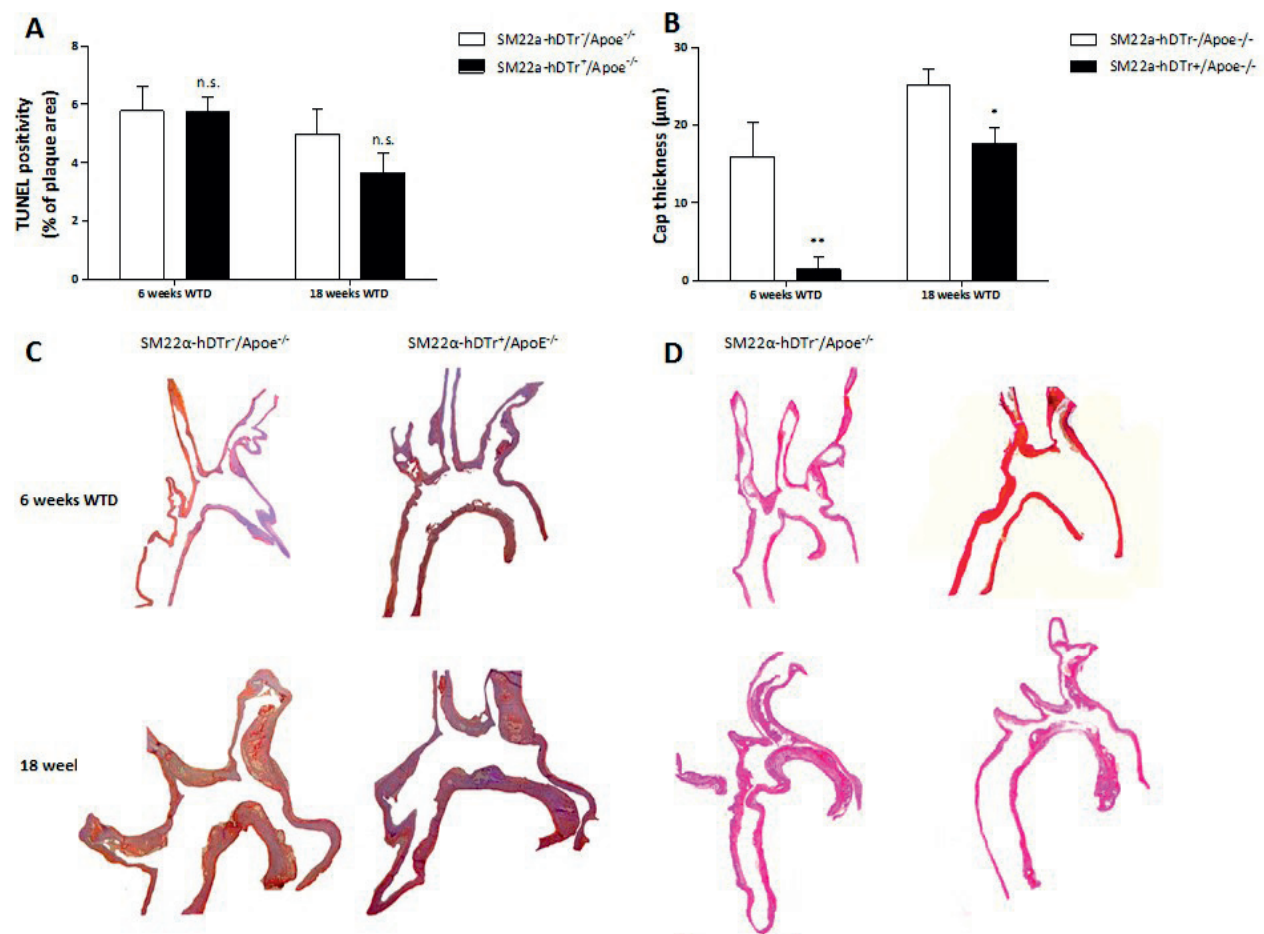

Figure 3. Loss of VSMC leads to thinned fibrous caps over atherosclerotic plaques but does not cause increased apoptosis.

Representative images of TUNEL (C) and picro sirius red (D) stained aortic arches of both DT and WT mice are shown after 6 and 18 weeks. The relative content of TUNEL positive cells (A) in the aortic arch and main branch points was analysed by quantitative immunohistochemistry. Picro sirius red stained sections were assessed for measuring the thickness of the fibrous cap overlying the necrotic core (B). Images were taken at 10x magnification. All values are represented as mean $\pm \operatorname{SEM}(n \geq 8)$ and considered statistically significant if $p \leq 0.05$.

(Figures 6B and 6D). After 6 weeks of western type diet, no calcification was detectable in both SM22a-hDTr ${ }^{+} / \mathrm{ApoE}^{-/}$or SM22a-hDTr/ApoE $/$mice (data not shown). After 18 weeks of western type diet, calcification could be detected. However, there was no significant difference between SM22a-hDTr ${ }^{+} / \mathrm{ApoE}^{-/}$and SM22a-hDTr/ApoE ${ }^{-/}$mice (Figure 6B and 6D).

\section{Discussion}

In this paper, we studied the role of medial VSMC in atherogenesis using SM22a-hDTr ${ }^{+}$/ ApoE $^{-/}$mice. Using this model, VSMC-specific apoptosis of medial VSMC in aorta and other large vessels was induced to study the contribution of the tunica media in atherosclerosis. We have demonstrated that a loss of VSMC results in larger atherosclerotic plaques. Additionally, these plaques were found to have a vulnerable phenotype. They had a thinner 
A
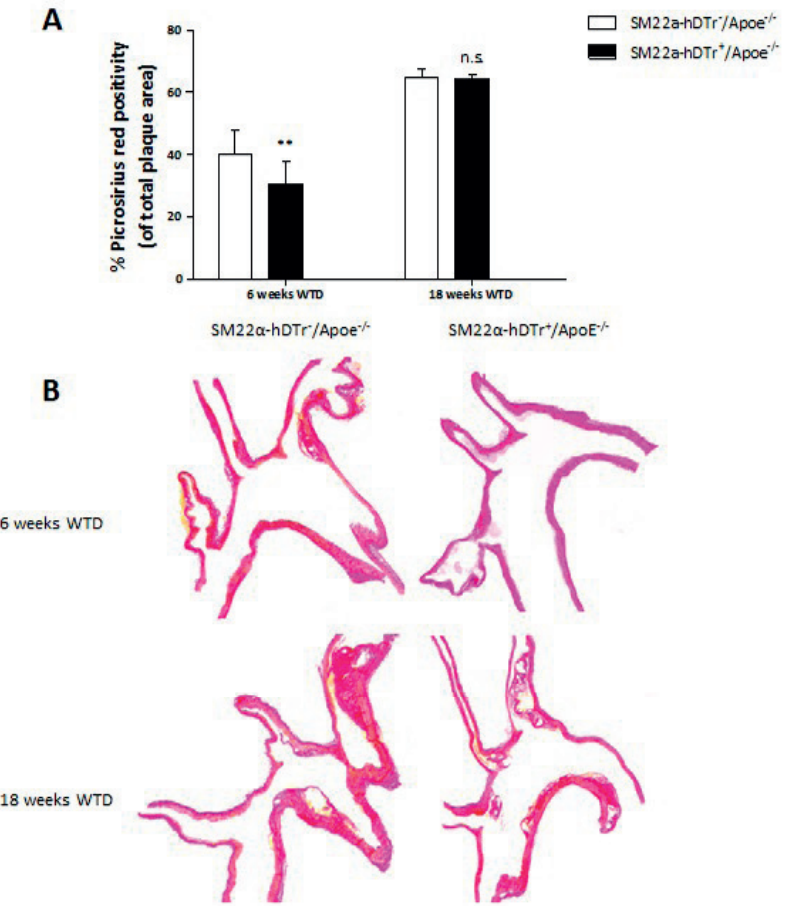

Figure 4. Loss of VSMC leads to a reduction in collagen content of atherosclerotic plaques after 6 weeks but not 18 weeks of atherogensis.

Representative images of picro Sirius red stained aortic arches of both DT and WT mice are shown after 6 and 18 weeks (B). The amount of collagen in atherosclerotic plaques of both DT and WT mice was determined using quantitative histochemistry (A). Images were taken at 10x magnification. All values are represented as mean \pm SEM ( $n \geq 8)$ and considered statistically significant if $p \leq 0.05$.

fibrous cap, a larger necrotic core, increased inflammation and reduced numbers of VSMC in the atherosclerotic plaque.

Our observation that reducing VSMC in the medial layer prior to atherogenesis accelerates plaque growth, extends the findings of Clarke et al. who demonstrated that inducing VSMC apoptosis in established atherosclerotic plaques increased plaque size, induced features of vulnerability, accelerates medial degeneration and enhanced plaque calcification $(12,13)$.

The accelerated growth of atherosclerotic plaques in SM22a-hDTr${ }^{+} / \mathrm{ApoE}^{-/}$mice (figure 2) might be due to a number of reasons. Firstly, VSMC may be able to slow down plaque growth by formation of a thick, fibrous cap (13). This can slow down monocyte and macrophage infiltration into the atherosclerotic plaque and reduce plaque inflammation and necrotic core formation (13). As shown in this report, atherosclerotic plaques of SM22a$\mathrm{hDTr}^{-} / \mathrm{ApoE}^{-/}$mice have thicker caps (figure 3B and 3D), a smaller necrotic core (figure 6A and 6D) and a less inflammatory phenotype (figure 4B and 4D) when compared to ath- 

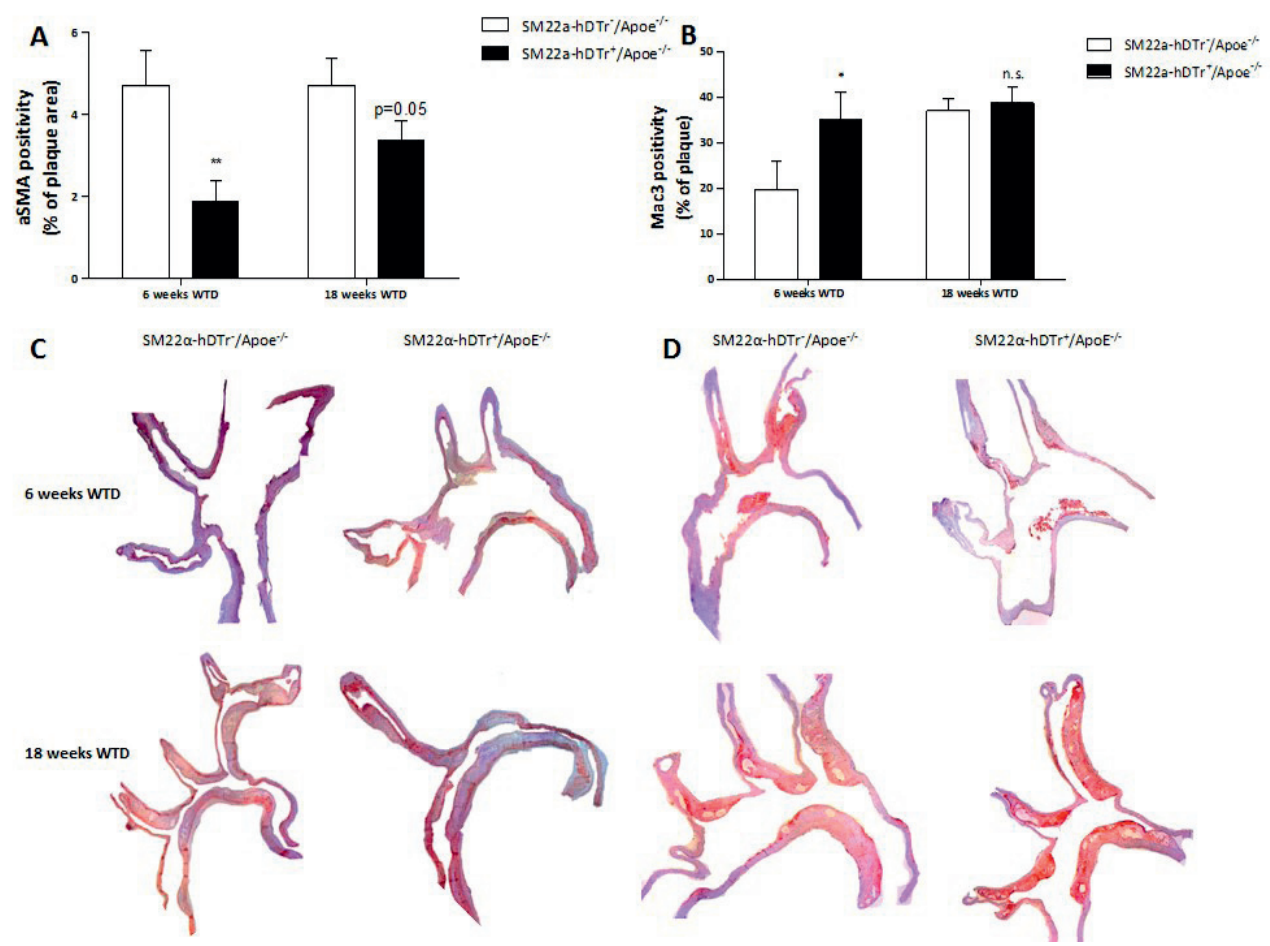

Figure 5 Loss of VSMC accelerates plaque inflammation after 6 weeks but not 18 weeks and significantly reduces plaque VSMC content.

Representative images of aSMA (B) and MAC3 (D) stained aortic arches of DT and WT mice are shown after 6 and 18 weeks. The relative content of aSMA positive (A) and MAC3 positive (B) cells in the aortic arch and its main branching points was analysed using quantitative immunohistochemistry. Images were taken at 10x magnification. All values are represented as mean \pm SEM $(n \geq 8)$ and considered statistically significant if $p \leq 0.05$.

erosclerotic plaques of SM22a-hDTr ${ }^{+} / \mathrm{ApoE}^{-/-}$mice. Fibrous cap thickness is determined by the presence of VSMC in the fibrous cap overlying the necrotic core and the extracellular matrix they deposit $(18,19)$. Our data support this observation as atherosclerotic plaques of SM22a-hDTr ${ }^{+} / \mathrm{ApoE}^{-/-}$mice show significantly less aSMA positivity (figure 5A and 5C), a much thinner fibrous cap (figure 3B and 3D) and reduced collagen content (figure 4).

Secondly, VSMC are efficient efferocytes and contribute to clearance of apoptotic remnants in their environment (20). Due to their high plasticity, VSMC can switch to a macrophage-like phenotype expressing typical macrophage markers like CD68 and Mac2 (21-23). However, during hyperlipidaemia, defective phagocytosis is induced when VSMC switch to macrophage like cells accompanied by IL-1 driven inflammation $(24,25)$. Reduced efferocytosis has been demonstrated to promote atherosclerotic plaque growth $(26,27)$. As significantly less VSMC are present in plaques of SM22a-hDTr ${ }^{+} / \mathrm{ApoE}^{--}$mice (figure 5A and 5C), and efferocytosis of apoptotic cells is reduced due to the conditions in the atherosclerotic plaque, necrotic core formation (figure 6A and 6C) and atherosclerotic 
A

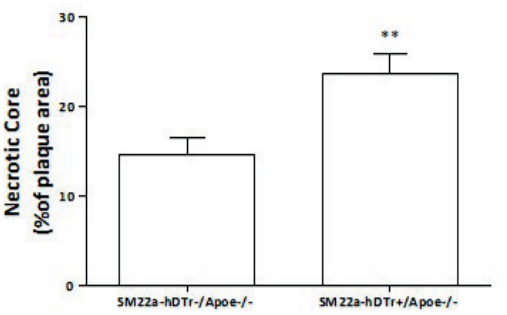

C

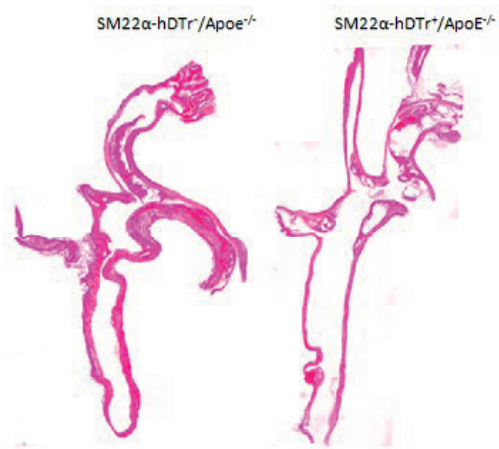

B

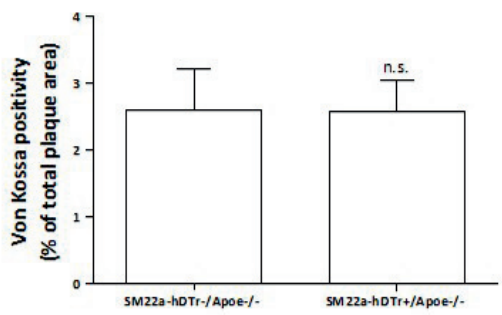

D

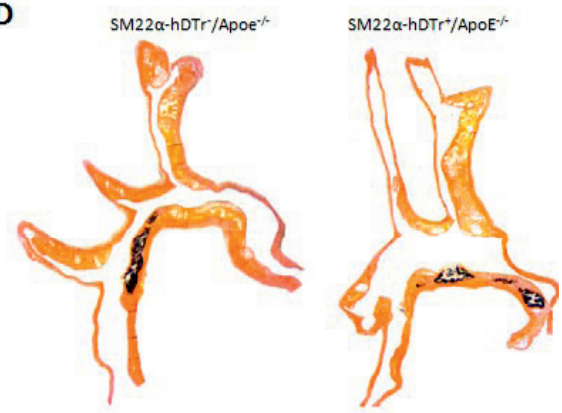

Figure 6. Loss of VSMC causes larger necrotic cores after 18 weeks of atherogenesis but does not increase plaque calcification.

Representative images of picro Sirius red (B) and Von Kossa stained aortic arches of DT and WT mice are shown after 18 weeks. The necrotic core size was determined on picro Sirius red stained aortic arches and quantified using analytical histochemistry (A). After 6 weeks of atherogenesis, no necrotic cores were present. The relative content of plaque calcification in the aortic arch and its main branching points was determined using quantitative histochemistry (C). All values are represented as mean $\pm \operatorname{SEM~(~} n \geq 8)$ and considered statistically significant if $p \leq 0.05$

plaque development (figure 2) are accelerated. The data presented in this manuscript are in support of this mechanism.

Aging of the vessel wall is accompanied by a loss of aortic elasticity, increased deposition of calcium in the media and vascular remodelling. Moreover, patients suffering from chronic kidney disease and diabetes have more medial calcification and have a higher cardiovascular morbidity and mortality (28). The prevalence of atherosclerosis increases with increasing age, chronic kidney disease stage and diabetes $(29,30)$. Blumenthal et al. demonstrated that calcification and degeneration of the media is an important risk factor for developing atherosclerosis in the affected areas (14). Clarke et al. demonstrated that inducing apoptosis in established plaques induced medial degeneration and vascular calcification. Hence, this may present as an additional mechanism for accelerating plaque formation. Here, we have also shown that reducing medial VSMC number (figure 1B) induces accelerated development of atherosclerosis. 
Contrastingly, we did not observe an increase in calcification of atherosclerotic plaques of both SM22a-hDTr $/ \mathrm{ApoE}^{-/}$and SM22a-hDTr/ApoE $E^{--}$mice (Figure 6). Apoptotic cell remnants like apoptotic bodies serve as a nidus for vascular calcification (7, 31). Additionally, clearance of apoptotic cells in the atherosclerotic plaque is severely impaired, in part due to oxidative stress and cytoplasmic saturation of indigestible components (25). Hence, the pro-calcifying environment in atherosclerotic plaques, combined with poor clearance of apoptotic bodies form a strong stimulus for calcification in this situation $(32,33)$. In our study, apoptosis is induced prior to atherogenesis. Under physiological conditions, apoptotic cells are rapidly cleared (34). Hence, the apoptotic bodies do not serve as hotspots for calcification. Additionally, there is no increased calcification pressure at the time of apoptosis. Therefore, in our study, there is no increased calcification potential in atherosclerotic plaques of SM22a-hDTr ${ }^{+} / \mathrm{ApoE}^{\%}$ mice as compared to SM22a-hDTr/ApoE ${ }^{\%}$ mice during atherogenesis.

Strikingly, we and others achieved a reduction by $50 \%$ of the medial cell count $(12,35$, 36). It remains unclear as to why a greater reduction of VSMC number cannot be achieved. One explanation might be due to VSMC heterogeneity $(37,38)$. In the vessel wall, VSMC are normally in a contractile phenotype. However, upon exposure to stress factors or due to degradation of the extracellular matrix, VSMC can phenotypically switch towards a synthetic or osteogenic phenotype (2). This is accompanied by the upregulation of calcification related proteins and the loss of the contractile cytoskeleton (2). Additionally, the expression of the hDTr receptor is dependent on the SM22a promotor. Considering the plasticity of VSMC, it is possible that some VSMC do not express SM22a and, consequently lack hDTr and thus rendering these VSMC immune to DT. Remarkably, the contractile response of DTtreated vessels is not lost after treatment with DT despite the loss of (contractile) VSMC due to apoptosis or phenotypic switching. A possible explanation for this is that fewer VSMC generate an increased force to compensate for the loss of VSMC (12).

Initially, VSMC were thought to promote atherosclerotic plaque growth by migrating into the plaque and proliferating causing the plaque to reduce the luminal area $(12,13$, 30). However, our study demonstrates that medial VSMC significantly contribute to the inhibition and stability of atherosclerotic plaques. This may occur through several different mechanisms including reducing macrophage infiltration and plaque inflammation, efferocytosis of apoptotic cells and by preventing vascular remodeling. Additionally, VSMC can dampen inflammation by producing the anti-inflammatory cytokine IL-10 (39). Our work highlights the need for further studies to unravel which of these mechanisms are driving forces behind accelerated atherosclerosis as a consequence of reduced medial VSMC and increased apoptosis. Additionally, our data highlight the need to reconsider the use of therapies aiming to reduce restenosis by inducing VSMC apoptosis as these therapies might have drastic effects on the stability of developing and established atherosclerotic plaques in patients (40-42). 


\section{References}

1. Wang H, Naghavi M, Allen C, Barber RM, Bhutta ZA, Carter A, et al. Global, regional, and national life expectancy, all-cause mortality, and cause-specific mortality for 249 causes of death, 1980\&\#x2013;2015: a systematic analysis for the Global Burden of Disease Study 2015. The Lancet.388(10053):1459-544.

2. Willems BA, Vermeer C, Reutelingsperger CP, Schurgers LJ. The realm of vitamin K dependent proteins: shifting from coagulation toward calcification. Mol Nutr Food Res. 2014 Aug;58(8):162035.

3. Owens GK, Kumar MS, Wamhoff BR. Molecular regulation of vascular smooth muscle cell differentiation in development and disease. Physiol Rev. 2004 Jul;84(3):767-801.

4. Shanahan CM, Crouthamel MH, Kapustin A, Giachelli CM. Arterial calcification in chronic kidney disease: key roles for calcium and phosphate. Circ Res. 2011 Sep 2;109(6):697-711.

5. Gerthoffer WT. Mechanisms of vascular smooth muscle cell migration. Circ Res. 2007 Mar 16; 100(5):607-21.

6. Chatrou ML, Winckers K, Hackeng TM, Reutelingsperger CP, Schurgers LJ. Vascular calcification: the price to pay for anticoagulation therapy with vitamin K-antagonists. Blood reviews. 2012; 26(4):155-66.

7. Proudfoot D, Skepper JN, Hegyi L, Bennett MR, Shanahan CM, Weissberg PL. Apoptosis regulates human vascular calcification in vitro: evidence for initiation of vascular calcification by apoptotic bodies. Circ Res. 2000 Nov 24;87(11):1055-62.

8. Pasterkamp G, Wensing PJ, Post MJ, Hillen B, Mali WP, Borst C. Paradoxical arterial wall shrinkage may contribute to luminal narrowing of human atherosclerotic femoral arteries. Circulation. 1995 Mar 01;91(5):1444-9.

9. Nishioka T, Luo H, Eigler NL, Berglund H, Kim CJ, Siegel RJ. Contribution of inadequate compensatory enlargement to development of human coronary artery stenosis: an in vivo intravascular ultrasound study. J Am Coll Cardiol. 1996 Jun;27(7):1571-6.

10. Smits PC, Bos L, Quarles van Ufford MA, Eefting FD, Pasterkamp G, Borst C. Shrinkage of human coronary arteries is an important determinant of de novo atherosclerotic luminal stenosis: an in vivo intravascular ultrasound study. Heart. 1998 Feb;79(2):143-7.

11. Ross R. Atherosclerosis-an inflammatory disease. New England Journal of Medicine. 1999; 340(2):115-26.

12. Clarke MC, Figg N, Maguire JJ, Davenport AP, Goddard M, Littlewood TD, et al. Apoptosis of vascular smooth muscle cells induces features of plaque vulnerability in atherosclerosis. Nat Med. 2006 Sep;12(9):1075-80.

13. Clarke MC, Littlewood TD, Figg N, Maguire JJ, Davenport AP, Goddard M, et al. Chronic apoptosis of vascular smooth muscle cells accelerates atherosclerosis and promotes calcification and medial degeneration. Circ Res. 2008 Jun 20;102(12):1529-38.

14. Blumenthal HT, Lansing Al, Wheeler PA. Calcification of the Media of the Human Aorta and Its Relation to Intimal Arteriosclerosis, Ageing and Disease. Am J Pathol. 1944 Jul;20(4):665-87. 
15. Kothapalli D, Liu SL, Bae YH, Monslow J, Xu T, Hawthorne EA, et al. Cardiovascular protection by ApoE and ApoE-HDL linked to suppression of ECM gene expression and arterial stiffening. Cell Rep. 2012 Nov 29;2(5):1259-71.

16. Nakashima Y, Plump AS, Raines EW, Breslow JL, Ross R. ApoE-deficient mice develop lesions of all phases of atherosclerosis throughout the arterial tree. Arterioscler Thromb. 1994 Jan;14(1): $133-40$.

17. Meir KS, Leitersdorf E. Atherosclerosis in the Apolipoprotein E-Deficient Mouse. A Decade of Progress. 2004;24(6):1006-14.

18. Ross R. The pathogenesis of atherosclerosis: a perspective for the 1990s. Nature. 1993 Apr 29; 362(6423):801-9.

19. Newby AC, Zaltsman AB. Fibrous cap formation or destruction-the critical importance of vascular smooth muscle cell proliferation, migration and matrix formation. Cardiovascular Research. 1999;41(2):345-60.

20. Bennett MR, Gibson DF, Schwartz SM, Tait JF. Binding and phagocytosis of apoptotic vascular smooth muscle cells is mediated in part by exposure of phosphatidylserine. Circ Res. 1995 Dec; 77(6):1136-42.

21. Feil S, Fehrenbacher B, Lukowski R, Essmann F, Schulze-Osthoff K, Schaller M, et al. Transdifferentiation of Vascular Smooth Muscle Cells to Macrophage-Like Cells During AtherogenesisNovelty and Significance. Circulation research. 2014;115(7):662-7.

22. Rong JX, Shapiro M, Trogan E, Fisher EA. Transdifferentiation of mouse aortic smooth muscle cells to a macrophage-like state after cholesterol loading. Proceedings of the National Academy of Sciences. 2003;100(23):13531-6.

23. Gomez D, Owens GK. Smooth muscle cell phenotypic switching in atherosclerosis. Cardiovascular Research. 2012:cvs115.

24. Clarke MC, Talib S, Figg NL, Bennett MR. Vascular Smooth Muscle Cell Apoptosis Induces Interleukin-1-Directed Inflammation. Circulation research. 2010;106(2):363-72.

25. Schrijvers DM, De Meyer GR, Kockx MM, Herman AG, Martinet W. Phagocytosis of apoptotic cells by macrophages is impaired in atherosclerosis. Arteriosclerosis, thrombosis, and vascular biology. 2005;25(6):1256-61.

26. Ait-Oufella H, Kinugawa K, Zoll J, Simon T, Boddaert J, Heeneman S, et al. Lactadherin deficiency leads to apoptotic cell accumulation and accelerated atherosclerosis in mice. Circulation. 2007 Apr 24;115(16):2168-77.

27. Thorp E, Cui D, Schrijvers DM, Kuriakose G, Tabas I. Mertk receptor mutation reduces efferocytosis efficiency and promotes apoptotic cell accumulation and plaque necrosis in atherosclerotic lesions of apoe-/- mice. Arterioscler Thromb Vasc Biol. 2008 Aug;28(8):1421-8.

28. Lanzer P, Boehm M, Sorribas V, Thiriet M, Janzen J, Zeller T, et al. Medial vascular calcification revisited: review and perspectives. European Heart Journal. 2014:ehu163.

29. Sarnak MJ, Levey AS, Schoolwerth AC, Coresh J, Culleton B, Hamm LL, et al. Kidney disease as a risk factor for development of cardiovascular disease. Circulation. 2003;108(17):2154-69. 
30. Kannel WB, McGee DL. Diabetes and cardiovascular disease: the Framingham study. Jama. 1979; 241(19):2035-8.

31. Proudfoot D, Skepper J, Hegyi L, Farzaneh-Far A, Shanahan C, Weissberg P. The role of apoptosis in the initiation of vascular calcification. Zeitschrift für Kardiologie. 2001;90(3):43-6.

32. Iyemere VP, Proudfoot D, Weissberg PL, Shanahan CM. Vascular smooth muscle cell phenotypic plasticity and the regulation of vascular calcification. J Intern Med. 2006 Sep;260(3):192-210.

33. Schurgers LJ, Joosen IA, Laufer EM, Chatrou ML, Herfs M, Winkens MH, et al. Vitamin K-antagonists accelerate atherosclerotic calcification and induce a vulnerable plaque phenotype. PLoS One. 2012;7(8):e43229.

34. Platt N, da Silva RP, Gordon S. Recognizing death: the phagocytosis of apoptotic cells. Trends in cell biology. 1998;8(9):365-72.

35. Clarke MC, Littlewood TD, Figg N, Maguire JJ, Davenport AP, Goddard M, et al. Chronic apoptosis of vascular smooth muscle cells accelerates atherosclerosis and promotes calcification and medial degeneration. Circulation research. 2008;102(12):1529-38.

36. Yu H, Clarke MC, Figg N, Littlewood TD, Bennett MR. Smooth muscle cell apoptosis promotes vessel remodeling and repair via activation of cell migration, proliferation, and collagen synthesis. Arterioscler Thromb Vasc Biol. 2011 Nov;31(11):2402-9.

37. Bennett MR, Sinha S, Owens GK. Vascular Smooth Muscle Cells in Atherosclerosis. Circ Res. 2016 Feb 19;118(4):692-702.

38. Shankman LS, Gomez D, Cherepanova OA, Salmon M, Alencar GF, Haskins RM, et al. KLF4dependent phenotypic modulation of smooth muscle cells has a key role in atherosclerotic plaque pathogenesis. Nat Med. 2015 Jun;21(6):628-37.

39. Kim HY, Cha HJ, Kim HS. CCL5 upregulates IL-10 expression and partially mediates the antihypertensive effects of IL-10 in the vascular smooth muscle cells of spontaneously hypertensive rats. Hypertens Res. 2015 Oct;38(10):666-74.

40. Marx SO, Jayaraman T, Go LO, Marks AR. Rapamycin-FKBP inhibits cell cycle regulators of proliferation in vascular smooth muscle cells. Circ Res. 1995 Mar;76(3):412-7.

41. Marx SO, Totary-Jain H, Marks AR. Vascular smooth muscle cell proliferation in restenosis. Circ Cardiovasc Interv. 2011 Feb 1;4(1):104-11.

42. Aizawa Y, Kawabe J-i, Hasebe N, Takehara N, Kikuchi K. Pioglitazone enhances cytokine-induced apoptosis in vascular smooth muscle cells and reduces intimal hyperplasia. Circulation. 2001; 104(4):455-60. 
Supplemental table 1. Flow cytometric analysis of blood after 6 and 18 weeks of western type diet.

\begin{tabular}{|c|c|c|c|c|c|c|}
\hline $\begin{array}{l}\text { Celltype } \\
\text { (\% of viable } \\
\text { cells) }\end{array}$ & $\begin{array}{c}\text { Subpopulation } \\
\text { ( } \% \text { of parent) }\end{array}$ & $\begin{array}{c}6 \text { weeks } \\
\text { SM22a-hDTr/ } \\
\text { ApoE }^{-1}\end{array}$ & $\begin{array}{c}6 \text { weeks } \\
\text { SM22a-hDTr } / \\
\text { ApoE }^{--}\end{array}$ & $\begin{array}{c}18 \text { weeks } \\
\text { SM22a-hDTr/ } \\
\text { ApoE }{ }^{--}\end{array}$ & $\begin{array}{c}18 \text { weeks } \\
\text { SM22a-hDTr }^{+} / \\
\text {ApoE }^{-{ }^{-}}\end{array}$ & $\mathbf{P}$ \\
\hline B-cells & & $37,80 \pm 1,19$ & $10,13 \pm 21,08$ & $25,31 \pm 13,20$ & $28,59 \pm 9,25$ & n.s. \\
\hline \multirow[t]{3}{*}{ T-cells } & & $10,30 \pm 2,25$ & $12,79 \pm 3,40$ & $8,90 \pm 5,07$ & $7,64 \pm 2,34$ & n.s. \\
\hline & CD4+T-cells & $54,56 \pm 2,61$ & $52,31 \pm 2,87$ & $47,85 \pm 4,30$ & $46,25 \pm 4,22$ & n.s. \\
\hline & CD8+T-cells & $51,35 \pm 3,40$ & $43,68 \pm 6,72$ & $55,96 \pm 7,11$ & $52,28 \pm 6,00$ & n.s. \\
\hline NK-cells & & $5,62 \pm 1,43$ & $4,10 \pm 1,21$ & $3,55 \pm 1,24$ & $3,15 \pm 0,73$ & n.s. \\
\hline Granulocytes & & $65,35 \pm 9,12$ & $69,21 \pm 15,86$ & $66,64 \pm 13,30$ & $67,55 \pm 9,24$ & n.s. \\
\hline \multirow[t]{4}{*}{ Monocytes } & & $29,28 \pm 7,55$ & $24,95 \pm 13,12$ & $27,49 \pm 11,36$ & $27,93 \pm 7,95$ & n.s. \\
\hline & Ly6C low & $28,78 \pm 13,15$ & $22,04 \pm 7,59$ & $22,28 \pm 9,75$ & $17,43 \pm 6,48$ & n.s. \\
\hline & Ly6C medium & $6,03 \pm 1,50$ & $6,71 \pm 2,84$ & $3,15 \pm 1,03$ & $3,47 \pm 0,95$ & n.s. \\
\hline & Ly6C high & $53,97 \pm 14,33$ & $55,25 \pm 15,78$ & $59,00 \pm 13,35$ & $67,00 \pm 11,41$ & n.s. \\
\hline
\end{tabular}

All values are represented as mean \pm SD. Significance was analysed using a one way ANOVA with Bonferroni's multiple comparison test.

Supplemental table 2. Flow cytometric analysis of bone marrow after 6 and 18 weeks of western type diet.

\begin{tabular}{|c|c|c|c|c|c|c|}
\hline $\begin{array}{l}\text { Celltype } \\
\text { (\% of viable } \\
\text { cells) }\end{array}$ & $\begin{array}{l}\text { Subpopulation } \\
\text { ( } \% \text { of parent) }\end{array}$ & $\begin{array}{c}6 \text { weeks } \\
\text { SM22a-hDTr/ } \\
\text { ApoE }{ }^{-/}\end{array}$ & $\begin{array}{c}6 \text { weeks } \\
\text { SM22a-hDTr } / \\
\text { ApoE }{ }^{--}\end{array}$ & $\begin{array}{c}18 \text { weeks } \\
\text { SM22a-hDTr/ } \\
\text { ApoE }^{-/-}\end{array}$ & $\begin{array}{c}18 \text { weeks } \\
\text { SM22a-hDTr } / \\
\text { ApoE }^{--}\end{array}$ & $\mathbf{P}$ \\
\hline B-cells & & $6,54 \pm 3,61$ & $10,46 \pm 3,54$ & $4,71 \pm 1,60$ & $5,89 \pm 2,48$ & $p<0,05$ \\
\hline NK-cells & & $0,36 \pm 0,17$ & $0,45 \pm 0,12$ & $0,33 \pm 0,29$ & $0,32 \pm 0,14$ & n.s. \\
\hline Granulocytes & & $53,54 \pm 6,22$ & $54,34 \pm 4,00$ & $50,41 \pm 5,84$ & $48,47 \pm 7,99$ & n.s. \\
\hline \multirow[t]{3}{*}{ Monocytes } & & $10,58 \pm 3,44$ & $12,91 \pm 3,68$ & $9,63 \pm 3,91$ & $10,37 \pm 3,06$ & n.s. \\
\hline & Ly6C low & $8,74 \pm 4,42$ & $11,97 \pm 3,61$ & $10,23 \pm 5,64$ & $14,52 \pm 6,32$ & n.s. \\
\hline & Ly6C high & $79,10 \pm 15,94$ & $74,13 \pm 14,44$ & $81,46 \pm 11,32$ & $75,88 \pm 10,64$ & n.s. \\
\hline T-cells & & $1,36 \pm 0,57$ & $1,72 \pm 0,71$ & $1,41 \pm 0,70$ & $1,66 \pm 0,51$ & n.s. \\
\hline
\end{tabular}

All values are represented as mean \pm SD. Significance was analysed using a one way ANOVA with Bonferroni's multiple comparison test. 



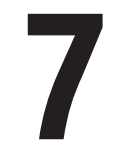

General Discussion 



\section{Key findings in perspective}

Cardiovascular disease is the leading cause of death in the western world (1, 2). Additionally, the number of deaths in developing countries, attributable to cardiovascular disease, continues to rise. Two of the most dominant, underlying causes of cardiovascular disease, contributing to the majority of cardiovascular morbidity and mortality, are atherosclerosis and arteriosclerosis (1, 3).

Vascular calcification was long considered as a passive, end stage process unamendable by therapeutic intervention (4). However, nowadays it is acknowledged as a highly regulated, pathobiological process involving multiple proteins, molecules and cells displaying similarities to embryonic ossification (3). Multiple key mechanisms are involved which can lead to vascular calcification: the loss of calcification inhibitors, circulating mineral complexes, apoptosis and extracellular vesicles and phenotypical transdifferentiation of vascular smooth muscle cells (VSMC) $(3,5)$. Vascular calcification can occur at two distinct vascular sites, dictated by its anatomical location: intimal as atherosclerosis or medial as arteriosclerosis $(6,7)$. Both intimal and medial calcification can occur in one and the same patient at the same vascular location. It is even hypothesized that medial calcification may serve as a nidus for developing atherosclerosis (8). Atherosclerosis is a chronic, inflammatory process caused by lodging of lipids underneath the endothelial layer and involves macrophages, endothelial cells and VSMC. Calcification has different effects on atherosclerosis depending on the location, size and quantity. Macrocalcification, i.e. > $50 \mu \mathrm{m}$ in size, is thought to have stabilizing effects and generally is found in advanced atherosclerotic plaques. Hence, quantification of arterial calcification by CT, with a resolution of $>200 \mu \mathrm{m}$, is an excellent method for determining atherosclerotic burden $(9,10)$. Microcalcification ( $<50 \mu \mathrm{m}$ in size), defined as small, spotty areas is thought to destabilize plaques. It remains challenging to detect microcalcification using conventional imaging modalities due to the limited spatial resolution (11). However, various new methods based on imaging probes (e.g. sodium fluoride-18, PET-imaging) or Raman spectroscopy are in development (12, 13). In the future, these methods may allow for separating vulnerable from non-vulnerable lesions and assist clinicians in prioritizing certain interventions over others. In arteriosclerosis, mineral deposits are formed along the elastin fibres of the vessel wall (14). It can occur throughout the entire vascular tree and is mainly observed in the elderly, diabetes mellitus and chronic kidney disease (CKD) patients $(15,16)$. Whereas multiple cell types are involved in atherosclerosis, arteriosclerosis is primarily driven by VSMC (17).

The research presented in this thesis focusses on the role of VSMC in the development of vascular disease and how VSMC are affected and contribute to calcification. Our findings demonstrated in this thesis might open up novel options for prevention of vascular calcification and intervention during its development. In chapter 3, we investigated effects of smoking on atherosclerotic plaque calcification in a patient cohort using ex vivo microcomputed tomography and in vitro analysis of nicotine treated VSMC. In chapters 4 and 5, we have looked into the role of a recently discovered, vitamin-K dependent protein, Ucma 
in vitro using VSMC culture models and tissue explants. In chapter 6, we used an ApoE ${ }^{-1-}$ mouse model in which we specifically induced VSMC apoptosis by injections with human diphtheria toxin. This allowed us to deplete VSMC prior to atherogenesis and study the effect of reduced medial VSMC on the development and stability of atherosclerotic plaques. The key findings of this thesis are:

I. Smoking induces microcalcification in atherosclerotic plaques (Chapter 3).

II. Nicotine induces microcalcification by increasing oxidative stress and secretion of exosomes in VSMC (Chapter $\mathbf{3}$ ).

III. Ucma acts as a calcification inhibitor in the human cardiovascular system (Chapter 4)

IV. Ucma deficiency causes VSMC to calcify more in vitro via accelerated osteogenic differentiation (Chapter 5)

V. Medial VSMC have a stabilizing effect on atherosclerotic plaques and inhibit atherosclerotic plaque formation (Chapter $\mathbf{6}$ )

\section{Nicotine induces microcalcifications in human atherosclerosis by increasing oxidative stress and exosome secretion}

The presence of vascular calcification is associated with increased cardiovascular risk (18, 19). However, the effect of vascular calcification on the stability of atherosclerotic lesions has been unclear for a long time. This was further complicated by the fact that calcification of atherosclerotic plaques was long considered to be only present in advanced plaques as macrocalcification (20). Recent work, however revealed that microcalcifications do exist and destabilize plaques by increasing mechanical stress on the fibrous cap overlying the plaque's contents and render it more prone to rupture (21-23). Additionally, they may further destabilize the plaque by inducing tumor necrosis factor (TNF)-a secretion in macrophages and induce inflammation (24). Contrastingly, macrocalcifications might stabilize atherosclerotic plaques (25-27).

It has long been acknowledged that smoking increases cardiovascular morbidity and mortality $(28,29)$. However, the mechanisms behind this effect remain incompletely understood. Previously, it has been demonstrated that nicotine induces VSMC proliferation and inhibits VSMC apoptosis via their nicotinic acetylcholine receptors (30). Proliferation of VSMC is associated with phenotype switching and development of atherosclerotic lesions $(31,32)$. Furthermore, nicotine was shown to induce secretion of pro-inflammatory cytokines including basic fibroblast growth factor (bFGF), transforming growth factor (TGF)- $\beta 1$ and platelet derived growth factor (PDGF) - BB $(33,34)$. Additionally, nicotine triggers the expression of matrix metalloproteinases (MMPs) (35).

In this thesis, we investigated whether nicotine induces microcalcification using both in vitro VSMC culture models and ex vivo micro-computed tomography (microCT) scanning of atherosclerotic plaques $(n=62)$ in carotid arteries of 30 patients. Our data show a clear association between smoking and the increased presence of microcalcifications in atherosclerotic plaques. Additionally, in vitro experiments revealed that nicotine accelerates 
calcification in VSMC by binding to the a7 nicotinic acetylcholine receptor, thereby increasing oxidative stress, inducing osteogenic transdifferentiation of VSMC and subsequently increases exosome secretion. These observations further extend findings in the past that have shown other nicotine effects on VSMC such as inhibition of apoptosis and stimulation proliferation of VSMC $(30,36)$.

These observations are in line with current research demonstrating that osteogenic differentiation, in part driven by Runx2, is a key event in the development of vascular calcification (37). Furthermore, the association of phenotypical transdifferentiation with increased oxidative stress and increased secretion of extracellular vesicles is further reinforced by our results $(38,39)$. In conclusion, nicotine enhances the propensity of VSMC to calcify by phenotypic switching and exosome release. Future work should aim at further identifying intracellular molecules downstream of the activation of the a7 nicotinic acetylcholine receptor. These may serve as targets for pharmaceutical intervention to reduce the detrimental effects of smoking on cardiovascular homeostasis. Additionally, it would be worthwhile to assess whether vascular calcification can be reduced or prevented by inhibiting extracellular vesicle secretion or by lowering oxidative stress levels.

\section{Ucma acts as calcification inhibitor in the vasculature}

Human body fluids are supersaturated with regard to both calcium and phosphate (40). However, despite these conditions, minerals do not spontaneously form calcium phosphate crystals. This is due to the action of calcification inhibitors that prevent this reaction (3). Fetuin-A and MGP are two important calcification inhibitors. Fetuin-A is a circulating inhibitor that prevents crystal precipitation by formation of a complex with MGP and mineral (41). MGP is a vitamin K dependent inhibitor which depends on Gla-residues to prevent calcification (42). MGP-deficient mice die at young age from extreme haemorrhages due to ruptures of calcified aorta (43). Ucma is a novel vitamin K-dependent protein and was shown to be expressed in the vasculature (44). Ucma-deficient mice do not develop a clear phenotype (45), however in vitro studies revealed that Ucma regulates osteogenic differentiation of osteoblasts (46).

We are the first to report the presence of Ucma in calcified arteries and expression by VSMC using in vitro VSMC culture methods and tissue explant cultures. This is in contrast to the earliest reports on the discovery of Ucma, in which it was stated to be a cartilage and chondrocyte specific protein $(46,47)$. In our study, we have confirmed Ucma expression is increased in VSMC exposed to calcifying conditions in vitro. The changes in expression of calcification inhibitors in response to calcifying conditions have already been reported in the past for other proteins such as MGP and osteopontin $(48,49)$. As Ucma was also shown to be a circulatory protein (50) and because of these changes in expression, it may serve as a potential biomarker for the presence of vascular calcification similar to other calcification inhibitors $(51,52)$. However, further research is required to confirm this. In addition, the presence of Ucma in advanced atherosclerotic lesions suggests calcifying VSMC increase 
expression of Ucma to protect them from adverse phenotypical changes. Our data that $U_{c m a}{ }^{-1}$ VSMC calcify significantly more than wild type VSMC strengthens this observation. It will be interesting to further investigate the role of Ucma in vivo by comparing calcification models in both Ucma-deficient and wild type mice on an atherosclerotic background.

Although both carboxylated and uncarboxylated Ucma have mineral binding affinity, the accumulation of uncarboxylated Ucma is associated with pathological calcifying conditions (53). Using an ex vivo model of human vessel explants, we showed that carboxylated Ucma was able to inhibit calcification of vessel explants whereas the effect after addition of uncarboxylated Ucma was less pronounced (54). This observation extends findings reported for MGP, where the calcification inhibitory function is highly dependent on its carboxylation status (55). Additionally, we have demonstrated that by adding carboxylated Ucma, downregulation of aSMA is counteracted which suggests a protective effect on VSMC phenotypic switching. Although a gamma-glutamylcarboxylase binding site in the amino acid sequence of $U c m a$ is present, there is no definite proof yet that $U c m a$ is effectively carboxylated. Demonstrating that Ucma is gamma-carboxylated and that this is critical for its activity will be crucial to further unravel its function. Additionally, this is essential as it further reinforces adverse effects of anticoagulant therapies based on depleting vitamin $\mathrm{K}$ stores in tissues $(56,57)$.

\section{Ucma inhibits vascular calcification by preventing osteogenic differentiation through a Smad-dependent pathway}

In response to intra- and extracellular triggers such as uremic toxins, increased circulating mineral concentrations or warfarin treatment, VSMC can alter their phenotype from a contractile towards a pro-calcifying osteogenic phenotype. Vitamin K-dependent proteins were shown to be involved in controlling this phenotypical plasticity (3). In the normal vasculature, contractile VSMC in the tunica media regulate vessel tone and diameter. However, upon stress signals VSMC differentiate towards an osteogenic phenotype with characteristics of osteoblasts and chondrocytes inducing calcification of the vascular wall. A potent trigger of osteogenic differentiation of VSMC is exposure to BMP-2 (3). As Ucma was shown to attenuate osteoblast differentiation in vitro and Ucma expression is greatly downregulated in chondrocytes when exposed to BMP-2, we hypothesized that Ucma is involved in controlling osteogenic differentiation of $\operatorname{VSMC}(46,58)$.

In this thesis, we present a novel role for Ucma as an inhibitory protein protecting against vascular calcification induced by exposure to elevated extracellular phosphate levels. In the past, this was described as an in vitro method of inducing osteogenic differentiation in VSMC (59). Ucma prevents vascular calcification by attenuating osteogenic transdifferentiation of VSMC through a pathway involving Smad signalling. BMP-2 was shown to bind to cell-surface receptors and cause phosphorylation of Smads (60). Phosphorylated Smad forms heterodimers and translocate to the nucleus, causing changes in gene expression that lead to osteogenic differentiation (61). Our results demonstrate that Ucma can prevent 
Smad-driven osteogenic differentiation by inhibiting Smad phosphorylation. Osteogenic transdifferentiation is accelerated in $\mathrm{Ucma}^{-/-}$VSMC and results in increased calcification of the extracellular matrix.

Our findings reveal a novel pathway by which Ucma inhibits phosphate driven Smad signalling and osteogenic differentiation thereby reducing the propensity of VSMC to calcify. These data suggest that Ucma is part of the group of calcification inhibitory proteins involved in controlling vascular calcification. Our work further extends the findings that vitamin K-dependent proteins have functions beyond blood coagulation (56, 62). Among the vitamin K-dependent proteins, MGP and osteocalcin have also been shown to affect vascular calcification and Ucma is a novel member of this group. It is thought that MGP acts in the earliest phases of vascular calcification as was shown by premature death in MGP-deficient mice due to ruptures of the calcified vasculature (43). Based on our data and due to the lack of a calcification phenotype in Ucma-deficient mice, we hypothesize that Ucma acts on osteochondrogenic differentiation which is late stage in the development of vascular calcification (45). Osteocalcin is not expressed by VSMC under physiological conditions but is present in osteoblast-like VSMC. Hence, osteocalcin can serve as a marker for osteogenic VSMC and it was shown that high levels of osteocalcin stimulate expression of other osteogenic genes such as Runx2 (3). This work has implications for VSMC driven vascular calcification and represents an advancement in the understanding of involved mechanisms. Manipulating Ucma levels, for example by pharmacological intervention could present itself as a novel therapeutic strategy for preventing vascular calcification.

\section{Medial VSMC have a protective effect against atherosclerotic plaque formation and promote a stable plaque phenotype}

Migration and proliferation of VSMC into the neointima was long considered a key event in atherosclerosis progression (31). Here, VSMC can confer stability or destabilize the atherosclerotic plaque. Stability might be promoted by the deposition of extracellular matrix proteins such as collagen to create a thick fibrous cap. On the other hand, apoptosis of VSMC in established atherosclerotic plaques has been shown to destabilize the atherosclerotic plaque $(63,64)$.

In this thesis we used an atherosclerosis prone $\mathrm{SM} 22 \mathrm{a}-\mathrm{hDTr}^{+} / \mathrm{ApoE}^{-/}$mouse model to study the contribution of medial VSMC on the initiation and early progression of atherosclerosis. This model allowed us to deplete medial VSMC prior to formation of atherosclerotic plaques. We demonstrated that a loss of medial VSMC results in significant larger atherosclerotic plaques. Additionally, these plaques displayed features of vulnerability including thinner fibrous cap, larger necrotic core, a pro-inflammatory environment and reduced numbers of VSMC. These findings extend previous observations made by Clarke et al (63, 64). The accelerated growth observed may be due to various reasons. Firstly, plaques from mice with reduced medial VSMC have a thinner fibrous cap. This might facilitate leucocyte infiltration, increase plaque inflammation and accelerate necrotic core formation. Sec- 
ondly, there are significantly less VSMC present in atherosclerotic plaques of SM22a-hDTr ${ }^{+}$/ $\mathrm{ApoE}^{-/}$mice. VSMC are efficient efferocytes and contribute to clearance of apoptotic remnants in their environment. However, in stages of hyperlipidaemia efferocytosis is impaired and accompanied by IL-1 driven inflammation (65). The impairment of efferocytosis has been shown to accelerate atherosclerotic plaque growth. In SM22a-hDTr $\mathrm{ST}^{+} / \mathrm{Apo}^{-/-}$mice, this effect is further exaggerated by reduced VSMC. Finally, calcification and degradation of the media is an important risk factor for developing atherosclerosis. As reducing medial VSMC induces medial remoddeling, this may present as an additional mechanism for accelerating plaque formation. Contrastingly, we did not observe an increase in calcification of atherosclerotic plaques of SM22a-hDTr $/ \mathrm{ApoE}^{-/-}$mice. Whereas VSMC were initially thought to promote atherosclerotic plaque growth, our study demonstrates that they contribute to the inhibition of plaque formation and promote plaque stability. These findings challenge some of the historic paradigms on the role of VSMC in development of atherosclerosis. Additionally, this suggests careful reconsideration of current therapies used to prevent restenosis in stents such as rapamycin (66). These therapies are often aimed at preventing restenosis by inhibiting VSMC proliferation and migration or induction of apoptosis. Hence, this work highlights the need to look into alternative methods to use or mechanisms to target for preventing restenosis.

\section{Concluding remarks and future perspectives}

The aim of this thesis was to gain further insight in the role of VSMC in both intimal and medial calcification. We provided new insights in the association of smoking with cardiovascular mortality and morbidity and propose nicotine as one of the main culprits for this effect. Our work also highlights the need to carefully reconsider the use of nicotine replacement therapies. Furthermore, we identified a new inherent calcification inhibitor, Ucma which protects against vascular calcification. This knowledge grants further insight into the mechanisms involved in development of vascular calcification. Inhibition of osteogenic differentiation may serve as a target for therapeutic intervention and allow for reduction of cardiovascular morbidity and mortality associated with vascular calcification. In particular, this may benefit patient populations at an elevated risk of developing vascular calcification such as chronic kidney disease (CKD) or diabetes mellitus patients and the elderly. Finally, our results emphasize the protective effect of VSMC on atherosclerotic plaques. We provide evidence that VSMC can slow down growth of atherosclerotic plaques and prevent plaque rupture by formation of a thick fibrous cap. Taken together, the research presented in this thesis provides further insights into the VSMC driven mechanisms that are involved in medial and intimal vascular calcification. 


\section{References}

1. Borissoff JI, Spronk HMH, ten Cate H. The Hemostatic System as a Modulator of Atherosclerosis. New England Journal of Medicine. 2011;364(18):1746-60.

2. Wang H, Naghavi M, Allen C, Barber RM, Bhutta ZA, Carter A, et al. Global, regional, and national life expectancy, all-cause mortality, and cause-specific mortality for 249 causes of death, 1980\&\#x2013;2015: a systematic analysis for the Global Burden of Disease Study 2015. The Lancet.388(10053):1459-544.

3. Willems BA, Vermeer C, Reutelingsperger CP, Schurgers LJ. The realm of vitamin K dependent proteins: shifting from coagulation toward calcification. Mol Nutr Food Res. 2014 Aug;58(8):162035.

4. Shanahan CM, Crouthamel MH, Kapustin A, Giachelli CM. Arterial calcification in chronic kidney disease: key roles for calcium and phosphate. Circ Res. 2011 Sep 2;109(6):697-711.

5. Speer MY, Giachelli CM. Regulation of cardiovascular calcification. Cardiovasc Pathol. 2004 MarApr;13(2):63-70.

6. Towler DA. Vascular calcification: a perspective on an imminent disease epidemic. IBMS BoneKEy. 2008;5(2):41-58.

7. Sage AP, Tintut Y, Demer LL. Regulatory mechanisms in vascular calcification. Nat Rev Cardiol. 2010 Sep;7(9):528-36.

8. Blumenthal HT, Lansing Al, Wheeler PA. Calcification of the Media of the Human Aorta and Its Relation to Intimal Arteriosclerosis, Ageing and Disease. Am J Pathol. 1944 Jul;20(4):665-87.

9. Sangiorgi G, Rumberger JA, Severson A, Edwards WD, Gregoire J, Fitzpatrick LA, et al. Arterial calcification and not lumen stenosis is highly correlated with atherosclerotic plaque burden in humans: a histologic study of 723 coronary artery segments using nondecalcifying methodology. Journal of the American College of Cardiology. 1998;31(1):126-33.

10. Budoff MJ, Achenbach S, Blumenthal RS, Carr JJ, Goldin JG, Greenland P, et al. Assessment of coronary artery disease by cardiac computed tomography. Circulation. 2006;114(16):1761-91.

11. Wexler L, Brundage B, Crouse J, Detrano R, Fuster V, Maddahi J, et al. Coronary artery calcification: pathophysiology, epidemiology, imaging methods, and clinical implications. Circulation. 1996;94(5):1175-92.

12. Haka AS, Shafer-Peltier KE, Fitzmaurice M, Crowe J, Dasari RR, Feld MS. Identifying microcalcifications in benign and malignant breast lesions by probing differences in their chemical composition using Raman spectroscopy. Cancer research. 2002;62(18):5375-80.

13. Irkle A, Vesey AT, Lewis DY, Skepper JN, Bird JL, Dweck MR, et al. Identifying active vascular microcalcification by $18 \mathrm{~F}$-sodium fluoride positron emission tomography. Nature communications. 2015;6.

14. Mizobuchi M, Towler D, Slatopolsky E. Vascular calcification: the killer of patients with chronic kidney disease. Journal of the American Society of Nephrology. 2009;20(7):1453-64.

15. Garimella PS, Sarnak MJ. Cardiovascular disease in CKD in 2012: moving forward, slowly but surely. Nat Rev Nephrol. 2013 Feb;9(2):69-70. 
16. Edmonds M. Medial arterial calcification and diabetes mellitus. Zeitschrift für Kardiologie. 2000; 89(14):S101-S4.

17. Shanahan CM, Cary NR, Salisbury JR, Proudfoot D, Weissberg PL, Edmonds ME. Medial localization of mineralization-regulating proteins in association with Mönckeberg's sclerosis evidence for smooth muscle cell-mediated vascular calcification. Circulation. 1999;100(21):2168-76.

18. Rennenberg RJ, Kessels AG, Schurgers LJ, van Engelshoven JM, de Leeuw PW, Kroon AA. Vascular calcifications as a marker of increased cardiovascular risk: a meta-analysis. Vasc Health Risk Manag. 2009;5(1):185-97.

19. London GM, Guérin AP, Marchais SJ, Métivier F, Pannier B, Adda H. Arterial media calcification in end-stage renal disease: impact on all-cause and cardiovascular mortality. Nephrology Dialysis Transplantation. 2003;18(9):1731-40.

20. Fayad Z, Fuster V. Clinical imaging of the high-risk or vulnerable atherosclerotic plaque. Circulation research. 2001;89(4):305-16.

21. Maldonado N, Kelly-Arnold A, Vengrenyuk Y, Laudier D, Fallon JT, Virmani R, et al. A mechanistic analysis of the role of microcalcifications in atherosclerotic plaque stability: potential implications for plaque rupture. Am J Physiol Heart Circ Physiol. 2012 Sep 1;303(5):H619-28.

22. Ehara S, Kobayashi Y, Yoshiyama M, Shimada K, Shimada Y, Fukuda D, et al. Spotty calcification typifies the culprit plaque in patients with acute myocardial infarction: an intravascular ultrasound study. Circulation. 2004 Nov 30;110(22):3424-9.

23. Hutcheson JD, Maldonado N, Aikawa E. Small entities with large impact: microcalcifications and atherosclerotic plaque vulnerability. Current opinion in lipidology. 2014;25(5):327-32.

24. Nadra I, Boccaccini AR, Philippidis P, Whelan LC, McCarthy GM, Haskard DO, et al. Effect of particle size on hydroxyapatite crystal-induced tumor necrosis factor alpha secretion by macrophages. Atherosclerosis. 2008;196(1):98-105.

25. Huang H, Virmani R, Younis H, Burke AP, Kamm RD, Lee RT. The impact of calcification on the biomechanical stability of atherosclerotic plaques. Circulation. 2001 Feb 27;103(8):1051-6.

26. Shaalan WE, Cheng H, Gewertz B, McKinsey JF, Schwartz LB, Katz D, et al. Degree of carotid plaque calcification in relation to symptomatic outcome and plaque inflammation. Journal of vascular surgery. 2004;40(2):262-9.

27. Pugliese G, Iacobini C, Fantauzzi CB, Menini S. The dark and bright side of atherosclerotic calcification. Atherosclerosis. 2015;238(2):220-30.

28. White WB. Smoking-Related Morbidity and Mortality in the Cardiovascular Setting. Preventive cardiology. 2007;10(s2):1-4.

29. Willett WC, Green A, Stampfer MJ, Speizer FE, Colditz GA, Rosner B, et al. Relative and absolute excess risks of coronary heart disease among women who smoke cigarettes. N Engl J Med. 1987 Nov 19;317(21):1303-9.

30. Cucina A, Fuso A, Coluccia P, Cavallaro A. Nicotine inhibits apoptosis and stimulates proliferation in aortic smooth muscle cells through a functional nicotinic acetylcholine receptor. Journal of Surgical Research. 2008;150(2):227-35. 
31. Ross R, Glomset JA. Atherosclerosis and the arterial smooth muscle cell: Proliferation of smooth muscle is a key event in the genesis of the lesions of atherosclerosis. Science. 1973 Jun 29; 180(4093):1332-9.

32. Alexander MR, Owens GK. Epigenetic control of smooth muscle cell differentiation and phenotypic switching in vascular development and disease. Annu Rev Physiol. 2012;74:13-40.

33. Cucina A, Sapienza P, Corvino V, Borrelli V, Mariani V, Randone B, et al. Nicotine-induced smooth muscle cell proliferation is mediated through bFGF and TGF- $\beta 1$. Surgery. 2000;127(3):316-22.

34. Cucina A, Sapienza P, Borrelli V, Corvino V, Foresi G, Randone B, et al. Nicotine reorganizes cytoskeleton of vascular endothelial cell through platelet-derived growth factor BB. Journal of Surgical Research. 2000;92(2):233-8.

35. Ait-Oufella H, Kinugawa K, Zoll J, Simon T, Boddaert J, Heeneman S, et al. Lactadherin deficiency leads to apoptotic cell accumulation and accelerated atherosclerosis in mice. Circulation. 2007 Apr 24;115(16):2168-77.

36. Yoshiyama S, Chen Z, Okagaki T, Kohama K, Nasu-Kawaharada R, Izumi T, et al. Nicotine exposure alters human vascular smooth muscle cell phenotype from a contractile to a synthetic type. Atherosclerosis. 2014 Dec;237(2):464-70.

37. Speer MY, Yang HY, Brabb T, Leaf E, Look A, Lin WL, et al. Smooth muscle cells give rise to osteochondrogenic precursors and chondrocytes in calcifying arteries. Circ Res. 2009 Mar 27;104(6): 733-41.

38. Idelevich A, Rais Y, Monsonego-Ornan E. Bone Gla protein increases HIF-1alpha-dependent glucose metabolism and induces cartilage and vascular calcification. Arterioscler Thromb Vasc Biol. 2011 Sep;31(9):e55-71.

39. Kapustin AN, Chatrou ML, Drozdov I, Zheng Y, Davidson SM, Soong D, et al. Vascular smooth muscle cell calcification is mediated by regulated exosome secretion. Circ Res. 2015 Apr 10; 116(8):1312-23.

40. Jahnen-Dechent W, Schafer C, Heiss A, Grotzinger J. Systemic inhibition of spontaneous calcification by the serum protein alpha 2-HS glycoprotein/fetuin. Z Kardiol. 2001;90 Suppl 3:47-56.

41. Price PA, Lim JE. The inhibition of calcium phosphate precipitation by fetuin is accompanied by the formation of a fetuin-mineral complex. J Biol Chem. 2003 Jun 13;278(24):22144-52.

42. Schurgers LJ, Spronk HM, Skepper JN, Hackeng TM, Shanahan CM, Vermeer C, et al. Posttranslational modifications regulate matrix Gla protein function: importance for inhibition of vascular smooth muscle cell calcification. J Thromb Haemost. 2007 Dec;5(12):2503-11.

43. Luo G, Ducy P, McKee MD, Pinero GJ, Loyer E, Behringer RR, et al. Spontaneous calcification of arteries and cartilage in mice lacking matrix GLA protein. Nature. 1997 Mar 6;386(6620):78-81.

44. Viegas CS, Simes DC, Laize V, Williamson MK, Price PA, Cancela ML. Gla-rich protein (GRP), a new vitamin K-dependent protein identified from sturgeon cartilage and highly conserved in vertebrates. J Biol Chem. 2008 Dec 26;283(52):36655-64.

45. Eitzinger N, Surmann-Schmitt C, Bosl M, Schett G, Engelke K, Hess A, et al. Ucma is not necessary for normal development of the mouse skeleton. Bone. 2012 Mar;50(3):670-80. 
46. Surmann-Schmitt C, Dietz U, Kireva T, Adam N, Park J, Tagariello A, et al. Ucma, a novel secreted cartilage-specific protein with implications in osteogenesis. J Biol Chem. 2008 Mar 14;283(11): 7082-93.

47. Tagariello A, Luther J, Streiter M, Didt-Koziel L, Wuelling M, Surmann-Schmitt C, et al. Ucma-A novel secreted factor represents a highly specific marker for distal chondrocytes. Matrix Biol. 2008 Jan;27(1):3-11.

48. Houben E, Neradova A, Schurgers LJ, Vervloet M. The influence of phosphate, calcium and magnesium on matrix Gla-protein and vascular calcification: a systematic review. G Ital Nefrol. 2016 Nov-Dec;33(6).

49. Proudfoot D, Skepper JN, Shanahan CM, Weissberg PL. Calcification of human vascular cells in vitro is correlated with high levels of matrix Gla protein and low levels of osteopontin expression. Arteriosclerosis, thrombosis, and vascular biology. 1998;18(3):379-88.

50. Viegas CS, Cavaco S, Neves PL, Ferreira A, Joao A, Williamson MK, et al. Gla-rich protein is a novel vitamin $\mathrm{K}$-dependent protein present in serum that accumulates at sites of pathological calcifications. Am J Pathol. 2009 Dec;175(6):2288-98.

51. Schurgers LJ, Barreto DV, Barreto FC, Liabeuf S, Renard C, Magdeleyns EJ, et al. The circulating inactive form of matrix gla protein is a surrogate marker for vascular calcification in chronic kidney disease: a preliminary report. Clin J Am Soc Nephrol. 2010 Apr;5(4):568-75.

52. Osorio A, Ortega E, Torres JM, Sanchez P, Ruiz-Requena E. Biochemical markers of vascular calcification in elderly hemodialysis patients. Mol Cell Biochem. 2013 Feb;374(1-2):21-7.

53. Rafael MS, Cavaco S, Viegas CS, Santos S, Ramos A, Willems BA, et al. Insights into the association of Gla-rich protein and osteoarthritis, novel splice variants and gamma-carboxylation status. Mol Nutr Food Res. 2014 Aug;58(8):1636-46.

54. Viegas CS, Rafael MS, Enriquez JL, Teixeira A, Vitorino R, Luis IM, et al. Gla-rich protein acts as a calcification inhibitor in the human cardiovascular system. Arterioscler Thromb Vasc Biol. 2015 Feb;35(2):399-408.

55. Murshed M, Schinke T, McKee MD, Karsenty G. Extracellular matrix mineralization is regulated locally; different roles of two gla-containing proteins. J Cell Biol. 2004 Jun 7;165(5):625-30.

56. Schurgers LJ, Joosen IA, Laufer EM, Chatrou ML, Herfs M, Winkens MH, et al. Vitamin K-antagonists accelerate atherosclerotic calcification and induce a vulnerable plaque phenotype. PLoS One. 2012;7(8):e43229.

57. Kruger T, Oelenberg S, Kaesler N, Schurgers LJ, van de Sandt AM, Boor P, et al. Warfarin induces cardiovascular damage in mice. Arterioscler Thromb Vasc Biol. 2013 Nov;33(11):2618-24.

58. Le Jeune M, Tomavo N, Tian TV, Flourens A, Marchand N, Camuzeaux B, et al. Identification of four alternatively spliced transcripts of the Ucma/GRP gene, encoding a new Gla-containing protein. Exp Cell Res. 2010 Jan 15;316(2):203-15.

59. Jono S, McKee MD, Murry CE, Shioi A, Nishizawa Y, Mori K, et al. Phosphate regulation of vascular smooth muscle cell calcification. Circ Res. 2000 Sep 29;87(7):E10-7.

60. Liu F, Hata A, Baker JC, Doody J. A human Mad protein acting as a BMP-regulated transcriptional activator. Nature. 1996;381(6583):620. 
61. Heldin C-H, Miyazono K, Ten Dijke P. TGF- $\beta$ signalling from cell membrane to nucleus through SMAD proteins. Nature. 1997;390(6659):465-71.

62. Chatrou ML, Winckers K, Hackeng TM, Reutelingsperger CP, Schurgers LJ. Vascular calcification: the price to pay for anticoagulation therapy with vitamin K-antagonists. Blood reviews. 2012; 26(4):155-66.

63. Clarke MC, Figg N, Maguire JJ, Davenport AP, Goddard M, Littlewood TD, et al. Apoptosis of vascular smooth muscle cells induces features of plaque vulnerability in atherosclerosis. Nat Med. 2006 Sep;12(9):1075-80.

64. Clarke MC, Littlewood TD, Figg N, Maguire JJ, Davenport AP, Goddard M, et al. Chronic apoptosis of vascular smooth muscle cells accelerates atherosclerosis and promotes calcification and medial degeneration. Circ Res. 2008 Jun 20;102(12):1529-38.

65. Schrijvers DM, De Meyer GR, Kockx MM, Herman AG, Martinet W. Phagocytosis of apoptotic cells by macrophages is impaired in atherosclerosis. Arteriosclerosis, thrombosis, and vascular biology. 2005;25(6):1256-61.

66. Marx SO, Jayaraman T, Go LO, Marks AR. Rapamycin-FKBP inhibits cell cycle regulators of proliferation in vascular smooth muscle cells. Circ Res. 1995 Mar;76(3):412-7. 



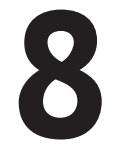

Summary 

In this thesis, the main focus was investigating the role of vascular smooth muscle cells (VSMC) in the manifestation of vascular calcification and atherosclerosis.

Chapter 1 highlights the importance of cardiovascular disease and elaborates on how atherosclerosis and vascular calcification can contribute to its development in addition to traditional risk factors. Atherosclerosis, associated with intimal calcification, is a chronic inflammatory disease of the vessel wall caused by lodging of lipids underneath the endothelial layer. Inflammation in the sub-endothelial space causes proliferation of VSMC and migration of both VSMC and macrophages. VSMC have both stabilizing and destabilizing effects on the stage of the atherosclerotic plaque. Atherosclerotic plaques often harbour both micro- and macrocalcifications. Medial calcification occurs throughout the entire vascular tree and is accompanied by a loss of contractile properties. It can develop via several actively regulated mechanisms including phenotypical switching of VSMC, apoptosis, secretion of extracellular vesicles and loss of calcification inhibitors. These mechanisms can all be affected via various pathways that either stimulate or inhibit VSMC function. The family of vitamin K-dependent proteins are examples of proteins that influence VSMC. In Chapter $\mathbf{2}$ we discuss how vitamin K has emerged from a single-function "haemostasis" vitamin to a multi-function vitamin involved in a multitude of processes unrelated to blood coagulation. We briefly discuss the normal physiology of vitamin $\mathrm{K}$ and touch upon the detrimental side effects of inhibiting blood coagulation using vitamin $\mathrm{K}$ antagonists. We discuss in detail the role of vitamin $\mathrm{K}$ and vitamin $\mathrm{K}$-dependent proteins in both physiological (i.e. bone) and pathological (i.e. vasculature) calcification. Special emphasis is put on the role of 3 vitamin K-dependent proteins: MGP, osteocalcin and the recently discovered Ucma and their interaction with calcification during different phases of VSMC driven calcification. Additionally, the clinical significance and therapeutical applications of vitamin $\mathrm{K}$ are discussed.

It has long been acknowledged that smokers are at increased risk for cardiovascular events. In Chapter $\mathbf{3}$ we report on the effects of smoking on VSMC-mediated microcalcification of human atherosclerotic plaques. Smoking causes a significant increase in microcalcifications of carotid atherosclerotic lesions in comparison to atherosclerotic lesions of non-smokers as was assessed using ex vivo microCT scanning. In vitro, the effect of nicotine on VSMC was identified as the driving force for this effect. Nicotine increased calcification of VSMC cultures by some $90 \%$. We found both oxidative stress levels and exosome secretion to be significantly increased in VSMC exposed to nicotine. Furthermore, we found that nicotine induced a loss of contractile properties of VSMC and induced a procalcifying phenotype. Using various nicotinergic receptor antagonists, we demonstrated that these findings were mediated via the nicotinic acetylcholine receptor, a7. Hence, it will be important to investigate the contribution of this receptor in the development of cardiovascular disease.

As nicotine is one of many extracellular factors that may have detrimental effects on VSMC, we investigated how VSMC are normally protected against vascular calcification. In 
Chapters 4 and 5 we reported that Ucma expression was increased in calcified arterial vessels including atherosclerotic plaques, both at RNA and protein level. In vivo, we found Ucma accumulation in the vessel wall in association with VSMC. This Ucma was further characterized. Mineral bound Ucma was associated with other calcification inhibitors (MGP, Fetuin A). These have already been shown to co-accumulate at sites of vascular calcification. Next, we showed that the addition of exogenous Ucma in an ex vivo aortic calcification model inhibits vascular calcification and upregulates aSMA expression. Next, we investigated how Ucma exerts this protective effect against vascular calcification in Chapter 5. We demonstrated that Ucma expression is increased in VSMC upon exposure to calcifying conditions. Ucma $\%$ VSMC were more prone to calcify and had increased levels of ALP activity. In addition to the pro-calcifying phenotype, Ucma $\%$ VSMC expressed higher levels of osteogenic genes in comparison to WT cells. Interestingly, we also observed increased expression of $\beta$-catenin and phosphorylated Smad 1/5/8, leading to Runx 2 mediated osteogenic phenotype switching of VSMC. Upon further investigation, we unravelled that Ucma protects VSMC from osteogenic differentiation by inhibiting the BMP-2-pSmad $1 / 5 / 8-\beta$-catenin pathway.

Finally, using SM22a-hDTr $/ \mathrm{ApoE}^{-/-}$mice we investigated the role of medial VSMC on the development of atherosclerotic plaques in Chapter 6. Mice received DT injections to partially deplete (some 50\%) medial VSMC prior to receiving a Western type diet for accelerated development of atherosclerotic plaques. After both 6 and 18 weeks of Western type diet, mice with reduced medial VSMC developed significantly larger plaques as compared to mice with normal medial VSMC numbers. In addition, plaques of mice with reduced medial VSMC contained less collagen, had an increased inflammatory profile, less intimal VSMC, a larger necrotic core and a significantly thinned fibrous cap. These are all hallmarks of a vulnerable plaque phenotype, making the plaque more prone to rupture. The mechanisms behind these observations still remain to be determined, however possible mechanisms are the lack of migrated medial VSMC to form a thick fibrous cap, thereby slowing down inflammatory cell infiltration. Secondly, due to the reduced migration of medial VSMC into the plaque, optimal efferocytosis might be reduced.

In conclusion, the data described in this thesis have provided further insights in the development of vascular calcification. Both Ucma and nicotine may serve as targets for treating or slowing down the development of vascular calcification and thereby atherosclerosis. The effect of reduced medial VSMC on the development of atherosclerosis highlights the need to carefully reconsider current therapies used to treat restenosis. 


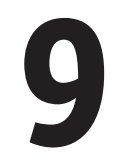

Nederlandse Samenvatting 

In dit proefschrift ligt de focus op het onderzoeken van de rol van gladde spiercellen (VSMC) in het ontstaan van vasculaire calcificatie en atherosclerose.

In hoofdstuk 1 wordt het belang van cardiovasculaire aandoeningen uitgelicht en wordt besproken hoe atherosclerose en vasculaire calcificatie, naast de traditionele risicofactoren, het ontstaan hiervan beïnvloeden. Atherosclerose, geassocieerd met intimale verkalking, is een chronisch ontstekingsproces in de vaatwand dat veroorzaakt wordt door opstapeling van lipiden onder de endotheel laag. Ontsteking van de sub-endotheliale ruimte lokt proliferatie van VSMC en migratie van zowel macrofagen als VSMC uit. VSMC kunnen zowel een stabiliserend als destabiliserend effect hebben op atherosclerotische plaques. In atherosclerotische plaques treft men vaak zowel micro- als macroverkalkingen aan. Mediale calcificatie komt door het gehele vaatstelsel voor en is vergezeld van een verlies aan contractiliteit in de vaatwand. Het kan zich ontwikkelen via verschillende, actief gereguleerde mechanismes waaronder fenotype wijzigingen van VSMCs, apoptose, secretie van extracellulaire vesicles en het verlies van calcificatie inhibitoren. Al deze mechanismes kunnen via verschillende pathways, die VSMC kunnen stimuleren of inhiberen, beïnvloedt worden. De familie van vitamine K-afhankelijke eiwitten zijn een voorbeeld van eiwitten die een effect uitoefenen op VSMC. In hoofdstuk 2 wordt besproken hoe de rol van vitamine K geëvolueerd is van een single-function "stollings" vitamine tot een multifunctioneel vitamine betrokken bij een groot aantal processen welke niet gerelateerd zijn aan de bloedstolling. De normale fysiologie van vitamine $\mathrm{K}$ wordt beknopt besproken en de nadelige effecten van het remmen van de bloedstolling met vitamine $K$ antagonisten worden toegelicht. Daarnaast wordt de rol van vitamine K en vitamine K-afhankelijke eiwitten in zowel fysiologische (bijv. bot) als pathologische (bijv. vaatwand) calcificatie in detail uiteengezet. De nadruk wordt gelegd op de rol van 3 vitamine K-afhankelijke eiwitten: MGP, osteocalcine en het recent ontdekte Ucma en hoe zij betrokken zijn in de verschillende fases van een door VSMC gedreven calcificatieproces. Daarnaast worden het klinisch belang en de therapeutische toepassingen van vitamine $\mathrm{K}$ besproken

Het is reeds lang geweten dat rokers een verhoogd risico hebben op het ontwikkelen van cardiovasculaire aandoeningen. In hoofdstuk $\mathbf{3}$ bespreken we de effecten van roken op VSMC-gemedieerde microverkalking van humane atherosclerotische plaques. Roken veroorzaakt een significante verhoging in microverkalkingen in atherosclerotische plaques van de carotiden ten opzichte van atherosclerotische plaques in de carotiden van nietrokers. Dit werd gemeten door gebruik te maken van ex vivo microCT scanning. In vitro werd het effect van nicotine op VSMC geïdentificeerd als een drijvende kracht van dit effect. Nicotine verhoogde de calcificatie van VSMC culturen met 90\%. Daarnaast observeerden we dat VSMC, blootgesteld aan nicotine significant meer oxidatieve stress hadden en significant meer exosomen secreteerden. Nicotine induceerde ook een verlies van contractiele eigenschappen in VSMC en stimuleerde een pro-calcificatie fenotype. Door gebruik te maken van verschillende antagonisten van nicotinerge receptoren demonstreerden we dat nicotine dit effect uitoefent via de nicotinerge acetylcholine receptor, a7. Aldus zal de 
rol van deze receptor in de ontwikkeling van cardiovasculaire aandoeningen verder onderzocht moeten worden.

Nicotine is slechts 1 van vele extracellulaire factoren met een nadelig effect op VSMC. Daarom hebben we onderzocht hoe VSMC normaal beschermd zijn tegen vasculaire calcificatie. In hoofdstukken 4 en 5 rapporteren we dat Ucma expressie verhoogd is in verkalkte aderen, inclusief atherosclerotische plaques, zowel op RNA als eiwit niveau. In vivo, hebben we gevonden dat Ucma accumuleerde in de vaatwand in associatie met VSMC. Ucma in associatie met VSMC werd verder gekarakteriseerd. We vonden dat mineraal gebonden Ucma geassocieerd is met andere calcificatie inhibitoren (MGP, Fetuine A). Van deze inhibitoren was reeds bekend dat ze co-accumuleren in zones met vasculaire calcificatie. Daarnaast hebben we aangetoond dat additie van exogeen Ucma aan een ex vivo model van verkalking van de aorta, deze verkalking kan remmen en de expressie van aSMA stimuleert. Vervolgens hebben we in hoofdstuk $\mathbf{5}$ verder uitgezocht hoe Ucma beschermt tegen vasculaire calcificatie. We hebben gedemonstreerd dat de expressie van Ucma verhoogd is in VSMC die zijn blootgesteld aan verkalkende condities. Ucma ${ }^{-/}$VSMC verkalkten sneller en hadden meer ALP activiteit. Naast dit pro-verkalkende fenotype hadden Ucma $\%$ VSMC een hogere expressie van osteogene genen ten opzichte van WT VSMC. We observeerden ook verhoogde expressieniveaus van $\beta$-catenin en gefosforyleerde Smad 1/5/8. Dit veroorzaakt Runx2 gemedieerde osteogene fenotype switching van VSMC. Verder onderzoek toonde aan dat Ucma VSMC beschermt tegen osteogene differentiatie door het inhiberen van de BMP-2-pSmad 1/5/8- $\beta$-catenin pathway.

Ten slotte hebben we de rol van mediale VSMC op de ontwikkeling van atherosclerotische plaques bestudeerd in hoofdstuk 6 door gebruik te maken van SM22a-hDTr ${ }^{+}$/ $\mathrm{ApoE}^{-/-}$muizen. Deze muizen werden geïnjecteerd met DT. DT zorgt er voor dat ze ca. 50\% van hun mediale VSMC verliezen alvorens een Westen type dieet te krijgen. Hierdoor wordt de ontwikkeling van atherosclerotische plaques versneld. Na zowel 6 als 18 weken Western type dieet ontwikkelden muizen met minder mediale VSMC significant grotere plaques ten opzichte van normale muizen. Daarnaast bevatten plaques van muizen met minder mediale VSMC minder collageen, minder intimale VSMC, een grotere necrotische kern, meer ontstekingscellen en hadden ze een significant dunnere fibreuze omkapseling. Dit zijn allemaal kenmerken van een kwetsbare atherosclerotische plaque welke makkelijker kan openscheuren. De mechanismen hierachter zijn nog onbekend, echter identificeerden wij een aantal mogelijke mechanismen waaronder minder VSMC die de omkapseling in migreren waardoor dit dunner is met als gevolg dat ontstekingscellen sneller de plaque kunnen infiltreren. Daarnaast is efferocytose in de plaques gereduceerd doordat minder mediale VSMC de plaque in migreren.

We kunnen besluiten dat het onderzoek wat in dit proefschrift besproken wordt verdere inzichten verschaft in de ontwikkeling van vasculaire calcificatie. Zowel Ucma als nicotine zijn 2 targets om de ontwikkeling van vasculaire calcificatie en atherosclerose te vertragen of vermijden. Het effect van de reductie in mediale VSMC op de ontwikkeling van 
atherosclerose benadrukt de nood aan een grondige herevaluatie van de therapieën die momenteel worden ingezet om restenose te behandelen 



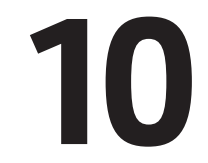

Valorization 

Since many years, a substantial amount of money from companies and private investors is going to research. Hence, valorisation of research supported by this money is gradually becoming mandatory from a socio-economical perspective. These groups expect a direct impact of this research or for it to be translated into value for their organisation. However, it is important to remain vigilant that research remains question-driven and not answerdriven. Thus, involvement of external parties providing funding should not influence the experimental results obtained and reported. Question-driven research might be valorisable but needs to a priory expand scientific knowledge. Being part of a knowledge-based economy, it should be possible, however, that external parties benefit from research. Although expanding scientific knowledge does not have a direct effect on society, its relevance in the scope of fact-based decision making can be of great value. Additionally, this knowledge is essential to remain a leader in innovation.

The key objective of this thesis was to gain further insights in the role of vascular smooth muscle cells (VSMC) in the development of both intimal and medial vascular calcification to find potential targets for holding or regressing vascular disease. Vascular calcification is gradually acknowledged as an important risk factor for developing cardiovascular disease. Cardiovascular disease is still the leading cause of death in the western world and has a vast impact on the financial cost of health care systems. Hence, the importance of cardiovascular research cannot be overestimated. The impact of cardiovascular disease is discussed into greater detail in chapters $\mathbf{1}$ and $\mathbf{2}$.

Chapter $\mathbf{3}$ investigates effects of smoking on development of microcalcification in atherosclerotic plaques. Smoking is one of the leading preventable causes of death worldwide, and quitting smoking is associated with a significant reduction in risk of developing cardiovascular disease. Our research identified nicotine as a major component of cigarettes increasing microcalcification of atherosclerotic plaques in smokers. Nicotine is well known to the general public as the addictive component of cigarettes making the process of smoking cessation a long and difficult one. Many different strategies for smoking cessation can be employed. As nicotine is the addictive component, a specific group of medications known as nicotine replacement therapy has been successfully used to assist people with smoking cessation. Although smoking cessation through nicotine replacement therapy impacts overall cardiovascular morbidity and mortality caused by smoking, our research presents a critical side note to reconsider nicotine replacement therapy. As microcalcifications greatly reduce plaque stability, the use of nicotine replacement therapy will still maintain nicotine blood levels. Hence, the development of microcalcification in plaques will not be reduced. This also indicates that reduction in cardiovascular morbidity may be less than what could be achieved. Thus, our research promotes the use of alternative smoking cessation therapies over nicotine replacement therapy.

Chapter 4 and chapter $\mathbf{5}$ elaborate on the role of Ucma, a recently discovered extra-hepatic vitamin K-dependent protein. Our research demonstrated that this protein is present in (calcified) cardiovascular tissue similar to MGP, another extra-hepatic vitamin 
K-dependent protein involved in the inhibition of ectopic calcification. Previously, it was shown that a specific form of MGP (desphosporylated and uncarboxylated MGP) serves as a biomarker for vascular vitamin $\mathrm{K}$ status and predicts vascular calcification in patients. The antibodies against MGP and the use of dp-UCMGP as a biomarker was patented and an ELISA was developed to measure circulating MGP levels. This patent and ELISA were developed within VitaK BV, a Maastricht University spin off. The patents and assay have recently been sold to IDS, an UK based company that markets biomarkers for cardiovascular disease. Also for Ucma, its use as a biomarker for cardiovascular disease has been patented. Based on this patent, a new company called GenoGla has been founded. These companies offer jobs and hence present themselves as a return-on-investment to society. In chapter $\mathbf{5}$ we have unravelled the role of $\mathrm{Ucm}$ a in the development of vascular calcification and highlighted the BMP-2-pSmad1/5/8- $\beta$-catenin dependent-pathway as a potential mechanism through which Ucma has a protective effect. Although additional research is still required to turn this pathway into a potential diagnostic or therapeutic target. In the future this knowledge will be of importance to develop therapies for vascular calcification.

Finally, in chapter 6 we focussed on the role of medial VSMC in the development of atherosclerotic plaques. Our results demonstrated that reduced medial VSMC in the vessel wall result in significantly larger, more vulnerable atherosclerotic plaques. This finding might have great clinical implications. Stents are often coated with anti-proliferative drugs to prevent restenosis. Our finding highlights the need to reconsider the coating of stents with agents inhibiting VSMC proliferation. Although there are short term benefits of this approach, the long term benefits remain questionable and may lead to accelerated atherosclerotic plaque formation in the affected area and hence translate to a larger atherosclerotic burden. 


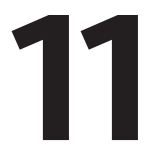

Curriculum Vitae 



\section{About the author}

Brecht Andy Ghislaine Willems was born on February 12th in Hasselt, Belgium. Here he graduated from the Virga-Jessecollege in 2006 completing a degree in Latin and Sciences. After graduating from high school, he started studying Biomedical Sciences at Hasselt University for which he obtained the Bachelor's degree in 2009. Upon completion of the Bachelor's program, Brecht began a 2 year Master in Biomedical Sciences specialising in Nanotechnology and Bioelectronics. Brecht completed his Master's degree in 2011 with great honours after a 9 months internship under the supervision of Dr. Erik Steenredeker.

In 2011, he started a PhD program at VitaK BV and the department of Biochemistry, both part of the University of Maastricht under the supervision of $d r$. Schurgers, $d r$. Vermeer and Prof. dr. Reutelingsperger. The aim of his PhD project was to investigate how vascular smooth muscle cell phenotype switching governs vascular calcification. During this PhD program, Brecht has published his data in international peer-reviewed scientific journals and presented it at international conferences including Amsterdam, Kyoto and Manchester.

Directly after his PhD, Brecht started as a consultant for USG professionals, a company providing scientific expertise for external organisations. Currently, Brecht is working on a project in the regulatory affairs department of the ophthalmology unit at Novartis.

\section{Over de auteur}

Brecht Andy Ghislaine Willems werd geboren op 12 februari 1988 te Hasselt, België waar hij in 2006 afstudeerde van het Virga-Jessecollege in de richting Latijn-Wetenschappen.

$\mathrm{Na}$ het afstuderen aan de middelbare school startte hij met Biomedische Wetenschappen aan de Universiteit Hasselt en behaalde zijn Bachelor diploma in 2009. Vervolgens startte Brecht een tweejarige Master in Biomedische Wetenschappen met als afstudeerrichting nanotechnologie en bio-elektronica. Brecht voltooide de Master opleiding in 2011 met grote onderscheiding na een 9 maanden durende stage onder leiding van dr. Erik Steenredeker.

In 2011 vatte Brecht een promotietraject aan bij Vitak BV en het departement Biochemie, beide onderdeel van de Universiteit Maastricht, onder supervisie van dr. Schurgers, dr. Vermeer en prof. dr. Reutelingsperger. Het doel van dit promotietraject was om te onderzoeken hoe fenotypische veranderingen in gladde spiercellen vasculaire calcificatie beïnvloeden. Tijdens zijn promotie onderzoek publiceerde Brecht zijn data in internationale, peer-gereviewde wetenschappelijke tijdschriften. Hij presenteerde deze data ook op internationale congressen in Amsterdam, Kyoto en Manchester.

Na zijn promotieonderzoek startte Brecht als consultant voor USG Professionals, een bedrijf gespecialiseerd in het verstrekken van wetenschappelijke expertise voor externe organisaties. Momenteel is Brecht werkzaam op een project in de registratie afdeling van de Ophthalmologische unit bij Novartis. 



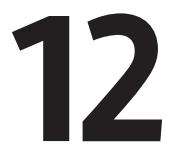

Publications 



\section{Publications}

Kusters DH, Chatrou ML, Willems BA, De Saint-Hubert M, Bauwens M, van der Vorst E, Bena S, Biessen EA, Perretti M, Schurgers LJ, Reutelingsperger CP. Pharmacological Treatment with Annexin A1 Reduces Athersclerotic Plaque Burden in LDLR-/- Mice on Western Type Diet. PLoS One. 2015 Jun 19;10(6):e0130484

Viegas CS, Rafael MS, Enriquez JL, Teixeira A, Vitorino R, Luís IM, Costa RM, Santos S, Cavaco S, Neves J, Macedo AL, Willems BA, Vermeer C, Simes DC. Gla-Rich protein acts as a calcification inhibitor in the human cardiovascular system. Arterioscler Thromb Vasc Biol. 2015 Feb; 35 (2):399-408

Burgmaier M, Schutters K, Willems BA, van der Vorst EP, Kusters D, Chatrou M, Norling L, Biessen EA, Cleutjens J, Perretti M, Schurgers LJ, Reutelingsperger CP. AnxA5 reduces plaque inflammation of advanced atherosclerotic lesions in apoE(-/-) mice. J Cell Mol Med. 2014 Oct;18(10):2117-24

Willems BA, Vermeer C, Reutelingsperger CP, Schurgers LJ. The realm of vitamin K dependent proteins: shifting from coagulation toward calcification. Mol Nutr Food Res. 2014 Aug;58(8):1620-35

Rafael MS, Cavaco S, Viegas CS, Santos S, Ramos A, Willems BA, Herfs M, Theuwissen E, Vermeer C, Simes DC. Insights into the association of Gla-rich protein and osteoarthritis, novel splice variants and y-carboxylation status. Mol Nutr Food Res. 2014 Aug;58(8):1636-46

\section{Publications (In preparation)}

Willems BA, Furmanik G, Chatrou ML, Kusters DH, Caron MM, Welting TJ, Stock M, Rafael M, Vermeer C, Reutelingsperger CP, Schurgers LJ. Ucma is involved in osteogenic transdifferentiation of vascular smooth muscle cells: role in phosphate-induced vascular calcification. (Submitted to Scientific Reports)

Willems BA, Jaminon A, Clarke M, Bennett M, Vermeer C,. Chatrou ML,. Kusters DH,. Reutelingsperger CP and Schurgers LJ. Apoptosis of medial vascular smooth muscle cells accelerates atherogenesis and induces a vulnerable plaque phenotype.

Willems BA,, Burgmaier M, Heenemann S, Gremse F, Furmanik G, Reith S, Kahles F, Marx $\mathrm{N}$, Reutelingsperger CP and Schurgers LJ. Nicotine increases oxidative stress and exosome secretion in human vascular smooth muscle cells and induces microcalcifications in human atherosclerosis. 
Chatrou ML, Kusters DH, Willems BA, Jaminon A, Norling L, Proudfoot D, Spohn G, Spronk HM, Gruell H, Reutelingsperger CP, Schurgers LJ. Vitamin K antagonists attenuate early and aggravate late atherogenesis in apo $\mathrm{E}^{-/-}$mice.

Chatrou ML, Willems BA, Kapustin A, Schmidt HH, Eys van G, Bochaton-Piallat M-L, Doroshow J, Proudfoot D, Jacobs M, Shanahan CM, Reutelingsperger CP, Schurgers LJ. Nox5 is upregulated by synthetic vascular smooth muscle cells and mediates extracellular vesicle calcification . (in preparation)

Kusters DH, Chatrou ML, Willems BA, Schutters K, Marsch E, Gijbels M, Brachvogel B, Schurgers LJm Reutelingsperger CP. Annexin A5-deficiency in ApoE-/- mice promotes efferocytosis and inhibits atherosclerosis. (in preparation)

\section{Oral presentations}

Willems BA, Chatrou ML, Kusters DH, Theuwissen E, Simes DC, Vermeer C, Reutelingsperger CP, Schurgers LJ. Ucma, a novel membner of the class of vitamin $\mathrm{K}$ dependent proteins is involved in osteochondrogenic transdifferentiation of vascular smooth muscle cells. $24^{\text {th }}$ International Symposium on Thrombosis and Hemostasis (ISTH), July 2013, Amsterdam, The Netherlands

Willems BA, Chatrou ML, Kusters DH, Clarke M, Bennett M, Vermeer C, Reutelingsperger C, Schurgers LJ. Medial vascular smooth muscle cell cytopenia accelerates atherogenesis in apoe $^{-/}$mice. British Atherosclerosis Society, July 2015, Manchester, Great Britain 


\begin{abstract}
s
Willems BA, Chatrou ML, Kusters DH, Theuwissen E, Simes DC, Vermeer C, Reutelingsperger CP, Schurgers LJ. Ucma, a novel membner of the class of vitamin $\mathrm{K}$ dependent proteins is involved in osteochondrogenic transdifferentiation of vascular smooth muscle cells. $24^{\text {th }}$ International Symposium on Thrombosis and Hemostasis (ISTH), July 2013, Amsterdam, The Netherlands
\end{abstract}

Chatrou ML, Kusters DHM, Willems BAG, Jaminon A, Norling L, Proudfoot D, Spohn G, Spronk HM. Gruell H, Reutelingsperger CP, Schurgers LJ. Vitamin K-antagonists: a two edged sword. Bi-phasic effect of VKA on atherosclerotic plaque development. $24^{\text {th }}$ International Symposium on Thrombosis and Hemostasis (ISTH), July 2013, Amsterdam, The Netherlands.

Kusters DHM, Chatrou ML, Willems BAG, Schutters K, Schurgers LJ, Reutelingsperger CPM. Deficiency of the anticoagulant annexin A5 attenuates atherosclerotic plaque development in ApoE ${ }^{-/}$mice. $24^{\text {th }}$ International Symposium on Thrombosis and Hemostasis (ISTH), July 2013, Amsterdam, The Netherlands.

Kusters DHM, Chatrou ML, Willems BAG, Schutters K, Schurgers LJ, Reutelingsperger CPM. Annexin A5 deficiency in $\mathrm{APOE}^{--}$mice: attenuated atherosclerotic plaque development. 7th International Conference on Annexins, September 2013, London, Great Britain.

Kusters DHM, Chatrou ML, Willems BAG, De Saint-Hubert M, Bauwens M, van der Vorst E, Bena S, Biessen EAL, Perretti M, Schurgers LJ, Reutelingsperger CPM. Exogenous annexin Al attenuates atherogensis in LDLR//- mice on Western Type Diet. 7th International Conference on Annexins, September 2013 London, Great Britain.

Willems BA, Chatrou ML, Kusters DH, Clarke M, Bennett M, Vermeer C, Reutelingsperger C, Schurgers LJ. Medial vascular smooth muscle cell cytopenia accelerates atherogenesis in apoe $^{-/}$mice. British Atherosclerosis Society, July 2015, Manchester, Great Britain

Thomas Theelen, Elke Marsch, Jasper Demandt, Marion Gijbels, Tom Mastenbroek, Judith Cosemans, Brecht Willems, Leon Schurgers, Erik Biessen, Peter Carmeliet, Mat Daemen, Judith Sluimer. Myeloid PHD2 deficiency impairs macrophage collagen degradation resulting in enlarged and fibrotic atherosclerotic plaques in mice. Keystone Hypoxia, May 2015, Ireland.

Burgmaier M, Schutters K, Willems BAG, Kusters DHM, Chatrou M, Biessen EAL, Cleutjens $J$, Schurgers LJ, Reutelingsperger CPM. AnxA5 decreases plaque inflammation of advanced atherosclerotic lesions in Apoe ${ }^{-/}$mice. The American Heart Association (AHA) Scientific 
Sessions and Resuscitation Science Symposium. November 2013, Dallas, United States of America.

Chatrou ML, Kusters DHM, Willems BAG, Norling L, Proudfoot D, Spronk H, Grull H, Reutelingsperger CPM, Schurgers LJ. Vitamin $\mathrm{K}$ antagonists attenuate early and aggravate late atherogenesis in ApoE $\%$ mice. $58^{\text {th }}$ Annual meeting of the society of Thrombosis and Haemostasis Research , February 2014, Vienna, Austria.

Kusters DHM, Chatrou ML, Willems BAG, De Saint-Hubert M, Bauwens M, van der Vorst E, Bena S, Biessen EAL, Perretti M, Schurgers LJ, Reutelingsperger CPM. Exogenous annexin A1 attenuates atherogenesis in $\mathrm{LDLR}^{-/}$mice on Western Type Diet. $18^{\text {th }}$ international vascular biology meeting (IVBM), April 2014, Kyoto, Japan.

Kusters DHM, Chatrou ML, Willems BAG, Schutters K, Marsch E, Gijbels M, Brachvogel B, Schurgers LJ, Reutelingsperger CPM. Annexin A5-deficiency in ApoE ${ }^{-}$mice promotes efferocytosis and inhibits atherosclerosis. $18^{\text {th }}$ international vascular biology meeting (IVBM), April 2014, Kyoto, Japan.

Willems BAG, Chatrou ML, Kusters DHM, Stock M, Rafael M, Vermeer C, Reutelingsperger CPM, Schurgers LJ. Loss of GRP \Ucma aggravates osteochondrogenic switching of vascular smooth muscle cells and induces vascular calcification. $18^{\text {th }}$ international vascular biology meeting (IVBM), April 2014, Kyoto, Japan.

Rick H. van Gorp, Brecht Willems, Billy Scaf, Henri Spronk, Chris Reutelingsperger, Leon J. Schurgers. Effect of Dabigatran Etexilate and Warfarin on atherosclerotic plaque calcification in $\mathrm{ApoE}^{-/}$mice. Nederlands vereniging voor Thrombose en Hemostase (NvTH), May2015, Koudekerke, The Netherlands.

Rick H. van Gorp, Brecht Willems, Billy Scaf, Henri Spronk, Chris Reutelingsperger, Leon J. Schurgers. Effect of Dabigatran Etexilate and Warfarin on atherosclerotic plaque calcification in ApoE $^{-/}$mice. International Society on Thrombosis and Haemostasis, June 2015, Toronto, Canada 


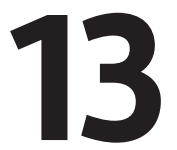

Dankwoord 

Na wat een lange, intense en leerzame reis was zijn we dan eindelijk beland bij het laatste (maar misschien eerst gelezen) hoofdstuk van dit proefschrift: het dankwoord. Aangezien ik er meestal weinig doekjes om wind zal ik het ook hier kort houden. Naast mijn wetenschappelijke vorming ben ik er van overtuigd dat 4,5 jaar Maastricht een mogelijk nog grotere impact hebben gehad op mijn vorming als mens. Zonder de steun en hulp van ontelbare collega's, vrienden en familie zou dit proefschrift er helemaal anders hebben uitgezien.

Eerst en vooral wil ik graag mijn promotieteam bedanken.

Mijn copromotor, dr. Schurgers. Beste Leon, jij was mijn begeleider van het eerste uur en jouw bijdrage aan dit proefschrift kan niet overschat worden. Je straalt van nature een enorm enthousiasme uit in alles wat je doet. Soms zo enthousiast dat we even de focus op de hoofdzaken van het onderzoek uit het oog verloren. Ik zal nooit vergeten hoe je soms opgewonden kwam vragen om het resultaat van een experiment waarvoor de metingen nog moesten starten. Als de resultaten dan toch tegenvielen en ik wat uit mijn lood was geslagen wist je er toch steeds nog iets goed in te zien. Jouw positivisme is werkelijk onuitputbaar en je wist mij steeds weer te motiveren. Ik vormde samen met jou en Martijn het kleine, beginnende verkalkingsgroepje en met zijn drieën hebben we, denk ik, toch aardig wat bereikt. Ik ben dankbaar dat je altijd zeer toegankelijk was voor al mijn vragen, ook al had je soms weinig tijd. Je bent ondertussen een succesvolle, eigen onderzoekslijn aan het uitbouwen waardoor je het nog drukker hebt. Ik wens je alle succes toe maar twijfel geen moment dat jij ook hierin met verve zal slagen. Naast de wetenschappelijke hebben we ook vele andere leuke momenten beleefd, al dan niet geaccompagneerd door de nodige biertjes, op de vele uitstappen, workshops en congressen. Dit zijn dingen die mij lang zullen bijblijven. Je hebt een enorm positieve invloed op mij gehad op alle gebieden. Ik ben je hier dan ook enorm dankbaar voor.

Mijn copromotor, dr. Vermeer. Beste Cees, ik zal nooit mijn eerste (sollicitatie) gesprek bij jou vergeten. Ik was erg nerveus maar die zenuwen vielen heel snel van mij af. Het leek dan ook meer op een gezellige babbel dan een sollicitatie. Jij gaf mij meteen een gerust gevoel. Ik zou je dan ook hartelijk willen bedanken voor de kans die je mij hebt geboden om een promotietraject te starten. Je had een heel concreet idee waar je naartoe wou met het promotieonderzoek. Uiteindelijk is dat helemaal anders uitgedraaid, maar dat is nu eenmaal wetenschap. Jij was steeds van dichtbij betrokken bij het onderzoek en straalde een aanstekelijk enthousiasme uit voor wetenschap. Je hebt met VitaK een toonaangevende onderzoeksgroep, en later een gerenommeerde spin-off uit de grond gestampt. Hier heb je gedurende vele jaren succesvol leiding aan gegeven. Ik wens jou en Hélène nog vele jaren toe in een goede gezondheid. 
Mijn promotor, prof. dr. Reutelingsperger. Beste Chris, hoewel je iets verder van het onderzoek afstond was de drempel om bij jou binnen te lopen heel laag. Ik heb er bewondering voor hoe je succesvol bent in het valideren van wetenschappelijk onderzoek en hoe je er in slaagt om een academische carrière te combineren met het bedrijfsleven. Jouw kritische vragen wisten steeds weer de hoofdzaak naar voren te brengen als we dreigden te verzanden in details. Jouw creativiteit, onuitputtelijke kennis en ervaring hebben dit proefschrift naar een hoger niveau gebracht. Je hebt mij veel bijgebracht over de wetenschap en de wetenschappelijke benadering waardoor complexe problemen plots een stuk eenvoudiger leken. Ik wil je ook bedanken voor alle kansen die je mij hebt gegeven.

I would like to acknowledge all other members of the assessment committee: prof. dr. Kroon, prof. dr. Habibovic, prof. dr. Brandenburg, dr. Kietselaar and dr. Vervloet, thank you for assessing my thesis.

Beste Mehrdad, hoewel je geen expliciet wetenschappelijke achtergrond hebt toonde je toch steeds oprecht enthousiasme in de gang van zaken betreffende mijn onderzoek. Ik wil je langs deze weg nog veel succes wensen met het verder leiden van Vitak en in je privéleven.

Dr. Chatrou, Martijn, ik kwam bij jou en Dennis op de kamer te zitten. Dat leek me op voorhand geen makkelijke opgave. Echter, beschouwde ik je al snel meer als een vriend dan een collega dus ik denk dat die twijfel onterecht was. Jij vormde samen met Leon de beginselen van het verkalkingsonderzoek op de afdeling. Hier heb ik gretig op in kunnen pikken. Ik denk dat we veel hebben geleerd van elkaar waarvoor mijn dank. De talloze late avonden in het lab staan in mijn geheugen gegrift. Zonder jou zou dit boekje niet hetzelfde zijn geworden. Ik wens je nog een mooie toekomst met Annemieke, Julia en recent ook Iris.

Beste dr. Kusters, Dennis. Ook jou ben ik al snel meer als een vriend dan een collega gaan beschouwen. Getuige daarvan de vele pub quizen, stapavonden in Maastricht en als hoogtepunt trip naar Japan. Je hebt mij veel ondersteund bij de dierproeven en mede door jouw ervaring en inspanningen zijn deze proeven zo vlot verlopen waarvoor dank. Je wist de sfeer op de kamer steeds optimaal te houden, al was het maar door je muzieksmaak.

Beste Armand en Rick. Jullie zijn in het laatste jaar van mijn promotietraject gestart en kwamen bij mij in de kamer te zitten ter vervanging van Martijn en Dennis. Jullie hebben je probleemloos weten te integreren in onze groep. Ondertussen zijn jullie ook al ver gevorderd in het promotietraject, ik wens jullie nog heel veel succes bij het afronden er van. Ook hartelijk bedankt om mijn paranimfen te zijn. 
Dear dr. Furmanik, Gosia, we met for the first time in Kyoto, Japan but in the end ended up as colleagues in Maastricht! I would like to thank you for helping me out with the final experiments required for the finalisation of this thesis. In particular I would also like to thank you for sharing lab protocols while you were still working in London, these protocols have been a great help and saved loads of time. I wish you all the best for the future, wherever it may take you.

Beste Marjolein en Elke, jullie waren mijn eerste aanspreekpunt bij VitaK. Jullie waren heel toegankelijk en hebben mij een aantal technieken aangeleerd die ik nooit eerder had gedaan. Marjolein, je ondersteunde me ook vaak door experimenten uit te voeren. Ik wens je nog een schitterende toekomst tegemoet, samen met Wouter en Bram. Voor jou hetzelfde Elke, maar dan met Stefan.

Beste Petra, Niko, Liset en Cecile. Ik wil jullie bedanken als collega's en voor alle geboden hulp. Jullie houden het lab draaiende en leveren een belangrijke bijdrage aan de gezellige sfeer in de groep.

Dear dr. Burgmaier, Mathias, it was a great experience to collaborate with you, both on a professional and personal level. You have a unique sense of humour. I admire the focus and drive you have to perform research and combine this with a career in the clinic. I wish you the best of luck in further building this career.

Dear Marta, Sofia, Carla and Dina, you were among the first in the world to discover Gla rich protein and are pioneers in this field. To be allowed to work in your lab was a great experience for which you have my gratitude. Your hospitality was truly remarkable!

Dear dr. Stock, thank you very much for being so open and helpfull to us. Without you, the Ucma project would not have been possible! I wish you the best of luck for the future.

Beste dr. Welting en dr. Caron, Tim en Marjolein, Don en Andy langs deze weg wil ik jullie bedanken voor alle hulp en inspirerende discussies die we over het Ucma project hebben gevoerd tijdens mijn promotietraject. Ik ben er van overtuigd dat er nog veel meer overlap is tussen onze verschillende onderzoeksgebieden en ik denk dat hier in de toekomst nog schitterende projecten uit kunnen voorkomen. Jullie enthousiasme voor het onderzoek was opmerkelijk.

Beste Peter, Jacques en Agnieska, hartelijk bedankt voor de assistentie en expertise bij het uitvoeren van de dierenproeven. 
Beste Elke, Thomas en Kosta, van harte bedankt voor de samenwerking de afgelopen jaren. Naast een intensieve wetenschappelijke samenwerking hebben we ook een hoop schitterende, niet-wetenschappelijke activiteiten gedeeld. Dit heeft de samenwerking tussen de departementen van Biochemie en Pathologie enkel op positieve wijze weten te beïnvloeden.

\section{Roy, Remco, Frauke, Marie-Claire, Rinske, Geert-Jan, Joke, Barbara, Farida, Karin,} Francesca, Stijn, Dennis S, Jiang en Kanin langs deze weg wil ik jullie bedanken voor de leuke avonden en inspirerende gesprekken.

Beste Stella en Elisabetta, jullie zijn het vrolijkste duo van de afdeling. Hoewel we niet echt hebben samengewerkt hebben we veel zowel wetenschappelijke als niet-wetenschappelijke discussies gehad. Bedankt voor de gezelligheid.

Beste Trees en Lideweij, als het kloppend hart van Biochemie verdienen ook jullie een plekje in dit dankwoord. Langs deze weg wil ik jullie bedanken voor de hulp bij administratieve rompslomp en de leuke gesprekken. Ik wens jullie beide nog een mooie toekomst toe met jullie dierbaren.

Beste Remo en Kevin, hoewel we drie volledig verschillende onderzoeksdomeinen hadden konden we toch vaak bij elkaar terecht, al was het maar voor wat ontspanning of mentale steun. Bedankt voor alle gezellige lunches en diners.

Naast alle collega's zijn er ook veel vrienden, die ik hier onmogelijk allemaal kan oplijsten, die onrechtstreeks hebben bijgedragen aan dit proefschrift. Hiervoor dan ook mijn dank!

Beste Bram en Kendra, ook jullie krijgen een plekje in dit dankwoord. Niet zozeer omdat jullie een bepaalde bijdrage hebben geleverd. Echter wel omdat jullie vaak hebben moeten luisteren naar mijn gezeur en geklaag wanneer de dingen niet gingen zoals ik wou. Nog vele mooie jaren samen.

Beste mama, en papa, als laatste wil ik jullie bedanken, het proefschrift mag dan wel aan jullie zijn opgedragen maar dat volstaat niet. Al mijn hele leven zijn jullie er altijd en op elk moment voor mij geweest. Jullie hebben mij altijd gesteund in mijn keuzes, wat ze ook waren. Graag wil ik van deze gelegenheid dan ook gebruik maken om jullie nog eens extra te bedanken voor de steun, het vertrouwen, geduld en de wijsheden welke ik door mijn hele opvoeding van jullie heb gekregen. Jullie staan echt altijd voor mij klaar. Ik zal jullie hier nooit genoeg voor kunnen bedanken, maar hopelijk is dit proefschrift toch een begin. 